University at Buffalo School of Law

Digital Commons @ University at Buffalo School of Law

Other Scholarship

Faculty Scholarship

$10-18-2018$

\title{
Reforming Restrictive Housing: The 2018 ASCA-Liman \\ Nationwide Survey of Time-in-Cell
}

Judith Resnik

Yale Law School

Anna VanCleave

Yale Law School

Kristen Bell

Yale Law School

Alexandra Harrington

University at Buffalo School of Law, aharr@buffalo.edu

Gregory Conyers

Yale Law School (Student)

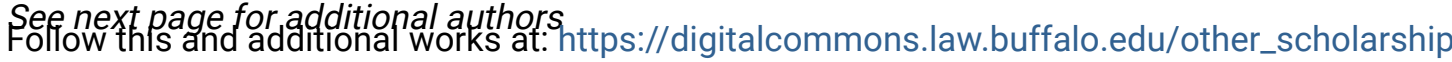

Part of the Criminal Law Commons, and the Law Enforcement and Corrections Commons

\section{Recommended Citation}

Judith Resnik, Anna VanCleave, Kristen Bell, Alexandra Harrington, Gregory Conyers, Catherine McCarthy, Jenny Tumas \& Annie Wang, Reforming Restrictive Housing: The 2018 ASCA-Liman Nationwide Survey of Time-in-Cell, (2018).

Available at: https://digitalcommons.law.buffalo.edu/other_scholarship/49

C) NON-COMMERCIAL

C) USN-COMMERCIAL

This Article is brought to you for free and open access by the Faculty Scholarship at Digital Commons @ University at Buffalo School of Law. It has been accepted for inclusion in Other Scholarship by an authorized administrator of Digital Commons @ University at Buffalo School of Law. For more information, please contact lawscholar@buffalo.edu. 


\section{Authors}

Judith Resnik, Anna VanCleave, Kristen Bell, Alexandra Harrington, Gregory Conyers, Catherine McCarthy, Jenny Tumas, and Annie Wang 
The Association of State Correctional Administrators The Liman Center for Public Interest Law at Yale Law School

October 2018
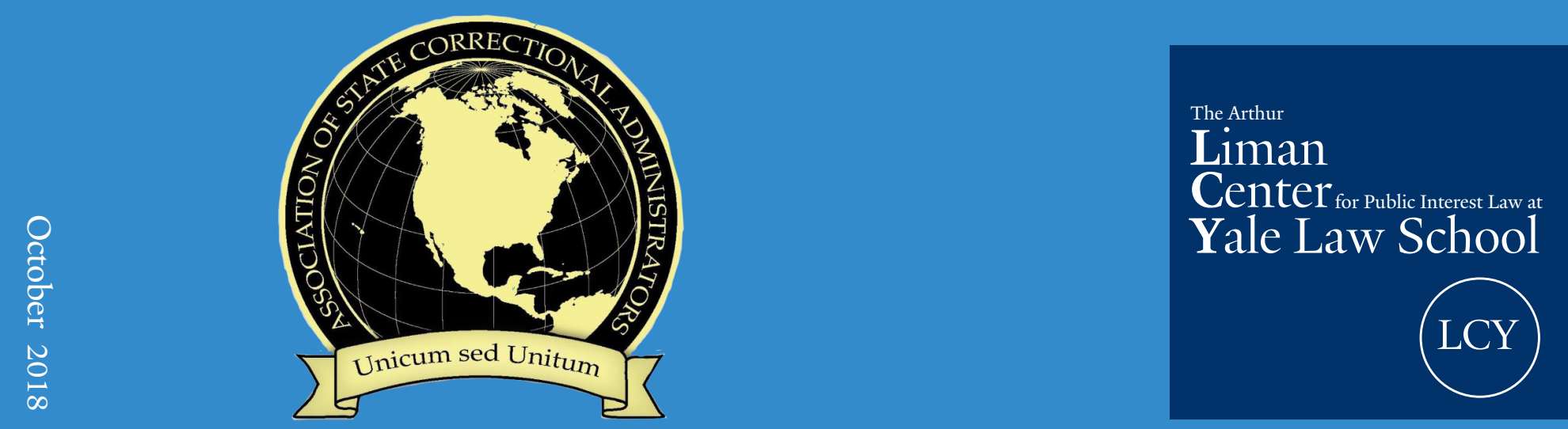


\title{
Reforming Restrictive Housing: The 2018 ASCA-Liman Nationwide Survey of Time-in-Cell
}

\author{
The Association of State Correctional Administrators \\ The Liman Center for Public Interest Law \\ at Yale Law School
}

October 2018 


\section{Association of State Correctional Administrators (ASCA)}

ASCA is the most exclusive correctional association in the world. ASCA members are the leaders of each U.S. state corrections agency, Los Angeles County, the District of Columbia, New York City, Philadelphia, the Federal Bureau of Prisons, U.S. Military Correctional Services (Army, Navy, Air Force, Marines), and United States territories, possessions, and commonwealths. ASCA members lead over 400,000 correctional professionals and supervise approximately eight million prisoners, probationers, and parolees. ASCA's goal is to increase public safety by utilizing correctional best practices, accountability, and providing opportunities for people to change.

\section{The Arthur Liman Center for Public Interest Law, Yale Law School}

The Liman Center was endowed to honor Arthur Liman, who graduated from Yale Law School in 1957. Throughout his distinguished career, he demonstrated how dedicated lawyers, in both private practice and public life, can respond to the needs of individuals and of causes that might otherwise go unrepresented. The Liman Center, which began as the Liman Program in 1997, continues the commitments of Arthur Liman by supporting work, in and outside of the academy, dedicated to public service in the furtherance of justice.

\section{Acknowledgements}

This report is based on a survey co-authored by ASCA and the Liman Center at Yale Law School. The research and report teams were led at ASCA by Leann Bertsch, Kevin Kempf, Bob Lampert, Gary Mohr, Rick Raemisch, A.T. Wall, and Wayne Choinski, and at Yale by Judith Resnik, Anna VanCleave, Kristen Bell, and Alexandra Harrington. Yale Law students Greg Conyers, Catherine McCarthy, Jenny Tumas, and Annie Wang played major roles in the research, analysis, and drafting of this Report. Yale Law students Faith Barksdale, Stephanie Garlock, and Daniel Phillips reviewed and edited the final drafts. We also received helpful suggestions from the Vera Institute of Justice.

Thanks are due to all the jurisdictions that responded to the survey and provided comments and reviews thereafter. This research has been supported by Yale Law School, the Liman Center, the Vital Projects Fund, and the Oscar M. Ruebhausen Fund at Yale Law School. This monograph was also made possible in part by a grant from Carnegie Corporation of New York to Judith Resnik, who is a 2018-2020 Andrew Carnegie Fellow. The Vital Projects Fund, the Ruebhausen Fund, and Carnegie Foundation are not responsible for the research and views expressed here. Special thanks are due to Bonnie Posick of Yale Law School's staff for expert editorial advice and to Elizabeth Keane, Program Coordinator of the Liman Center.

To download copies of this Report, please visit the website of the Liman Center at https://law.yale.edu/centers-workshops/arthur -liman-center-public-interest-law/liman-center -publications. The report can also be found on ASCA's website at: http://asca.net/documents/. This Report may be reproduced free of charge and without the need for additional permission. All rights reserved, 2018.

\section{Inquiries:}

Kevin Kempf

Executive Director, ASCA

kkempf@asca.net

Wayne Choinski

Project Manager, ASCA

wchoinski@asca.net

Judith Resnik

Arthur Liman Professor of Law

Yale Law School

judith.resnik@yale.edu

Anna VanCleave

Liman Center Director

anna.vancleave@yale.edu 


\title{
Reforming Restrictive Housing: The 2018 ASCA-Liman Nationwide Survey of Time-in-Cell
}

\author{
Table of Contents
}

Executive Summary

I. UNDERSTANDING RESTRICTIVE HOUSING OVER TIME AND ACROSS JURISDICTIONS

The ASCA-Liman Research Agenda $\quad 7$

The 2017-2018 Survey's Design and Distribution $\quad 8$

Research Challenges and Caveats 9

II. THE DATA FROM THE 2017-2018 ASCA-LIMAN SURVEY

The Numbers and Percentages of Prisoners in Restrictive Housing:

Counting and Comparing General and Restrictive Populations $\quad 10$

Length of Time in Restrictive Housing $\quad 14$

The Demographics of Restrictive Housing $\quad 17$

$\begin{array}{ll}\text { Sex / Gender } & 17\end{array}$

Race and Ethnicity $\quad \mathbf{2 2}$

Age $\quad 36$

Subpopulations $\quad \mathbf{4 6}$

Prisoners with Mental Health Issues $\quad 46$

Pregnant Women $\quad 55$

Transgender Prisoners $\quad \mathbf{5 5}$

A Snapshot of Two Jails

\section{REVISING POLICIES ON RESTRICTIVE HOUSING}

$\begin{array}{ll}\text { Entry and Oversight } & \mathbf{6 0}\end{array}$

Time Out-of-Cell, Sociability, and Programming $\quad 61$

Staff Training $\quad \mathbf{6 2}$

Release $\quad \mathbf{6 2}$

Implementing the 2016 ACA Restrictive Housing Performance Based Standards $\quad 63$

Evaluating the Effects of Policy Changes $\quad \mathbf{6 5}$

Aspiring for More Time Out-of-Cell 


\section{WORKING TO LIMIT RESTRICTIVE HOUSING:} FOUR JURISDICTIONS MAKING CHANGES

Colorado Reforms: What Do You Mean "Culture”?

Rick Raemisch, Executive Director, Colorado Department of Corrections

Idaho: Efforts to Reform Restrictive Housing

Henry Atencio, Director, Idaho Department of Correction and

Keith Yordy, Warden, Idaho State Correctional Institution

Reflections on North Dakota's Sustained Solitary Confinement Reform

Leann Bertsch, Director, North Dakota Department of

Corrections and Rehabilitation

Restrictive Housing: The Challenge of Reforming the Fabric of an Agency

Gary Mohr, Director, Ohio Department of Rehabilitation and Correction

V. CALLS FOR REFORM AND FOR ABOLITION: RESTRICTIVE HOUSING IN 2018

Correctional Systems Making Changes

Understanding the Harms of Isolation

Legislative Regulations

Litigation and Consent Decrees

Restrictive Housing as a Global Concern

\section{COMPARING THE NUMBERS OF PEOPLE IN RESTRICTIVE} HOUSING IN 2015-2016 AND IN 2017-2018

Endnotes

Appendices

Appendix A: ASCA-Liman 2017-2018 Restrictive Housing Survey

Appendix B: This Report's Tables and Figures

Appendix C: Definitions of "Serious Mental Illness" in 43 Jurisdictions 


\section{Executive Summary}

\section{Reforming Restrictive Housing: The 2018 ASCA-Liman Nationwide Survey of Time-in-Cell}

This Report is the fourth in a series of research projects co-authored by the Association of State Correctional Administrators (ASCA) and the Arthur Liman Center at Yale Law School. These monographs provide nationwide data on "restrictive housing," defined in this Report as separating prisoners from the general population and holding them in their cells for an average of 22 hours or more per day for 15 continuous days or more. This practice is often termed "solitary confinement." Reforming Restrictive Housing documents the changes underway as prison administrators aim to limit the use of segregation and find alternatives to the isolation of restrictive housing.

In 2013, the first report of the series, Administrative Segregation, Degrees of Isolation, and Incarceration, analyzed the restrictive housing policies of 47 jurisdictions. The 2013 Report found that the criteria for placement in isolation were broad. Getting into segregation was relatively easy, but few policies addressed release. In contrast, in 2018, directors around the country reported narrowing the bases for placement in restrictive housing, increasing oversight, and limiting time spent in isolation. In some places, behaviors that once put people into restrictive housing-from "horse play" to possession of small amounts of marijuana - no longer do. And for those people in restrictive housing, efforts are reportedly underway in some jurisdictions to create more out-ofcell time and more group-based activities.

Since 2013, ASCA and the Liman Center have conducted national surveys of the number of people in restrictive housing. The 2015 report, Time-in-Cell, estimated that 80,000 to 100,000 prisoners were in segregation across the country. The 2016 report, Aiming to Reduce Time-in-Cell, identified almost 68,000 people held in isolation.

For the 2017-2018 data collection, ASCA-Liman sent surveys to the 50 states, the Federal Bureau of Prisons (FBOP), the District of Columbia, and four jail systems in large metropolitan areas. The 43 prison systems that provided data on prisoners in restrictive housing held $80.6 \%$ of the U.S. prison population. They reported that 49,197 individuals $-4.5 \%$ of the people in their custody - were in restrictive housing. Across all the reporting jurisdictions, the median percentage of the population held in restrictive housing was $4.2 \%$; the average was $4.6 \%$. The percentage of prisoners in restrictive housing ranged from $0.05 \%$ to $19 \%$. Extrapolating from these numbers to the systems not reporting, we estimate that some 61,000 individuals were in isolation in prisons in the fall of 2017.

Thirty jurisdictions reported when they began to track how long people had been in restrictive housing. Some jurisdictions began tracking this information as recently as 2017 . Within the responding jurisdictions, most people were held in segregation for a year or less. Twenty-five 
jurisdictions counted more than 3,500 individuals who were held for more than three years. Almost 2,000 of those individuals had been there for more than six years.

The 2017-2018 survey also gathered information about gender, race and ethnicity, and age. Men were much more likely than women to be in solitary confinement. Black prisoners comprised a greater percentage of the restrictive housing population than they did the total custodial population. The reverse was true for White prisoners. Likewise, in the jurisdictions reporting on ethnicity, Hispanic male prisoners represented a greater percentage of the restrictive housing population than they did the total custodial population. Prisoners between the ages of 18 and 36 were more likely to be segregated than were older individuals.

Reforming Restrictive Housing also documents the many and varying definitions of "serious mental illness." Using each jurisdiction's own definition, we learned that more than 4,000 people with serious mental illness are in restrictive housing.

Other subpopulations counted were pregnant prisoners and transgender individuals. Responses indicated a total of 613 pregnant prisoners, none of whom were in restrictive housing. Prison systems reported incarcerating roughly 2,500 transgender individuals, of whom about 150 were reported to be in segregation.

In addition to the prison systems responding, the jail systems in Los Angeles County and Philadelphia provided restrictive housing data. In these two systems, the restrictive housing population ranged from $3.6 \%$ to $6.2 \%$ of the total jail population. Both jurisdictions described revising their restrictive housing policies, including by limiting its use for people with serious mental illness. One of the jail systems explained that, given the turnover in some jail populations, the administrators faced challenges in avoiding direct release from restrictive housing into the community.

The 2018 Report tracks the impact of the 2016 American Correctional Association's (ACA) Restrictive Housing Performance Based Standards. Thirty-six prison systems reported reviewing their policies since the release of the ACA Standards. More than half had implemented one or more reforms to align with the ACA. Those Standards reflect the national consensus to limit the use of restrictive housing for pregnant women, juveniles, and seriously mentally ill individuals, as well as not to use a person's gender identity as the sole basis for segregation.

In this Report and the related 2018 ASCA-Liman monograph, Efforts in Four Jurisdictions to Make Changes, the directors of the prison systems in Colorado, Idaho, Ohio, and North Dakota detail how they were limiting and, in Colorado, abolishing holding people in cells 22 hours or more for 15 days or more. These individual accounts reflect the broader trend of policy changes.

This Report puts the data collected from the 2017-2018 survey in the context of national and international actions regulating the use of restrictive housing. Correctional systems around the country are engaging in targeted efforts to reform their practices of isolating prisoners. Examples 
of such efforts are contained in the Vera Institute of Justice's 2018 monograph, Rethinking Restrictive Housing.

In other instances, reforms have come from state legislatures. Some statutes now place limits on the length of time individuals can be held in segregation, require reviews of placement decisions, and ban the use of isolation for juveniles and other subpopulations. Litigation has also resulted in decisions that highlight the harms of restrictive housing and, in some cases, prohibit its use. Parallel efforts and mandates can be found outside the United States-from implementation of the Nelson Mandela Rules to litigation and reform through policy changes.

The ASCA-Liman surveys provide a longitudinal database to enable evidence-based analysis of the practice of holding people in isolation. This Report compares the responses of the 40 prison systems that answered the ASCA-Liman surveys in both 2015 and 2017. In those 40 systems, we learned about 56,000 people in restrictive housing in 2015 . The number of prisoners reported to be in restrictive housing decreased by almost 9,500 to 47,000 people in 2017 . The percentage of individuals in isolation decreased from $5.0 \%$ to $4.4 \%$.

The changes are not uniform. In more than two dozen states, the numbers of people in restrictive housing decreased. In 11 states, the numbers went up. What accounts for the changing numbers is unclear. Variables include new policies and practices, litigation, legislation, fluctuations in the overall prison population, and staffing patterns. For example, in 20 of the 29 jurisdictions in which restrictive housing numbers declined, so too did the total prison population. In two of the 11 jurisdictions that had an increase in restrictive housing numbers, the total prison population increased as well.

The amount of time spent in restrictive housing is of increasing concern. Not all correctional systems track length of confinement. Nineteen jurisdictions reported that they began tracking in 2013 or thereafter. In 31 jurisdictions responding to questions about length of time in both 2015 and 2017, the number of individuals in restrictive housing for three months or less increased. The number of people in isolation for longer than three months decreased. The decreases were greatest for time periods longer than six months.

Correctional administrations' efforts to reduce the numbers of people in restrictive housing are part of a larger picture in which legislatures, courts, and other institutions are seeking to limit holding people in cells 22 hours or more for 15 days or more. These endeavors reflect the national and international consensus that restrictive housing imposes grave harms on individuals confined, on staff, and on the communities to which prisoners return. Once solitary confinement was seen as a solution to a problem. Now prison officials around the United States are finding ways to solve the problem of restrictive housing. 


\section{Understanding Restrictive Housing Over Time and Across Jurisdictions}

\section{The ASCA-Liman Research Agenda}

ASCA and the Liman Center at Yale Law School have worked together on a variety of projects and seminars related to the interactions among prisoners, correctional departments, communities, and courts. Research studies have included 50-state surveys of correctional departments' policies on visiting incarcerated people ${ }^{1}$ and on restrictive housing, and we have joined together to convene workshops and make presentations at conferences. ${ }^{2}$

This report is the fourth in a series of ASCA-Liman research projects focused on "restrictive housing" (known in the general literature as "solitary confinement"), defined in this report as placing individuals in cells for an average of 22 hours or more per day for 15 continuous days or more. Our goals have been to gather information and to build a database so that discussions of these practices are informed by accurate information on the use of restrictive housing that permits evidence-based analyses of policies and practices.

Over the course of the past several years, ASCA and the Liman Center have asked each of the correctional departments in the fifty states, the Federal Bureau of Prisons, and a few jail systems to answer survey questions about their populations and to provide policies so as to paint a composite picture at particular intervals and to have the ability to do longitudinal assessments. Through surveys every two years, we can learn about changes in the rules governing restrictive housing and the impact of changes on the people who live and who work in prisons and on the communities to which prisoners return.

Our first report of the series, Administrative Segregation, Degrees of Isolation, and Incarceration: A National Overview of State and Federal Correctional Policies, ${ }^{3}$ in 2013 was based on responses from 47 jurisdictions. By analyzing the policies, we learned that criteria for entry were generally broad, permitting confinement based on nonspecific concerns about "threats to security." Staff had broad discretion to determine both the placement and the duration of confinement. ${ }^{4}$ Getting in was easy, but few of the policies detailed how individuals were to be released from isolation, once segregated. ${ }^{5}$

In 2014, the ASCA-Liman survey asked departments of corrections more than 130 questions about the numbers of people in restrictive housing and the conditions in which they lived. Our 2015 Time-In-Cell Report provided an overview of the data collected. ${ }^{6}$ Answers came from 34 jurisdictions, housing $73 \%$ of the prison population, where more than 66,000 individuals were held in various types of restrictive housing. ${ }^{7}$ We thus estimated that approximately 80,000 to 100,000 prisoners were in isolation in prison systems across the country. ${ }^{8}$ The U.S. Department of Justice relied on the ASCA-Liman research when formulating its rules for federal facilities, ${ }^{9}$ and many news outlets, including the Wall Street Journal, ${ }^{10}$ the New York Times, ${ }^{11}$ and USA Today, ${ }^{12}$ discussed the findings. 
The 2016 Report, Aiming to Reduce Time-in-Cell, ${ }^{13}$ sought updated numbers and information on the demographics and duration of confinement among prisoners in restrictive housing. We learned that, as of the fall of 2015, 67,442 people were held in restrictive housing in 48 jurisdictions, which housed about $96 \%$ of the United States prison population. ${ }^{14}$ Data on duration of confinement came from a subset of 41 jurisdictions, housing 54,382 people in segregation. ${ }^{15}$ Of the people for whom we had duration data, 9,638 or $18 \%$ were held in restrictive housing for 15 to 30 days; 15,725 or $29 \%$ for one to three months; 15,978 or $29 \%$ for three months to one year; 7,132 or $13 \%$ for one to three years; and 5,909 or $11 \%$ were in isolation for three years or more. ${ }^{16}$ As the 2016 Report's title reflects, several corrections department were changing policies governing the criteria for placement in restrictive housing, oversight, programs for prisoners, and pathways to release. ${ }^{17}$ The 2016 Report was also widely distributed and discussed. ${ }^{18}$

\section{The 2017-2018 Survey's Design and Distribution}

For the 2017-2018 data collection, a subcommittee of ASCA members and Liman Center staff worked together to refine the survey questions. Again, we sought to gather information about the numbers and demographics of people held in restrictive housing, the length of time people spent in restrictive housing, and whether, how, and why policies governing restrictive housing were changing. While the questions generally followed their prior format, we had learned that some inquiries were insufficiently clear, and we identified new topics about which to ask.

For example, because our focus is on the people held in isolation for almost the entire day, the definition of restrictive housing for the 2016 survey needed to be improved. Instead of defining restrictive housing as "separating prisoners from the general population and holding them in their cells for 22 hours per day or more for 15 or more continuous days," 19 we shifted from the "22 hours per day" formulation to "an average of 22 hours." ${ }^{20}$ In addition, because the American Correctional Association (ACA) adopted new Standards on restrictive housing in August of $2016,{ }^{21}$ we also sought to learn about whether jurisdictions relied on the ACA Standards in formulating their own policies.

As in the past, ASCA-Liman used a Qualtrics online platform to distribute the survey to the corrections departments in all 50 states, the District of Columbia, and the Federal Bureau of Prisons. In addition, because of the large numbers of individuals detained in jails, we sent surveys to the four large metropolitan jail systems that are ASCA members. ${ }^{22}$ Asking 76 questions, we sought data as of the fall of 2017 from each jurisdiction. ${ }^{23}$

Responses to at least some of the questions came in the fall of 2017 from 46 of the 52 prison jurisdictions ${ }^{24}$ and from two of the four major metropolitan area jails $;^{25}$ materials related to the two jails are discussed separately. Thereafter, we emailed each jurisdiction a customized follow-up survey, seeking clarifications of specific responses. Forty-three jurisdictions responded with information on the total number of people in restrictive housing. According to statistics on prison populations from the Bureau of Justice Statistics (BJS), those jurisdictions housed about 80 percent of the total prison population. ${ }^{26}$ Thirty-four jurisdictions completed follow-up surveys. We 
then followed up again via email and telephone calls with jurisdictions from which clarifications were needed.

\section{Research Challenges and Caveats}

As in past reports, the analyses are based on self-reports from each jurisdiction, describing its population, its policies, and their impact. We did not do site visits or obtain information from other data sources. ${ }^{27}$ By way of conclusion, we put the data collected here in context through an overview of some of the recent research, legislation, and court decisions that are part of national and international work on restrictive housing.

We remind readers that sketching a national picture is made complex because of variations across jurisdictions in definitions, the kinds of restrictive housing, and methods of keeping information. In an effort to standardize answers across jurisdictions, we provided definitions of restrictive housing, age cohorts, and the like. However, in light of the various definitions used for identifying individuals with "serious mental illness," we asked each jurisdiction to provide its own definition, listed in Appendix C. Further, in many instances we have information from a subset of jurisdictions, in that some respondents reported that they either did not keep or could not provide responses to all the inquiries.

Another important reminder is that, while we have gathered more national data than are otherwise available, we cannot account for all the persons held in restrictive housing. Our materials come primarily from prison system administrators, and most prison systems do not include jails, which are often run at the local level, or juvenile facilities. We know that as of midyear 2016, about 740,700 people were confined in county and city jails in the United States; some of these detainees were held in isolation. ${ }^{28}$ As noted, we did send surveys to four major metropolitan jail systems that are ASCA members. We received information from two, which enabled us to provide a snapshot of restrictive housing in the jails in Los Angeles and in Philadelphia. We also did not gather data on restrictive housing in immigration and military facilities. Moreover, some jurisdictions gave information on less than all of their prison population as of the fall of 2017, and, in some jurisdictions, large numbers of state prisoners are sent to local jails, to private facilities, or to other venues about which information on restrictive housing was not available. 


\section{The Data from the 2017-2018 ASCA-Liman Survey}

\section{The Numbers and Percentages of Prisoners in Restrictive Housing: Counting and Comparing General and Restrictive Populations}

The survey asked jurisdictions to report, as of the fall of 2017, both on their total prison populations and on the number of prisoners held in restrictive housing. The definition provided of restrictive housing was "separating prisoners from the general population and holding them in their cells for an average of 22 or more hours per day for 15 or more continuous days." 29

Of the 46 responding jurisdictions, 43 provided data on both the total custodial population and the numbers of prisoners in restrictive housing. ${ }^{30}$ These 43 jurisdictions reported housing a total of 1,087,671 prisoners, of whom 49,197 were in restrictive housing - or $4.5 \%$ of the prisoners confined across this set. ${ }^{31}$

According to the Bureau of Justice Statistics, as of December 31, 2016, the total state and federal prison population in the United States was $1,506,757 .{ }^{32}$ Using that baseline, the 43 responding jurisdictions housed $80.6 \%$ of the total prison population in the United States.

By assuming that the same percentage of prisoners are placed in restrictive housing in the jurisdictions for which we lack data as those for which we do have data and that the distribution of prisoners across states was the same in December 2016 and fall 2017, we estimate that approximately 61,000 prisoners were in restrictive housing across the United States in the fall of $2017 . .^{33}$

One clarification is in order. This Report uses "total custodial population" to refer to the number of people under each system's direct control and for whom the jurisdiction provided 2017 restrictive housing data. The 2016 BJS overview used a broader definition that reflected the total number of people under the legal authority of a prison system. In this report, 43 jurisdictions told us about 1,087,671 prisoners in their total custodial populations, which is less than the BJS December 2016 aggregate of those systems. When using the total custodial population as counted by the 43 jurisdictions, this report describes not $80.6 \%$ of the U.S. prison population, but rather data on $72.2 \%$.

We provide jurisdiction-specific data on the numbers of prisoners in restrictive housing in Figure 1, Figure 2, and Table 1, below. The numbers are taken from responses to two survey questions about the restrictive housing population and the total custodial population: "How many people are in restrictive housing in those facilities?" and "Please provide the total custodial population under your direct control." The survey asked about both "short-term restrictive housing," (15-29 days) and "extended restrictive housing" (30 or more days). Figure 1, Figure 2, and Table 1 include the sum of both of these forms of restrictive housing. In responses to other questions, some jurisdictions provided numbers that did not add up to the same totals reflected in the answers that are the basis for Figure 1. We note such variations in endnotes to the relevant tables and figures.

The percentage of prisoners in restrictive housing - calculated as the number in restrictive housing divided by the total custodial population reported by each respective jurisdiction-ranged 
from $0.05 \%$ to $19.0 \% .{ }^{34}$ Across all the reporting jurisdictions, the median percentage of the population held in restrictive housing was $4.2 \%$; the average was $4.6 \%$. To make readily accessible the numbers on restrictive housing, we provide one figure ordered alphabetically and another ordered by the percentage of prisoners in restrictive housing.

\section{Figure 1 Percentages of Prisoners in Restrictive Housing by Jurisdiction}

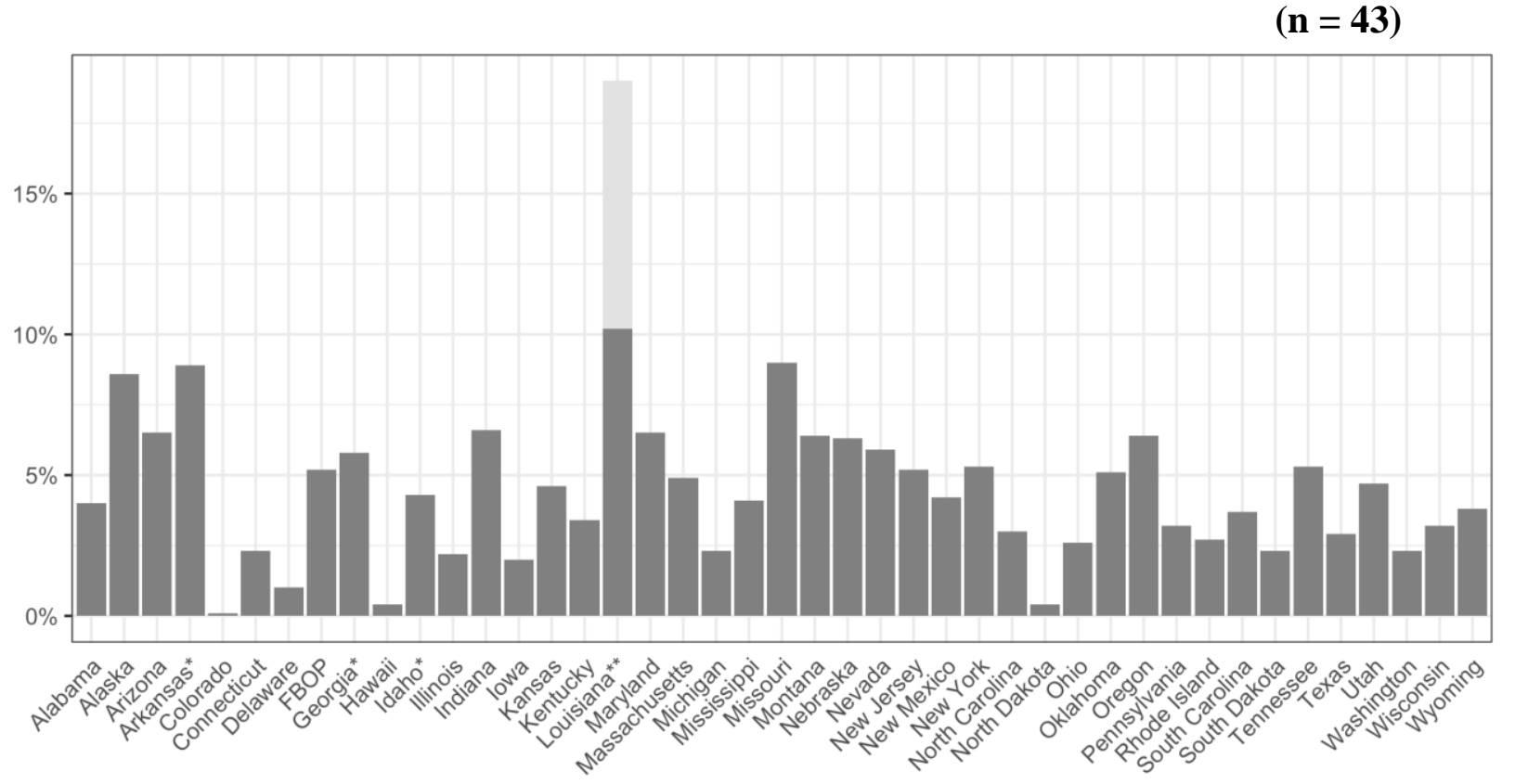

* A caveat is in order for Figure 1, Figure 2, and Table 1. Responding jurisdictions were not consistent in using our definition of short-term restrictive housing, 15-29 days, as contrasted with the definition of 1-29 days. Jurisdictions were asked about both "short-term" and "extended" restrictive housing. Some jurisdictions understood the definition of "short-term" to refer to 15-29 days, while others understood the definition to refer to 1-29 days. The majority of jurisdictions were able to clarify their answer after their initial survey response and, if they utilized the 1-29 day definition, provide the restrictive housing population number consistent with the definition of 15-29 days. We note with an asterisk those jurisdictions that were unable to clarify which definition they used, as well as Idaho, which used the definition of $1-29$ days. ${ }^{35}$

** Louisiana counted 14,291 men in its custody in prisons and 20,122 prisoners in local jails. Thus, as of fall 2017, 34,413 individuals were serving prison sentences, and $58.5 \%$ of these prisoners were in jails rather than in prisons. Louisiana reported that $2,709(19 \%)$ of the men in its prisons were in restrictive housing. Louisiana did not provide restrictive housing data for its female prison population. Louisiana staff identified 784 "restrictive housing beds" in the jails. The number of beds that were occupied was not reported. If one assumed that all the restrictive housing beds for state-sentenced prisoners in the jails were full and combined the jail and prison population, the percentage of people in restrictive housing would go down from $19 \%$ to $10.2 \%$. Shaded bars in the figures mark the different possibilities. 
Figure 2 Percentages of Prisoners in Restrictive Housing by Percentage

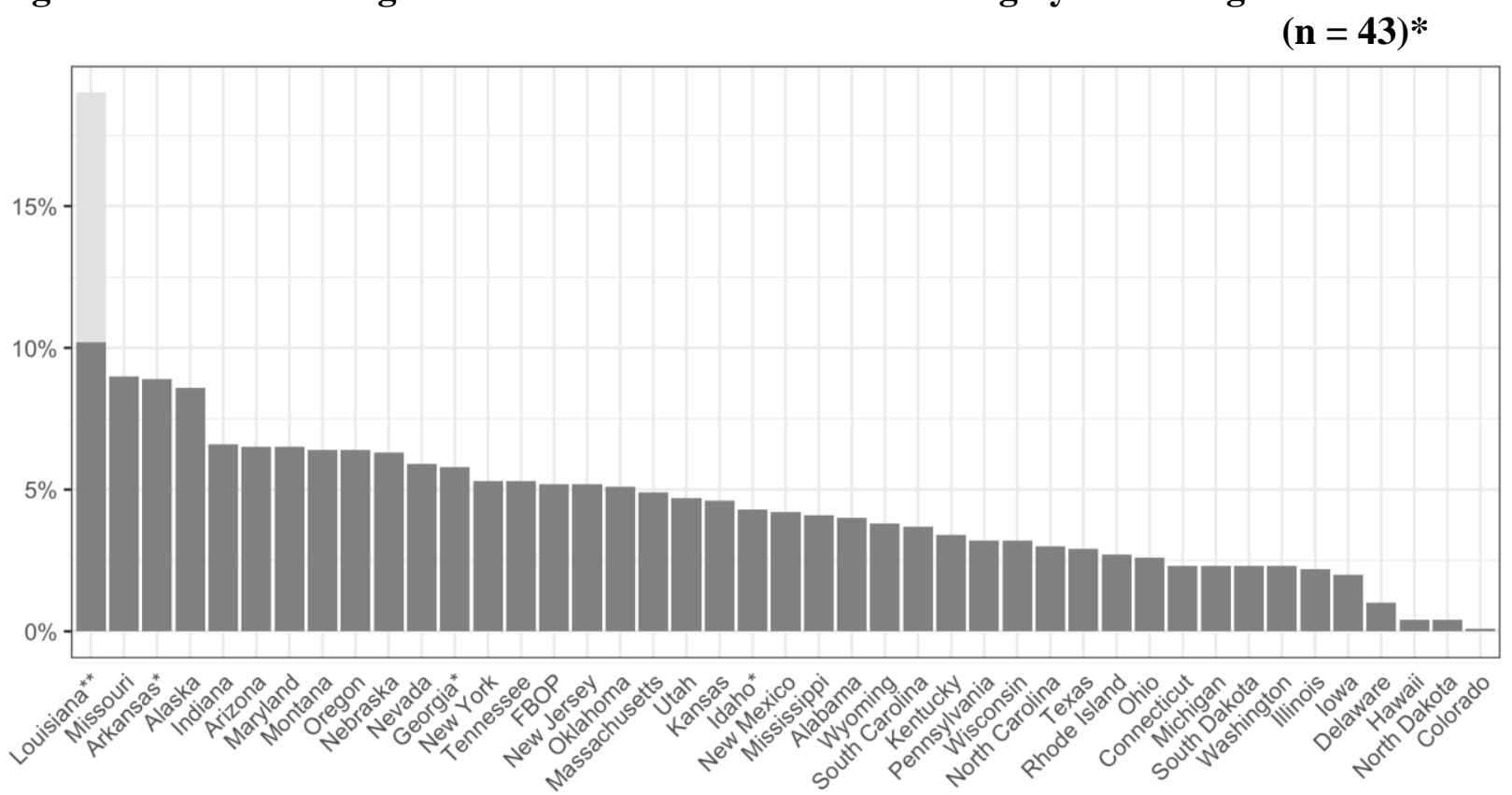

* See notes to Figure 1

Table 1 Numbers and Percentages of Men and Women in Restrictive Housing (RH) by Jurisdiction $\quad(n=43)^{*}$

Total Custodial

Jurisdiction

Reporting

RH Data ${ }^{36}$

\section{Population in}

Restrictive Percentage in Housing ${ }^{37}$ Restrictive Housing

\begin{tabular}{lrrr}
\hline Alabama & 21,592 & 855 & $4.0 \%$ \\
\hline Alaska & 4,393 & 378 & $8.6 \%$ \\
\hline Arizona & 42,146 & 2,723 & $6.5 \%$ \\
\hline Arkansas* & 15,905 & 1,418 & $8.9 \%$ \\
\hline Colorado & 18,297 & 10 & $0.1 \%$ \\
\hline Connecticut & 14,137 & 328 & $2.3 \%$ \\
\hline Delaware & 4,333 & 43 & $1.0 \%$ \\
\hline FBOP & 153,839 & 7,974 & $5.2 \%$ \\
\hline Georgia* & 54,723 & 3,200 & $5.8 \%$ \\
\hline Hawaii & 3,713 & 13 & $0.4 \%$ \\
\hline Idaho* & 7,161 & 310 & $4.3 \%$ \\
\hline Illinois & 42,177 & 921 & $2.2 \%$ \\
\hline Indiana & 26,317 & 1,741 & $6.6 \%$ \\
\hline Iowa & 8,283 & 167 & $2.0 \%$ \\
\hline
\end{tabular}




\begin{tabular}{lrrr} 
Kansas & 9,886 & 459 & $4.6 \%$ \\
\hline Kentucky & 12,000 & 408 & $3.4 \%$ \\
\hline Louisiana** & 14,291 & 2,709 & $19.0 \%$ \\
\hline Maryland & 21,785 & 1,417 & $6.5 \%$ \\
\hline Massachusetts & 9,047 & 443 & $4.9 \%$ \\
\hline Michigan & 39,858 & 903 & $2.3 \%$ \\
\hline Mississippi & 12,940 & 529 & $4.1 \%$ \\
\hline Missouri & 33,204 & 2,990 & $9.0 \%$ \\
\hline Montana & 1,769 & 113 & $6.4 \%$ \\
\hline Nebraska & 5,178 & 328 & $6.3 \%$ \\
\hline Nevada & 13,718 & 810 & $5.9 \%$ \\
\hline New Jersey & 19,368 & 1,011 & $5.2 \%$ \\
\hline New Mexico & 7,047 & 294 & $4.2 \%$ \\
\hline New York & 50,764 & 2,666 & $5.3 \%$ \\
\hline North Carolina & 37,259 & 1,109 & $3.0 \%$ \\
\hline North Dakota & 1,830 & 8 & $0.4 \%$ \\
\hline Ohio & 49,954 & 1,282 & $2.6 \%$ \\
\hline Oklahoma & 26,895 & 1,368 & $5.1 \%$ \\
\hline Oregon & 14,574 & 938 & $6.4 \%$ \\
\hline Pennsylvania & 46,920 & 1,498 & $3.2 \%$ \\
\hline Rhode Island & 2,852 & 76 & $2.7 \%$ \\
\hline South Carolina & 19,938 & 737 & $3.7 \%$ \\
\hline South Dakota & 3,927 & 90 & $2.3 \%$ \\
\hline Tennessee & 22,160 & 1,181 & $5.3 \%$ \\
\hline Texas & 145,409 & 4,272 & $2.9 \%$ \\
\hline Utah & 6,293 & 296 & $4.7 \%$ \\
\hline Washington & 17,046 & 387 & $2.3 \%$ \\
\hline Wisconsin & 22,589 & 713 & $3.2 \%$ \\
\hline Wyoming & 2,154 & 81 & $3.8 \%$ \\
\hline Total & $\mathbf{1 , 0 8 7 , 6 7 1}$ & $\mathbf{4 9 , 1 9 7}$ & $\mathbf{4 . 5 \%}$ \\
\hline See & & &
\end{tabular}

* See notes to Figure 1 


\section{Length of Time in Restrictive Housing}

The survey asked jurisdictions about how many prisoners were held in-cell for different lengths of time. The intervals ran from 15-30 days to six years or more. Answers came from 36 jurisdictions that, in total, held 41,061 prisoners in restrictive housing.

More than a fifth $(9,345$ or $22.8 \%)$ of those prisoners were in restrictive housing for 15 days to one month. Almost $32 \%$ (12,968 people or 31.6\%) were in restrictive housing for one to three months. About a quarter (11,055 or 26.9\%) were in restrictive housing for three months to a year. Almost 10\% (3,972 or 9.7\%) were held for one to three years. The responses identified 3,721 people ( $9.1 \%$ of 41,061 people) were held for more than three years. Of that number, 1,950 were reported to have been in restrictive housing for more than six years.

The survey also asked whether jurisdictions "regularly gather, collect, or report information on each prisoner's length of stay in restrictive housing." Forty-five jurisdictions answered this question, ${ }^{38}$ and 37 reported collecting data individually, in aggregate, or grouped by reason for placement or by another measure. ${ }^{39}$ Eight jurisdictions reported that they do not regularly track information on length of stay, ${ }^{40}$ yet some of this subgroup supplied numbers for the fall of 2017. ${ }^{41}$

Thus, the data on length of stay come both from jurisdictions that reported tracking length of stay regularly and from a few that did not. In addition, some jurisdictions have begun to keep such data in more recent years, and hence their numbers may reflect the time period for which they have gathered the data, rather than the actual length of time that individuals were held in restrictive housing. ${ }^{42}$ The length-of-time intervals are reported in Figure 3 below and by jurisdiction in Table 2. Table 3 details responses from thirty jurisdictions providing information on when they began to collect length-of-time data, which may or may not include retrospective information.

Figure 3 Prisoners in Restrictive Housing by Length of Time $\quad(n=36)$

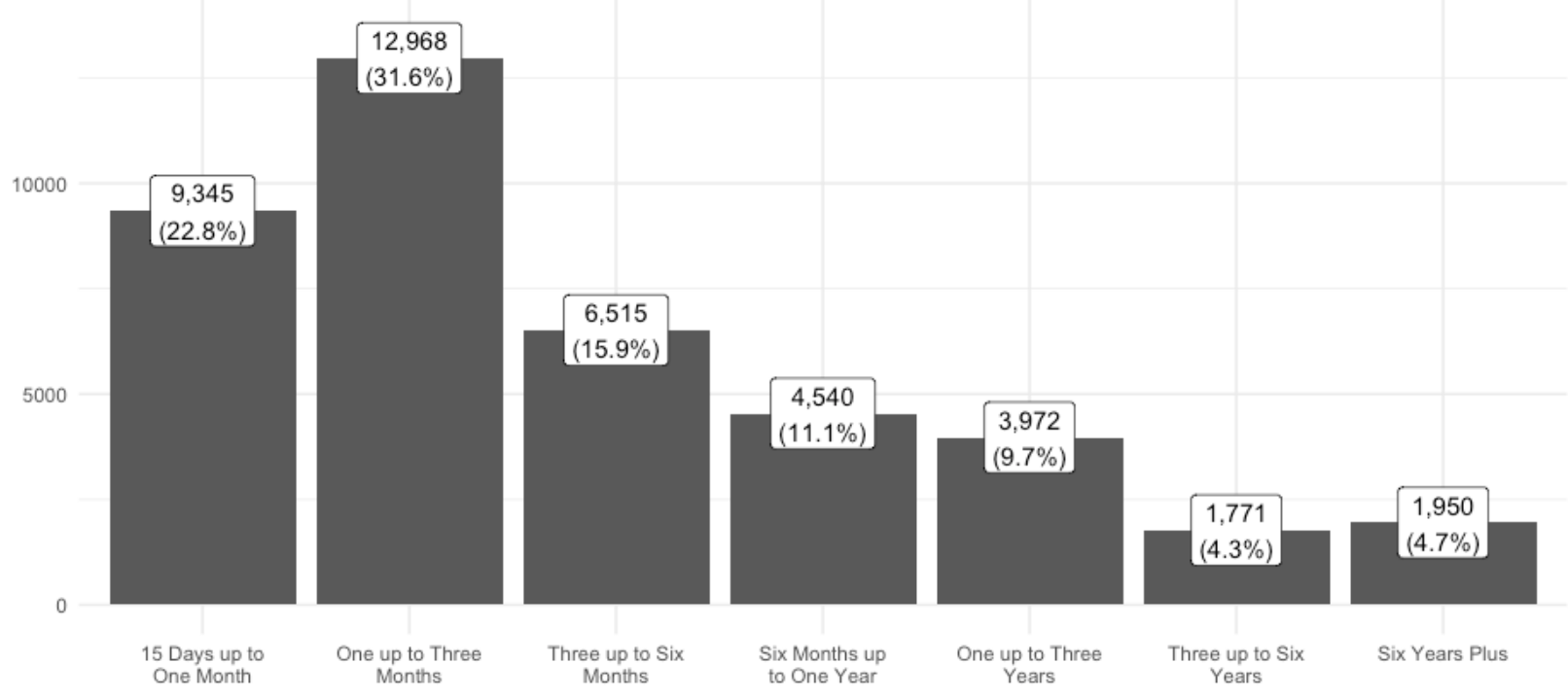


Table 2 Numbers of Prisoners in Restrictive Housing by Length of Time and by Jurisdiction $\quad(n=36)^{43}$

\begin{tabular}{lrrrrrrr} 
& $\begin{array}{r}\text { 15 Days up } \\
\text { to One } \\
\text { Month }\end{array}$ & $\begin{array}{r}\text { One up to } \\
\text { Three } \\
\text { Months }\end{array}$ & $\begin{array}{r}\text { Three up } \\
\text { to Six } \\
\text { Months }\end{array}$ & $\begin{array}{r}\text { Six up to } \\
\text { Twelve } \\
\text { Months }\end{array}$ & $\begin{array}{r}\text { One up } \\
\text { to Three } \\
\text { Years }\end{array}$ & $\begin{array}{r}\text { Three up } \\
\text { to Six } \\
\text { Years }\end{array}$ & $\begin{array}{r}\text { Six Years } \\
\text { Plus }\end{array}$ \\
\hline Alabama & 222 & 355 & 166 & 65 & 41 & 1 & 5 \\
\hline Alaska & 72 & 78 & 50 & 25 & 31 & 0 & 0 \\
\hline Arizona & 428 & 831 & 433 & 462 & 489 & 72 & 8 \\
\hline Colorado & 10 & 0 & 0 & 0 & 0 & 0 & 0 \\
\hline Delaware & 5 & 25 & 6 & 7 & 0 & 0 & 0 \\
\hline FBOP & 1,764 & 3,690 & 1,382 & 609 & 254 & 120 & 155 \\
\hline Hawaii & 23 & 0 & 9 & 0 & 0 & 0 & 0 \\
\hline Illinois & 335 & 342 & 122 & 136 & 113 & 34 & 16 \\
\hline Indiana & 131 & 348 & 281 & 354 & 391 & 121 & 115 \\
\hline Iowa & 56 & 98 & 10 & 3 & 0 & 0 & 0 \\
\hline Kansas & 176 & 207 & 61 & 15 & 0 & 0 & 0 \\
\hline Kentucky & 671 & 130 & 45 & 14 & 1 & 0 & 0 \\
\hline Louisiana & 332 & 630 & 449 & 445 & 517 & 346 & 0 \\
\hline Massachusetts & 76 & 118 & 50 & 28 & 31 & 5 & 4 \\
\hline Michigan & 256 & 409 & 171 & 50 & 16 & 1 & 0 \\
\hline Mississippi & 399 & 69 & 40 & 12 & 7 & 1 & 1 \\
\hline Missouri & 1,122 & 842 & 215 & 229 & 80 & 20 & 2 \\
\hline Montana & 8 & 34 & 30 & 24 & 11 & 6 & 0 \\
\hline Nebraska & 19 & 94 & 102 & 81 & 32 & 1 & 3 \\
\hline New Jersey & 150 & 398 & 178 & 100 & 79 & 36 & 70 \\
\hline New York & 757 & 1,218 & 416 & 182 & 73 & 13 & 7 \\
\hline North Carolina & 602 & 205 & 280 & 21 & 1 & 0 & 0 \\
\hline North Dakota & 3 & 4 & 2 & 0 & 0 & 0 & 0 \\
\hline Ohio & 226 & 288 & 243 & 271 & 183 & 49 & 22 \\
\hline Oklahoma & 384 & 481 & 224 & 156 & 106 & 17 & 0 \\
\hline Oregon & 126 & 291 & 152 & 41 & 30 & 7 & 1 \\
\hline Pennsylvania & 305 & 517 & 252 & 126 & 106 & 41 & 151 \\
\hline Rhode Island & 31 & 23 & 13 & 5 & 4 & 0 & 0 \\
\hline South Carolina & 138 & 207 & 105 & 131 & 102 & 12 & 42 \\
\hline South Dakota & 18 & 6 & 10 & 16 & 21 & 12 & 7 \\
\hline Tennessee & 110 & 276 & 237 & 280 & 244 & 31 & 3 \\
\hline Texas & 141 & 263 & 326 & 474 & 931 & 811 & 1,326 \\
\hline Utah & 2 & 33 & 232 & 29 & 0 & 0 & 0 \\
\hline Washington & 5 & 82 & 107 & 106 & 64 & 11 & 12 \\
\hline Wisconsin & 221 & 345 & 91 & 41 & 13 & 2 & 0 \\
\hline Wyoming & 21 & 31 & 25 & 2 & 1 & 1 & 0 \\
\hline Total & 9,345 & 12,968 & 6,515 & 4,540 & 3,972 & 1,771 & 1,950 \\
\hline & & & & & & &
\end{tabular}


Table 3 Years When Tracking Length of Time in Restrictive Housing Began in Thirty Jurisdictions*

\begin{tabular}{|c|c|}
\hline $\begin{array}{l}\text { Year that Jurisdiction } \\
\text { Began Tracking }\end{array}$ & Jurisdiction \\
\hline 1985 & Colorado \\
\hline 1990 & Nevada \\
\hline 1991 & Kansas \\
\hline 1993 & Alabama \\
\hline 1999 & New Mexico \\
\hline 2000 & Oklahoma \\
\hline 2006 & Kentucky \\
\hline 2010 & Iowa \\
\hline \multirow[t]{2}{*}{2011} & Connecticut \\
\hline & Wisconsin \\
\hline 2012 & Pennsylvania \\
\hline 2013 & FBOP \\
\hline \multirow[t]{4}{*}{2014} & Hawaii \\
\hline & Louisiana \\
\hline & New York \\
\hline & South Dakota \\
\hline \multirow[t]{6}{*}{2015} & Maryland \\
\hline & Montana \\
\hline & North Dakota \\
\hline & Texas \\
\hline & Washington \\
\hline & Wyoming \\
\hline \multirow[t]{4}{*}{2016} & Nebraska \\
\hline & New Jersey \\
\hline & Rhode Island \\
\hline & South Carolina \\
\hline \multirow[t]{4}{*}{2017} & Delaware \\
\hline & Massachusetts \\
\hline & Oregon \\
\hline & Utah \\
\hline
\end{tabular}

*Information was not provided on whether, when the tracking began, data included retrospective analysis. 


\section{The Demographics of Restrictive Housing}

As in prior reports, we sought to learn about the people placed in restrictive housing in terms of their sex/gender, race, and age, and whether they were identified as having serious mental illness. Below, we provide a composite picture drawn from the jurisdictions that responded about the populations under their direct control. Once again, we note when jurisdictions provided data that varied from the questions posed.

\section{Sex/Gender}

Thirty-four jurisdictions provided data on men in restrictive housing and 32 of those systems did so for women. As shown in Figure 4 below, $4.6 \%$ of the total male custodial population was in restrictive housing, and $1.2 \%$ of the total female custodial population was in restrictive housing in these jurisdictions.

\section{Figure 4 Percent of Total Population in Restrictive Housing by Gender}

(Male: $\mathbf{n}=34$; Female: $\mathbf{n}=32$ )

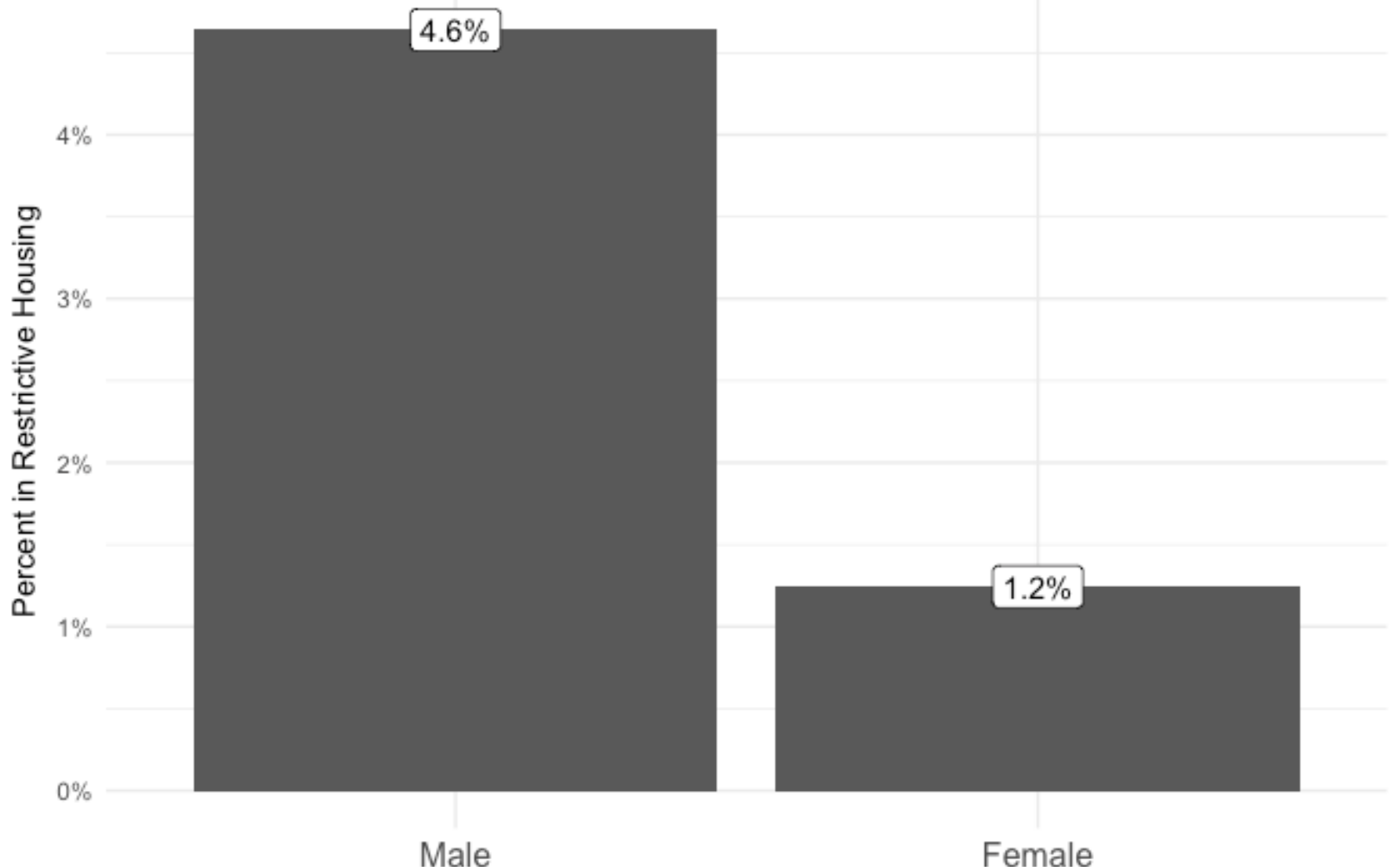

Figure 5, Figure 6, and Table 4 provide jurisdiction-by-jurisdiction information about the number of men in restrictive housing. Across the 34 jurisdictions providing data about the numbers of men, a total of 37, 690 men were reported in restrictive housing. The median percentage of male prisoners in restrictive housing was $4.2 \%$. The percentage held in restrictive housing ranged from $19 \%$ of the male custodial population (2,709 out of 14,291 male prisoners) to under $0.1 \%$ (10 out of 16,624 male prisoners) ${ }^{45}$ To make the information readily accessible, Figure 5 and Figure 6 provide the same information, arranged alphabetically and then in decreasing order of the percentage of the male custodial population in restrictive housing. 
Figure 5 Percentage of Male Prisoners in Restrictive Housing by Jurisdiction*

$(\mathbf{n}=34)$

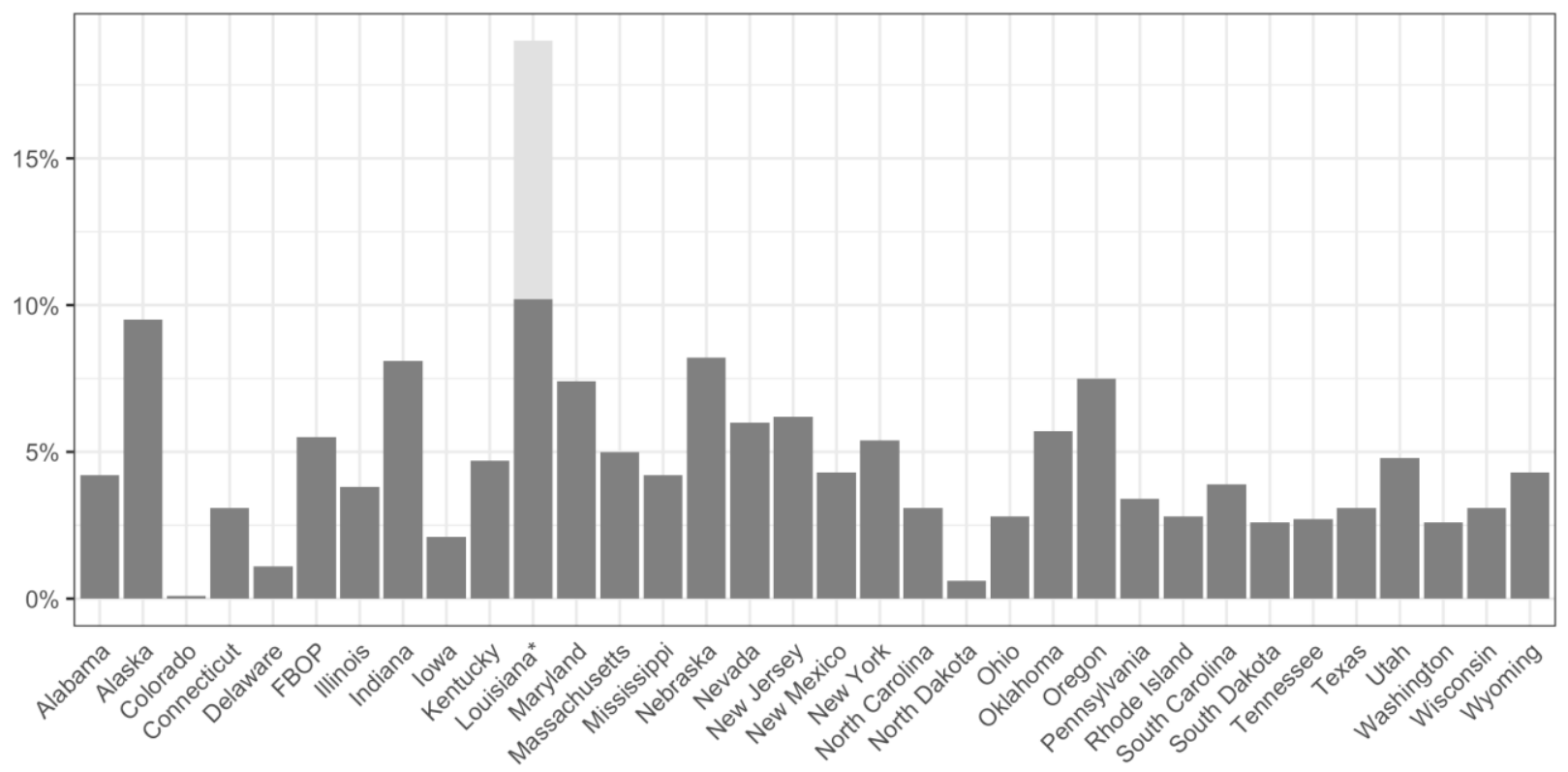

Figure 6 Percentage of Male Prisoners in Restrictive Housing by Percentage *

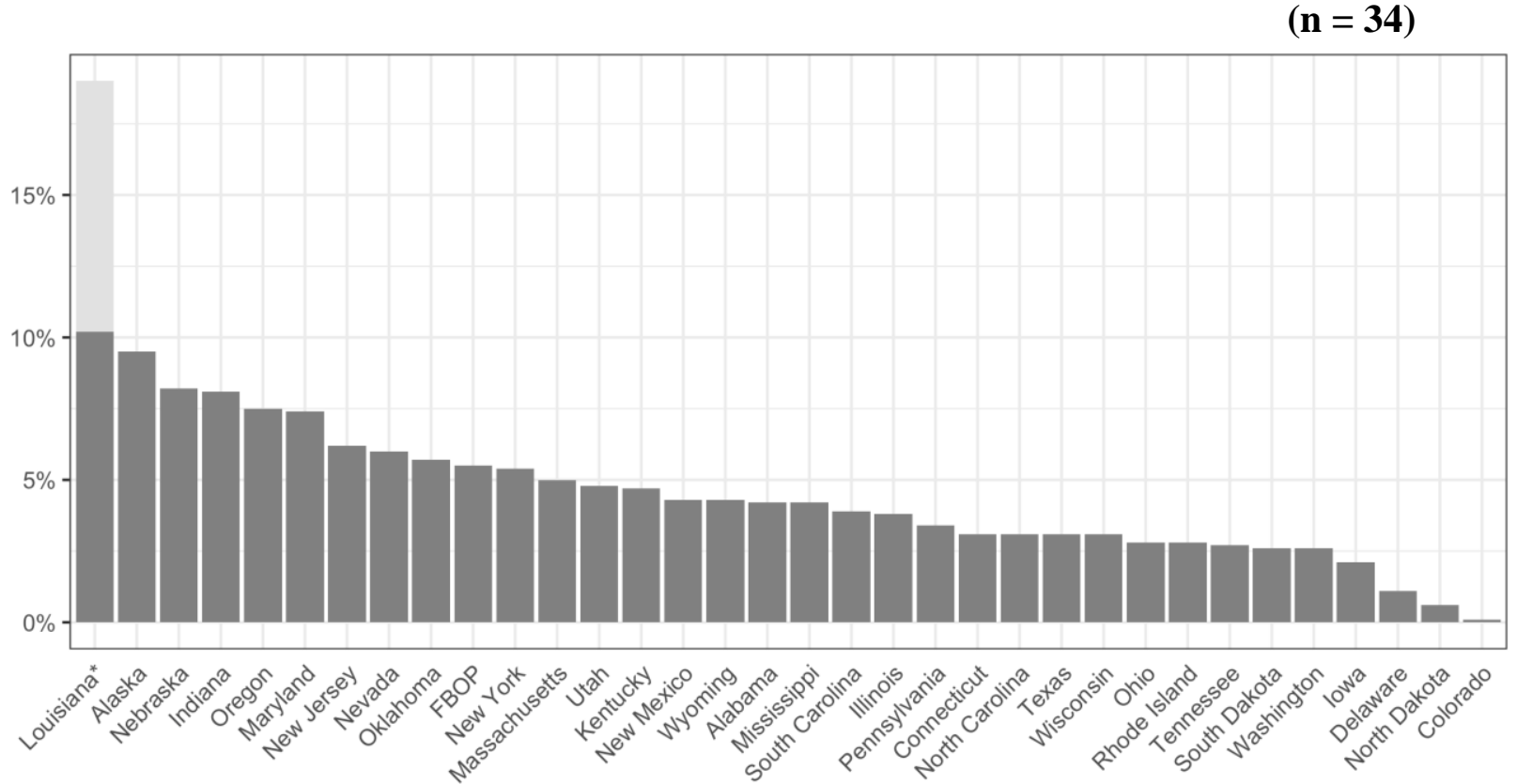

* As discussed in the notes to Figure 1, the bar for Louisiana represents two different calculations for Louisiana's percentage of male prisoners in restrictive housing,. 
Table 4 Number and Percentage of Male Custodial Population in Restrictive Housing $(n=34)^{46}$

\section{Jurisdiction}

\begin{tabular}{|c|c|c|c|}
\hline Alabama & 20,282 & 852 & $4.2 \%$ \\
\hline Alaska & 3,990 & 378 & $9.5 \%$ \\
\hline Colorado & 16,624 & 10 & $0.1 \%$ \\
\hline Connecticut & 13,182 & 403 & $3.1 \%$ \\
\hline Delaware & 4,100 & 43 & $1.1 \%$ \\
\hline FBOP & 142,762 & 7,873 & $5.5 \%$ \\
\hline Illinois & 39,767 & 1,510 & $3.8 \%$ \\
\hline Indiana & 23,847 & 1,923 & $8.1 \%$ \\
\hline Iowa & 7,578 & 159 & $2.1 \%$ \\
\hline Kentucky & 20,427 & 951 & $4.7 \%$ \\
\hline Louisiana & 14,291 & 2,709 & $19.0 \%$ \\
\hline Maryland & 20,723 & 1,536 & $7.4 \%$ \\
\hline Massachusetts & 8,459 & 420 & $5.0 \%$ \\
\hline Mississippi & 12,038 & 504 & $4.2 \%$ \\
\hline Nebraska & 4,762 & 389 & $8.2 \%$ \\
\hline Nevada & 12,434 & 751 & $6.0 \%$ \\
\hline New Jersey & 18,594 & 1,143 & $6.2 \%$ \\
\hline New Mexico & 6,306 & 273 & $4.3 \%$ \\
\hline New York & 48,407 & 2,630 & $5.4 \%$ \\
\hline North Carolina & 34,326 & 1,076 & $3.1 \%$ \\
\hline North Dakota & 1,606 & 9 & $0.6 \%$ \\
\hline Ohio & 45,796 & 1,273 & $2.8 \%$ \\
\hline Oklahoma & 23,816 & 1,349 & $5.7 \%$ \\
\hline Oregon & 13,302 & 1,003 & $7.5 \%$ \\
\hline Pennsylvania & 44,300 & 1,492 & $3.4 \%$ \\
\hline Rhode Island & 2,722 & 76 & $2.8 \%$ \\
\hline South Carolina & 18,483 & 718 & $3.9 \%$ \\
\hline South Dakota & 3,402 & 89 & $2.6 \%$ \\
\hline Tennessee & 20,214 & 546 & $2.7 \%$ \\
\hline Texas & 133,229 & 4,176 & $3.1 \%$ \\
\hline Utah & 5,822 & 277 & $4.8 \%$ \\
\hline Washington & 15,744 & 407 & $2.6 \%$ \\
\hline Wisconsin & 21,050 & 661 & $3.1 \%$ \\
\hline Wyoming & 1,894 & 81 & $4.3 \%$ \\
\hline Total & 824,279 & 37,690 & 4.2\% (Median) \\
\hline
\end{tabular}


Among the 32 jurisdictions that provided data about the number of women in restrictive housing, a total of 790 women were reported in isolation. The median percentage of female prisoners in restrictive housing in responding jurisdictions was $1.1 \%$. The percentage held in restrictive housing ranged from $4.6 \%$ of the female custodial population (59 out of 1,280 female prisoners) to $0 \%$ of the female custodial population. ${ }^{47}$ Jurisdiction-by-jurisdiction information is provided in Figure 7 and Figure 8, arranged by jurisdiction and by percentages, and in Table 5.

\section{Figure 7 Percentage of Female Prisoners in Restrictive Housing By Jurisdiction}

$(\mathbf{n}=\mathbf{3 2})$

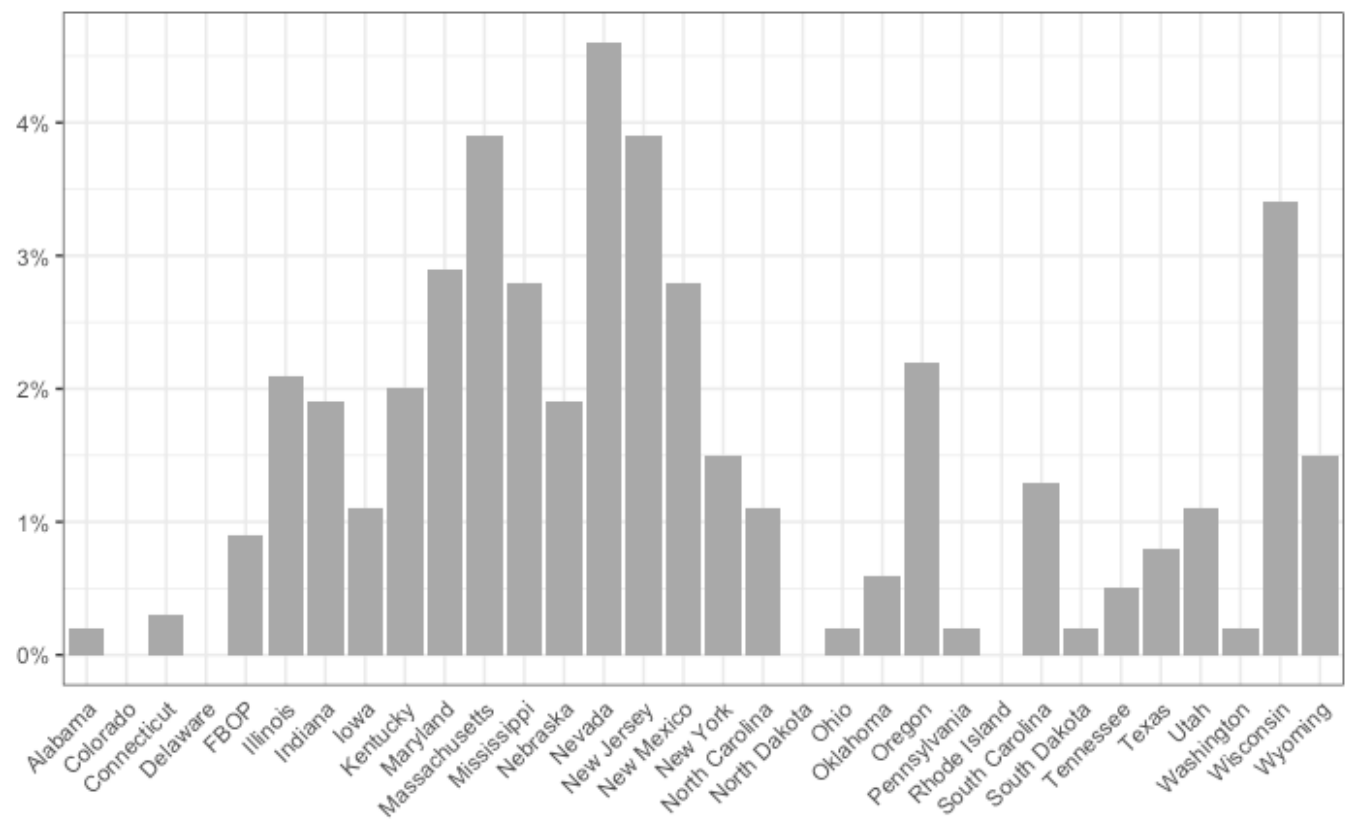

Figure 8 Percentage of Female Prisoners in Restrictive Housing by Percentage $(\mathbf{n}=32)$

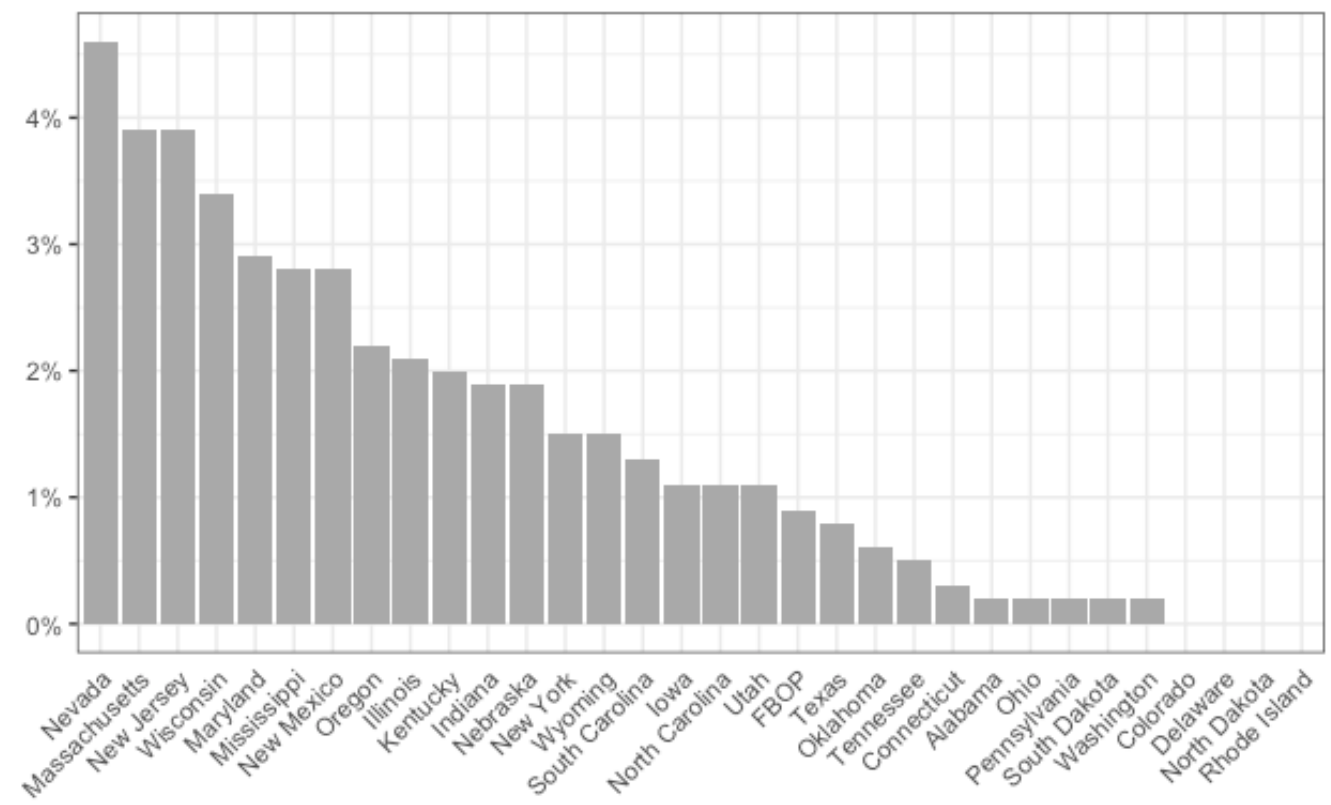


Table 5 Number and Percentage of Female Custodial Population in

$$
\begin{array}{ll}
\text { Restrictive Housing } & (\mathrm{n}=32)^{48}
\end{array}
$$

\begin{tabular}{|c|c|c|c|}
\hline Jurisdiction & $\begin{array}{r}\text { Total Custodial } \\
\text { Population } \\
\end{array}$ & $\begin{array}{r}\text { Restrictive Housing } \\
\text { Population }\end{array}$ & $\begin{array}{r}\text { Percentage in } \\
\text { Restrictive Housing }\end{array}$ \\
\hline Alabama & 1,310 & 3 & $0.2 \%$ \\
\hline Colorado & 1,673 & 0 & $0.0 \%$ \\
\hline Connecticut & 955 & 3 & $0.3 \%$ \\
\hline Delaware & 233 & 0 & $0.0 \%$ \\
\hline FBOP & 11,077 & 101 & $0.9 \%$ \\
\hline Illinois & 2,410 & 50 & $2.1 \%$ \\
\hline Indiana & 2,470 & 48 & $1.9 \%$ \\
\hline Iowa & 705 & 8 & $1.1 \%$ \\
\hline Kentucky & 3,139 & 64 & $2.0 \%$ \\
\hline Maryland & 1,062 & 31 & $2.9 \%$ \\
\hline Massachusetts & 588 & 23 & $3.9 \%$ \\
\hline Mississippi & 902 & 25 & $2.8 \%$ \\
\hline Nebraska & 416 & 8 & $1.9 \%$ \\
\hline Nevada & 1,280 & 59 & $4.6 \%$ \\
\hline New Jersey & 774 & 30 & $3.9 \%$ \\
\hline New Mexico & 741 & 21 & $2.8 \%$ \\
\hline New York & 2,357 & 36 & $1.5 \%$ \\
\hline North Carolina & 2,933 & 33 & $1.1 \%$ \\
\hline North Dakota & 224 & 0 & $0.0 \%$ \\
\hline Ohio & 4,158 & 9 & $0.2 \%$ \\
\hline Oklahoma & 3,079 & 19 & $0.6 \%$ \\
\hline Oregon & 1,272 & 28 & $2.2 \%$ \\
\hline Pennsylvania & 2,620 & 6 & $0.2 \%$ \\
\hline Rhode Island & 130 & 0 & $0.0 \%$ \\
\hline South Carolina & 1,455 & 19 & $1.3 \%$ \\
\hline South Dakota & 525 & 1 & $0.2 \%$ \\
\hline Tennessee & 1,946 & 9 & $0.5 \%$ \\
\hline Texas & 12,180 & 93 & $0.8 \%$ \\
\hline Utah & 471 & 5 & $1.1 \%$ \\
\hline Washington & 1,302 & 2 & $0.2 \%$ \\
\hline Wisconsin & 1,539 & 52 & $3.4 \%$ \\
\hline Wyoming & 260 & 4 & $1.5 \%$ \\
\hline Total & 66,186 & 790 & $1.1 \%$ (Median) \\
\hline
\end{tabular}




\section{Race and Ethnicity}

The survey asked about race and ethnicity data by sex/gender for the total custodial and the restrictive housing populations. Thirty-three jurisdictions responded to questions about the racial and ethnic composition of male prisoners in restrictive housing, and 32 jurisdictions responded to questions about race and ethnicity among female prisoners in restrictive housing. Figure 9 and Figure 10 describe the number of prisoners by sex/gender in each racial group in the total custodial population and in restrictive housing.

We asked jurisdictions about the categories of White, Black (African-American), Hispanic or Latino, Asian, Native American or Alaskan Native, Native Hawaiian or Pacific Islander, and Other. Table 6 details the number of jurisdictions that used each category. Endnotes explain the differences when jurisdictions varied their categories. ${ }^{49}$ As detailed, some jurisdictions relied on self-reports, and others categorized individuals based on correctional records or on appearance. ${ }^{50}$

Table 6 Number of Jurisdictions Reporting on Racial or Ethnic Groups $(\mathbf{n}=33)$

\begin{tabular}{l|r} 
Category & Number of Jurisdictions \\
\hline White & 33 \\
\hline Black (African-American) & 33 \\
\hline Hispanic or Latino & 32 \\
\hline Asian & 30 \\
\hline Native American or Alaskan Native & 29 \\
\hline Native Hawaiian or Pacific Islander & 16 \\
\hline Other & 25
\end{tabular}


Figure 9 Racial and Ethnic Composition of Male Prisoners in Total Custodial Population and in Restrictive Housing Population $\quad(\mathbf{n}=33)$

$\%$ of Restrictive Housing Population $\%$ of Total Custodial Population

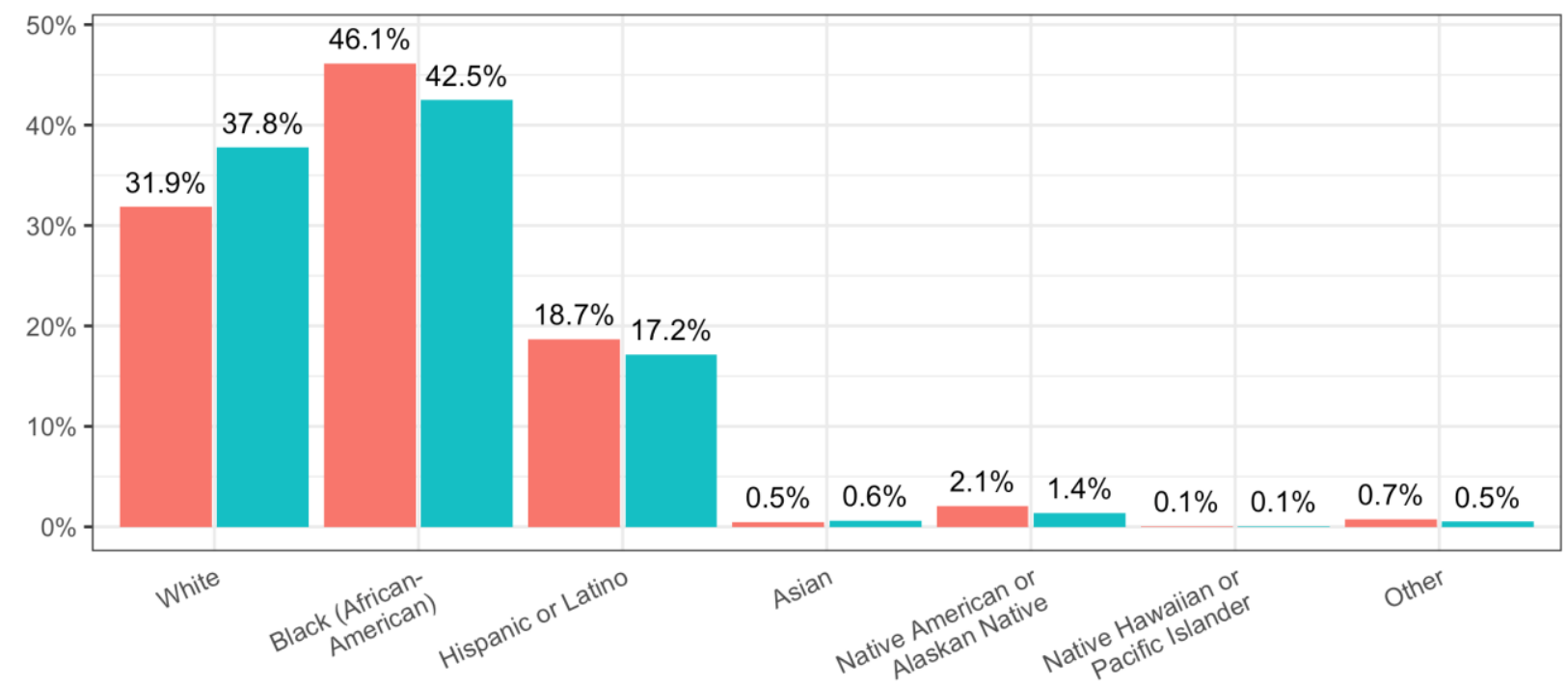

Figure 10 Racial and Ethnic Composition of Female Prisoners in Total Custodial Population and in Restrictive Housing Population $\quad(n=32)$

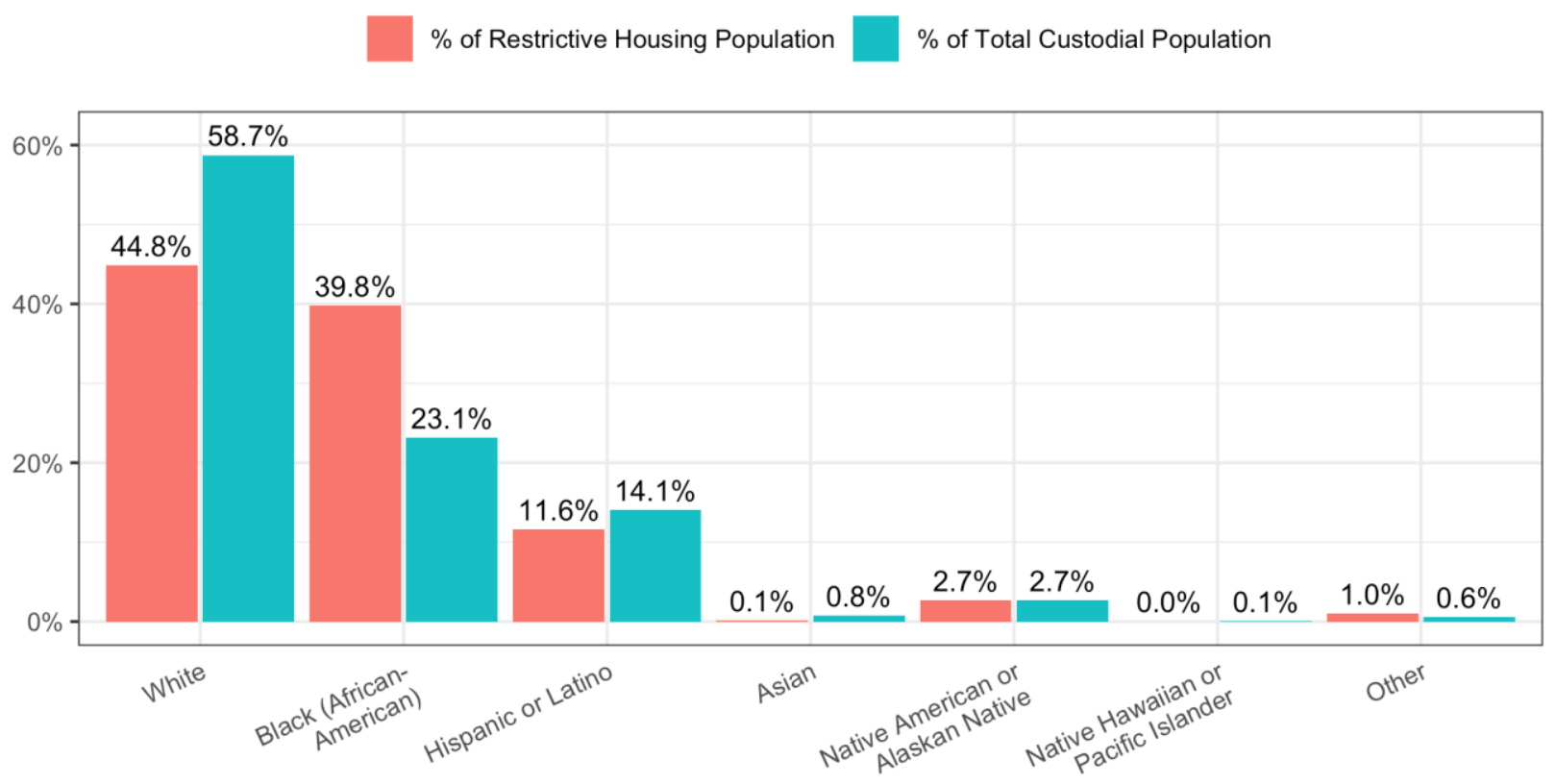


Among the 33 jurisdictions reporting on race and ethnicity among male prisoners in the total custodial population and in restrictive housing, Black men comprised $46.1 \%$ of the male restrictive housing population, as compared to $42.5 \%$ of the total male custodial population in those jurisdictions. In 24 of the 33 jurisdictions reporting on the racial composition of male prisoners in the total custodial population and in restrictive housing, the male restrictive housing population had a greater percentage of Black prisoners than did the total male custodial population in each of those jurisdictions. In 9 of the 33 jurisdictions, the male restrictive housing population had a lower percentage of Black prisoners than did the total male custodial population in each of those jurisdictions. Across all jurisdictions, the difference between the percentage of the male restrictive housing population that was Black and the percentage of the total male custodial population that was Black ranged from +14.5 percentage points to -9.4 percentage points. Figure 11 maps those spreads in the 31 jurisdictions where 25 or more people were reported in restrictive housing.

One of the 33 reporting jurisdictions did not use "Hispanic" as a racial category. ${ }^{51}$ Among the remaining 32, Hispanic male prisoners comprised $18.7 \%$ of the male restrictive housing population, as compared to $17.2 \%$ of the total male custodial population. In 17 of the 32 reporting jurisdictions, the male restrictive housing population had a greater percentage of Hispanic prisoners than did the total male custodial population in each of those jurisdictions. In 14 of the 32 jurisdictions, the male restrictive housing population had a lower percentage of Hispanic prisoners than did the total male custodial population in each of those jurisdictions. In one jurisdiction, the percentage was the same.

Across all jurisdictions, the difference between the percentage of the male restrictive housing population that was Hispanic and the percentage of the total male custodial population that was Hispanic ranged from +15.8 percentage points to -3.8 percentage points. Figure 12 maps those spreads in the 30 jurisdictions where 25 or more people were reported in restrictive housing. 
Figure 11 Differences in Restrictive Housing and Total Male Custodial Population for Black Male Prisoners $(\mathbf{n}=31)^{*}$

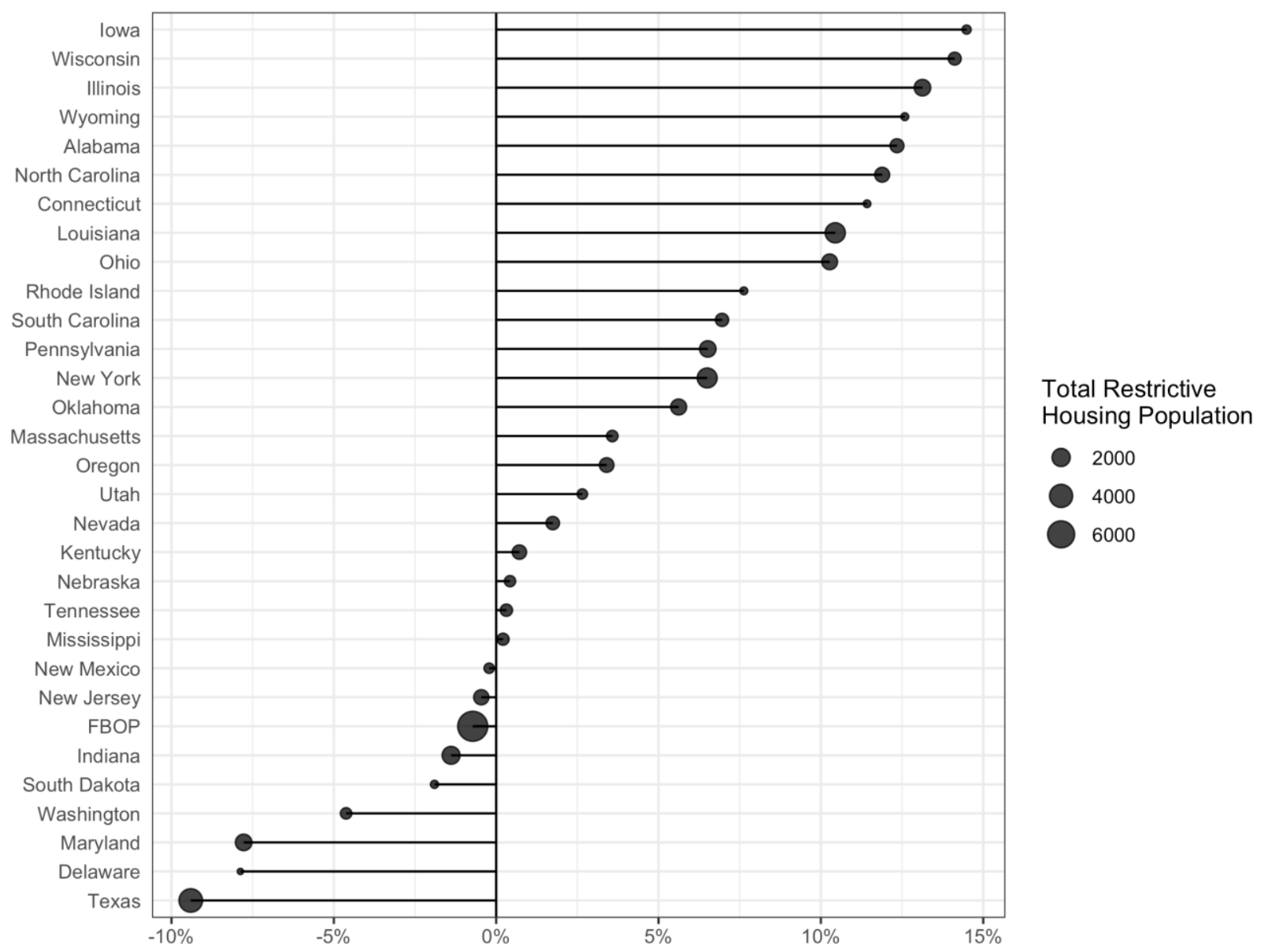

*The jurisdictions included in this graph reported more than 25 people in restrictive housing. 
Figure 12 Differences in Restrictive Housing and Total Male Custodial Population for Hispanic Male Prisoners $(\mathbf{n}=30)^{*}$

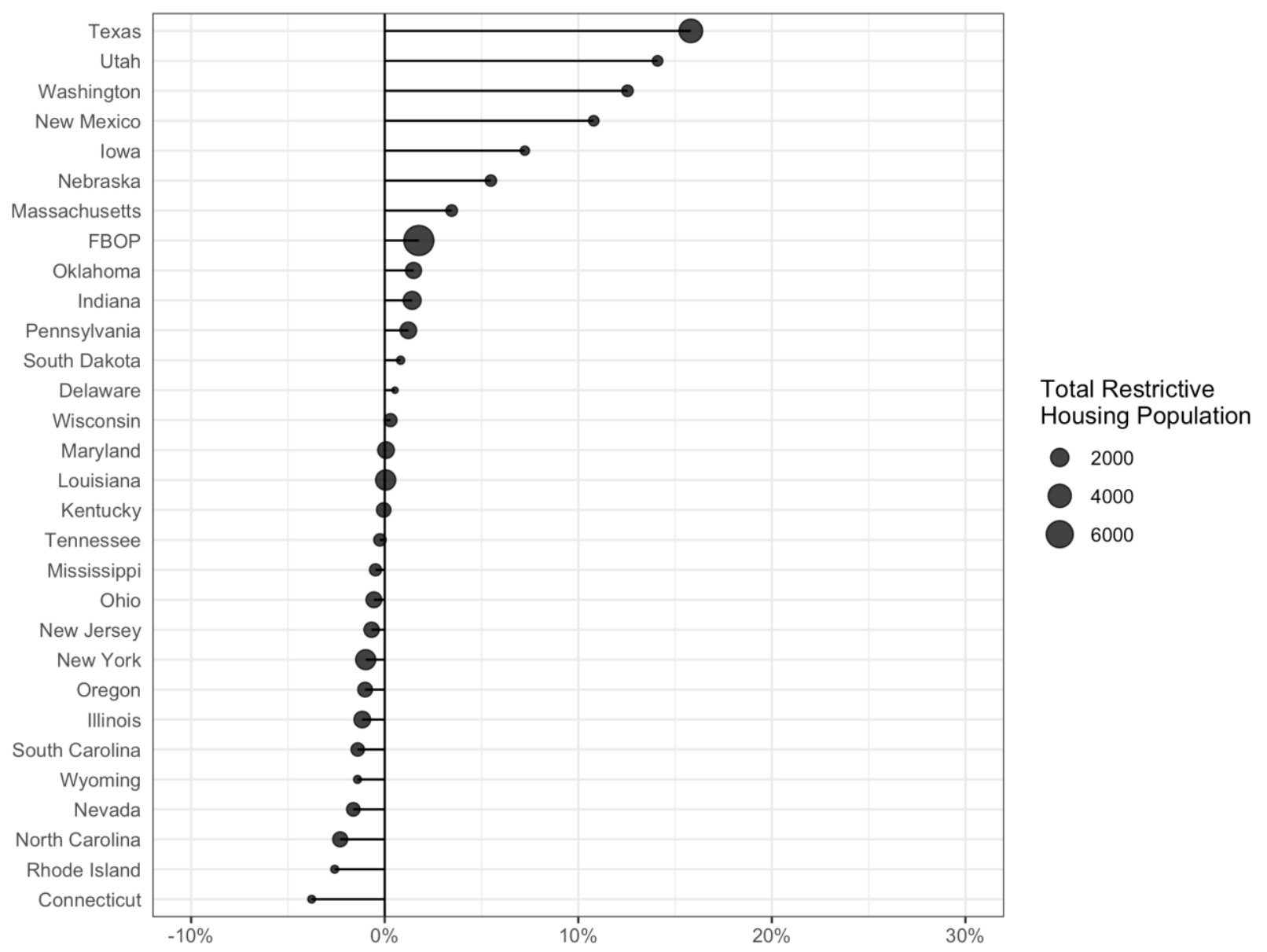

*The jurisdictions included in this graph reported more than 25 people in restrictive housing.

In 29 of the 33 reporting jurisdictions, the male restrictive housing population contained a smaller percentage of White prisoners than the total male custodial population. As detailed below, jurisdictions reported a small percentage of Asian, Native American or Alaskan Native, and Native Hawaiian or Pacific Islander prisoners in their general prison populations and a similarly small percentage in their populations in restrictive housing. ${ }^{52}$ Those categorized as "Other" appeared to be comparable in percentages in the general and in the restrictive housing populations. Given the small numbers of individuals, we do not provide details.

Table 7 lists by jurisdiction and by race/ethnicity the number of male prisoners in the general population and in restrictive housing. Table 8 compares the percentages by race and ethnicity of all male prisoners and of those in restrictive housing. 
Table 7 Demographic Composition of Total Male Custodial Population and Male Restrictive Housing Population $(\mathbf{n}=33)^{53}$

Total Custodial Population

\begin{tabular}{|c|c|c|c|c|c|c|c|c|c|c|c|c|c|c|c|c|}
\hline & & & & & & & & & \\
\hline & White & Black & Hisp. & Asian & NHPI & $\begin{array}{l}\text { Am. } \\
\text { Ind. }\end{array}$ & Other & Total & White & Black & Hisp. & Asian & NHPI & $\begin{array}{l}\text { Am. } \\
\text { Ind. }\end{array}$ & Other & Total \\
\hline Alabama & 8,115 & 12,033 & & & & & 120 & 20,268 & 240 & 611 & & & & & 1 & 852 \\
\hline Colorado & 7,489 & 3,025 & 5,396 & 190 & & 523 & 1 & 16,624 & 2 & 2 & 6 & 0 & 0 & 0 & 0 & 10 \\
\hline Connecticut & 3,970 & 5,563 & 3,554 & 57 & & 38 & & 13,182 & 15 & 37 & 16 & 0 & 0 & 1 & 0 & 69 \\
\hline Delaware & 1,408 & 2,516 & 169 & 5 & & 0 & 2 & 4,100 & 17 & 23 & 2 & 1 & & 0 & 0 & 43 \\
\hline FBOP & 41,116 & 57,914 & 38,629 & 1,902 & & 3,201 & & 142,762 & 2,126 & 3,137 & 2,269 & 64 & & 277 & & 7,873 \\
\hline Illinois & 11,505 & 22,827 & 5,228 & 142 & 0 & 43 & 22 & 39,767 & 257 & 1,065 & 181 & 3 & 0 & 1 & 3 & 1,510 \\
\hline Indiana & 14,070 & 8,553 & 1,026 & 59 & 12 & 41 & 86 & 23,847 & 1,131 & 663 & 110 & 3 & 2 & 5 & 9 & 1,923 \\
\hline Iowa & 4,890 & 2,000 & 500 & 60 & & 128 & & 7,578 & 67 & 65 & 22 & 3 & & 2 & & 159 \\
\hline Kentucky & 15,063 & 4,760 & 312 & & & 11 & 318 & 20,464 & 698 & 228 & 14 & & & 1 & 10 & 951 \\
\hline Louisiana & 10,393 & 22,420 & 81 & 38 & 0 & 21 & & 32,953 & 569 & 2,126 & 8 & 4 & 0 & 2 & 0 & 2,709 \\
\hline Maryland & 4,702 & 14,829 & 753 & 59 & 9 & 98 & 273 & 20,723 & 400 & 965 & 56 & 2 & 1 & 6 & 83 & 1,513 \\
\hline Massachusetts & 3,618 & 2,356 & 2,245 & 121 & 0 & 56 & 63 & 8,459 & 149 & 132 & 126 & 9 & 0 & 1 & 3 & 420 \\
\hline Mississippi & 3,922 & 7,976 & 105 & 20 & & 14 & 1 & 12,038 & 166 & 335 & 2 & & & 1 & & 504 \\
\hline Nebraska & 2,469 & 1,363 & 657 & 36 & 5 & 196 & 36 & 4,762 & 174 & 113 & 75 & 1 & 0 & 23 & 3 & 389 \\
\hline Nevada & 5,117 & 3,939 & 2,768 & 342 & & 219 & 49 & 12,434 & 302 & 251 & 155 & 18 & & 22 & 3 & 751 \\
\hline New Jersey & 3,801 & 11,489 & 2,908 & 113 & 1 & 7 & 275 & 18,594 & 245 & 701 & 171 & 5 & 1 & 0 & 20 & 1,143 \\
\hline New Mexico & 1,560 & 544 & 3,679 & 13 & 18 & 447 & 35 & 6,296 & 50 & 23 & 189 & & & 9 & 2 & 273 \\
\hline New York & 11,337 & 23,561 & 11,979 & 236 & 0 & 397 & 897 & 48,407 & 476 & 1,451 & 625 & 6 & 0 & 21 & 51 & 2,630 \\
\hline North Carolina & 12,841 & 18,729 & 1,683 & 93 & & & 980 & 34,326 & 279 & 715 & 28 & 1 & & & 53 & 1076 \\
\hline North Dakota & 1,063 & 160 & 99 & 7 & 0 & 273 & 4 & 1,606 & 4 & 1 & & & & 4 & & 9 \\
\hline Ohio & 22,765 & 21,378 & 1,263 & 60 & & 71 & 259 & 45,796 & 509 & 725 & 28 & 2 & & 2 & 7 & 1,273 \\
\hline Oklahoma & 12,545 & 6,677 & 1,905 & 71 & 23 & 2,555 & 40 & 23,816 & 547 & 454 & 128 & 2 & 5 & 210 & 3 & 1,349 \\
\hline Oregon & 9,804 & 1,245 & 1,713 & 196 & 4 & 339 & 1 & 13,302 & 697 & 128 & 119 & 13 & 1 & 45 & 0 & 1,003 \\
\hline Pennsylvania & 17,995 & 21,460 & 4,536 & 118 & & 27 & 164 & 44,300 & 489 & 820 & 171 & 5 & 0 & 0 & 7 & 1,492 \\
\hline Rhode Island & 1,083 & 831 & 715 & 44 & & 19 & 30 & 2,722 & 28 & 29 & 18 & 1 & 0 & 0 & 0 & 76 \\
\hline
\end{tabular}

ASCA-Liman Restrictive Housing 2018 revised September 252018 


\begin{tabular}{|c|c|c|c|c|c|c|c|c|c|c|c|c|c|c|c|c|}
\hline South Carolina & 6,338 & 11,534 & 438 & 26 & 1 & 21 & 125 & 18,483 & 207 & 498 & 7 & 1 & 0 & 0 & 5 & 718 \\
\hline South Dakota & 1,944 & 294 & 125 & 17 & 2 & 1,015 & 5 & 3,402 & 34 & 6 & 4 & 0 & 0 & 44 & 1 & 89 \\
\hline Tennessee & 10,659 & 9,007 & 457 & 66 & 0 & 25 & 0 & 20,214 & 288 & 245 & 11 & 2 & & & & 546 \\
\hline Texas & 41,571 & 45,170 & 45,734 & 453 & 0 & 97 & 204 & 133,229 & 1,051 & 1,023 & 2,094 & 7 & 0 & 1 & & 4,176 \\
\hline Utah & 3,665 & 413 & 1,176 & 62 & 118 & 291 & 97 & 5,822 & 110 & 27 & 95 & 3 & 12 & 24 & 6 & 277 \\
\hline Washington & 9,210 & 2,977 & 2,091 & 647 & & 699 & 150 & 15,774 & 208 & 58 & 105 & 14 & & 19 & 3 & 407 \\
\hline Wisconsin & 9,392 & 8,806 & 1,879 & & 234 & 719 & 10 & 21,040 & 197 & 370 & 61 & 4 & 0 & 29 & 0 & 661 \\
\hline Wyoming & 1,413 & 106 & 248 & 5 & 0 & 122 & 0 & 1,894 & 40 & 14 & 9 & 0 & 0 & 14 & 0 & 77 \\
\hline Total & 316,833 & 356,455 & 144,051 & 5,258 & 427 & 11,713 & 4,247 & 838,984 & 11,772 & 17,041 & 6,905 & 174 & 22 & 764 & 273 & 36,951 \\
\hline
\end{tabular}


Table 8 Demographic Percentage Composition of Total Male Custodial Population and Male Restrictive Housing Population

$(\mathbf{n}=33)$

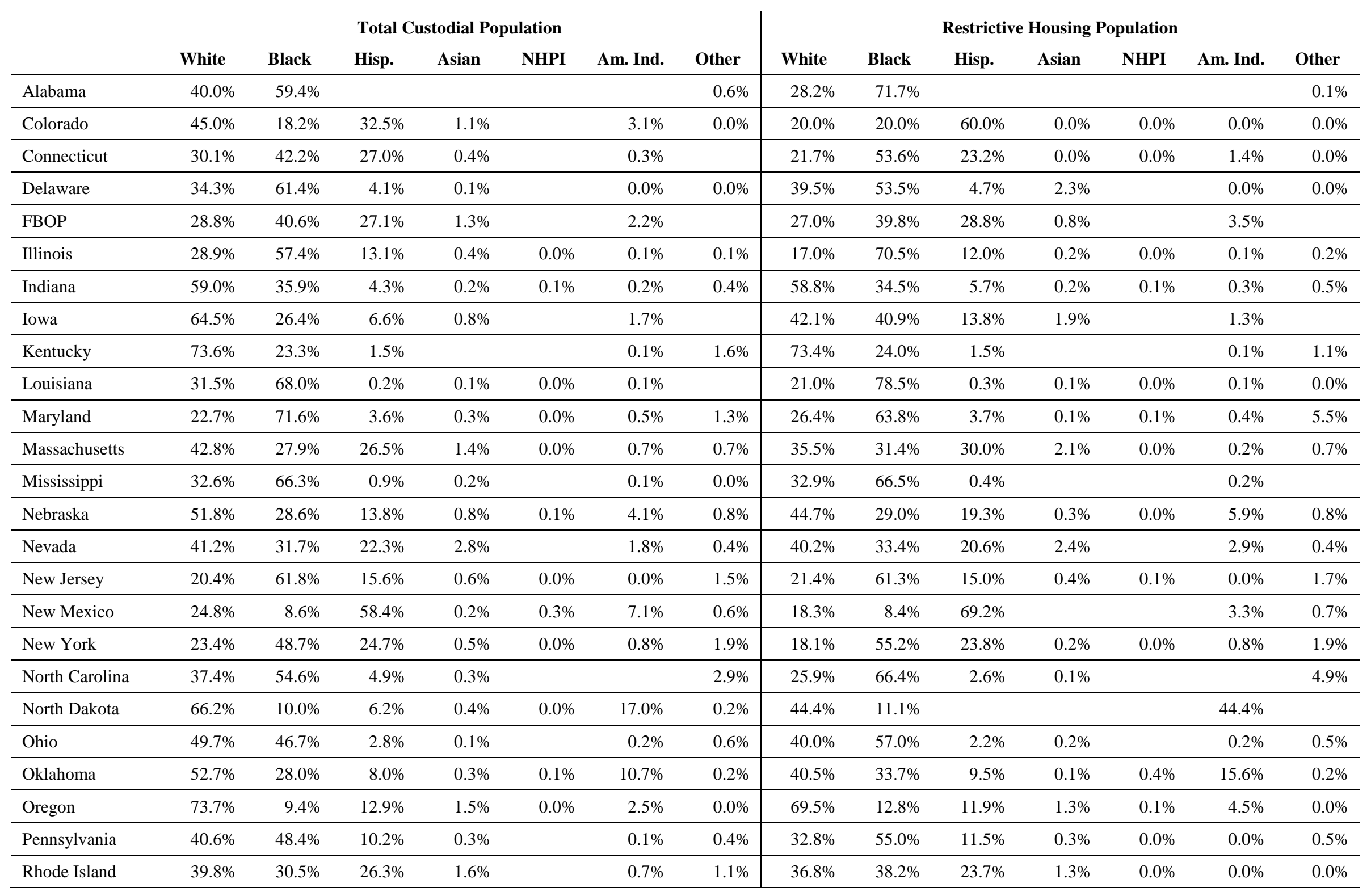

ASCA-Liman Restrictive Housing 2018 revised September 252018 


\begin{tabular}{|c|c|c|c|c|c|c|c|c|c|c|c|c|c|c|}
\hline South Carolina & $34.3 \%$ & $62.4 \%$ & $2.4 \%$ & $0.1 \%$ & $0.0 \%$ & $0.1 \%$ & $0.7 \%$ & $28.8 \%$ & $69.4 \%$ & $1.0 \%$ & $0.1 \%$ & $0.0 \%$ & $0.0 \%$ & $0.7 \%$ \\
\hline South Dakota & $57.1 \%$ & $8.6 \%$ & $3.7 \%$ & $0.5 \%$ & $0.1 \%$ & $29.8 \%$ & $0.1 \%$ & $38.2 \%$ & $6.7 \%$ & $4.5 \%$ & $0.0 \%$ & $0.0 \%$ & $49.4 \%$ & $1.1 \%$ \\
\hline Tennessee & $52.7 \%$ & $44.6 \%$ & $2.3 \%$ & $0.3 \%$ & $0.0 \%$ & $0.1 \%$ & $0.0 \%$ & $52.7 \%$ & $44.9 \%$ & $2.0 \%$ & $0.4 \%$ & & & \\
\hline Texas & $31.2 \%$ & $33.9 \%$ & $34.3 \%$ & $0.3 \%$ & $0.0 \%$ & $0.1 \%$ & $0.2 \%$ & $25.2 \%$ & $24.5 \%$ & $50.1 \%$ & $0.2 \%$ & $0.0 \%$ & $0.0 \%$ & \\
\hline Utah & $63.0 \%$ & $7.1 \%$ & $20.2 \%$ & $1.1 \%$ & $2.0 \%$ & $5.0 \%$ & $1.7 \%$ & $39.7 \%$ & $9.7 \%$ & $34.3 \%$ & $1.1 \%$ & $4.3 \%$ & $8.7 \%$ & $2.2 \%$ \\
\hline Washington & $58.4 \%$ & $18.9 \%$ & $13.3 \%$ & $4.1 \%$ & & $4.4 \%$ & $1.0 \%$ & $51.1 \%$ & $14.3 \%$ & $25.8 \%$ & $3.4 \%$ & & $4.7 \%$ & $0.7 \%$ \\
\hline Wisconsin & $44.6 \%$ & $41.9 \%$ & $8.9 \%$ & & $1.1 \%$ & $3.4 \%$ & $0.0 \%$ & $29.8 \%$ & $56.0 \%$ & $9.2 \%$ & $0.6 \%$ & $0.0 \%$ & $4.4 \%$ & $0.0 \%$ \\
\hline Wyoming & $74.6 \%$ & $5.6 \%$ & $13.1 \%$ & $0.3 \%$ & $0.0 \%$ & $6.4 \%$ & $0.0 \%$ & $51.9 \%$ & $18.2 \%$ & $11.7 \%$ & $0.0 \%$ & $0.0 \%$ & $18.2 \%$ & $0.0 \%$ \\
\hline Median & $41.2 \%$ & $35.9 \%$ & $11.6 \%$ & $0.4 \%$ & $0.0 \%$ & $0.7 \%$ & $0.4 \%$ & $35.5 \%$ & $39.8 \%$ & $11.9 \%$ & $0.3 \%$ & $0.0 \%$ & $0.6 \%$ & $0.5 \%$ \\
\hline
\end{tabular}


Thirty-two jurisdictions provided data about race and ethnicity among women in restrictive housing. As with the male restrictive housing population, the percentage of Black female prisoners among all female prisoners in restrictive housing (39.8\%) was higher than the percentage of Black female prisoners among all female prisoners in the total custodial population (22.8\%). In 19 of the 32 reporting jurisdictions, the female restrictive housing population contained a greater percentage of Black prisoners in restrictive housing than were in the total female custodial population. In 13 of the 32 jurisdictions, the female restrictive housing population had a lower percentage of Black prisoners than did the total female custodial population.

One of the 32 reporting jurisdictions did not use "Hispanic" as a racial category. ${ }^{54}$ Among the remaining 31 , Hispanic prisoners comprised $11.6 \%$ of the female restrictive housing population, as compared to $14.3 \%$ of the total female custodial population. In 14 of the 31 reporting jurisdictions, the female restrictive housing population contained a greater percentage of Hispanic prisoners than the total female custodial population. In 17 jurisdictions, the female restrictive housing population had a lower percentage of Hispanic prisoners than did the total female custodial population.

In 24 of the 32 reporting jurisdictions, the female restrictive housing population contained a smaller percentage of White prisoners than the total female custodial population. The percentages of other ethnicities were small and roughly comparable in both general and restrictive housing populations. Figure 10 provides an overview of these numbers, and Table 9 and Table 10 provide information by jurisdiction. Because in many jurisdictions the total number of women in restrictive housing is under 25 , we do not display pictorially the relative differences across jurisdictions. 
Table 9 Demographic Composition of Total Female Custodial Population and Female Restrictive Housing Population $(\mathbf{n}=32)^{55}$

Total Custodial Population

Restrictive Housing Population

\begin{tabular}{|c|c|c|c|c|c|c|c|c|c|c|c|c|c|c|c|c|}
\hline & & & & & & & & & \\
\hline & White & Black & Hisp. & Asian & NHPI & $\begin{array}{l}\text { Am. } \\
\text { Ind. }\end{array}$ & Other & Total & White & Black & Hisp. & Asian & NHPI & $\begin{array}{l}\text { Am. } \\
\text { Ind. }\end{array}$ & Other & Total \\
\hline Alabama & 909 & 414 & & & & & 1 & 1,324 & 1 & 2 & & & & & 0 & 3 \\
\hline Colorado & 925 & 196 & 462 & 16 & & 73 & 1 & 1,673 & 0 & 0 & 0 & 0 & & 0 & 0 & 0 \\
\hline Connecticut & 520 & 240 & 184 & 7 & & 4 & & 955 & 0 & 3 & 2 & 0 & 0 & 0 & 0 & 5 \\
\hline Delaware & 135 & 91 & 5 & 1 & & 1 & 0 & 233 & 0 & 0 & 0 & 0 & & 0 & 0 & 0 \\
\hline FBOP & 4,365 & 2,462 & 3,667 & 237 & & 346 & & 11,077 & 36 & 37 & 25 & 0 & & 3 & & 101 \\
\hline Illinois & 1,243 & 920 & 189 & 16 & 0 & 16 & 26 & 2,410 & 14 & 34 & 1 & 1 & 0 & 0 & 0 & 50 \\
\hline Indiana & 2,016 & 367 & 49 & 4 & 2 & 9 & 23 & 2,470 & 32 & 15 & 0 & 0 & 0 & 0 & 1 & 48 \\
\hline Iowa & 538 & 109 & 34 & 0 & 0 & 24 & & 705 & 6 & 1 & 1 & 0 & & 0 & & 8 \\
\hline Kentucky & 2,875 & 207 & 18 & & & 2 & 38 & 3,140 & 51 & 11 & 1 & & & 0 & 1 & 64 \\
\hline Maryland & 484 & 539 & 12 & 3 & 0 & 6 & 18 & 1,062 & 12 & 17 & 0 & 0 & 0 & 0 & 2 & 31 \\
\hline Massachusetts & 397 & 90 & 49 & 1 & 0 & 0 & 51 & 588 & 16 & 2 & 4 & 0 & 0 & 0 & 1 & 23 \\
\hline Mississippi & 536 & 357 & 3 & 3 & & 2 & 1 & 902 & 8 & 17 & & & & & & 25 \\
\hline Nebraska & 267 & 79 & 40 & 1 & 1 & 22 & 6 & 416 & 1 & 3 & 1 & 0 & 0 & 1 & 2 & 8 \\
\hline Nevada & 757 & 303 & 148 & 44 & & 23 & 5 & 1,280 & 25 & 24 & 9 & 0 & & 1 & 0 & 59 \\
\hline New Jersey & 277 & 376 & 101 & 10 & 1 & 0 & 9 & 774 & 9 & 20 & 1 & 0 & 0 & 0 & 0 & 30 \\
\hline New Mexico & 222 & 45 & 410 & 1 & 0 & 57 & 6 & 741 & 7 & 1 & 12 & & & 1 & & 21 \\
\hline New York & 1,149 & 812 & 323 & 13 & 0 & 21 & 39 & 2,357 & 21 & 10 & 5 & 0 & 0 & 0 & 0 & 36 \\
\hline $\begin{array}{l}\text { North } \\
\text { Carolina }\end{array}$ & 1,977 & 814 & 52 & 6 & & & 84 & 2,933 & 13 & 19 & 0 & 0 & & & 1 & 33 \\
\hline North Dakota & 132 & 11 & 5 & 0 & 0 & 76 & 0 & 224 & 0 & 0 & 0 & 0 & 0 & 0 & 0 & 0 \\
\hline Ohio & 3,093 & 1,014 & 34 & 9 & & 3 & 5 & 4,158 & 3 & 6 & 0 & 0 & & 0 & 0 & 9 \\
\hline Oklahoma & 1,892 & 451 & 163 & 5 & 7 & 553 & 8 & 3,079 & 4 & 6 & 2 & 0 & 0 & 7 & 0 & 19 \\
\hline Oregon & 1,077 & 84 & 50 & 23 & 0 & 38 & 0 & 1,272 & 24 & 3 & 0 & 0 & 0 & 1 & 0 & 28 \\
\hline Pennsylvania & 1,660 & 734 & 187 & 11 & & 13 & 15 & 2,620 & 4 & 1 & 1 & 0 & 0 & 0 & 0 & 6 \\
\hline
\end{tabular}




\begin{tabular}{|c|c|c|c|c|c|c|c|c|c|c|c|c|c|c|c|c|}
\hline Rhode Island & 83 & 23 & 17 & 1 & & 3 & 3 & 130 & 0 & 0 & 0 & 0 & & 0 & 0 & 0 \\
\hline $\begin{array}{l}\text { South } \\
\text { Carolina } \\
\end{array}$ & 939 & 471 & 27 & 0 & 0 & 6 & 12 & 1455 & 11 & 8 & 0 & 0 & 0 & 0 & 0 & 19 \\
\hline South Dakota & 243 & 10 & 16 & 3 & 0 & 252 & 1 & 525 & 1 & 0 & 0 & 0 & 0 & 0 & 0 & 1 \\
\hline Tennessee & 1,491 & 423 & 19 & 5 & 0 & 8 & 0 & 1,946 & 7 & 1 & 1 & & & & & 9 \\
\hline Texas & 6,219 & 2,985 & 2,915 & 31 & 0 & 18 & 12 & 12,180 & 20 & 51 & 22 & 0 & 0 & 0 & & 93 \\
\hline Utah & 341 & 18 & 60 & 3 & 13 & 30 & 6 & 471 & 4 & 0 & 1 & 0 & 0 & 0 & 0 & 5 \\
\hline Washington & 820 & 131 & 190 & 52 & & 97 & 12 & 1,302 & 1 & & 1 & & & & & 2 \\
\hline Wisconsin & 1,033 & 325 & 39 & & 19 & 122 & 1 & 1,539 & 23 & 22 & 2 & 0 & 0 & 5 & 0 & 52 \\
\hline Wyoming & 205 & 4 & 26 & 2 & 0 & 23 & 0 & 260 & 1 & 1 & 0 & 0 & 0 & 2 & 0 & 4 \\
\hline Total & 38,820 & 15,105 & 9,494 & 508 & 43 & 1,848 & 383 & 66,201 & 355 & 315 & 92 & 1 & 0 & 21 & 8 & 792 \\
\hline
\end{tabular}


Table 10 Demographic Percentage Composition of Total Female Custodial Population and Female Restrictive Housing Population

$(\mathbf{n}=32)$

\begin{tabular}{|c|c|c|c|c|c|c|c|c|c|c|c|c|c|c|}
\hline & \multicolumn{7}{|c|}{ Total Custodial Population } & \multicolumn{7}{|c|}{ Restrictive Housing Population } \\
\hline & White & Black & Hisp. & Asian & NHPI & Am. Ind. & Other & White & Black & Hisp. & Asian & NHPI & Am. Ind. & Other \\
\hline Alabama & $68.7 \%$ & $31.3 \%$ & & & & & $0.1 \%$ & $33.3 \%$ & $66.7 \%$ & & & & & $0.0 \%$ \\
\hline Colorado & $55.3 \%$ & $11.7 \%$ & $27.6 \%$ & $1.0 \%$ & & $4.4 \%$ & $0.1 \%$ & $0.0 \%$ & $0.0 \%$ & $0.0 \%$ & $0.0 \%$ & & $0.0 \%$ & $0.0 \%$ \\
\hline Connecticut & $54.5 \%$ & $25.1 \%$ & $19.3 \%$ & $0.7 \%$ & & $0.4 \%$ & & $0.0 \%$ & $60.0 \%$ & $40.0 \%$ & $0.0 \%$ & $0.0 \%$ & $0.0 \%$ & $0.0 \%$ \\
\hline Delaware & $57.9 \%$ & $39.1 \%$ & $2.1 \%$ & $0.4 \%$ & & $0.4 \%$ & $0.0 \%$ & $0.0 \%$ & $0.0 \%$ & $0.0 \%$ & $0.0 \%$ & & $0.0 \%$ & $0.0 \%$ \\
\hline FBOP & $39.4 \%$ & $22.2 \%$ & $33.1 \%$ & $2.1 \%$ & & $3.1 \%$ & & $35.6 \%$ & $36.6 \%$ & $24.8 \%$ & $0.0 \%$ & & $3.0 \%$ & \\
\hline Illinois & $51.6 \%$ & $38.2 \%$ & $7.8 \%$ & $0.7 \%$ & $0.0 \%$ & $0.7 \%$ & $1.1 \%$ & $28.0 \%$ & $68.0 \%$ & $2.0 \%$ & $2.0 \%$ & $0.0 \%$ & $0.0 \%$ & $0.0 \%$ \\
\hline Indiana & $81.6 \%$ & $14.9 \%$ & $2.0 \%$ & $0.2 \%$ & $0.1 \%$ & $0.4 \%$ & $0.9 \%$ & $66.7 \%$ & $31.2 \%$ & $0.0 \%$ & $0.0 \%$ & $0.0 \%$ & $0.0 \%$ & $2.1 \%$ \\
\hline Iowa & $76.3 \%$ & $15.5 \%$ & $4.8 \%$ & $0.0 \%$ & $0.0 \%$ & $3.4 \%$ & & $75.0 \%$ & $12.5 \%$ & $12.5 \%$ & $0.0 \%$ & & & \\
\hline Kentucky & $91.6 \%$ & $6.6 \%$ & $0.6 \%$ & & & $0.1 \%$ & $1.2 \%$ & $79.7 \%$ & $17.2 \%$ & $1.6 \%$ & & & $0.0 \%$ & $1.6 \%$ \\
\hline Maryland & $45.6 \%$ & $50.8 \%$ & $1.1 \%$ & $0.3 \%$ & $0.0 \%$ & $0.6 \%$ & $1.7 \%$ & $38.7 \%$ & $54.8 \%$ & $0.0 \%$ & $0.0 \%$ & $0.0 \%$ & $0.0 \%$ & $6.5 \%$ \\
\hline Massachusetts & $67.5 \%$ & $15.3 \%$ & $8.3 \%$ & $0.2 \%$ & $0.0 \%$ & $0.0 \%$ & $8.7 \%$ & $69.6 \%$ & $8.7 \%$ & $17.4 \%$ & $0.0 \%$ & $0.0 \%$ & $0.0 \%$ & $4.3 \%$ \\
\hline Mississippi & $59.4 \%$ & $39.6 \%$ & $0.3 \%$ & $0.3 \%$ & & $0.2 \%$ & $0.1 \%$ & $32.0 \%$ & $68.0 \%$ & & & & & \\
\hline Nebraska & $64.2 \%$ & $19.0 \%$ & $9.6 \%$ & $0.2 \%$ & $0.2 \%$ & $5.3 \%$ & $1.4 \%$ & $12.5 \%$ & $37.5 \%$ & $12.5 \%$ & $0.0 \%$ & $0.0 \%$ & $12.5 \%$ & $25.0 \%$ \\
\hline Nevada & $59.1 \%$ & $23.7 \%$ & $11.6 \%$ & $3.4 \%$ & & $1.8 \%$ & $0.4 \%$ & $42.4 \%$ & $40.7 \%$ & $15.3 \%$ & $0.0 \%$ & & $1.7 \%$ & $0.0 \%$ \\
\hline New Jersey & $35.8 \%$ & $48.6 \%$ & $13.0 \%$ & $1.3 \%$ & $0.1 \%$ & $0.0 \%$ & $1.2 \%$ & $30.0 \%$ & $66.7 \%$ & $3.3 \%$ & $0.0 \%$ & $0.0 \%$ & $0.0 \%$ & $0.0 \%$ \\
\hline New Mexico & $30.0 \%$ & $6.1 \%$ & $55.3 \%$ & $0.1 \%$ & $0.0 \%$ & $7.7 \%$ & $0.8 \%$ & $33.3 \%$ & $4.8 \%$ & $57.1 \%$ & & & $4.8 \%$ & \\
\hline New York & $48.7 \%$ & $34.5 \%$ & $13.7 \%$ & $0.6 \%$ & $0.0 \%$ & $0.9 \%$ & $1.7 \%$ & $58.3 \%$ & $27.8 \%$ & $13.9 \%$ & $0.0 \%$ & $0.0 \%$ & $0.0 \%$ & $0.0 \%$ \\
\hline North Carolina & $67.4 \%$ & $27.8 \%$ & $1.8 \%$ & $0.2 \%$ & & & $2.9 \%$ & $39.4 \%$ & $57.6 \%$ & $0.0 \%$ & $0.0 \%$ & & & $3.0 \%$ \\
\hline North Dakota & $58.9 \%$ & $4.9 \%$ & $2.2 \%$ & $0.0 \%$ & $0.0 \%$ & $33.9 \%$ & $0.0 \%$ & $0.0 \%$ & $0.0 \%$ & $0.0 \%$ & $0.0 \%$ & $0.0 \%$ & $0.0 \%$ & $0.0 \%$ \\
\hline Ohio & $74.4 \%$ & $24.4 \%$ & $0.8 \%$ & $0.2 \%$ & & $0.1 \%$ & $0.1 \%$ & $33.3 \%$ & $66.7 \%$ & $0.0 \%$ & $0.0 \%$ & & $0.0 \%$ & $0.0 \%$ \\
\hline Oklahoma & $61.4 \%$ & $14.6 \%$ & $5.3 \%$ & $0.2 \%$ & $0.2 \%$ & $18.0 \%$ & $0.3 \%$ & $21.1 \%$ & $31.6 \%$ & $10.5 \%$ & $0.0 \%$ & $0.0 \%$ & $36.8 \%$ & $0.0 \%$ \\
\hline Oregon & $84.7 \%$ & $6.6 \%$ & $3.9 \%$ & $1.8 \%$ & $0.0 \%$ & $3.0 \%$ & $0.0 \%$ & $85.7 \%$ & $10.7 \%$ & $0.0 \%$ & $0.0 \%$ & $0.0 \%$ & $3.6 \%$ & $0.0 \%$ \\
\hline Pennsylvania & $63.4 \%$ & $28.0 \%$ & $7.1 \%$ & $0.4 \%$ & & $0.5 \%$ & $0.6 \%$ & $66.7 \%$ & $16.7 \%$ & $16.7 \%$ & $0.0 \%$ & $0.0 \%$ & $0.0 \%$ & $0.0 \%$ \\
\hline
\end{tabular}

ASCA-Liman Restrictive Housing 2018 revised September 252018 


\begin{tabular}{|c|c|c|c|c|c|c|c|c|c|c|c|c|c|c|}
\hline Rhode Island & $63.8 \%$ & $17.7 \%$ & $13.1 \%$ & $0.8 \%$ & & $2.3 \%$ & $2.3 \%$ & $0.0 \%$ & $0.0 \%$ & $0.0 \%$ & $0.0 \%$ & & $0.0 \%$ & $0.0 \%$ \\
\hline South Carolina & $64.5 \%$ & $32.4 \%$ & $1.9 \%$ & $0.0 \%$ & $0.0 \%$ & $0.4 \%$ & $0.8 \%$ & $57.9 \%$ & $42.1 \%$ & $0.0 \%$ & $0.0 \%$ & $0.0 \%$ & $0.0 \%$ & $0.0 \%$ \\
\hline South Dakota & $46.3 \%$ & $1.9 \%$ & $3.0 \%$ & $0.6 \%$ & $0.0 \%$ & $48.0 \%$ & $0.2 \%$ & $100.0 \%$ & $0.0 \%$ & $0.0 \%$ & $0.0 \%$ & $0.0 \%$ & $0.0 \%$ & $0.0 \%$ \\
\hline Tennessee & $76.6 \%$ & $21.7 \%$ & $1.0 \%$ & $0.3 \%$ & $0.0 \%$ & $0.4 \%$ & $0.0 \%$ & $77.8 \%$ & $11.1 \%$ & $11.1 \%$ & & & & \\
\hline Texas & $51.1 \%$ & $24.5 \%$ & $23.9 \%$ & $0.3 \%$ & $0.0 \%$ & $0.1 \%$ & $0.1 \%$ & $21.5 \%$ & $54.8 \%$ & $23.7 \%$ & $0.0 \%$ & $0.0 \%$ & $0.0 \%$ & \\
\hline Utah & $72.4 \%$ & $3.8 \%$ & $12.7 \%$ & $0.6 \%$ & $2.8 \%$ & $6.4 \%$ & $1.3 \%$ & $80.0 \%$ & $0.0 \%$ & $20.0 \%$ & $0.0 \%$ & $0.0 \%$ & $0.0 \%$ & $0.0 \%$ \\
\hline Washington & $63.0 \%$ & $10.1 \%$ & $14.6 \%$ & $4.0 \%$ & & $7.5 \%$ & $0.9 \%$ & $50.0 \%$ & & $50.0 \%$ & & & & \\
\hline Wisconsin & $67.1 \%$ & $21.1 \%$ & $2.5 \%$ & & $1.2 \%$ & $7.9 \%$ & $0.1 \%$ & $44.2 \%$ & $42.3 \%$ & $3.8 \%$ & $0.0 \%$ & $0.0 \%$ & $9.6 \%$ & $0.0 \%$ \\
\hline Wyoming & $78.8 \%$ & $1.5 \%$ & $10.0 \%$ & $0.8 \%$ & $0.0 \%$ & $8.8 \%$ & $0.0 \%$ & $25.0 \%$ & $25.0 \%$ & $0.0 \%$ & $0.0 \%$ & $0.0 \%$ & $50.0 \%$ & $0.0 \%$ \\
\hline Median & $63.2 \%$ & $21.4 \%$ & $7.1 \%$ & $0.4 \%$ & $0.0 \%$ & $1.4 \%$ & $0.6 \%$ & $37.2 \%$ & $31.2 \%$ & $3.6 \%$ & $0.0 \%$ & $0.0 \%$ & $0.0 \%$ & $0.0 \%$ \\
\hline
\end{tabular}


Age

The question of the placement of juveniles, variously defined as from under 18 to under 24 , has come to the fore in a variety of contexts. For example, the ACA has called for the prohibition of confinement of persons under the age of $18 .^{56}$ The elderly incarcerated are yet another locus of concern.

To understand the age distribution in restrictive housing, we asked jurisdictions to provide information about the age of prisoners in cohorts ranging from under 18 to over 50 . We sought to understand the distribution of age cohorts within restrictive housing populations as well as in the total custodial population. Thirty-four jurisdictions responded with the numbers of male prisoners in the respective age cohorts, and 32 jurisdictions provided the numbers of female prisoners.

The 34 responding jurisdictions housed a total of 842,941 male prisoners in their total custodial populations, delineated by age cohorts as follows: 105,827 male prisoners were between the ages of 18 to $25 ; 269,179$ male prisoners were between the ages of 26 to $35 ; 306,980$ male prisoners were between the ages of 36 to 50; and 158,298 male prisoners were over the age of 50 . Four jurisdictions reported holding a total of 18 individuals (16 boys and two girls) under the age of 18 in restrictive housing. ${ }^{57}$

Within these 34 jurisdictions, $6.4 \%(6,734)$ of male prisoners between the ages of 18 to 25 in the total custodial population were in restrictive housing; $5.6 \%(14,957)$ of male prisoners between the ages of 26 to 35 were in restrictive housing, $4.0 \%(12,339)$ of male prisoners between the ages of 36 to 50 were in restrictive housing, and $2.3 \%(3,605)$ of male prisoners over the age of 50 were in restrictive housing.

The 32 jurisdictions that provided information about the age distribution of women in restrictive housing housed a total of 66,189 female prisoners in their total custodial populations in the following age cohorts: 8,024 female prisoners between the ages of 18 to 25; 24,960 female prisoners between the ages of 26 to $35 ; 24,146$ female prisoners between the ages of 36 to 50; and 8,880 female prisoners over the age of 50 .

Of those, $2.2 \%$ (173) of women between the ages of 18 to 25 in the total custodial population were in restrictive housing, 1.4\% (352) of women between the ages of 26 to 35 were in restrictive housing, $0.9 \%$ (215) of women between the ages of 36 to 50 were in restrictive housing, and $0.9 \%$ (77) of women over the age of 50 were in restrictive housing.

We provide the aggregate information in Figure 13 and Figure 14. We provide jurisdictionby-jurisdiction data in Table 11, Table 12, Table 13, and Table 14. 
Figure 13 Age Distribution of Male Prisoners in Restrictive Housing and Total

Custodial Population

$(\mathbf{n}=34)$

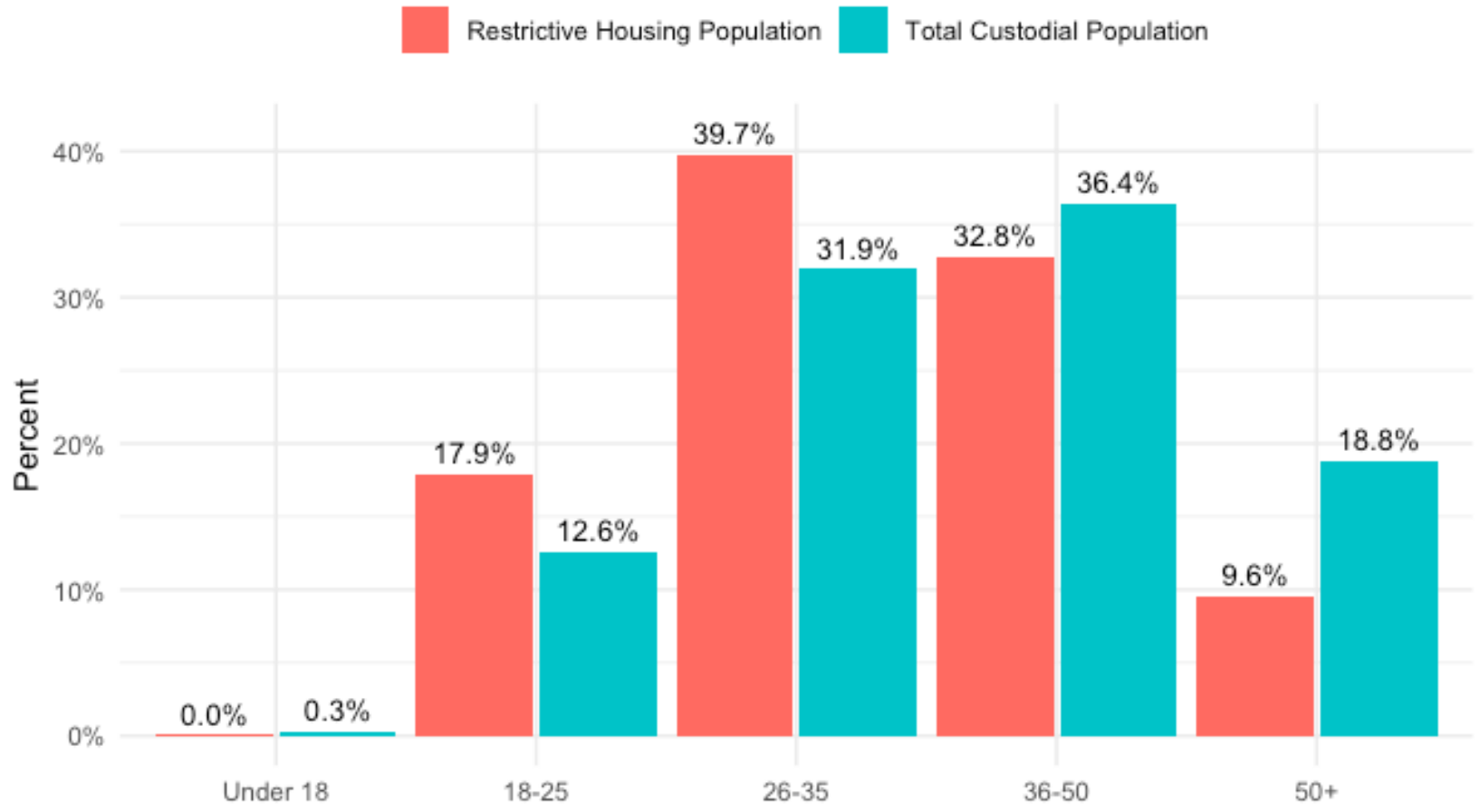

Figure 14 Age Distribution of Female Prisoners in Restrictive Housing and Total Custodial Population

$(\mathbf{n}=32)$

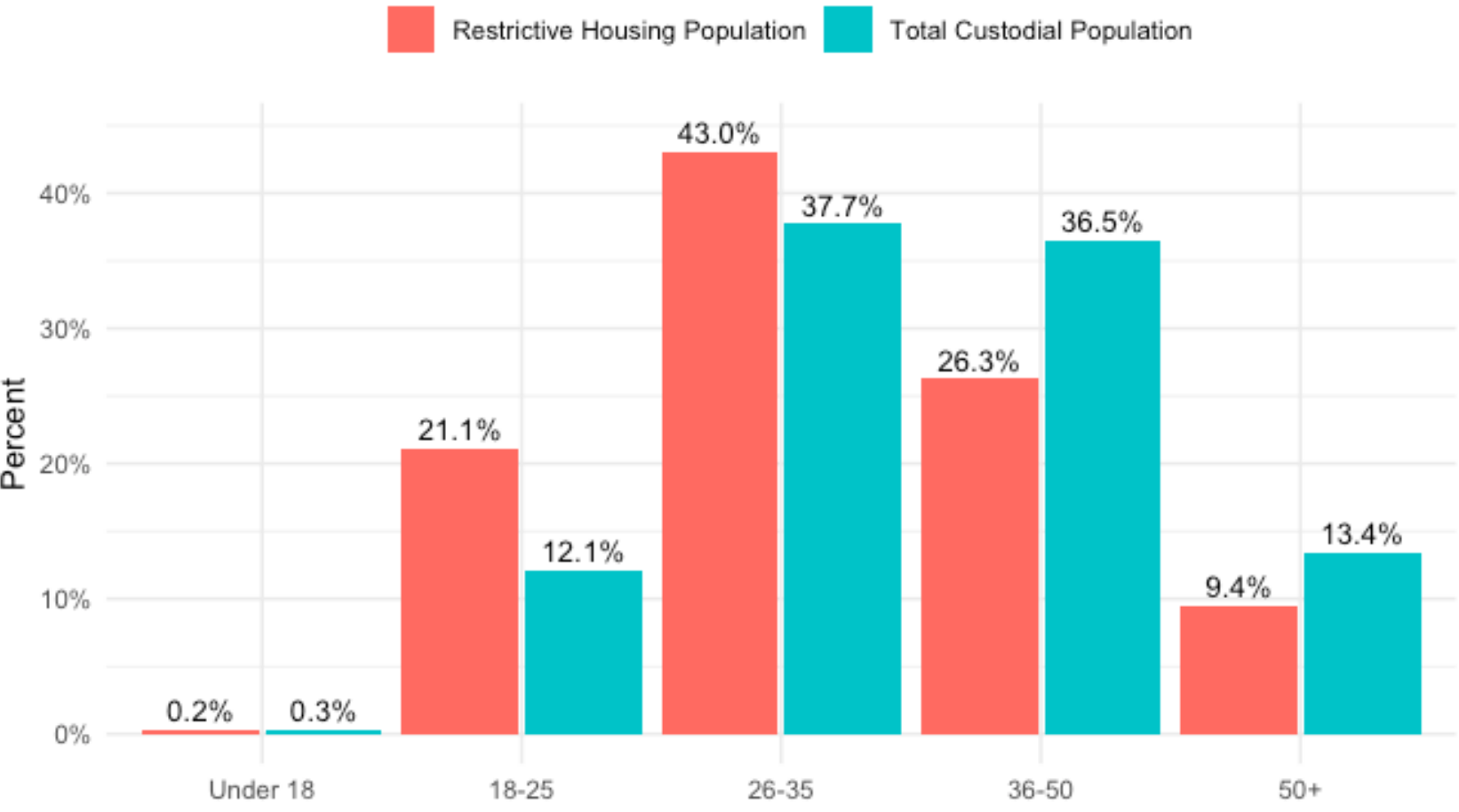


Table 11 Age Cohorts of Male Total Custodial Population and of Male Restrictive Housing Population

$$
(\mathbf{n}=\mathbf{3 4})^{\mathbf{5 8}}
$$

Total Custodial Population

Restrictive Housing Population

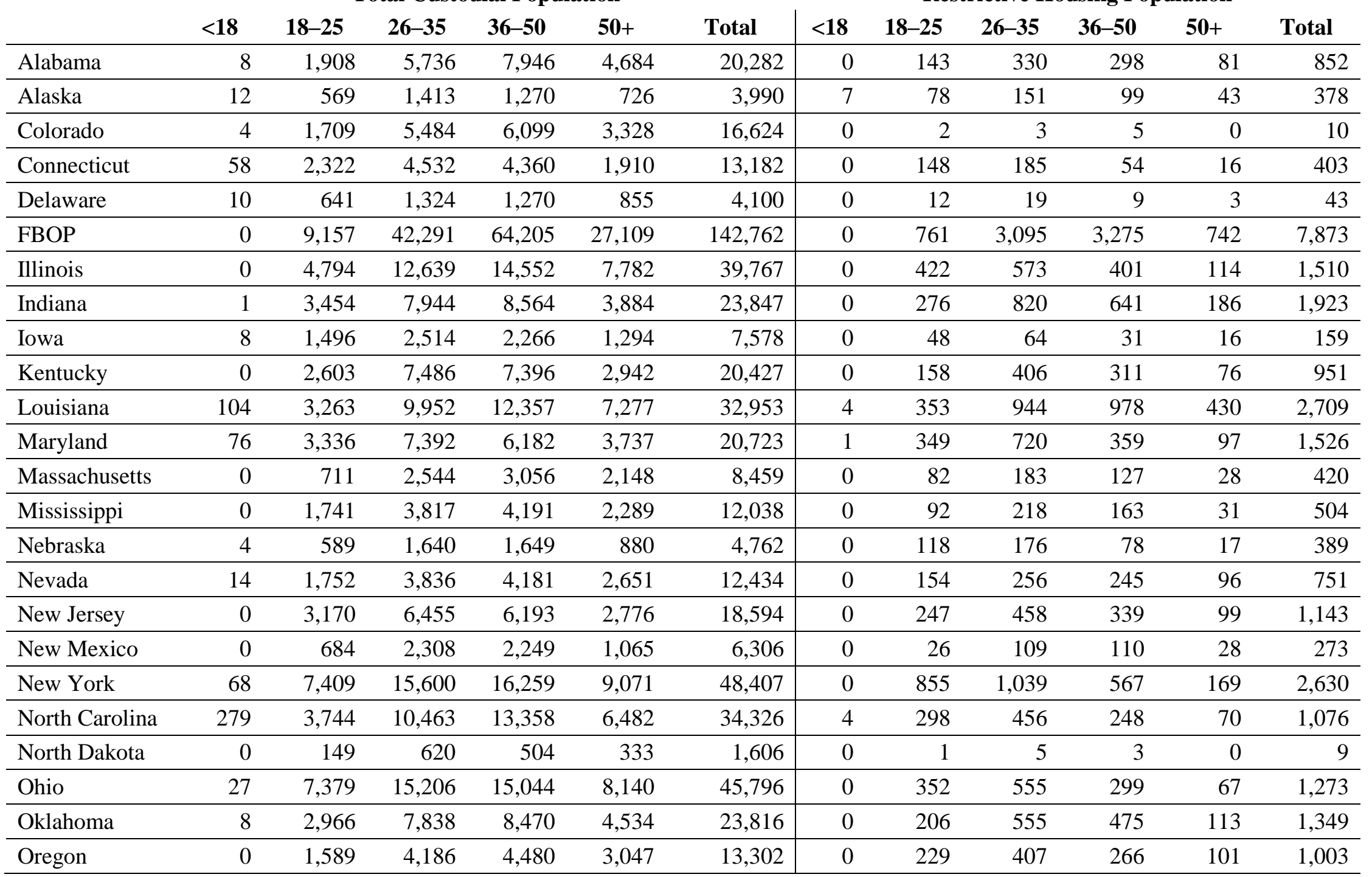




\begin{tabular}{|c|c|c|c|c|c|c|c|c|c|c|c|c|}
\hline Pennsylvania & 28 & 5,451 & 14,732 & 15,040 & 9,049 & 44,300 & 0 & 259 & 632 & 419 & 182 & 1,492 \\
\hline Rhode Island & 0 & 544 & 914 & 850 & 414 & 2,722 & 0 & 19 & 30 & 20 & 7 & 76 \\
\hline South Carolina & 40 & 2,686 & 6,119 & 6,320 & 3,318 & 18,483 & 0 & 181 & 324 & 170 & 43 & 718 \\
\hline South Dakota & 0 & 633 & 1,183 & 1,032 & 554 & 3,402 & 0 & 25 & 32 & 19 & 13 & 89 \\
\hline Tennessee & 9 & 2,363 & 6,549 & 7,723 & 3,570 & 20,214 & 0 & 87 & 259 & 168 & 32 & 546 \\
\hline Texas & 27 & 17,542 & 41,366 & 47,280 & 27,014 & 133,229 & 0 & 357 & 1,343 & 1,815 & 661 & 4,176 \\
\hline Utah & 1 & 566 & 1,933 & 2,145 & 1,177 & 5,822 & 0 & 70 & 143 & 59 & 5 & 277 \\
\hline Washington & 1,871 & 5,338 & 5,691 & 2,844 & & 15,744 & 0 & 84 & 185 & 105 & 33 & 407 \\
\hline Wisconsin & 0 & 3,290 & 6,882 & 7,054 & 3,824 & 21,050 & 0 & 221 & 246 & 160 & 5 & 632 \\
\hline Wyoming & 0 & 279 & 590 & 591 & 434 & 1,894 & 0 & 21 & 36 & 23 & 1 & 81 \\
\hline Total & 2,657 & 105,827 & 269,179 & 306,980 & 158,298 & 842,941 & 16 & 6,734 & 14,957 & 12,339 & 3,605 & 37,651 \\
\hline
\end{tabular}


Table 12 Age Cohorts Percentage of Male Total Custodial Population and of Male Restrictive Housing Population

$(\mathbf{n}=34)$

\begin{tabular}{|c|c|c|c|c|c|c|c|c|c|c|}
\hline & \multicolumn{5}{|c|}{ Total Custodial Population } & \multicolumn{5}{|c|}{ Restrictive Housing Population } \\
\hline & $<18$ & $18-25$ & $26-35$ & $36-50$ & $50+$ & $<18$ & $18-25$ & $26-35$ & $36-50$ & $50+$ \\
\hline Alabama & $0.0 \%$ & $9.4 \%$ & $28.3 \%$ & $39.2 \%$ & $23.1 \%$ & $0.0 \%$ & $16.8 \%$ & $38.7 \%$ & $35.0 \%$ & $9.5 \%$ \\
\hline Alaska & $0.3 \%$ & $14.3 \%$ & $35.4 \%$ & $31.8 \%$ & $18.2 \%$ & $1.9 \%$ & $20.6 \%$ & $39.9 \%$ & $26.2 \%$ & $11.4 \%$ \\
\hline Colorado & $0.0 \%$ & $10.3 \%$ & $33.0 \%$ & $36.7 \%$ & $20.0 \%$ & $0.0 \%$ & $20.0 \%$ & $30.0 \%$ & $50.0 \%$ & $0.0 \%$ \\
\hline Connecticut & $0.4 \%$ & $17.6 \%$ & $34.4 \%$ & $33.1 \%$ & $14.5 \%$ & $0.0 \%$ & $36.7 \%$ & $45.9 \%$ & $13.4 \%$ & $4.0 \%$ \\
\hline Delaware & $0.2 \%$ & $15.6 \%$ & $32.3 \%$ & $31.0 \%$ & $20.9 \%$ & $0.0 \%$ & $27.9 \%$ & $44.2 \%$ & $20.9 \%$ & $7.0 \%$ \\
\hline FBOP & $0.0 \%$ & $6.4 \%$ & $29.6 \%$ & $45.0 \%$ & $19.0 \%$ & $0.0 \%$ & $9.7 \%$ & $39.3 \%$ & $41.6 \%$ & $9.4 \%$ \\
\hline Illinois & $0.0 \%$ & $12.1 \%$ & $31.8 \%$ & $36.6 \%$ & $19.6 \%$ & $0.0 \%$ & $27.9 \%$ & $37.9 \%$ & $26.6 \%$ & $7.5 \%$ \\
\hline Indiana & $0.0 \%$ & $14.5 \%$ & $33.3 \%$ & $35.9 \%$ & $16.3 \%$ & $0.0 \%$ & $14.4 \%$ & $42.6 \%$ & $33.3 \%$ & $9.7 \%$ \\
\hline Iowa & $0.1 \%$ & $19.7 \%$ & $33.2 \%$ & $29.9 \%$ & $17.1 \%$ & $0.0 \%$ & $30.2 \%$ & $40.3 \%$ & $19.5 \%$ & $10.1 \%$ \\
\hline Kentucky & $0.0 \%$ & $12.7 \%$ & $36.6 \%$ & $36.2 \%$ & $14.4 \%$ & $0.0 \%$ & $16.6 \%$ & $42.7 \%$ & $32.7 \%$ & $8.0 \%$ \\
\hline Louisiana & $0.3 \%$ & $9.9 \%$ & $30.2 \%$ & $37.5 \%$ & $22.1 \%$ & $0.1 \%$ & $13.0 \%$ & $34.8 \%$ & $36.1 \%$ & $15.9 \%$ \\
\hline Maryland & $0.4 \%$ & $16.1 \%$ & $35.7 \%$ & $29.8 \%$ & $18.0 \%$ & $0.1 \%$ & $22.9 \%$ & $47.2 \%$ & $23.5 \%$ & $6.4 \%$ \\
\hline Massachusetts & $0.0 \%$ & $8.4 \%$ & $30.1 \%$ & $36.1 \%$ & $25.4 \%$ & $0.0 \%$ & $19.5 \%$ & $43.6 \%$ & $30.2 \%$ & $6.7 \%$ \\
\hline Mississippi & $0.0 \%$ & $14.5 \%$ & $31.7 \%$ & $34.8 \%$ & $19.0 \%$ & $0.0 \%$ & $18.3 \%$ & $43.3 \%$ & $32.3 \%$ & $6.2 \%$ \\
\hline Nebraska & $0.1 \%$ & $12.4 \%$ & $34.4 \%$ & $34.6 \%$ & $18.5 \%$ & $0.0 \%$ & $30.3 \%$ & $45.2 \%$ & $20.1 \%$ & $4.4 \%$ \\
\hline Nevada & $0.1 \%$ & $14.1 \%$ & $30.9 \%$ & $33.6 \%$ & $21.3 \%$ & $0.0 \%$ & $20.5 \%$ & $34.1 \%$ & $32.6 \%$ & $12.8 \%$ \\
\hline New Jersey & $0.0 \%$ & $17.0 \%$ & $34.7 \%$ & $33.3 \%$ & $14.9 \%$ & $0.0 \%$ & $21.6 \%$ & $40.1 \%$ & $29.7 \%$ & $8.7 \%$ \\
\hline New Mexico & $0.0 \%$ & $10.8 \%$ & $36.6 \%$ & $35.7 \%$ & $16.9 \%$ & $0.0 \%$ & $9.5 \%$ & $39.9 \%$ & $40.3 \%$ & $10.3 \%$ \\
\hline New York & $0.1 \%$ & $15.3 \%$ & $32.2 \%$ & $33.6 \%$ & $18.7 \%$ & $0.0 \%$ & $32.5 \%$ & $39.5 \%$ & $21.6 \%$ & $6.4 \%$ \\
\hline North Carolina & $0.8 \%$ & $10.9 \%$ & $30.5 \%$ & $38.9 \%$ & $18.9 \%$ & $0.4 \%$ & $27.7 \%$ & $42.4 \%$ & $23.0 \%$ & $6.5 \%$ \\
\hline North Dakota & $0.0 \%$ & $9.3 \%$ & $38.6 \%$ & $31.4 \%$ & $20.7 \%$ & $0.0 \%$ & $11.1 \%$ & $55.6 \%$ & $33.3 \%$ & $0.0 \%$ \\
\hline Ohio & $0.1 \%$ & $16.1 \%$ & $33.2 \%$ & $32.9 \%$ & $17.8 \%$ & $0.0 \%$ & $27.7 \%$ & $43.6 \%$ & $23.5 \%$ & $5.3 \%$ \\
\hline Oklahoma & $0.0 \%$ & $12.5 \%$ & $32.9 \%$ & $35.6 \%$ & $19.0 \%$ & $0.0 \%$ & $15.3 \%$ & $41.1 \%$ & $35.2 \%$ & $8.4 \%$ \\
\hline Oregon & $0.0 \%$ & $11.9 \%$ & $31.5 \%$ & $33.7 \%$ & $22.9 \%$ & $0.0 \%$ & $22.8 \%$ & $40.6 \%$ & $26.5 \%$ & $10.1 \%$ \\
\hline
\end{tabular}




\begin{tabular}{|c|c|c|c|c|c|c|c|c|c|c|}
\hline Pennsylvania & $0.1 \%$ & $12.3 \%$ & $33.3 \%$ & $34.0 \%$ & $20.4 \%$ & $0.0 \%$ & $17.4 \%$ & $42.4 \%$ & $28.1 \%$ & $12.2 \%$ \\
\hline Rhode Island & $0.0 \%$ & $20.0 \%$ & $33.6 \%$ & $31.2 \%$ & $15.2 \%$ & $0.0 \%$ & $25.0 \%$ & $39.5 \%$ & $26.3 \%$ & $9.2 \%$ \\
\hline South Carolina & $0.2 \%$ & $14.5 \%$ & $33.1 \%$ & $34.2 \%$ & $18.0 \%$ & $0.0 \%$ & $25.2 \%$ & $45.1 \%$ & $23.7 \%$ & $6.0 \%$ \\
\hline South Dakota & $0.0 \%$ & $18.6 \%$ & $34.8 \%$ & $30.3 \%$ & $16.3 \%$ & $0.0 \%$ & $28.1 \%$ & $36.0 \%$ & $21.3 \%$ & $14.6 \%$ \\
\hline Tennessee & $0.0 \%$ & $11.7 \%$ & $32.4 \%$ & $38.2 \%$ & $17.7 \%$ & $0.0 \%$ & $15.9 \%$ & $47.4 \%$ & $30.8 \%$ & $5.9 \%$ \\
\hline Texas & $0.0 \%$ & $13.2 \%$ & $31.0 \%$ & $35.5 \%$ & $20.3 \%$ & $0.0 \%$ & $8.5 \%$ & $32.2 \%$ & $43.5 \%$ & $15.8 \%$ \\
\hline Utah & $0.0 \%$ & $9.7 \%$ & $33.2 \%$ & $36.8 \%$ & $20.2 \%$ & $0.0 \%$ & $25.3 \%$ & $51.6 \%$ & $21.3 \%$ & $1.8 \%$ \\
\hline Washington & $11.9 \%$ & $33.9 \%$ & $36.1 \%$ & $18.1 \%$ & & $0.0 \%$ & $20.6 \%$ & $45.5 \%$ & $25.8 \%$ & $8.1 \%$ \\
\hline Wisconsin & $0.0 \%$ & $15.6 \%$ & $32.7 \%$ & $33.5 \%$ & $18.2 \%$ & $0.0 \%$ & $35.0 \%$ & $38.9 \%$ & $25.3 \%$ & $0.8 \%$ \\
\hline Wyoming & $0.0 \%$ & $14.7 \%$ & $31.2 \%$ & $31.2 \%$ & $22.9 \%$ & $0.0 \%$ & $25.9 \%$ & $44.4 \%$ & $28.4 \%$ & $1.2 \%$ \\
\hline Median & $0.0 \%$ & $13.7 \%$ & $33.0 \%$ & $34.1 \%$ & $18.9 \%$ & $0.0 \%$ & $21.1 \%$ & $41.8 \%$ & $27.4 \%$ & $7.8 \%$ \\
\hline
\end{tabular}


Table 13 Age Cohorts of Female Total Custodial Population and of Female Restrictive Housing Population

$$
(\mathbf{n}=\mathbf{3 2})^{\mathbf{5 9}}
$$

Total Custodial Population

Restrictive Housing Population

\begin{tabular}{|c|c|c|c|c|c|c|c|c|c|c|c|c|}
\hline & $<18$ & 18-25 & 26-35 & $36-50$ & $>\mathbf{5 0}$ & Total & $<18$ & 18-25 & 26-35 & $36-50$ & $>\mathbf{5 0}$ & Total \\
\hline Alabama & 0 & 118 & 467 & 520 & 205 & 1,310 & 0 & 0 & 2 & 1 & 0 & 3 \\
\hline Colorado & 0 & 172 & 700 & 606 & 195 & 1,673 & 0 & 0 & 0 & 0 & 0 & 0 \\
\hline Connecticut & 4 & 147 & 390 & 316 & 98 & 955 & 0 & 1 & 2 & 0 & 0 & 3 \\
\hline Delaware & 0 & 44 & 87 & 72 & 30 & 233 & 0 & 0 & 0 & 0 & 0 & 0 \\
\hline FBOP & 0 & 912 & 3,465 & 4,563 & 2,137 & 11,077 & 0 & 11 & 53 & 31 & 6 & 101 \\
\hline Illinois & 0 & 216 & 844 & 911 & 439 & 2,410 & 0 & 24 & 12 & 13 & 1 & 50 \\
\hline Indiana & 0 & 339 & 1,032 & 886 & 213 & 2,470 & 0 & 14 & 17 & 13 & 4 & 48 \\
\hline Iowa & 0 & 128 & 267 & 237 & 73 & 705 & 0 & 4 & 4 & 0 & 0 & 8 \\
\hline Kentucky & 0 & 380 & 1,393 & 1,149 & 217 & 3,139 & 0 & 9 & 31 & 20 & 4 & 64 \\
\hline Maryland & 2 & 160 & 418 & 336 & 146 & 1,062 & 0 & 4 & 15 & 9 & 3 & 31 \\
\hline Massachusetts & 0 & 76 & 238 & 188 & 86 & 588 & 0 & 4 & 10 & 9 & 0 & 23 \\
\hline Mississippi & 0 & 101 & 352 & 324 & 125 & 902 & 0 & 6 & 10 & 6 & 3 & 25 \\
\hline Nebraska & 0 & 42 & 156 & 153 & 65 & 416 & 0 & 1 & 3 & 4 & 0 & 8 \\
\hline Nevada & 0 & 182 & 478 & 467 & 153 & 1,280 & 0 & 17 & 22 & 17 & 3 & 59 \\
\hline New Jersey & 0 & 90 & 286 & 268 & 130 & 774 & 0 & 6 & 13 & 9 & 2 & 30 \\
\hline New Mexico & 0 & 70 & 328 & 259 & 84 & 741 & 0 & 4 & 10 & 6 & 1 & 21 \\
\hline New York & 2 & 329 & 871 & 803 & 355 & 2,360 & 0 & 9 & 22 & 4 & 1 & 36 \\
\hline $\begin{array}{l}\text { North } \\
\text { Carolina }\end{array}$ & 27 & 285 & 1,050 & 1,183 & 388 & 2,933 & 1 & 6 & 17 & 8 & 1 & 33 \\
\hline North Dakota & 0 & 49 & 99 & 64 & 12 & 224 & 0 & 0 & 0 & 0 & 0 & 0 \\
\hline Ohio & 0 & 663 & 1,728 & 1,360 & 407 & 4,158 & 0 & 4 & 4 & 1 & 0 & 9 \\
\hline Oklahoma & 2 & 356 & 1,226 & 1,139 & 356 & 3,079 & 1 & 7 & 8 & 3 & 0 & 19 \\
\hline Oregon & 0 & 137 & 488 & 454 & 193 & 1,272 & 0 & 4 & 12 & 10 & 2 & 28 \\
\hline Pennsylvania & 1 & 308 & 1,019 & 886 & 406 & 2,620 & 0 & 1 & 3 & 2 & 0 & 6 \\
\hline
\end{tabular}




\begin{tabular}{lrrrrrr|rrrrrr}
\hline Rhode Island & 0 & 20 & 55 & 45 & 10 & 130 & 0 & 0 & 0 & 0 & 0 & 0 \\
\hline $\begin{array}{l}\text { South } \\
\text { Carolina }\end{array}$ & 2 & 179 & 539 & 531 & 204 & 1,455 & 0 & 3 & 11 & 3 & 2 & 19 \\
\hline South Dakota & 0 & 82 & 256 & 157 & 30 & 525 & 0 & 0 & 1 & 0 & 0 \\
\hline Tennessee & 0 & 147 & 769 & 808 & 222 & 1,946 & & & 4 & 2 & 3 \\
\hline Texas & 6 & 1,468 & 4,587 & 4,487 & 1,632 & 12,180 & 0 & 21 & 35 & 30 & 7 \\
\hline Utah & 0 & 51 & 196 & 182 & 42 & 471 & 0 & 3 & 2 & 0 & 0 \\
\hline Washington & 133 & 530 & 457 & 182 & & 1,302 & 0 & 1 & 1 & 0 & 0 \\
\hline Wisconsin & 0 & 210 & 632 & 505 & 192 & 1,539 & 0 & 9 & 25 & 13 & 34 \\
\hline Wyoming & 0 & 33 & 87 & 105 & 35 & 260 & 0 & 0 & 3 & 1 & 0 \\
\hline Total & 179 & 8,024 & 24,960 & 24,146 & 8,880 & 66,189 & 2 & 173 & 352 & 215 & 77 & 819 \\
\hline
\end{tabular}


Table 14 Age Cohorts Percentage of Female Total Custodial Population and of Female Restrictive Housing Population

$(\mathbf{n}=32)$

\begin{tabular}{|c|c|c|c|c|c|c|c|c|c|c|}
\hline & \multicolumn{5}{|c|}{ Total Custodial Population } & \multicolumn{5}{|c|}{ Restrictive Housing Population } \\
\hline & $<18$ & $18-25$ & $26-35$ & $36-50$ & $>\mathbf{5 0}$ & $<18$ & 18-25 & $26-35$ & $36-50$ & $>\mathbf{5 0}$ \\
\hline Alabama & $0.0 \%$ & $9.0 \%$ & $35.6 \%$ & $39.7 \%$ & $15.6 \%$ & $0.0 \%$ & $0.0 \%$ & $66.7 \%$ & $33.3 \%$ & $0.0 \%$ \\
\hline Colorado & $0.0 \%$ & $10.3 \%$ & $41.8 \%$ & $36.2 \%$ & $11.7 \%$ & $0.0 \%$ & $0.0 \%$ & $0.0 \%$ & $0.0 \%$ & $0.0 \%$ \\
\hline Connecticut & $0.4 \%$ & $15.4 \%$ & $40.8 \%$ & $33.1 \%$ & $10.3 \%$ & $0.0 \%$ & $33.3 \%$ & $66.7 \%$ & $0.0 \%$ & $0.0 \%$ \\
\hline Delaware & $0.0 \%$ & $18.9 \%$ & $37.3 \%$ & $30.9 \%$ & $12.9 \%$ & $0.0 \%$ & $0.0 \%$ & $0.0 \%$ & $0.0 \%$ & $0.0 \%$ \\
\hline FBOP & $0.0 \%$ & $8.2 \%$ & $31.3 \%$ & $41.2 \%$ & $19.3 \%$ & $0.0 \%$ & $10.9 \%$ & $52.5 \%$ & $30.7 \%$ & $5.9 \%$ \\
\hline Illinois & $0.0 \%$ & $9.0 \%$ & $35.0 \%$ & $37.8 \%$ & $18.2 \%$ & $0.0 \%$ & $48.0 \%$ & $24.0 \%$ & $26.0 \%$ & $2.0 \%$ \\
\hline Indiana & $0.0 \%$ & $13.7 \%$ & $41.8 \%$ & $35.9 \%$ & $8.6 \%$ & $0.0 \%$ & $29.2 \%$ & $35.4 \%$ & $27.1 \%$ & $8.3 \%$ \\
\hline Iowa & $0.0 \%$ & $18.2 \%$ & $37.9 \%$ & $33.6 \%$ & $10.4 \%$ & $0.0 \%$ & $50.0 \%$ & $50.0 \%$ & $0.0 \%$ & $0.0 \%$ \\
\hline Kentucky & $0.0 \%$ & $12.1 \%$ & $44.4 \%$ & $36.6 \%$ & $6.9 \%$ & $0.0 \%$ & $14.1 \%$ & $48.4 \%$ & $31.2 \%$ & $6.2 \%$ \\
\hline Maryland & $0.2 \%$ & $15.1 \%$ & $39.4 \%$ & $31.6 \%$ & $13.7 \%$ & $0.0 \%$ & $12.9 \%$ & $48.4 \%$ & $29.0 \%$ & $9.7 \%$ \\
\hline Massachusetts & $0.0 \%$ & $12.9 \%$ & $40.5 \%$ & $32.0 \%$ & $14.6 \%$ & $0.0 \%$ & $17.4 \%$ & $43.5 \%$ & $39.1 \%$ & $0.0 \%$ \\
\hline Mississippi & $0.0 \%$ & $11.2 \%$ & $39.0 \%$ & $35.9 \%$ & $13.9 \%$ & $0.0 \%$ & $24.0 \%$ & $40.0 \%$ & $24.0 \%$ & $12.0 \%$ \\
\hline Nebraska & $0.0 \%$ & $10.1 \%$ & $37.5 \%$ & $36.8 \%$ & $15.6 \%$ & $0.0 \%$ & $12.5 \%$ & $37.5 \%$ & $50.0 \%$ & $0.0 \%$ \\
\hline Nevada & $0.0 \%$ & $14.2 \%$ & $37.3 \%$ & $36.5 \%$ & $12.0 \%$ & $0.0 \%$ & $28.8 \%$ & $37.3 \%$ & $28.8 \%$ & $5.1 \%$ \\
\hline New Jersey & $0.0 \%$ & $11.6 \%$ & $37.0 \%$ & $34.6 \%$ & $16.8 \%$ & $0.0 \%$ & $20.0 \%$ & $43.3 \%$ & $30.0 \%$ & $6.7 \%$ \\
\hline New Mexico & $0.0 \%$ & $9.4 \%$ & $44.3 \%$ & $35.0 \%$ & $11.3 \%$ & $0.0 \%$ & $19.0 \%$ & $47.6 \%$ & $28.6 \%$ & $4.8 \%$ \\
\hline New York & $0.1 \%$ & $13.9 \%$ & $36.9 \%$ & $34.0 \%$ & $15.0 \%$ & $0.0 \%$ & $25.0 \%$ & $61.1 \%$ & $11.1 \%$ & $2.8 \%$ \\
\hline North Carolina & $0.9 \%$ & $9.7 \%$ & $35.8 \%$ & $40.3 \%$ & $13.2 \%$ & $3.0 \%$ & $18.2 \%$ & $51.5 \%$ & $24.2 \%$ & $3.0 \%$ \\
\hline North Dakota & $0.0 \%$ & $21.9 \%$ & $44.2 \%$ & $28.6 \%$ & $5.4 \%$ & $0.0 \%$ & $0.0 \%$ & $0.0 \%$ & $0.0 \%$ & $0.0 \%$ \\
\hline Ohio & $0.0 \%$ & $15.9 \%$ & $41.6 \%$ & $32.7 \%$ & $9.8 \%$ & $0.0 \%$ & $44.4 \%$ & $44.4 \%$ & $11.1 \%$ & $0.0 \%$ \\
\hline Oklahoma & $0.1 \%$ & $11.6 \%$ & $39.8 \%$ & $37.0 \%$ & $11.6 \%$ & $5.3 \%$ & $36.8 \%$ & $42.1 \%$ & $15.8 \%$ & $0.0 \%$ \\
\hline Oregon & $0.0 \%$ & $10.8 \%$ & $38.4 \%$ & $35.7 \%$ & $15.2 \%$ & $0.0 \%$ & $14.3 \%$ & $42.9 \%$ & $35.7 \%$ & $7.1 \%$ \\
\hline Pennsylvania & $0.0 \%$ & $11.8 \%$ & $38.9 \%$ & $33.8 \%$ & $15.5 \%$ & $0.0 \%$ & $16.7 \%$ & $50.0 \%$ & $33.3 \%$ & $0.0 \%$ \\
\hline Rhode Island & $0.0 \%$ & $15.4 \%$ & $42.3 \%$ & $34.6 \%$ & $7.7 \%$ & $0.0 \%$ & $0.0 \%$ & $0.0 \%$ & $0.0 \%$ & $0.0 \%$ \\
\hline
\end{tabular}




\begin{tabular}{lrrrrr|rrrrr}
\hline South Carolina & $0.1 \%$ & $12.3 \%$ & $37.0 \%$ & $36.5 \%$ & $14.0 \%$ & $0.0 \%$ & $15.8 \%$ & $57.9 \%$ & $15.8 \%$ & $10.5 \%$ \\
\hline South Dakota & $0.0 \%$ & $15.6 \%$ & $48.8 \%$ & $29.9 \%$ & $5.7 \%$ & $0.0 \%$ & $0.0 \%$ & $100.0 \%$ & $0.0 \%$ & $0.0 \%$ \\
\hline Tennessee & $0.0 \%$ & $7.6 \%$ & $39.5 \%$ & $41.5 \%$ & $11.4 \%$ & $0.0 \%$ & $0.0 \%$ & $44.4 \%$ & $22.2 \%$ & $33.3 \%$ \\
\hline Texas & $0.0 \%$ & $12.1 \%$ & $37.7 \%$ & $36.8 \%$ & $13.4 \%$ & $0.0 \%$ & $22.6 \%$ & $37.6 \%$ & $32.3 \%$ & $7.5 \%$ \\
\hline Utah & $0.0 \%$ & $10.8 \%$ & $41.6 \%$ & $38.6 \%$ & $8.9 \%$ & $0.0 \%$ & $60.0 \%$ & $40.0 \%$ & $0.0 \%$ & $0.0 \%$ \\
\hline Washington & $10.2 \%$ & $40.7 \%$ & $35.1 \%$ & $14.0 \%$ & & $0.0 \%$ & $50.0 \%$ & $50.0 \%$ & $0.0 \%$ & $0.0 \%$ \\
\hline Wisconsin & $0.0 \%$ & $13.6 \%$ & $41.1 \%$ & $32.8 \%$ & $12.5 \%$ & $0.0 \%$ & $11.1 \%$ & $30.9 \%$ & $16.0 \%$ & $42.0 \%$ \\
\hline Wyoming & $0.0 \%$ & $12.7 \%$ & $33.5 \%$ & $40.4 \%$ & $13.5 \%$ & $0.0 \%$ & $0.0 \%$ & $75.0 \%$ & $25.0 \%$ & $0.0 \%$ \\
\hline Median & $\mathbf{0 . 0} \%$ & $\mathbf{1 2 . 2 \%}$ & $\mathbf{3 9 . 0} \%$ & $\mathbf{3 5 . 8 \%}$ & $\mathbf{1 2 . 9 \%}$ & $\mathbf{0 . 0} \%$ & $\mathbf{1 7 . 8 \%}$ & $\mathbf{4 4 . 0 \%}$ & $\mathbf{2 4 . 1 \%}$ & $\mathbf{2 . 0 \%}$ \\
\hline
\end{tabular}




\section{Subpopulations}

The rules governing the placement of individuals in restrictive housing reflect concerns about its harms to individuals. Certain subpopulations may face additional challenges, as evidenced by regulations focused on limiting the placement of these groups in restrictive housing. In this section, we provide an overview of data on incarcerated people identified as mentally ill as well as on the use of restrictive housing for pregnant women and transgender individuals.

\section{Prisoners with Mental Health Issues}

Reports identify a large number of incarcerated people who have mental health issues, with a recent estimate as high as one-third of the prison population. ${ }^{60}$ Even as debate exists as to what level of distress should create buffers to placement in restrictive housing, a consensus has emerged that individuals identified as having serious mental illness should not be placed into restrictive housing.

Illustrative of these concerns are the 2016 ACA Restrictive Housing Performance Based Standards, which called for regular "behavioral health assessments" for individuals placed in restrictive housing. Standard 4-RH-0010 provides that corrections departments should have written policies to ensure that "a mental health practitioner/provider" evaluates and files written reports on prisoners "placed in restrictive housing within 7 days of placement." ${ }^{21}$ If an individual is held "beyond 30 days, a behavioral health assessment by a mental health practitioner/provider" is to be completed "at least every 30 days" for individuals diagnosed with a "behavioral health disorder and more frequently if clinically indicated." If an assessment concludes that a person has no "behavioral health disorder," reassessments are to occur "every 90 days and more frequently if clinically indicated." Those evaluations are to take place in "a confidential area."62

Further, the ACA Standards detail that, "at a minimum," the mental health provider is to inquire into whether a person has a present "suicide ideation" or a "history of suicidal behavior," is on "prescribed psychotropic medication," has a current "mental health complaint," is being treated for "mental health problems," has "a history of inpatient and outpatient psychiatric treatment," or has a history of "treatment for substance abuse." The mental health provider must also observe an individual's "general appearance and behavior" and look for "evidence of abuse and/or trauma" or "current symptoms of psychosis, depression, anxiety, and/or aggression." 63 The provider is then to conclude whether a referral to mental health care is necessary and whether "emergency treatment" is needed. ${ }^{64}$

The ACA Standards also provide that once a person is placed in restrictive housing, both written policies and practices should require that prisoners are "personally observed by a correctional officer twice per hour, but no more than 40 minutes apart, on an irregular schedule."65 Individuals who are "violent or mentally disordered or who demonstrate unusual or bizarre behavior or self-harm" are to be observed more often. ${ }^{66}$ Prisoners who are "suicidal" are to be under continuous observation, all of which is to be logged ${ }^{67}$ The need for observation is a decision for a "qualified mental health professional." 68 Unless "medical attention is needed more frequently," each person in restrictive housing is to be visited daily by health care personnel in an 
announced and recorded visit ${ }^{69}$ and weekly by a "mental health staff" member, unless more frequent visits are called for by health personnel. ${ }^{70}$

The ACA Standards also state that "the agency will not place a person with serious mental illness in Extended Restrictive Housing," defined as "housing that separates the offender from contact with the general population while restricting an offender/inmate to his/her cell for at least 22 hours per day and for more than 30 days for the safe and secure operation of the facility."71 The ACA defines serious mental illness as "Psychotic Disorders, Bipolar Disorders, and Major Depressive Disorder; any diagnosed mental disorder (excluding substance use disorders) currently associated with serious impairment in psychological, cognitive, or behavioral functioning that substantially interferes with the person's ability to meet the ordinary demands of living and requires an individualized treatment plan by a qualified mental health professional(s)."72

To gather information about the use of restrictive housing for persons identified as facing mental health challenges, the 2017-2018 ASCA-Liman survey asked each jurisdiction about people whom it deemed to have "serious mental illness" (SMI), including the total number as well as the gender and race of the seriously mentally ill population both in the total custodial population and in restrictive housing. ${ }^{73}$ Thirty-three jurisdictions provided data on both the total custodial population with SMI and the population with SMI in restrictive housing for male prisoners, and 31 for female prisoners. ${ }^{74}$

An additional word of explanation is needed about this aspect of the questionnaire. After surveying jurisdictions in 2015 and again in 2017, we learned that the definitions of serious mental illness vary substantially, as do the policies governing placement of individuals with mental health issues - classified as "serious" or otherwise - in restrictive housing. In addition to correctional department rules, some legislatures provide statutory direction and, in some jurisdictions, litigation has resulted in specified definitions and constraints. ${ }^{75}$

For example, some jurisdictions provide a sentence or two explaining their definition of serious mental illness, such as, "chronic mental health treatment or inpatient mental health treatment." 76 Other jurisdictions have more detailed descriptions, such as any "mental health condition that current medical science affirms is caused by a biological disorder of the brain and that substantially limits the life activities of the person with the serious mental illness. Serious mental illness includes but is not limited to (i) schizophrenia, (ii) schizoaffective disorder, (iii) delusional disorder, (iv) bipolar affective disorder, (v) major depression, and (vi) obsessive compulsive disorder." 77 Yet others have several paragraphs or pages of descriptions. ${ }^{78}$

Given this variation in scope and detail, a person could be classified as seriously mentally ill in one jurisdiction but not in another. We therefore have neither aggregated nor scaled the data but rather provide, in Table 15 and Table 16, the numbers of persons in the general population with serious mental illness and the numbers placed in restrictive housing, as provided by each jurisdiction's own account. We provide the definitions used in 43 jurisdictions in Appendix C. 
Table 15 Male Prisoners with Serious Mental Illness (SMI, variously defined) in Restrictive Housing (RH)

$(\mathbf{n}=\mathbf{3 3})$

\begin{tabular}{|c|c|c|c|c|c|}
\hline & $\begin{array}{r}\text { Total Male } \\
\text { Custodial } \\
\text { Population }\end{array}$ & $\begin{array}{r}\text { Male } \\
\text { Custodial } \\
\text { Population } \\
\text { with SMI } \\
\end{array}$ & $\begin{array}{r}\% \text { Male } \\
\text { Custodial } \\
\text { Population } \\
\text { with SMI }\end{array}$ & $\begin{array}{r}\text { Male } \\
\text { Population } \\
\text { with SMI } \\
\text { in RH }\end{array}$ & $\begin{array}{r}\text { \% Male } \\
\text { Population with } \\
\text { SMI in RH }\end{array}$ \\
\hline Alabama & 20,282 & 1,064 & $5.3 \%$ & 248 & $23.3 \%$ \\
\hline Arizona & 38,117 & 1,559 & $4.1 \%$ & 284 & $18.2 \%$ \\
\hline Arkansas & 14,561 & 397 & $2.7 \%$ & 21 & $5.3 \%$ \\
\hline Colorado & 16,624 & 1,234 & $7.4 \%$ & 1 & $0.1 \%$ \\
\hline Connecticut & 13,182 & 28 & $0.2 \%$ & 3 & $10.7 \%$ \\
\hline Delaware & 4,100 & 354 & $8.6 \%$ & 3 & $0.9 \%$ \\
\hline Illinois & 39,767 & 3,998 & $10.1 \%$ & 356 & $8.9 \%$ \\
\hline Indiana & 23,847 & 4,762 & $20.0 \%$ & 567 & $11.9 \%$ \\
\hline Iowa & 7,578 & 1,009 & $13.3 \%$ & 24 & $2.4 \%$ \\
\hline Kansas & 8,999 & 2,677 & $29.7 \%$ & 43 & $1.61 \%$ \\
\hline Kentucky & 20,427 & 386 & $1.9 \%$ & 66 & $17.1 \%$ \\
\hline Louisiana & 32,953 & 2,113 & $6.4 \%$ & 417 & $19.7 \%$ \\
\hline Massachusetts & 8,459 & 608 & $7.2 \%$ & 10 & $1.6 \%$ \\
\hline Mississippi & 12,038 & 61 & $0.5 \%$ & 10 & $16.4 \%$ \\
\hline Missouri & 29,675 & 3,768 & $12.7 \%$ & 703 & $18.7 \%$ \\
\hline Nebraska & 4,762 & 192 & $4.0 \%$ & 50 & $26 \%$ \\
\hline New Jersey & 18,594 & 208 & $1.1 \%$ & 1 & $0.5 \%$ \\
\hline New Mexico & 6,306 & 36 & $0.6 \%$ & 23 & $63.9 \%$ \\
\hline New York & 48,407 & 2,420 & $5.0 \%$ & 47 & $1.9 \%$ \\
\hline North Carolina & 34,326 & 385 & $1.1 \%$ & 27 & $7.0 \%$ \\
\hline North Dakota & 1,606 & 345 & $21.5 \%$ & 5 & $1.5 \%$ \\
\hline Ohio & 45,796 & 3,477 & $7.6 \%$ & 150 & $4.3 \%$ \\
\hline Oklahoma & 23,816 & 7,011 & $29.4 \%$ & 615 & $8.8 \%$ \\
\hline Oregon & 13,302 & 812 & $6.1 \%$ & 112 & $13.8 \%$ \\
\hline Pennsylvania & 44,300 & 3,691 & $8.3 \%$ & 0 & $0.0 \%$ \\
\hline Rhode Island & 2,722 & 140 & $5.1 \%$ & 16 & $11.4 \%$ \\
\hline South Dakota & 3,402 & 111 & $3.3 \%$ & 12 & $10.8 \%$ \\
\hline Tennessee $^{79}$ & 20,214 & & & 98 & \\
\hline Texas $^{80}$ & 133,229 & 1,440 & $1.1 \%$ & 0 & $0.0 \%$ \\
\hline Utah & 5,822 & 199 & $3.4 \%$ & 11 & $5.5 \%$ \\
\hline Washington & 15,744 & 1,628 & $10.3 \%$ & 99 & $6.1 \%$ \\
\hline Wisconsin & 21,050 & 1,654 & $7.9 \%$ & 90 & $5.4 \%$ \\
\hline Wyoming & 1,894 & 204 & $10.8 \%$ & 41 & $20.1 \%$ \\
\hline Total & 735,901 & 47,971 & $6.1 \%$ (median) & 4,153 & $7.9 \%$ (median) \\
\hline
\end{tabular}


Table 16 Female Prisoners with Serious Mental Illness (SMI, variously defined) in Restrictive Housing (RH)

$(\mathbf{n}=31)$

\begin{tabular}{lrrrrr} 
& $\begin{array}{r}\text { Total } \\
\text { Female } \\
\text { Custodial } \\
\text { Population }\end{array}$ & $\begin{array}{r}\text { Female } \\
\text { Custodial } \\
\text { Population } \\
\text { with SMI }\end{array}$ & $\begin{array}{r}\text { \% Female } \\
\text { Custodial } \\
\text { Population } \\
\text { with SMI }\end{array}$ & $\begin{array}{r}\text { Female } \\
\text { Population } \\
\text { with SMI } \\
\text { in RH }\end{array}$ & $\begin{array}{r}\text { \% Female } \\
\text { Population } \\
\text { with SMI } \\
\text { in RH }\end{array}$ \\
\hline Alabama & 1,310 & 86 & $6.6 \%$ & 1 & $1.2 \%$ \\
\hline Arizona & 4,029 & 313 & $7.8 \%$ & 14 & $4.5 \%$ \\
\hline Arkansas & 1,344 & 2 & $0.1 \%$ & 0 & $0.0 \%$ \\
\hline Colorado & 1,673 & 497 & $29.7 \%$ & 0 & $0.0 \%$ \\
\hline Connecticut & 955 & 8 & $0.8 \%$ & 0 & $0.0 \%$ \\
\hline Delaware & 233 & 64 & $27.5 \%$ & 0 & $0.0 \%$ \\
\hline Illinois & 2,410 & 619 & $25.7 \%$ & 24 & $3.9 \%$ \\
\hline Indiana & 2,470 & 954 & $38.6 \%$ & 36 & $3.8 \%$ \\
\hline Iowa & 705 & 167 & $23.7 \%$ & 3 & $1.8 \%$ \\
\hline Kansas & 897 & 525 & $58.5 \%$ & 0 & $0.0 \%$ \\
\hline Kentucky & 3,139 & 163 & $5.19 \%$ & 8 & $4.9 \%$ \\
\hline Massachusetts & 588 & 46 & $7.82 \%$ & 0 & $0.0 \%$ \\
\hline Missouri & 3,529 & 1,102 & $31.2 \%$ & 48 & $4.4 \%$ \\
\hline Nebraska & 416 & 71 & $17.1 \%$ & 4 & $5.6 \%$ \\
\hline New Jersey & 774 & 24 & $3.1 \%$ & 0 & $0.0 \%$ \\
\hline New Mexico & 741 & 9 & $1.2 \%$ & 0 & $0.0 \%$ \\
\hline New York & 2,357 & 188 & $8.0 \%$ & 3 & $1.6 \%$ \\
\hline North Carolina & 2,933 & 80 & $2.7 \%$ & 2 & $2.5 \%$ \\
\hline North Dakota & 224 & 37 & $16.5 \%$ & 0 & $0.0 \%$ \\
\hline Ohio & 4,158 & 1,113 & $26.8 \%$ & 10 & $0.9 \%$ \\
\hline Oklahoma & 3,079 & 2,086 & $67.7 \%$ & 14 & $0.7 \%$ \\
\hline Oregon & 1,272 & 168 & $13.2 \%$ & 11 & $6.6 \%$ \\
\hline Pennsylvania & 2,620 & 529 & $20.2 \%$ & 0 & $0.0 \%$ \\
\hline Rhode Island & 130 & 9 & $6.9 \%$ & 0 & $0.0 \%$ \\
\hline South Dakota & 525 & 40 & $7.6 \%$ & 1 & $2.5 \%$ \\
\hline Tennessee & 1,946 & & & 1 & \\
\hline Texas & 12,180 & 84 & $0.7 \%$ & 0 & $0.0 \%$ \\
\hline Utah & 471 & 21 & $4.5 \%$ & 0 & $0.0 \%$ \\
\hline Washington & 1,302 & 193 & $14.8 \%$ & 0 & $0.0 \%$ \\
\hline Wisconsin & 1,539 & 414 & $26.9 \%$ & 19 & $4.6 \%$ \\
\hline Wyoming & 260 & 64 & $24.6 \%$ & 2 & $3.1 \%$ \\
\hline Total & $\mathbf{6 0 , 2 0 9}$ & $\mathbf{9 , 6 7 6}$ & $\begin{array}{r}\mathbf{1 3 . 2 \%} \\
(\text { median) }\end{array}$ & $\mathbf{2 0 1}$ & $\begin{array}{r}\mathbf{0 . 8 \%} \\
\text { (median) }\end{array}$ \\
\hline & & & & & \\
\hline
\end{tabular}


We also sought to learn about the intersection of race, ethnicity, gender, and mental illness. Thirty-one jurisdictions provided information by race and ethnicity about male prisoners with serious mental illness, and 28 jurisdictions provided information by race and ethnicity about female prisoners with serious mental illness. Table 17 and Table 18 provide the information, jurisdiction-by-jurisdiction. 
Table 17 Male Prisoners with Serious Mental Illness by Race and Ethnicity in the Total Custodial Population and in the Restrictive Housing Population

$$
(\mathbf{n}=31)
$$

Total Custodial Population

Restrictive Housing Population

\begin{tabular}{|c|c|c|c|c|c|c|c|c|c|c|c|c|c|c|c|c|}
\hline & \multirow[b]{2}{*}{ White } & & \\
\hline & & Black & Hisp. & Asian & NHPI & $\begin{array}{l}\text { Am. } \\
\text { Ind. }\end{array}$ & Other & Total & White & Black & Hisp & Asian & NHPI & $\begin{array}{l}\text { Am. } \\
\text { Ind. }\end{array}$ & Other & Total \\
\hline Alabama & 497 & 564 & & & & & 3 & 1,064 & 75 & 172 & & & & & 1 & 248 \\
\hline Arizona & 743 & 339 & 393 & 7 & & 53 & 24 & 1,559 & 105 & 52 & 99 & 0 & & 15 & 13 & 284 \\
\hline Arkansas & 206 & 180 & 0 & 0 & 0 & 0 & 11 & 397 & 3 & 18 & 0 & 0 & 0 & 0 & 0 & 21 \\
\hline Colorado & 633 & 270 & 276 & 9 & & 46 & 0 & 1,234 & 0 & 1 & 0 & 0 & 0 & 0 & 0 & 1 \\
\hline Connecticut & 10 & 10 & 8 & 0 & & 0 & & 28 & 3 & 0 & 0 & 0 & & 0 & & 3 \\
\hline Delaware & 110 & 236 & 7 & 1 & & 0 & 0 & 354 & 1 & 2 & 0 & 0 & & 0 & 0 & 3 \\
\hline Illinois & 1,415 & 2,283 & 286 & 8 & 0 & 4 & 2 & 3,998 & 69 & 263 & 23 & 0 & 0 & 0 & 1 & 356 \\
\hline Indiana & 3,297 & 1,294 & 125 & 10 & 3 & 13 & 20 & 4,762 & 379 & 150 & 33 & 0 & 0 & 2 & 3 & 567 \\
\hline Iowa & 717 & 215 & 50 & 5 & 5 & 17 & & 1,009 & 18 & 4 & 2 & & & & & 24 \\
\hline Kansas & 1,679 & 697 & 235 & 19 & 0 & 47 & 0 & 2,677 & 33 & 9 & 0 & 0 & 0 & 1 & 0 & 43 \\
\hline Kentucky & 307 & 76 & 1 & & & & 2 & 386 & 52 & 9 & 2 & & 2 & 0 & 1 & 66 \\
\hline Louisiana & 766 & 1,342 & 4 & 1 & 0 & 0 & & 2,113 & 110 & 307 & 0 & 0 & 0 & 0 & 0 & 417 \\
\hline Massachusetts & 336 & 155 & 96 & 5 & 0 & 6 & 10 & 608 & 4 & 4 & 2 & 0 & 0 & 0 & 0 & 10 \\
\hline Mississippi & 21 & 38 & & & & 2 & & 61 & 0 & 9 & & & & 1 & & 10 \\
\hline Missouri & 2,676 & 1,074 & & 3 & & 8 & 7 & 3,768 & 452 & 246 & & & & 4 & 1 & 703 \\
\hline Nebraska & & & & & & & & 192 & 25 & 12 & 11 & & & 1 & 1 & 50 \\
\hline New Jersey & 80 & 93 & 33 & 2 & 0 & 0 & 0 & 208 & 0 & 1 & 0 & 0 & 0 & 0 & 0 & 1 \\
\hline New Mexico & 15 & 2 & 18 & 0 & 0 & 1 & 0 & 36 & 6 & 1 & 15 & 0 & 0 & 1 & 0 & 23 \\
\hline New York & 638 & 1,155 & 546 & 0 & 0 & 0 & 81 & 2,420 & 8 & 23 & 14 & 0 & 0 & 1 & 1 & 47 \\
\hline $\begin{array}{l}\text { North } \\
\text { Carolina }\end{array}$ & 189 & 164 & 11 & 3 & & & 18 & 385 & 10 & 14 & 1 & & & & 2 & 27 \\
\hline North Dakota & 235 & 32 & 14 & 2 & 0 & 61 & 1 & 345 & 3 & 0 & 0 & 0 & 0 & 2 & 0 & 5 \\
\hline Ohio & 2,149 & 1,237 & 56 & 3 & & 9 & 23 & 3,477 & 92 & 55 & 1 & 1 & & 0 & 1 & 150 \\
\hline Oklahoma & 4,303 & 1,609 & 321 & 16 & 2 & 746 & 14 & 7,011 & 292 & 193 & 47 & 0 & 3 & 79 & 1 & 615 \\
\hline
\end{tabular}




\begin{tabular}{lrrrrrrrrrrrrrrrrrrrrrrr}
\hline Pennsylvania & 1,696 & 1,692 & 277 & 11 & 0 & 2 & 13 & 3,691 & 0 & 0 & 0 & 0 & 0 & 0 & 0 & 0 \\
\hline Rhode Island & 72 & 40 & 24 & 1 & 0 & 2 & 1 & 140 & 8 & 3 & 5 & 0 & 0 & 0 & 0 & 16 \\
\hline South Dakota & 71 & 9 & 1 & 1 & 0 & 29 & 0 & 111 & 6 & 1 & 1 & 0 & 0 & 4 & 0 & 12 \\
\hline Tennessee & & & & & & & & & 61 & 36 & 1 & 0 & 0 & 0 & 0 & 98 \\
\hline Utah & 137 & 21 & 28 & 2 & 3 & 7 & 1 & 199 & 5 & 2 & 3 & 1 \\
\hline Washington & 1,000 & 372 & 130 & 47 & & 64 & 15 & 1,628 & 62 & 16 & 11 & 5 & & 3 & 2 & 99 \\
\hline Wisconsin & 869 & 581 & 124 & & 13 & 66 & 1 & 1,654 & 35 & 36 & 14 & 0 & 0 & 5 & 0 & 90 \\
\hline Wyoming & 166 & 8 & 20 & 0 & 2 & 8 & 0 & 204 & 17 & 3 & 1 & 0 & 0 & 4 & 0 & 25 \\
\hline Total & $\mathbf{2 5 , 0 3 3}$ & $\mathbf{1 5 , 7 8 8}$ & $\mathbf{3 , 0 8 4}$ & $\mathbf{1 5 6}$ & $\mathbf{2 8}$ & $\mathbf{1 , 1 9 1}$ & $\mathbf{2 4 7}$ & $\mathbf{4 5 , 7 1 9}$ & $\mathbf{1 , 9 3 4}$ & $\mathbf{1 , 6 4 2}$ & $\mathbf{2 8 6}$ & $\mathbf{6}$ & $\mathbf{5}$ & $\mathbf{1 2 4}$ & $\mathbf{2 8}$ & $\mathbf{4 , 0 2 5}$ \\
\hline
\end{tabular}


Table 18 Female Prisoners with Serious Mental Illness by Race and Ethnicity in the Total Custodial Population and in the Restrictive Housing Population

Total Custodial Population Restrictive Housing Population

\begin{tabular}{|c|c|c|c|c|c|c|c|c|c|c|c|c|c|c|c|c|}
\hline & White & Black & Hisp. & Asian & NHPI & $\begin{array}{l}\text { Am. } \\
\text { Ind. }\end{array}$ & Other & Total & White & Black & Hisp & Asian & NHPI & $\begin{array}{l}\text { Am. } \\
\text { Ind. }\end{array}$ & Other & Total \\
\hline Alabama & 60 & 26 & & & & & & 86 & 0 & 1 & & & & & & 1 \\
\hline Arizona & 181 & 57 & 44 & 2 & & 24 & 5 & 313 & 8 & 1 & 5 & 0 & & 0 & 0 & 14 \\
\hline Arkansas & 0 & 2 & 0 & 0 & 0 & 0 & 0 & 2 & 0 & 0 & 0 & 0 & 0 & 0 & 0 & 0 \\
\hline Colorado & 269 & 73 & 122 & 5 & & 28 & 0 & 497 & 0 & 0 & 0 & 0 & 0 & 0 & 0 & 0 \\
\hline Connecticut & 3 & 4 & 1 & 0 & & 0 & & 8 & 0 & 0 & 0 & 0 & & 0 & & 0 \\
\hline Delaware & 37 & 26 & 0 & 1 & & 0 & 0 & 64 & 0 & 0 & 0 & 0 & & 0 & 0 & 0 \\
\hline Illinois & 294 & 270 & 50 & 4 & 0 & 1 & 0 & 619 & 7 & 14 & 3 & 0 & 0 & 0 & 0 & 24 \\
\hline Indiana & 757 & 166 & 17 & 1 & 0 & 4 & 9 & 954 & 24 & 12 & 0 & 0 & 0 & 0 & 0 & 36 \\
\hline Kansas & 370 & 87 & 44 & 5 & 0 & 19 & 0 & 525 & 0 & 0 & 0 & 0 & 0 & 0 & 0 & 0 \\
\hline Kentucky & 135 & 22 & & & & & 6 & 163 & 8 & 0 & 0 & & & & 0 & 8 \\
\hline Massachusetts & 27 & 12 & 3 & 1 & 0 & 0 & 3 & 46 & 0 & 0 & 0 & 0 & 0 & 0 & 0 & 0 \\
\hline Missouri & 932 & 156 & 3 & 1 & & 10 & & 1,102 & 34 & 14 & 0 & 0 & & 0 & & 48 \\
\hline Nebraska & & & & & & & & 71 & & 2 & & & & 1 & 1 & 4 \\
\hline New Jersey & 12 & 9 & 2 & 1 & 0 & 0 & 0 & 24 & 0 & 0 & 0 & 0 & 0 & 0 & 0 & 0 \\
\hline New Mexico & 7 & 0 & 2 & 0 & 0 & 0 & 0 & 9 & 0 & 0 & 0 & 0 & 0 & 0 & 0 & 0 \\
\hline New York & 52 & 109 & 24 & 0 & 0 & 0 & 3 & 188 & 1 & 1 & 1 & 0 & 0 & 0 & 0 & 3 \\
\hline $\begin{array}{l}\text { North } \\
\text { Carolina } \\
\end{array}$ & 43 & 34 & 0 & 1 & & & 2 & 80 & 1 & 1 & 0 & 0 & & & 0 & 2 \\
\hline North Dakota & 20 & 0 & 3 & 0 & 13 & 0 & 1 & 37 & 0 & 0 & 0 & 0 & 0 & 0 & 0 & 0 \\
\hline Ohio & 833 & 270 & 7 & 2 & & 1 & 0 & 1,113 & 4 & 6 & 0 & 0 & & 0 & 0 & 10 \\
\hline Oklahoma & 1,353 & 274 & 90 & 3 & 6 & 355 & 5 & 2,086 & 2 & 5 & 2 & 0 & 0 & 5 & 0 & 14 \\
\hline Pennsylvania & 295 & 188 & 35 & 4 & 0 & 2 & 5 & 529 & 0 & 0 & 0 & 0 & 0 & 0 & 0 & 0 \\
\hline Rhode Island & 7 & 2 & 0 & 0 & 0 & 0 & 0 & 9 & 0 & 0 & 0 & 0 & 0 & 0 & 0 & 0 \\
\hline South Dakota & 21 & 0 & 2 & 0 & 0 & 17 & 0 & 40 & 1 & 0 & 0 & 0 & 0 & 0 & 0 & 1 \\
\hline
\end{tabular}




\begin{tabular}{lrrrrrrrrrrrrrrrr}
\hline Tennessee & & & & & & & & & 1 & 0 & 0 & 0 & 0 & 0 & 0 & 1 \\
\hline Utah & 16 & 0 & 1 & 0 & 0 & 4 & 0 & 21 & 0 & 0 & 0 & 0 & 0 & 0 & 0 & 0 \\
\hline Washington & 116 & 29 & 24 & 9 & & 11 & 4 & 193 & 0 & 0 & 0 & 0 & 0 \\
\hline Wisconsin & 268 & 98 & 9 & & 4 & 35 & 0 & 414 & 8 & 9 & 0 & 0 & 0 & 2 & 0 & 19 \\
\hline Wyoming & 51 & 3 & 6 & 0 & 0 & 4 & 0 & 64 & 0 & 1 & 0 & 0 & 0 & 1 & 0 & 2 \\
\hline Total & $\mathbf{6 , 1 5 9}$ & $\mathbf{1 , 9 1 7}$ & $\mathbf{4 8 9}$ & $\mathbf{4 0}$ & $\mathbf{2 3}$ & $\mathbf{5 1 5}$ & $\mathbf{4 3}$ & $\mathbf{9 , 2 5 7}$ & $\mathbf{9 9}$ & $\mathbf{6 7}$ & $\mathbf{1 1}$ & $\mathbf{0}$ & $\mathbf{0}$ & $\mathbf{9}$ & $\mathbf{1}$ & $\mathbf{1 8 7}$ \\
\hline
\end{tabular}




\section{Pregnant Women}

Restrictive housing has sometimes been used as a placement for prisoners identified as "different" on various metrics, including being pregnant. In 2016, the ACA Standards provided that "female inmates determined to be pregnant" 81 should not be housed in extended restrictive housing.

We sought to learn how many pregnant prisoners were in the custodial population as a whole and how many were placed in restrictive housing. In the 41 jurisdictions that had sufficiently detailed and consistent information to describe, three reported that, as of the fall of 2017, they housed no pregnant prisoners in their total custodial populations. ${ }^{82}$ The other 38 jurisdictions reported that they counted a total of 613 pregnant women prisoners. ${ }^{83}$ None of the 41 jurisdictions reported that, as of the fall of 2017, any pregnant prisoners were held in restrictive housing.

\section{Transgender Prisoners}

As with pregnancy, "protection" has been a basis for putting other persons with specific needs in restrictive housing. Concerns about the misuse of restrictive housing as a placement for transgender individuals prompted the ACA to promulgate a Standard that prisoners not be "placed in Restrictive Housing on the basis of Gender Identity alone." ${ }^{84}$ Therefore, the ASCA-Liman survey sought to learn about transgender prisoners in the total custodial population and in restrictive housing.

Of the 43 jurisdictions responding about transgender prisoners in the total custodial population, ${ }^{85}$ four indicated that they either did not track or could not report the number of transgender prisoners in their total custodial populations ${ }^{86}$ One jurisdiction reported having no transgender prisoners in its total custodial population. ${ }^{87}$ The remaining 38 jurisdictions reported a total of 2,444 transgender prisoners in their total custodial populations. When jurisdictions described different methods to identify transgender prisoners, those differences are documented in endnotes. $^{88}$

Five of these 43 jurisdictions indicated that they either did not track or could not report the number of transgender prisoners in their restrictive housing populations ${ }^{89}$ Of the remaining 38 jurisdictions, 17 reported that no transgender prisoners were in restrictive housing. ${ }^{90}$ The other 21 jurisdictions identified a total of 157 transgender prisoners in restrictive housing. Within those 21 systems, nine states each counted one to three transgender prisoners in segregation, another nine states reported six to ten, and three states identified 19-24 people in this category. ${ }^{91}$ 


\section{A Snapshot of Two Jails}

According to the Bureau of Justice Statistics (BJS), as of 2016, the 2,850 jail systems in the United States held an average daily population of 731,300 people. ${ }^{92}$ According to an earlier BJS report based on survey responses from people confined in jails in 2011-2012, on an average day, some $2.7 \%$ of these individuals were held in administrative segregation or solitary confinement. ${ }^{93}$

BJS has identified six jurisdictions (Alaska, Connecticut, Delaware, Hawaii, Rhode Island, and Vermont) as "integrated systems," in which correctional departments are in charge of prisons and jails. ${ }^{94}$ Of the 46 state jurisdictions responding to the survey, four-Delaware, Hawaii, Maryland, and Rhode Island-indicated that they had included jail populations in their counts of total custodial populations. ${ }^{95}$ Alaska and Connecticut, also responding, did not discuss jails as under their "direct control" and did not count people in jails in their responses. Given that these integrated jurisdictions are predominately prison systems and we have some but not comprehensive data delineating the characteristics of their jail populations, this section focuses on the information from the two jail systems that separately responded to our survey.

\section{Demographics}

We sent surveys to the four major metropolitan jails that are ASCA members, and we received responses from Los Angeles and Philadelphia. ${ }^{96}$ Los Angeles reported that, as of March 2018 , it had 17,278 people in its jails, or about $2.4 \%$ of the national jail population. As of September 2017, Philadelphia held 6,695 people, or about $0.9 \%$ of the national jail population. Thus, these two systems accounted for about $3.3 \%$ of the people in jails across the country. Each system also provided demographic information (detailed in Tables 19 and 20) about the sex/gender, race, ethnicity, and age of those in their jails.

Table 19 Total Custodial Population by Race and Ethnicity and Delineated by Sex/Gender in Los Angeles and Philadelphia Jails

Men

\begin{tabular}{ccccccccc} 
& White & Black & Hisp. & Asian & NHPI & $\begin{array}{l}\text { Am. } \\
\text { Ind. }\end{array}$ & Other & Total \\
\hline Los Angeles & 2,200 & 4,468 & 7,784 & 29 & 30 & 5 & 541 & 15,057 \\
\hline Philadelphia & 627 & 4,127 & 1,205 & 46 & & & 91 & 6,096 \\
\hline
\end{tabular}

\section{Women}

\begin{tabular}{lcccccccc} 
& White & Black & Hisp. & Asian & NHPI & $\begin{array}{l}\text { Am. } \\
\text { Ind. }\end{array}$ & Other & Total \\
\hline Los Angeles & 467 & 672 & 981 & 7 & 6 & 0 & 88 & 2,221 \\
\hline Philadelphia & 146 & 342 & 99 & 2 & & & 10 & 599 \\
\hline
\end{tabular}


The 2017-2018 ASCA-Liman survey defined short-term restrictive housing as "separating prisoners from the general population and holding them in their cells for an average of 22 or more hours per day," for 15-29 continuous days. The survey defined long-term restrictive housing as "separating prisoners from the general population and holding them in their cells for an average of 22 or more hours per day," for longer than 29 days. Both jurisdictions relied on the definition of 15-29 days in confinement for short-term restrictive housing.

Los Angeles reported that 619 people (3.6\%) out of its total custodial population of 17,278 were in restrictive housing, and it provided delineations of those populations by age and gender. Philadelphia reported that 416 detainees (6.2\%) out of its total custodial population of 6,695 were in restrictive housing, but did not provide demographic information on these individuals. ${ }^{97}$ Neither jurisdiction provided information on how long individuals stayed in restrictive housing. ${ }^{98}$ Table 20 details the gender and the age of both the custodial population and, for Los Angeles, ${ }^{99}$ the restrictive housing population.

Table 20 Age Cohorts of Men and Women in the Total Custodial Population in Los Angeles and Philadelphia Jails and in the Restrictive Housing Population in Los Angeles Jails

Men

Total Custodial Population

\begin{tabular}{lccccc} 
& $\mathbf{1 8}$ & $\mathbf{1 8}-\mathbf{2 5}$ & $\mathbf{2 6}-\mathbf{3 5}$ & $\mathbf{3 6}-\mathbf{5 0}$ & $\mathbf{5 0 +}$ \\
\hline Los Angeles & 0 & 3,706 & 4,971 & 3,386 & 2,994 \\
\hline Philadelphia & 36 & 1,730 & 2,180 & 1,577 & 573 \\
\hline
\end{tabular}

Restrictive Housing Population

\begin{tabular}{lccccc} 
& $<\mathbf{1 8}$ & $\mathbf{1 8}-\mathbf{2 5}$ & $\mathbf{2 6}-\mathbf{3 5}$ & $\mathbf{3 6}-\mathbf{5 0}$ & $\mathbf{5 0 +}$ \\
\hline Los Angeles & 0 & 90 & 192 & 148 & 49 \\
\hline
\end{tabular}

\section{Women}

\begin{tabular}{lccccc} 
& \multicolumn{7}{c}{ Total Custodial Population } & & \\
& $<\mathbf{1 8}$ & $\mathbf{1 8}-\mathbf{2 5}$ & $\mathbf{2 6}-\mathbf{3 5}$ & $\mathbf{3 6}-\mathbf{5 0}$ & $\mathbf{5 0 +}$ \\
\hline Los Angeles & 0 & 497 & 837 & 489 & 398 \\
\hline Philadelphia & 1 & 107 & 235 & 186 & 70 \\
\hline
\end{tabular}

\begin{tabular}{lcccccc} 
& \multicolumn{7}{c}{ Restrictive Housing Population } & & \\
& $<\mathbf{1 8}$ & $\mathbf{1 8}-\mathbf{2 5}$ & $\mathbf{2 6}-\mathbf{3 5}$ & $\mathbf{3 6}-\mathbf{5 0}$ & $\mathbf{5 0 +}$ \\
\hline Los Angeles & 0 & 8 & 14 & 8 & 2 \\
\hline
\end{tabular}




\section{Mental Illness in Jails}

The survey also asked the jails for information about certain subpopulations. As in the survey of prison systems, we asked each jurisdiction for its own definition of serious mental illness. Los Angeles, referencing the outcome of a lawsuit in its definition, ${ }^{100}$ stated that

"Serious mental illness" includes psychotic disorders, major mood disorders (including major depression and bipolar disorders), and any other conditions (excluding personality disorders, substance abuse and dependence disorders, dementia, and developmental disability) that is associated with serious or recurrent significant self-harm, suicidal ideation, imminent danger to others, current grave disability, or that prevents access to available programs. Although personality disorders alone generally do not qualify as serious mental illness, personality disorders associated with serious or recurrent significant self-harm do qualify as serious mental illness.

Los Angeles reported that, of its 17,278-person jail population, 4,000 people-23.2\% - had serious mental illness, and that no one was in restrictive housing whom it identified as having serious mental illness and who "also displayed signs of suicidal ideations, was gravely disabled," was in danger of "recurrent self-harm, or had an active psychosis."

Philadelphia defined serious mental illness as "having a diagnosis from one of the following categories: Bipolar, Schizophrenia, Psychosis, Depression, Borderline Personality." Philadelphia reported that it housed 1,136 people-17.0\%-with serious mental illness in its custodial population. The jail system also reported that of the 6,096 men who were in jail, 939$15.4 \%$ - were classified as seriously mentally ill, and that of the 599 women who were in jail, 197-32.9\% — were classified as seriously mentally ill. Philadelphia did not report the number of individuals in restrictive housing with a serious mental illness.

\section{Pregnant and Transgender People}

Los Angeles reported "approximately" 60 transgender individuals in its total custodial population, and that fewer than five transgender individuals were in short-term restrictive housing (15-29 days), and fewer than five people were in long-term restrictive housing (longer than 29 days). Philadelphia reported that it does not track transgender individuals "in a manner that is easily reportable."

Los Angeles reported 12 pregnant individuals, none of whom were in restrictive housing. Philadelphia explained that, in terms of pregnant people, that "data could not be sorted to respond to this question.",101

\section{Revising Policies}

Although Philadelphia indicated that it had not made any changes to its policies regarding restrictive housing since January 1, 2016, it explained that it had reviewed its policies after the ACA released its 2016 Performance Based Standards and had relied on them. Philadelphia 
reported implementing the ACA prohibition on extended restrictive housing (more than 29 continuous days) for individuals under the age of 18. Philadelphia said that it had substantially implemented, with exceptions, ACA prohibitions on the use of extended restrictive housing for those diagnosed as seriously mentally ill. Philadelphia stated that it also aimed not to release individuals from restrictive housing directly into the community. Philadelphia responded that, before the 2016 ACA revisions, its policy had been not to use extended restrictive housing for females determined to be pregnant.

Los Angeles detailed several changes in its policies. Los Angeles stated that it had shifted its entry criteria from those based on general information about prisoners ("intel based") to those based on prisoners' "behavior." In terms of process, placement required approval from a "Restrictive Housing Panel" and pre-entry mental health screening prior to moving an individual into restrictive housing. Within five days of initial placements, Los Angeles stated that it required individualized needs assessments. ${ }^{102}$

Los Angeles reported increasing the total time out-of-cell by three hours per week. Los Angeles stated that its programs included activities focused on self-help, religion, education, and anger-management. Los Angeles said it had added "self-directed educational programs for volunteers," and access to more "entertainment" or literary materials to "those who show positive behavior."

Los Angeles reported it had developed a "STEP program" for release from restrictive housing in which an individual who had demonstrated positive behavior would participate for two to four months in "several graduated programming groups in increasing size." Although Los Angeles did not change its policy to mandate that detainees be told the criteria for their release, it indicated that the pamphlets it gave detainees included this information.

Los Angeles stated that it had reviewed its policies since the ACA released its 2016 Performance Based Standards, and that it uses these Standards "as a guide." Los Angeles reported implementing the ACA Standard prohibiting the use of extended restrictive housing (more than 29 continuous days) for females determined to be pregnant. Los Angeles said that it had not implemented the ACA Standard about direct release from restrictive housing into the community. Los Angeles stated that it "found this standard to be extremely difficult to implement in a jail setting due to the unknown and often short stays of jail inmates." Los Angeles indicated that, by providing "an increase in out-of-cell time," it had substantially implemented, with exceptions, the policy prohibiting the placement of those diagnosed as seriously mentally ill in extended restrictive housing. Los Angeles noted that it provided 32 hours of mental health training for staff and twoyear staff rotations for those working in restrictive housing units.

Both jails were asked, "In an ideal situation (i.e. if you had the necessary resources, and if you could do so consistent with institutional safety), what number of hours out-of-cell do you believe is desirable for prisoners?" Los Angeles responded that it believed six to eight hours outof-cell per day is desirable. Philadelphia responded, "General population inmates generally get 911 hours each day out of their cells." 


\section{Revising Policies on Restrictive Housing}

ASCA-Liman surveys have sought to learn about changes in the restrictive housing policies of corrections departments. As reflected below, dozens of departments have expressed concerns about restrictive housing and reported policy revisions, some of which aim to reduce and, in some instances, to eliminate holding people in cells an average of 22 hours or more per day for 15 days or more.

In the 2014 Report, Time-in-Cell, we noted that the majority of the jurisdictions surveyed had convened or planned to convene a task force to review their use of isolation. ${ }^{103}$ Two years later, jurisdictions reported more efforts underway, as reflected in the title of the 2016 Report, Aiming to Reduce Time-in-Cell. Jurisdictions described narrowing criteria for placement in restrictive housing and increasing oversight; creating step-down and release procedures; and increasing time out-of-cell and opportunities for activities inside restrictive housing. ${ }^{104}$

In the 2017-2018 ASCA-Liman survey, we again asked about reforms. Our questions focused on entry, oversight, programs, and release, as well as on the impact of the 2016 ACA Performance Based Standards. The survey also queried jurisdictions about what they would like to do, if resources were available, in terms of time out-of-cell. Forty-four jurisdictions responded to at least some of the questions about changes in policies. ${ }^{105}$ Several jurisdictions provided their regulations and additional materials. ${ }^{106}$ Some jurisdictions also noted that they were influenced by guidance from the U.S. Department of Justice, the National Institute of Corrections, the National Commission on Correctional Health Care, and the Vera Institute of Justice. Below, we synthesize the answers to detail the changes reported,

\section{Entry and Oversight}

In 2014, we learned that the criteria for placing prisoners in isolation were broad, as was the discretion afforded correctional staff to place individuals in administrative segregation. Few policies focused on pathways out of isolation. ${ }^{107}$ For the 2017-2018 survey, we sought to learn about whether and how criteria for placement in restrictive housing had changed since 2016. Thirty-nine jurisdictions responded to at least one of the questions discussed below, and 23 reported making revisions to placement processes. ${ }^{108}$

We asked whether jurisdictions had removed "behaviors ... from the list of infractions qualifying prisoners for restrictive housing placement" or had otherwise narrowed the criteria for entry. ${ }^{109}$ Sixteen jurisdictions reported that they had done so. ${ }^{110}$ Examples included eliminating some behaviors from categories prompting isolation. One jurisdiction had deleted "horse play, possession of small amounts of marijuana, etc." from infractions leading to restrictive housing. ${ }^{111}$ As another explained, it has shifted its rules so that acts which "qualify an inmate for RH are those that are considered violent or compromise security in a significant manner." 112 A third jurisdiction noted that non-violent behavior was less likely to result in being sent to restrictive housing, ${ }^{113}$ and another stated it no longer used restrictive housing when prisoners misbehaved in ways that did not "pose a direct threat." 114 Similarly, one jurisdiction reported that it had "discontinued the use 
of solitary confinement as a punishment for disciplinary infractions" altogether. ${ }^{115}$ In contrast, one jurisdiction reported that, because of increased prison violence, it had changed criteria to increase the length of stay in what it called "long-term RHU." 116 Another jurisdiction had "added three more behaviors, when 'chronic' or severe": fighting, possession of "gang-related material," and "disobeying staff directive/insolence to staff.", 117

We also inquired about decision-making by asking about the authority and the steps taken in the decision-making process. Sixteen jurisdictions reported that they had created policies requiring senior-level approval of restrictive housing decisions. ${ }^{118}$ Twenty jurisdictions reported that the outcomes of mental health screenings affected their decisions to put individuals into restrictive housing. ${ }^{119}$ Fourteen jurisdictions reported that they conducted mental health screenings prior to placement in restrictive housing. ${ }^{120}$ Four jurisdictions stated that they performed mental health screenings upon placement in restrictive housing. ${ }^{121}$ Jurisdictions also mentioned screenings before placement for issues such as medical status, ${ }^{122}$ disability, and PREA (Prison Rape Elimination Act) requirements. ${ }^{123}$

Twenty-one jurisdictions reported having put in place policies requiring consideration of less restrictive alternatives prior to placement in restrictive housing. ${ }^{124}$ Examples were use of a "Restricted Privileges dorm"125 and mental health special housing. ${ }^{126}$ One jurisdiction had a set of alternatives: "confinement" in general population cells "for a specified period," "'blue room' placement," meetings with a counselor, and placement in a "protective custody housing unit."127 Another jurisdiction considered, for drug trafficking and related offenses, placement in a special "Drug Suppression Unit" within its general population. ${ }^{128}$

Twenty-eight jurisdictions also reported changes in how they monitored placements in restrictive housing. ${ }^{129}$ Changes included the frequency of reviews ${ }^{130}$ (from weekly, to every 30 days, to every 90 days, to annually, to as needed); the individuals or groups undertaking reviews; ${ }^{131}$ and a new grievance procedure for prisoners in restrictive housing. ${ }^{132}$ Twenty-two jurisdictions reported increased monitoring of the mental health of prisoners in restrictive housing ${ }^{133}$ through regular rounds or visits from mental health care professionals (from daily to weekly ${ }^{134}$ ) and placement reviews every 30 days. ${ }^{135}$

\section{Time Out-of-Cell, Sociability, and Programming}

We asked a number of questions about whether time out-of-cell had increased and what types of out-of-cell activities or unstructured time were organized. Forty jurisdictions responded to at least one of these questions. Twenty reported that they had implemented policies to increase time out-of-cell for prisoners, and many others described changing how that time was structured. ${ }^{136}$

Twenty jurisdictions reported adding more structured time out-of-cell, ${ }^{137}$ such as programs or therapy, and six described permitting meals in social settings. ${ }^{138}$ Eleven jurisdictions noted increasing "unstructured (recreational)" time out-of-cell, ${ }^{139}$ and ten referenced more outdoor recreation opportunities. ${ }^{140}$ Eleven jurisdictions stated that some classes were available. ${ }^{141}$ 
Thirteen reported adding an out-of-cell GED or diploma program for prisoners in restrictive housing. ${ }^{142}$

A focus for many jurisdictions was sociability and group programming. Nine jurisdictions reported that they had increased times for visitors. ${ }^{143}$ Ten jurisdictions said that they had increased phone time for prisoners. ${ }^{144}$ Twenty-four jurisdictions stated that they had added out-of-cell group programming or classes, ${ }^{145}$ such as "career readiness," 146 correspondence courses, ${ }^{147}$ horticulture, ${ }^{148}$ and classes on "thinking errors" and "criminal attitudes." 149 Sixteen jurisdictions noted more group recreation opportunities. ${ }^{150}$

Twenty-two jurisdictions reported that they had added "in-cell learning opportunities."151 Among these 22 jurisdictions, new in-cell educational opportunities included distance learning at both the GED and post-secondary levels, ${ }^{152}$ as well as vocational certification testing. ${ }^{153}$ Materials available for in-cell use included videos, ${ }^{154}$ tablets or smartboards, ${ }^{155}$ and paper packets. ${ }^{156}$

\section{Staff Training}

Twenty-nine jurisdictions (out of 35 responding to the question) reported adding some form of mental health training for staff. ${ }^{157}$ Several jurisdictions described receiving guidance on this issue from groups such as the Department of Justice, the National Institute of Corrections, other government agencies, and the National Commission on Correctional Health Care. ${ }^{158}$

Education programs for staff included topics such as the functioning of a restrictive housing unit, ${ }^{159}$ basic general training on mental health, ${ }^{160}$ understanding risks of suicide, ${ }^{161}$ crisis intervention, ${ }^{162}$ and what is called "motivational interviewing"-a style of clinical counseling. ${ }^{163}$ One jurisdiction reported that its "Behavioral Intervention Unit staff" received "training on the risks of mental health deterioration for those who are exposed to prolonged stays in isolation and the importance of reducing isolation by having an increase in out-of-cell activities, structured activities, and staff interaction." 164 Another reported that "staff working with offenders under age 18 receive specialized training on youth brain development." ${ }^{165}$ One jurisdiction noted that it helped pay for training if mental health personnel sought "additional training on their own."166 Fourteen jurisdictions said that they had implemented staff rotation policies, ${ }^{167}$ with intervals ranging from 56 days ${ }^{168}$ to five years. ${ }^{169}$

\section{Release}

The survey also sought to learn about how individuals exit restrictive housing. Thirty-seven jurisdictions responded to at least one of these questions.

Twenty jurisdictions reported that they had implemented policies "mandating that prisoners be told the criteria for their release in advance." 170 Twenty-one jurisdictions reported making changes to their policies on who decides whether a prisoner exits restrictive housing so that "the decision to release or transition an individual from restrictive housing" was "now made by a committee, rather than by an individual."171 
Over half of the jurisdictions surveyed reported that they had added step-down ${ }^{172}$ or transitional programs to the release process. ${ }^{173}$ Some of these programs involved progressive levels or phases with increasingly less-restrictive conditions; ${ }^{174}$ and some entailed separate housing units. ${ }^{175}$ For example, one jurisdiction reported that its step-down plan, which ranged "from 30 to 360 days" included "increasing privileges, amenities, and movement," was "individually tailored to the offender's needs and may include education, cognitive skills, and/or mental health programming." ${ }^{176}$ Another jurisdiction reported:

Generally, behavior intervention unit residents who served more than 30 days disciplinary segregation or who have been on administrative segregation status will have a period of time residing in a transition unit. The transition unit is a step down program to help prepare people who have been living in the behavior intervention unit for general population. A person may be eligible for transition based on their placing behavior, assessment of risk, and participation and progress in the behavior modification wing. Individuals residing in the transition unit have access to general population activities and the opportunity to attend a regular treatment group and receive support from the unit staff. Individuals residing on the transition unit are reviewed weekly for general population housing options by the placement and review team. Opportunities for structured enrichment activities, development and implementation of success plans and increased support from facility staff exist while being housed in the transition unit. ${ }^{177}$

Twenty-eight jurisdictions responded with information about step-down programs they had implemented or were developing. ${ }^{178}$

The survey asked jurisdictions whether, since January of 2016, they had put into place "maximum durations on restrictive housing" and to specify what they were. Thirteen jurisdictions reported establishing some kind of limit on length of stay in restrictive housing, based on factors such as subpopulation, category of restrictive housing, or type of infraction. ${ }^{179}$ For example, one jurisdiction described establishing a maximum duration for "locked housing." 180 Another stated it had implemented a 30-day maximum length of stay for prisoners with serious mental illness. ${ }^{181}$ Other jurisdictions said they had implemented maximums for disciplinary restrictive housing ranging from 60 days to 10 years. ${ }^{182}$ Some jurisdictions reported implementing maximum durations for the phases of restrictive housing. ${ }^{183} \mathrm{~A}$ few other jurisdictions reported a limit for a given offense but did not preclude consecutive sanction. ${ }^{184}$ Some jurisdictions required administrative review of continued placement in restrictive housing. The frequency of reviews varied from a few months to almost a year. ${ }^{185}$

\section{Implementing the 2016 ACA Restrictive Housing Performance Based Standards}

The ACA, an accrediting body for "correctional facilities, detention centers and community correctional programs" as well as "probation and parole agencies, health care programs and electronic monitoring programs," 186 assesses compliance with its Performance Based Standards 
by reviewing accredited systems every three years. ${ }^{187}$ In 2016, the ACA adopted new Standards on restrictive housing. ${ }^{188}$ The 2017-2018 ASCA-Liman survey asked whether jurisdictions had reviewed their internal restrictive housing policies since the ACA revisions and, if so, whether jurisdictions relied on the ACA Standards when developing policies. ${ }^{189}$ We also focused on four ACA Standards related to release to the community, mental health, juveniles, and pregnancy, and asked whether jurisdictions had implemented each policy; "substantially implemented this policy with exceptions;" already had the policy in place prior to the 2016 ACA revisions; or had not implemented the policy.

Thirty-six jurisdictions reported that they had reviewed their restrictive housing policies since the release of the 2016 ACA Standards. ${ }^{190}$ Twenty-five jurisdictions reported that they relied on the ACA Standards when making jurisdiction-specific policies; ${ }^{191}$ nine jurisdictions reported that they considered the Standards, relied on them in part, or used them as a resource in making policies. ${ }^{192}$ Eight jurisdictions reported that they did not consult or rely on the ACA Standards. ${ }^{193}$

Under the 2016 ACA Standard 4-RH-0030, a jurisdiction's “written policy, procedure and practice require that the agency will attempt to ensure offenders are not released directly into the community from Restrictive Housing." ${ }^{194}$ Forty-one jurisdictions responded to the survey question about this Standard. Twenty-six of the 41 jurisdictions reported that they had implemented this policy, ${ }^{195}$ and five jurisdictions reported that they had "substantially implemented this policy, with exceptions." 196 Some of the jurisdictions reporting that they had partially implemented this Standard explained that release directly to the community could not always be avoided. ${ }^{197}$

With regard to mental health, the 2016 ACA Standards defined "serious mental illness" as:

Psychotic Disorders, Bipolar Disorders, and Major Depressive Disorder; any diagnosed mental disorder (excluding substance use disorders) currently associated with serious impairment in psychological, cognitive, or behavioral functioning that substantially interferes with the person's ability to meet the ordinary demands of living and requires an individualized treatment plan by a qualified mental health professional(s). ${ }^{198}$

ACA Standard 4-RH-0031 states that a jurisdiction's correctional "agency will not place a person with serious mental illness in Extended Restrictive Housing." "199 Twenty-one jurisdictions told us that they had implemented this Standard. ${ }^{200}$ Four jurisdictions reported that they had "substantially implemented this policy, with exceptions." ${ }^{201}$ We should note that it is not clear if jurisdictions used the ACA definition of serious mental illness or their own definitions which varied widely. See Appendix C.. ${ }^{202}$

As for age, the 2016 ACA Standard 4-RH-0034 states that confining individuals "under the age of 18 years of age in Extended Restrictive Housing is prohibited." 203 Of the 40 jurisdictions responding, 22 reported that they had implemented the Standard, ${ }^{204}$ and two jurisdictions reported that they had "substantially implemented this policy, with exceptions.",205 
With regard to pregnancy, ACA Standard 4-RH-0033 states that prisoners "determined to be pregnant will not be housed in Extended Restrictive Housing." 206 Twenty-five of the 41 jurisdictions that responded to this question said that they had implemented it. ${ }^{207}$ Four jurisdictions reported that they had "substantially implemented this policy, with exceptions." 208

\section{Evaluating the Effects of Policy Changes}

The survey asked whether jurisdictions had studied the effects of reforms in terms of incidents of violence, prisoner self-harm, prisoner and staff morale, the numbers of persons (or subsets of persons) placed in restrictive housing, the length of time spent confined, successes of prisoners on release to the general population and in returning to communities, and the costs of restrictive housing.

The 14 jurisdictions responding to this question reported that they had or were undertaking studies. ${ }^{209}$ Nine jurisdictions reported a focus on incidents of violence in prison. ${ }^{210}$ Six had studied the effects on prisoner self-harm, ${ }^{211}$ three on prisoner morale, ${ }^{212}$ five on staff morale, ${ }^{213}$ six on prisoner success upon return to the community, ${ }^{214}$ six on prisoner success with coping with life in prison, ${ }^{215}$ seven on duration of time in restrictive housing, ${ }^{216}$ and two on administrative costs. ${ }^{217}$ Four jurisdictions reported studying the numbers or subsets of people placed in restrictive housing. 218

Conducting research on the many variables affecting restrictive housing is complex and requires significant funding. One jurisdiction described working with the Vera Institute of Justice to collect data. ${ }^{219}$ Another jurisdiction stated that it had "completed a study on the impacts of restrictive housing. The study permitted grant funding for empirical research on long-term effects of Restrictive Housing on both inmates and staff." ${ }^{220}$ One prison system reported receiving a Bureau of Justice grant to study "interventions in restrictive housing settings" such as group programming and an "individualized Success Plan" for each inmate that "details how he plans to apply skills in high risk future situations." 221 Another jurisdiction directed us to published research based on its collection of data about restrictive housing. The 2018 study suggested that "a more therapeutic restrictive status housing program has the potential to improve the future behavior of program graduates," but cautioned that more research was needed. ${ }^{222}$ Another prison system stated that it had "revised its data collection system to track information on restricted housing," such as "the effectiveness of the restricted housing program," in order to "provide bases for modifying the program."223

\section{Aspiring for More Time Out-of-Cell}

The survey also sought information on the number of hours out-of-cell that jurisdictions believed was desirable for prisoners in an "ideal situation"-i.e., with sufficient resources and no problems regarding institutional safety. ${ }^{224}$ Thirty-eight prison jurisdictions provided answers to this question, ${ }^{225}$ and 31 specified a desirable number of hours out-of-cell. ${ }^{226}$

Some jurisdictions specified a certain number of hours per day or per week. ${ }^{227}$ The responses that were given in hours per day ranged from three hours ${ }^{228}$ to $15-16$ hours per day ${ }^{229}$ 
out-of-cell. The responses given in hours per week ranged from 7.5 hours ${ }^{230}$ to 56 hours per week out-of-cell. ${ }^{231}$ A few jurisdictions noted that different times out-of-cell would depend on prisoners' custody level. ${ }^{232}$ For example, one jurisdiction replied that for the general population a minimum of 12 hours daily would be desirable, while for those in disciplinary segregation two hours daily would be desirable. ${ }^{233}$

Ten jurisdictions described the kinds of activities that would, in an ideal situation, be reasons for having time out-of-cell. ${ }^{234}$ For example, one jurisdiction explained that all prisoners:

should have a productive work or program assignment that occupies 6.5 to 10 hours per day. Assigned offenders have an additional 2-4 hours of free/recreation time per day plus movement for meals and medications. The majority of offenders are in their cells from about $10 \mathrm{pm}$ to $6 \mathrm{am}$....We aim to maximize out-of-cell time, but there must be productive activities. We have learned that too much unstructured out-of-cell time leads to increased disruptive behavior. ${ }^{235}$

Another jurisdiction explained that an hour or two of daily out-of-cell time "during the sunlight hours would be good." 236 The jurisdiction elaborated: "Preferably, prisoners should get one hour in the morning and one hour in the afternoon of sunlight. This practice would allow the inmate enough time in direct sunlight to allow the human body to manufacture Vitamin D."237 One jurisdiction prefaced its answer with the comment that, "ultimately, no confinement would be the goal, however, realistically that will not happen."238

Six jurisdictions stated that they could not provide a concrete number of ideal hours outof-cell because it would depend on a variety of factors. ${ }^{239}$ One of those jurisdictions explained:

Regrettably, this question is too overbroad and vague to answer specifically as it varies depending on the type and kind of inmate being managed and, in addition to dozens of other variables, their historic, recent, and immediate behavior. It also can vary based on individual preference by the inmate. There are many inmates who do not want out of cell time, so the term desirable is subjective to the inmate themselves. In addition, the meaning, content, and quality of the out of cell time is also a considerable variable that makes it impossible to make a single statement about the amount of out of cell time which is desirable for prisoners. Finally, it is a topic that is more rooted in a sociological and philosophical discussion, especially because it is phrased as a hypothetical. ${ }^{240}$ 


\section{Working to Limit Restrictive Housing: Four Jurisdictions Making Changes}

We move from an overview of policy changes across the jurisdictions responding to the survey to reports from four jurisdictions - Colorado, Idaho, North Dakota, and Ohio - in which correctional leaders describe efforts to make profound changes in the use of restrictive housing. Below, we provide what correctional leaders wrote about the ways in which they have revised policies, the challenges they have faced, and the impact of their efforts.

\section{Colorado Reforms: What Do You Mean "Culture"? \\ Rick Raemisch, Executive Director, Colorado Department of Corrections}

During the fall of 2017, Colorado became the first, and thus far, the only state in the United States to limit the use of Restrictive Housing to 15 days maximum, and this use is only for the most serious violations. Extended Restrictive Housing, the former Administrative Segregation, has been abolished. Following the United Nations Mandela Rules, this change means that a person in the Colorado prison system who was involved in a serious violation will be in Restrictive Housing for 22 hours per day, 7 days per week for a maximum of 15 days. Violations are not to be "stacked." In other words, no one will be placed in Restrictive Housing for 15 days, removed, then immediately placed back in.

This change comes on top of others. Through the Department's policy and then by statute, Colorado had already ended Restrictive Housing for seriously mentally ill prisoners. In fact, Colorado developed the policy that, if a person is involved in a disciplinary incident, and it is determined by a team consisting of correctional officers and clinicians that mental illness was the cause of the incident, the offender is taken out of the disciplinary process and given treatment. In addition, Colorado policies prohibit placing pregnant females and juveniles in Restrictive Housing under any circumstances.

When we initially started our reforms we adopted the philosophy "just open the door." We control it. Open it. Of course many discussions, debates, committee work, and staff input were completed in order to develop the proper procedures and programs to allow us to open the door. As I have explained elsewhere, when we went in the direction of abolishing extended restrictive housing, there was no map, and there was no road. Dedicated staff were challenged to complete the reforms, and they not only accepted the challenge but excelled at it.

When the decision was made to finally go to the 15 day maximum Restrictive Housing, we adopted a new philosophy: "You can restrain, but you don't have to isolate." We were unable to find proper restraint tables, and we have never used cages, nor would we. Once again, staff answered the challenges, and we built our own furniture to fit our needs. Formerly dangerous, restrictive housing prisoners are now out of their cells for a minimum of four hours per day, at restraint tables with up to four other inmates, for programing and other activities. 
We have all heard the adage: "You can lead a horse to water, but can't make them drink." I don't believe that. I believe that: "If you throw the horse in the pond they are going to get some water just trying to get the hell out of the pond." The point is to give them programming regardless of whether they want it or not. Although this practice is new, it appears to be working. The goal of course is first to get them at the table, then give programming, and work towards safely removing the restraints. The goal is to have the programming be successful to the point where they can be back in general population.

We have been asked numerous times how we were able to accomplish this. How were you able to change the culture? When we have responded, we have heard: "That won't work here, the culture is too embedded in the way we are doing business now." Culture was never an issue with us. Of course our staff was used to using segregation on a regular if not overused basis. It's not a question of culture. It's a question of leadership. There is debate as to whether or not Henry Ford actually made this famous quote, but he is credited with saying: "If I had asked my customers what they wanted, they'd have said a faster horse."

The point obviously is that sometimes the vision needs to come directly from the leader. I gave the Colorado Department of Corrections the vision of where the Department would go. My approach was not "should we or would we?" Rather, it was: "This is what we are going to do." I put together an executive team that believed in my vision. My other philosophy is that if you have someone who wants to try something different, and it makes sense, give it a try. I've stated many times that if what we do doesn't work, we can always go back to the way things were before.

I consider my Executive Team and the other corrections leaders here as jet fighter pilots. I give them the target and then allow them to figure out how to get there. Not all of our staff believed in our reforms. Some retired, some transferred, but the results of our reforms have changed a good number of those who did not think it would work. At our two mental health prisons, where restrictive housing is completely banned, assaults, self-harm, and suicides have decreased dramatically. Staff enjoy work more because prisoners are acting in a more positive manner. It is quiet and safer. Safer facilities mean safer communities when they are released.

In the past, we had a waiting list for people with mental illness to be transferred to our facility for the seriously mentally ill. Today we have over fifty vacant beds. Our other facility for those with mental health issues has over 45 empty beds. It is too early to tell if the reason for this is because we have stopped manufacturing or multiplying mental illness by the overuse of segregation, but before our reforms there were none.

The bottom line: We have one vacant super max, and one re-purposed super max. We are back on track with our mission of public safety. 


\title{
Idaho: Efforts to Reform Restrictive Housing
}

\author{
Henry Atencio \\ Director, Idaho Department of Correction \\ Keith Yordy \\ Warden, Idaho State Correctional Institution, \\ Idaho Department of Correction
}

Idaho Department of Correction [IDOC] made a decision to reform restrictive housing because it was the right thing to do for public and for community safety. Given that ninety-eight percent of prisoners in IDOC will return to the community, it is inconsistent with IDOC's mission to keep a prisoner in long-term restrictive housing, which results in no access to programming or educational opportunities, until they are released back into the community. Moreover, reforming restrictive housing has many benefits. It encourages safe and humane practices for the prison population. Reform permits compliance with international and national law, as the United Nations has declared that being confined in a cell 23 hours a day for more than 15 days is considered torture. Prison-based reform reduces IDOC's exposure to litigation regarding restrictive housing.

IDOC's reform process began in 2016 and was guided by nationwide standards addressing restrictive housing, which included principles of the U.S. Department of Justice and the thirteen guiding principles provided by the Association for State Correctional Administrators (ASCA). ${ }^{1}$ Early on in the process, IDOC made the decision to include staff from multiple disciplines and at various leadership levels in the command structure. IDOC formed a command staff group comprised of agency and division leadership and reached out to external entities, who agreed to provide feedback and guidance to the agency during the reform process. The external partners included staff from the State Appellate Public Defenders' Office, the Office of the Federal Defenders of Idaho, and the Idaho Chapter of the American Civil Liberties Union. They have been an integral part of the process, as they have provided feedback on policy revisions, suggested language to use, and identified areas where the policy was unclear.

IDOC's path to reform also entailed having individual members of the department attend trainings and go on site visits to other states. Wardens, joined by correctional and mental health staff, visited Arizona and Washington Departments of Correction to see firsthand how reforms were implemented and to have discussions with those jurisdictions' staff about challenges and innovative ideas. In addition, several IDOC agency and facility leaders participated in training at the National Institute of Corrections (NIC) on restrictive housing reform. Idaho was selected as a pilot for an on-site NIC restrictive housing training that took place in August of 2017. Attendance at the training by wardens from facilities that housed men and women and that had long-term restrictive housing was crucial, as they both gained insight and learned about the importance and implementation of the restrictive housing guidelines of the U.S. Department of Justice.

\footnotetext{
${ }^{1}$ The ASCA principles are available here: https://www.asca.net/pdfdocs/9.pdf.
} 
As a result of this process, Idaho wardens began reviewing all prisoners who had been in long-term restrictive housing to reevaluate them with the goal that placement in restrictive housing should be reserved only for individuals who posed an imminent threat to the security of the institution. Doing so entailed taking a comprehensive approach to restrictive housing reform. The agency decided that two key policies, addressing restrictive housing and the disciplinary process, had to be updated. As a consequence, a revamped disciplinary policy added an alternative sanction process and changed the Disciplinary Offense Report (DOR) codes, and the restrictive housing policy was split into three separate policies - a short-term restrictive housing policy, a long-term restrictive housing policy, and a protective custody policy. The new policies ${ }^{2}$ reflect and implement a shift in the purposes and in the practices, and the result has been that fewer people are placed in restrictive housing.

A few specifics are in order. The short-term restrictive housing policy begins with a statement of purpose reflecting IDOC's mission statement on restrictive housing reform: "Restrictive housing protects staff and inmates by segregating those who are the most violent or present the greatest danger to the safe operations of the facilities." The policy provides that time spent in short-term restrictive housing is capped at fifteen days. Past that point, prisoners must be afforded, at a minimum, three hours of out-of-cell time a day and provided with personal property as they would have in general population. The policy also requires prisoners who have a language barrier, physical/sight/hearing impairment, or medical or mental health issues to have accommodations when placed in restrictive housing or an alternative placement, as needed.

Further, IDOC has limited the behaviors that can result in short-term restrictive housing placement to those that pose an imminent risk to safety. This change in the criteria for entry has reduced the number of short-term restrictive housing beds at some facilities, and, at others, the people put into such beds. In addition, some facilities have implemented "calm down" areas for prisoners to de-escalate, while others have implemented diversionary tiers for those in possession of drugs or alcohol or who have tested positive on urinalysis tests.

The long-term restrictive housing policy (addressing individuals in such housing for fifteen days or more) also begins with a statement of purpose, again stemming from IDOC's mission statement. "Restrictive housing is a structured program that protects staff and inmates by segregating those who are the most violent or present the greatest danger to the safe operations of the facilities." The policy requires that all prisoners placed into long-term restrictive housing programs are in Idaho's "Step Up Program," which consists of five stages designed to provide behavioral expectations to prisoners, teach them to identify concepts and skills to assist in behavior change, and assess their behavior to determine if placement in long-term restrictive housing is necessary. The policy requires that prisoners identified as having a serious mental illness be exempted from long-term restrictive housing placement and instead be placed in an alternative setting, which is usually a mental health unit. Further, the policy adds an administrative review

\footnotetext{
2 Idaho's policies can be found at www.idoc.idaho.gov.
} 
committee for all long-term restrictive housing placements. That committee is at the prisons' division leadership level and includes both of the deputy chiefs of prisons and the chief psychologist, who is a non-voting member.

As of the writing of this report in the spring of 2018, the new disciplinary policy is in effect; the short-term and long-term restrictive housing and the protective custody policies are in the final drafting stage. The command staff is doing a policy review, and the goal is to have training in place during the summer of 2018 to complete a rollout of the reforms. And even before the full implementation, IDOC has seen the impact in the reduction in the numbers of people in long-term restrictive housing and new methods of responding to problems. One example comes from Idaho Maximum Security Institution (IMSI), a facility whose operating capacity was 412 inmates prior to restrictive housing reform and which had included 320 single-occupancy restrictive housing cells. IMSI has expanded its capacity to house 564 prisoners and as of the end of June, IMSI has 134 prisoners in long-term restrictive housing and 24 in short-term restrictive housing. The facility has revised its practices to have more prisoners in close-custody general population.

At Pocatello Women's Correctional Center (PWCC), the facility operating capacity was 313 prisoners prior to restrictive housing reform, with a total of 20 single-occupancy restrictive housing cells. The current operating capacity has increased to 333. Today, one prisoner under the sentence of death is in what is termed long-term restrictive housing status, but, in practice, she is out of her cell three or more hours per day. At the South Idaho Correctional Institution (SICI), 17 short-term restrictive housing beds were taken off line, which enabled the placement of 34 minimum custody general population prisoners to be housed there. As of the end of June 2018, the population in restricted housing had declined from 294 long-term restrictive housing prisoners to 134 people held in long-term restrictive housing. 


\section{Reflections on North Dakota's Sustained Solitary Confinement Reform \\ Leann Bertsch \\ Director, North Dakota Department of Corrections and Rehabilitation}

Since late 2015, the North Dakota Department of Corrections and Rehabilitation (ND DOCR) has maintained an approximately $60-70 \%$ reduction in the population of its Administrative Segregation Unit (renamed the Behavioral Intervention Unit or BIU) at the North Dakota State Penitentiary (NDSP). The number of people residing in BIU as of April 5, 2018 was 24. The daily count within this unit has remained under 40 people over more than two years, down from over 100 people in 2015. The average length of stay in BIU has fluctuated between 30 and 60 days, although there are a few people who reside in the unit much longer based on the severity of violence, their expression of continued risk for violence, or their own preference for the BIU setting.

This population reduction has been sustained by continuing to adhere to a multi-faceted screening and assessment process. In fact, NDSP was able to convert one of the tiers within BIU to a preferred housing tier, which is home to 20 of the most consistently pro-social residents within the facility. Another 20-cell unit was converted to the Administrative Transition Unit, where people live when they are in the process of moving from BIU to a general population setting. ND DOCR continues to focus on those who commit any of 10 of the most serious in-custody offenses that may make a person eligible for BIU placement, with some exceptions for fighting and other harmful behaviors when they become severe or chronic. ND DOCR also continues to avoid placing people diagnosed with serious mental illnesses in BIU when possible and divert them to the Special Assistance Unit for more individualized services when it is determined that it is not safe to keep them in general population.

The sustained decrease in the number of people in the BIU setting has allowed for staff to make much better use of their time and to have a greater impact. Corrections officers engage each resident in friendly conversation, change-oriented discussion, or practice of a cognitive or behavioral skill at least twice per day. The unit Sergeant is also tasked with planning one prosocial, structured recreational activity each weekend to increase positive engagement with staff and out-of-cell socialization. Unit staff also provides reinforcement in the form of tangible property items, extra recreation time, extra showers, and the like, based on the person's participation in therapeutic and social activities, as well as the parameters of individualized behavior plans. Currently, BIU residents can access up to two hours and 40 minutes of recreation per day when they engage in skill practices and therapeutic groups, in addition to time spent in groups, individual sessions, and specially-planned enrichment activities.

Behavioral health staff also provides at least one structured leisure activity each week, such as an art project, mindfulness practice, or a movie. Three times per week they facilitate a group that focuses on applying skills to reduce or eliminate the use of violence, manage trauma reactions, 
and cope with segregation. Each resident completes an individualized Success Plan, detailing how he plans to apply skills in high-risk future situations, prior to or soon after moving to the Administrative Transition Unit. Once the person has moved to the Administrative Segregation Unit, he has the opportunity to continue to participate in group two times per week to work on skills application as the amount of time spent in general population settings increases. These group curricula and the Success Plan served as the foundation to inform a curriculum developed by Dr. Paula Smith for a Bureau of Justice Assistance Encouraging Innovation Grant related to applying interventions in restrictive housing settings, which ND DOCR will continue to implement as a data collection site related to that grant project.

Over the past two and a half years, ND DOCR has sustained a substantial reduction in the use of the Special Operations Response Team within the BIU (no use of the team at all in this unit since October 2017), along with a reduction in overall uses of force. The prevalence of negative behaviors by residents of the unit has also dramatically decreased. ND DOCR believes the focus on reinforcement of positive change, building friendly relationships between staff and residents, and allowing residents access to pro-social coping skills (music, television, puzzle books, etc.) are collectively responsible for these changes. Perhaps our most exciting outcome to date is the fact that, of the 149 residents placed on BIU program status from October of 2015 to February of 2018, only 26 have returned to BIU program status. That is a 17\% "recidivism" rate into the BIU program. ND DOCR is working to collect more precise data regarding these outcomes, but we are very encouraged by these initial results.

These changes, while overwhelmingly positive, have not been without challenges. NDSP did see a significant increase in physical fights between residents in mid-2016 to mid-2017. This increase occurred at the same time that our overall prison population was the highest it has ever been and we have some suspicions that this may be correlated more strongly with the population increase than the changes in the use of restrictive housing. As the population has slowly stabilized and begun to decrease, the prevalence of fighting has decreased as well. While most staff members have been supportive of the changes, there has been a perception that the overall safety of the facility has been compromised. Factually, there has been no increase in assaults on staff, assaults on residents by peers, or the overall level of violence perpetrated within the institution. There has also been a perception that residents are not "held accountable" for rule violations. In reality, residents continue to receive significant sanctions - the only difference is those sanctions are much less likely to include lengthy placements in restrictive housing, especially for non-violent offenses.

In order to address the problem of institutional violence more thoroughly, ND DOCR is excited to begin assessing people entering prison using the Risk of Administrative Segregation Tool (Labrecque \& Smith, 2017) in order to identify those at highest risk for displaying institutional violence resulting in placement in restrictive housing. A copy of the tool is below. 


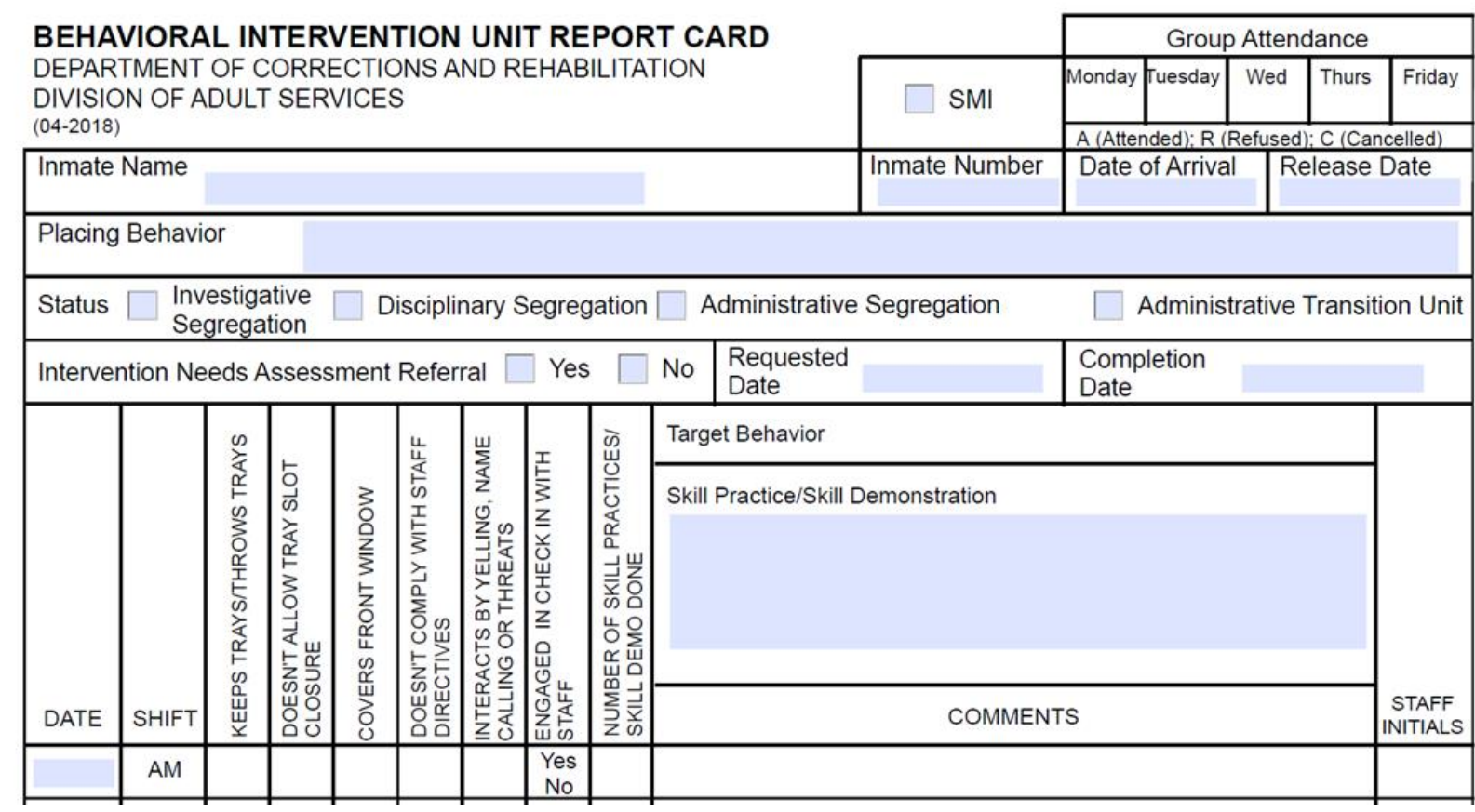

Those identified as high risk will then be offered a 10-session group intervention program focused on establishing a pro-social adjustment to prison and managing high-risk situations for violence in an effective, non-violent manner. This program will begin in April 2018. Dr. Paula Smith and Dr. Ryan Labrecque will evaluate the effectiveness of this intervention in preventing future violence as compared to a no-treatment control group. Another future direction is to develop a peer support specialist certification program for prison residents, with the goal of providing additional support to those at risk for placement or placed in BIU.

One way to provide an overview of the outcomes, as of the spring of 2018 , is by the chart below.

\begin{tabular}{|l|l|l|l|l|}
\hline Type of Seg. & Investigative & Disciplinary & BIU Program & Total Unit \\
\hline Avg. \# of days & 5.55 & 7.63 & 18.97 & 32.14 \\
\hline
\end{tabular}

\begin{tabular}{|l|l|l|l|l|}
\hline Type of Seg. & Investigative & Disciplinary & BIU Program & Total Unit \\
\hline $\begin{array}{l}\text { Total \# Stays } \\
\text { Over 14 Days }\end{array}$ & 30 & 38 & 60 & 128 \\
\hline
\end{tabular}




\section{Restrictive Housing: The Challenge of Reforming the Fabric of an Agency}

\section{Gary Mohr, Director, Ohio Department of Rehabilitation and Correction}

Restrictive housing reform represents one of the most extensive reforms in the history of corrections in the United States. The use of restrictive housing to respond to prisoner misbehavior has been the foundation of correctional management philosophy for over a century. The practice is embedded in the philosophy and logic of nearly all agency staff and is interwoven into the fabric of any correctional agency's culture.

The use of restrictive housing remains an essential part of managing safe and secure prisons. Changing the way a correctional organization uses restrictive housing requires a delicate balancing act of improving conditions of confinement for prisoners who are more conducive to rehabilitative ends, while simultaneously ensuring we protect our staff and prisoners from individuals whose behavior indicates they are poised to harm others. Further, for most of my 44 years in this work, restrictive housing has been used as the default penalty for all types of rule violations, whether violent or not. Changing practices associated with the use of restrictive housing is a delicate operation because our staff, those who work in the trenches of our prisons, firmly believe the use of restrictive housing as a default disciplinary sanction is tied directly to their safety. Reforming the system to use restrictive housing only when there is a threat to safety and security, rather than as punishment, often becomes viewed as an attempt to jeopardize safety.

Today, that cultural belief has been reinforced by the horrific incidents in prisons throughout our country from North and South Carolina, to Pennsylvania, Arizona and many other jurisdictions including Ohio. In 2018, an Ohio Correctional Officer was stabbed 32 times by two prisoners who were in extended restrictive housing; miraculously, he survived. This event not only magnified the challenge of continuing to reform restrictive housing, but also changed my life, as it was a vivid reminder of how precious life is and how we as leaders carry the heavy responsibility for the welfare of so many. As we continue the much-needed reform regarding the practice of placing prisoners in confined settings, an area where there is still much work to be done, the realities and images of individuals who have experienced serious, life-changing incidents cannot be ignored. The impact on their lives, as well as on the lives of their loved ones and fellow staff members, must be of paramount concern.

Ohio can clearly report success in reducing prisoners in restrictive housing as evidenced by data comparing the use of restrictive housing between 2013 to 2017. In fact, there has been a $45 \%$ reduction in the number of prisoners in restrictive housing during that time period. While this reduction is meaningful and significant, it is also a reminder of the need for restrictive housing now and in the future. The reality is that there are people in prison who pose a serious and direct threat to others, and we have a duty to protect others from these prisoners. As agency leaders, we count on our staff in all correctional systems to carry out post orders and follow our directives 24 
hours a day, 7 days a week. Those dedicated public servants must acknowledge and trust their leaders, even though they will not always agree, or the overall agency goals will not be achieved. Leaders cannot merely issue edicts directing a course of action when those directives are contrary to the will of the workforce if they expect the vision of the policy to be realized. In matters that challenge the foundational beliefs and values of the staff, change must occur over time through consistent reinforcement of the philosophy underlying the policy direction.

Operational Challenges to Restrictive Housing Reform: The Ohio Department of Rehabilitation and Corrections (DRC) began restrictive housing reform in late 2013 by conducting wide-ranging discussions on how and why correctional supervisors/executives use restrictive housing. In 2014 and 2015, the DRC examined all policies and procedures, even hiring external consultants to provide insight into current practices, assess areas for improvement, and recommend a pathway for reform. In 2015, it became apparent restrictive housing reform was intrinsically linked to discipline reform. As such, the DRC needed to re-examine the entire way prisoner rule violations were addressed. Below, I outline our reforms.

Reform Initiative A: Prison Disciplinary Reform (Swift, Certain, and Fair): In late 2015 and early 2016, the DRC began to change the philosophy associated with the offender disciplinary system to encourage sanctions that adhere to swift, certain, and fair (SCF) principles of discipline. Most importantly, this change included using alternative sanctions to reduce the use of restrictive housing. Implementation required, and continues to require, ongoing changes to organizational culture.

Challenge 1: Operationalizing the changes in sanctioning practices remains an ongoing challenge by trying to achieve consistency, fairness, and immediacy of application across all prisons.

Reform Initiative B: Alternatives to Restrictive Housing_Limited Privilege Housing: The DRC has the option in Ohio's Administrative Regulations to use limited privilege housing. Limited privilege housing is a condition of confinement that significantly limits a prisoner's privileges, so it can be used to respond to low-to-moderate severity rule violations. Limited privilege housing is not restrictive housing. It is, however, a meaningful sanction that adheres to swift, certain, and fair principles of sanctioning. It also removes prisoners from the housing area where they committed their offense. In late 2015 and lasting until today, the DRC greatly expanded the use of limited privilege housing and encouraged staff to not use restrictive housing as the default placement for prisoners who have misbehaved unless they posed a danger to the prison or to others.

Challenge 2: Proper utilization of the limited privilege housing sanction has been a challenge. DRC continues to experience under-utilization and over-utilization of the sanction as an alternative to restrictive housing, and there is inconsistency in the security practices between areas. 
Challenge 3: One of the greatest cultural challenges was passive resistance by staff who, in frustration over being asked not to use "segregation" for many offenses, assumed an "all or nothing" stance towards security. Simply put, if they could not place a prisoner in segregation (restrictive housing), then they just had to let prisoners do "whatever they wanted" and could take no meaningful action. Others felt a limited privilege housing unit could have a "relaxed" security posture when in reality limited privilege housing units can be just as secure as a restrictive housing unit if the type/kind of prisoner needs such levels of supervision. The critical difference is the out of cell time and access to programming and services which require all staff to change the way they work.

Challenge 4: A cultural myth developed that restrictive housing reform's goal was to reduce the use of restrictive housing regardless of the prisoner's behavior. DRC leadership was compelled to constantly remind staff that restrictive housing reform never meant prisons could not use restrictive housing to address violence or seriously disruptive behavior. This myth was persistent and remains even when policies were released providing staff the option of stronger and lengthier disciplinary sanctions. The written words contained in the policy, as well as emails sent to all staff, were overshadowed by this mythology that is still persistent five years into reform.

Reform Initiative C: Widespread Training/Communication on Restrictive Housing: Throughout 2016 and carrying into 2018, the DRC has revised dozens of policies, lesson plans, and in-service training on restrictive housing Reform and its related components within the DRC.

Challenge 5: Communication of the "why" behind restrictive housing Reform remains our prevailing challenge. A significant number of staff still report they do not understand the reasons for reform despite training, memos, policies, and emails that have tried to explain all aspects of the reform effort. More importantly, many of them do not understand the permanence of these changes and are "waiting to go back to the way it was." Finally, it cannot be ignored that there are some staff who simply believe prisoners should be severely restricted while in prison and especially when they commit any rule violations. It is reasonable to say that when an organization operates for nearly a century in one manner, it will take a very long time to change the fundamental beliefs of the staff who operate that organization. These individuals who, regrettably, exist at all levels in our agency continue to passively, or sometimes actively, resist restrictive housing reform, likely in the hope the reform will fail and the DRC will have to return to the status quo which existed in 2013.

Challenge 6: The volume and pace of change is a significant, on-going challenge for staff at all levels. Change for any organization is difficult, but the root nature of 
this change coupled with the fact the change requires a shift in personal, organizational, and leadership philosophy makes it incredibly challenging.

Challenge 7: Staff perceptions exist by some at all levels (line, supervisor, and executive staff) that are less than supportive of/favorable to restrictive housing reform efforts thus far. There is a strong feeling these policies are making people less safe and reform values prisoners over staff safety. The serious incident of the stabbing of our correctional officer mentioned earlier has kept this belief alive.

Challenge 8: There is substantial message dilution in training and communication. As information is passed down from each level of leadership and supervision, the message gets changed and altered, greatly affected by the cultural resistance outlined in previous challenges. As such, the DRC must continually improve the content and delivery of the restrictive housing Reform "communication plan."

Reform Initiative D: Serious Misconduct Panels and External Oversight of Extended Restrictive Housing: Prior to reform, local wardens possessed the authority independently to place prisoners into restrictive housing for six months, and in some cases, for a year or more. There was no centralized oversight for these two review processes. Wardens applied this power based on their individual perspective about misbehavior rather than an organizational view. In response, the DRC established the "serious misconduct panel" (SMP) as the only process by which offenders can be referred to "extended restrictive housing" and implemented centralized oversight of all placements and releases. The SMP referral is still made by a warden but is approved by a regional director and the panel is comprised of two exempt employees from a prison other than the one where the offense occurred.

Challenge 9: There have been concerns expressed that the use of the SMP implies a mistrust of the professional judgment of local teams who know the prisoners best. The delicate balancing act of ensuring consistency across all prisons while respecting local decision makers becomes interpreted as a form of heavy-handed oversight. In addition, prison leaders believe the new policies curtailed their ability to control violence and disruption at their prisons.

Challenge 10: The procedural aspects of the SMP are cumbersome and time consuming. The ongoing challenge is to streamline the SMP process without hindering the objectivity, due process, or thoroughness of the review.

Reform Initiative E: Conditions of Confinement and Programming for Extended Restrictive Housing: The DRC examined the conditions of confinement for offenders in extended restrictive housing and implemented additional programming, meaningful activities, and out-of-cell time. This process includes enhanced release preparation programs as best exemplified by the Ohio State Penitentiary $[\mathrm{OSP}]$ reversion program. This program introduces pro-social elements such as 
employer engagement, family activities/events, and meals in group settings, including meals with the warden, into our highest security setting.

Challenge 11: The physical plant and infrastructure of all DRC facilities were not designed to provide a lot of out-of-cell time for prisoners in restrictive housing. The facilities were designed according to the philosophy of corrections in the United States at the time. The last prisons constructed were designed in the mid-1990s, almost a quarter of a century ago. The only way to offset some of these design issues is with significant staffing resources, which are very costly and difficult to appropriate in challenging budgetary environments.

Challenge 12: Self-imposed isolation, even when out-of-cell opportunities are granted, remains a considerable challenge. Prisoners choose these environments in a significant number of circumstances.

Challenge 13: It is a continuing challenge to ensure conditions of confinement differ between restrictive housing, limited privilege housing, and general population in a meaningful way that sufficiently deters prisoners from engaging in misbehavior. The more you give prisoners in restrictive housing/extended restrictive housing/limited privilege housing, the less appealing rule compliant behavior becomes for prisoners in general population. Over-compensating to assist restrictive housing/extended restrictive housing prisoners can exacerbate the problems associated with Challenge 12 and, as has been proven by some cases in Ohio, actively encourage prisoner misbehavior to achieve a placement into extended restrictive housing.

Reform Initiative F: Limiting Extended Restrictive Housing for Seriously Mentally Ill Prisoners and Enhanced Monitoring: The DRC recognizes the potential effects of restrictive housing on the seriously mentally ill. However, seriously mentally ill prisoners, like others, can commit very serious acts of violence and disruption unrelated to their mental illness. Furthermore, even if the violence is related to their mental illness, the threat to the safety of others cannot be ignored. Therefore, the DRC has implemented practices to closely monitor the utilization of extended restrictive housing for prisoners with serious mental illness, and placement in extended restrictive housing for a person with serious mental illness must be approved at the departmental level. We also use and have expanded high security Residential Treatment Units [RTUs] as an assessment/diversion opportunity to avoid placement in extended restrictive housing for some people with serious mental illness.

Challenge 14: The single greatest challenge in this effort is to develop and implement a "space between" restrictive housing and general population for dangerous, disruptive, and violent seriously mentally ill prisoners. Efforts to operate a "secure adjustment unit" for violent, seriously mentally ill offenders were 
unsuccessful. We have added a significant number of Residential Treatment Unit [RTU] beds for the seriously mentally ill. There remain prisoners who are seriously mentally ill and violent/disruptive, but do not meet the standard of our mental health staff for an RTU level of care.

Challenge 15: DRC has expanded the number of high security RTUs, but there remains a substantial need for more beds and staff.

Challenge 16: Although philosophically we understand the need to treat seriously mentally ill prisoners differently, if one lessens the sanctions on prisoners solely because they are seriously mentally ill, other prisoners may perceive a tremendous injustice. This can cause disruption in housing units where both seriously mentally ill and non-caseload prisoners are held. In addition, as we attempt to grant more out-of-cell time and increased staff engagement for seriously mentally ill prisoners even after they have committed serious acts of violence against staff, we experience a growing cultural resistance to reform. Staff who are victimized, sometimes repeatedly, by these prisoners perceive these acts as being unfair and proof there is lack of care for staff and for the impact that violence by prisoners has on them. Thus the challenge continues.

Reform Initiative G: Tracking and Data Collection: The DOTS system, our tracking system, in present form, cannot effectively track people placed in restrictive housing or limited privilege housing. Since 2013, the DRC has continually developed new methods for measuring restrictive housing, primarily by using snapshots. Currently, Operations and IT staff are developing a restrictive housing/limited privilege housing Disciplinary Tracking System integrated into the DOTS system that, once completed, will provide a comprehensive system for examining disciplinary sanctions and their utilization, as well as profiles and real-time data on prisoners in restrictive housing/limited privilege housing. It will track the work flows associated with major job processes which may affect length of stay in restrictive housing/limited privilege housing including, but not limited to:

1) Hearing Officer and RIB Decisions

2) SMP referrals, extended restrictive housing placements, and extended restrictive housing reviews

3) Investigations regarding prison administrative functions such as misbehavior, protective control, separations, and staff nexus

4) Security Classification Reviews and Increases/Decreases

5) Prisoner Movement and Transfers 
Challenge 17: While waiting for these changes, it is not acceptable to forgo efforts to track restrictive housing. Reporting mechanisms have changed somewhat over time and to get accurate data is a cumbersome process that is very labor-intensive.

Conclusion: On December 27, 2010, when I met with Governor Kasich and decided to accept this journey to oversee the Ohio Department of Rehabilitation and Correction, he asked me to do two things. First, we could not afford another Lucasville, the riot that lasted 11 days and resulted in 10 deaths. Secondly, "Go reform the most unreformed part of government." While we have made some very progressive changes in creating reintegration environments, expanded programming including treatment of the addicted both in and outside our prison walls, expanded residential treatment beds for the mentally ill, employment partnerships with employers with experiences both inside the prisons and out in the communities, and engagement with community faith partners, the challenge of reforming restrictive housing is at the core of that challenge. Restrictive housing reform remains a challenge to us in Ohio and many other jurisdictions around our great country. 


\section{Calls for Reform and for Abolition: Restrictive Housing in 2018}

In this section, we put the data collected through the 2017-2018 ASCA-Liman survey in the context of actions, in and outside of prison systems, focused on regulating the use of restrictive housing. As reflected in the analyses thus far, efforts by prison officials to reform isolating conditions have intensified.

Below we provide a sample of initiatives, legislation, litigation, and public discussion in the United States and abroad. From these many vectors, we can see that a consensus has emerged about the harms to individuals held in deeply isolating conditions; to staff working in restrictive housing; ${ }^{241}$ and to community safety. ${ }^{242}$ The reiterated theme is that 22 hours or more of confinement in a small cell for days on end is unwise, unjust, and inefficient. As a result, rules of correctional systems, statutes, litigation, and research - shaped by prison and health professionals, prisoners, their families, and their communities - have produced a nationwide commitment to limit and, in some instances, to abolish, the practices that fall under the rubric of restrictive housing.

\section{Correctional Systems Making Changes}

In addition to changes chronicled in responses to our survey, targeted efforts are underway in several other jurisdictions. Support for some of these efforts comes from the National Institute of Corrections and the U.S. Department of Justice, Bureau of Justice Assistance. Many reforms have garnered media attention.

As described in its 2018 monograph, Rethinking Restrictive Housing: Lessons from Five U.S. Jails and Prisons Systems, the Vera Institute of Justice worked on site with the state prison systems of Nebraska, Oregon, and North Carolina, and with two local jails in New York City and Middlesex County, New Jersey, all of which were "committed to change."243

Vera's 2018 study echoes many of the findings from ASCA-Liman analyses of the policies governing administrative segregation. ${ }^{244}$ In the 2013 monograph, we described the broad discretion afforded correctional officials in placing individuals in restrictive housing, ${ }^{245}$ and in 2014 and 2016, we provided a database of the impact, in terms of the widespread use of restrictive housing. ${ }^{246}$ As Vera's 2018 report recounted, when Vera began working in the five jurisdictions, it found that restrictive housing conditions were typically "stark, isolated environments with little sensory stimulation or social interaction." 247 Vera detailed the heavy reliance on disciplinary segregation, often imposed for non-violent offenses, such as "disobeying an order," 248 using "profane language," or "disruption." ${ }^{249}$ Individuals placed in administrative segregation were not given "predetermined" release dates or frequently considered for release. ${ }^{250}$

Vera also raised concerns that some jurisdictions lacked methods to appropriately identify individuals with mental health needs. In those that did, "high levels of placement in restrictive housing" were common. ${ }^{251}$ As in the ASCA-Liman 2014 Time-in-Cell report, Vera identified thousands of individuals with mental health needs who were placed in restrictive housing. ${ }^{252}$ Further, akin to the findings in this Report, ${ }^{253}$ Vera concluded that people of color were "placed in 
restrictive housing at higher rates than white people were." ${ }^{254}$ Vera also determined that people of color were "underrepresented in more treatment-oriented forms of restrictive housing and in lessstringent alternatives." ${ }^{255}$ In addition, Vera found, as does this report, that young people were "more likely than older people to be placed in restrictive housing." ${ }^{256}$ And, as ASCA-Liman had found in its 2014 survey, ${ }^{257}$ thousands of people in the jurisdictions Vera studied were sent directly from restrictive housing to the community. ${ }^{258}$

Vera's recommendations likewise reflect the goals of many correctional departments, courts, legislatures, and prisoners - to reduce "the flow of people into various types of restrictive housing," to "shorten the length of time people spend in restrictive housing," and to improve conditions of restrictive housing. ${ }^{259}$ Vera recommended using restrictive housing only "as a last resort; as a response to the most serious and threatening behavior; for the shortest time possible; and with the least restrictive conditions possible." 260

Examples of what might improve conditions by providing more stimulation were stark reminders of the isolation that was the ordinary state of conditions. Thus, digital music players and "blue rooms" in which prisoners could see nature videos were illustrations of what could be added. ${ }^{261}$ Vera proposed that prisons and jails "minimize social isolation and provide access to programming and mental health treatment" and aim to maximize "out-of-cell time," reduce "sensory deprivation and isolation," and increase "access to medical, mental health, and program staff." 262 As for specific subpopulations, "Vera recommended that its partner corrections agencies prohibit the placement of youth (younger than 18), pregnant women, and people who have serious mental illness, developmental disabilities, or neurodegenerative diseases in any form of restrictive housing that limits meaningful access to social interaction, exercise, environmental stimulation, and therapeutic programming." 263 According to the report, as of 2018, the five correctional sites with which Vera worked were implementing many of these recommendations. ${ }^{264}$

Several media reports in 2017 and 2018 highlighted reforms of restrictive housing. For example, in July of 2018, the news program 60 Minutes aired an episode with Oprah Winfrey on the conditions in solitary confinement in California's Pelican Bay Prison. ${ }^{265}$ Winfrey interviewed men currently in segregation, former prisoners who had been held in isolation, and prison officials who explained how the use of restrictive housing had been changed. The broadcast described how, after a 2015 legal settlement, California ended indefinite isolation and stopped using gang affiliation as a basis for sending people to segregation. The program reported $80 \%$ fewer prisoners in the state's restrictive housing units than had been there a few years ago.

Changes in North Dakota and in Colorado have also been covered in the national media. Morning Edition, a weekday news program on National Public Radio (NPR), devoted a segment in July of 2018 to North Dakota's restrictive housing reforms. ${ }^{266}$ The piece featured interviews with Director Leann Bertsch and with correctional staff members. Prison administrators described implementing group therapeutic sessions for people in segregation and changing how officers interact with prisoners. For example, officers reported writing up positive prisoner behavior, not 
just citing negative conduct. Prison staff described the improvements they saw, as a result of these changes, in how prisoners behaved and in prisoner-staff rapport. The same month as the NPR broadcast, Dashka Slater, a reporter for the magazine Mother Jones, wrote about the state's reforms. ${ }^{267}$ The article described how North Dakota's changes were inspired by a visit Director Bertsch and her staff made to a Norway prison. At that facility, prisoners were allowed relative freedom of movement, the use of solitary confinement was rare, and violent behavior was uncommon. North Dakota prison administrators related how, after the visit, they set out to reform their system, including by limiting time spent in restrictive housing. In October of 2017, the New York Times published an op-ed by Director Rick Raemisch on the decision in Colorado to end long-term solitary confinement. ${ }^{268} \mathrm{He}$ wrote about his conviction that "long-term isolation manufactures and aggravates mental illness." He explained that, because the vast majority of prisoners "eventually leave prison," ending long-term isolation was "simply the right thing to dofor the inmates and for their communities."

Other state reforms have been featured in local media. In May of 2018, Oregon news station KTVZ covered the correctional system's work with Vera to reduce the use of restrictive housing. ${ }^{269}$ The broadcast cited Vera's Rethinking Restrictive Housing, which found that Oregon's Department of Corrections had reduced the percentage of people in restrictive housing from $8.8 \%$ to $7.7 \%$ over the course of a year. The segment quoted Department of Corrections Director Colette Peters: "We are committed to both reducing the number of men and women in special housing and the length of time spent in these units in a safe manner for staff and other adults in custody." In September of 2017, Keri Blakinger of the Houston Chronicle reported on the Texas prison system's elimination of solitary confinement as punishment. ${ }^{270}$ Blakinger stated that the change would affect the roughly 75 people in isolation for disciplinary reasons, but would not affect those in administrative segregation for reasons like gang affiliation or security threats. The article framed the state's reform in the context of a national trend to reduce the use of solitary confinement.

\section{Understanding the Harms of Isolation}

Researchers have sought to identify the impact of living in isolation for long periods of time, and many professionals have concluded that doing so is harmful to physical health, wellbeing, and mental health. Further, young individuals, older adults, and those with physical and mental disabilities or challenges experience these harms acutely. ${ }^{271}$

Age — being young or old - is a factor that exacerbates the dislocations of isolating conditions. In 2017, when supporting federal legislation to restrict the use of solitary confinement of juveniles, the American Psychological Association explained that isolation had "especially devastating consequences to youth whose developmental immaturity leaves them more vulnerable to adverse reactions to prolonged isolation." These "effects may be exacerbated for children with disabilities or histories of trauma or abuse." 272 Older adults face other challenges, given that when subjected to "a lack of physical exercise, and loneliness," they have an "elevated risk for the earlier onset of dementia, physical deconditioning resulting in a heightened subsequent risk of falls, Vitamin D deficiency, and cardiovascular disease."273 
For individuals with physical disabilities, isolation can have a "devastating impact," as detailed in a 2017 report from the American Civil Liberties Union, Caged In: Solitary Confinement's Devastating Harm on Prisoners with Physical Disabilities. ${ }^{274}$ As that report explained, no national data were available on the numbers of persons with disabilities in restrictive housing; state studies had found that ten to twenty percent of the general prison population had forms of impairment, including to sight, mobility, and hearing. ${ }^{275}$

To learn about the impact of isolating conditions, Caged In researchers interviewed prisoners and staff and reviewed grievances filed by individuals with disabilities in 10 state systems. ${ }^{276}$ As the report recounts, restrictive housing generally provided no accommodations for people unable to hear or see or in need of wheelchairs and other devices to enable them to manage basic daily tasks. ${ }^{277}$ Many people went without hearing aids, Braille materials, sign language interpreters, and physical therapy. ${ }^{278}$

To respond, the report proposed that correctional officials: 1) "End all placements of prisoners with physical disabilities into solitary confinement where their disabilities will be worsened by such placements;" 2) "Prohibit all placements of individuals with physical disabilities into solitary confinement due to a lack of accessible cells;" 3) "Provide all accommodations, including assistive devices and auxiliary aids, to prisoners with physical disabilities who are held in solitary confinement, unless substantial and immediate security threat is documented," in which case, "alternative arrangements must be made and documented;" 4) "Establish data procedures to improve tracking and monitoring of prisoners with physical disabilities in prisons and jails, including the number of people with disabilities and those in solitary confinement, or other forms of restrictive housing, and the reasons for their placement." ${ }^{279}$ As that report also noted, litigation under the Americans with Disabilities Act (ADA) and section 504 of the Rehabilitation Act ${ }^{280}$ has been brought to respond to some of the problems. ${ }^{281}$

Depriving individuals of virtually all normal sociability has long been understood as disabling. For individuals whose mental well-being is already impaired, restrictive housing has come to be seen as adding injury to insult. Illustrative is the 2012 statement, adopted by the American Psychiatric Association, that "prolonged segregation of adult inmates with serious mental illness, with rare exceptions, should be avoided due to the potential for harm to such inmates."282 In 2014, the Committee on Causes and Consequences of High Rates of Incarceration, an ad hoc committee of the National Research Council, concluded that isolation in prisons "can create or exacerbate serious psychological change in some inmates and make it difficult for them to return to the general population of a prison or to the community outside prison . . . Long-term segregation is not an appropriate setting for seriously mentally ill inmates."283

In 2016, the National Commission on Correctional Health Care (NCCHC) issued a "position statement," to "assist health care professionals in addressing the use of solitary confinement in the facilities" in which they worked. ${ }^{284}$ Defining solitary confinement as housing with "minimal to rare meaningful contact with other individuals," NCCHC promulgated 
"principles," including that what it termed "prolonged (greater than 15 consecutive days) solitary confinement" was cruel, inhumane, and degrading treatment, and harmful to an individual's health, ${ }^{285}$ and that correctional health professionals ought not to "condone or participate" in its use. ${ }^{286} \mathrm{NCCHC}$ also called for solitary confinement not to "exceed 15 days," 287 and that health care professionals not "be involved in determining whether adults or juveniles are physically or psychologically able to be placed in isolation." 288 Further, the organization called for those placed in solitary confinement to have "as much human contact as possible with people from outside the facility and with custodial, educational, religious, and medical staff.",289

As reflected in these statements, health care experts (some of whom have participated in litigation challenging restrictive housing) have concluded that solitary confinement is harmful to individuals. Those views have been predicated on clinical judgments and academic research, some of which has been summarized in overview essays that take different views about how to synthesize the research. One synthesis, published in 2016, concluded that prisoners in isolation suffered no greater psychological deterioration over time as compared to general population prisoners and, in fact, showed some improvement. ${ }^{290}$ A 2017 overview disagreed, in part because the 2016 meta-analysis was not a complete account of the existing research ${ }^{291}$ and included some studies that had serious flaws. ${ }^{292}$ The 2017 essay noted that one of the prominent sources for the no-comparative-harm point of view had not controlled for the prior experience of prisoners in segregation before being placed in the less severe form of restrictive housing, and that prisoners moved in and out of different levels of isolation. ${ }^{293}$ In contrast, other research has documented a set of stress-related reactions, sleep disturbances, anxiety, panic, rage, anger, and aggression associated with profoundly isolating conditions. ${ }^{294}$

Another researcher termed this impact a "SHU Post-Release Syndrome," entailing a sense of "disorientation following release, anxiety in unfamiliar places, a tendency to retreat into small spaces and limit social interactions, hyper-vigilance and heightened suspicion of others, and difficulty expressing feelings or trusting others." ${ }^{295}$ Further, he and other researchers have investigated the physiological impact of solitary confinement, and focused on adrenaline and cortisol levels, neuron pathways, and brain waves. ${ }^{296}$ In other studies, researchers have concluded that isolation created a greater risk of self-harm among prisoners ${ }^{297}$ and that, during and after release, individuals were significantly more likely to show signs of post-traumatic stress disorder (PTSD) than those not held in isolating conditions. ${ }^{298}$

The Minnesota Department of Corrections and Minnesota Department of Public Safety sought to understand the effects of restrictive housing on recidivism. ${ }^{299}$ The study's authors selected a sample of 6,500 cases from all adult prisoners released in 2014 in Minnesota. ${ }^{300}$ The report examined "three different forms of recidivism: supervision revocations (also known as technical violations), new arrests, and new felony convictions within three years of release." ${ }^{301}$,The researchers concluded that time spent in restrictive housing "increased the risk of supervision violations," which are infractions that break the rules set for supervised release but do not necessarily break the law; however, time in isolation "did not significantly affect the risk of rearrest 
or reconviction." ${ }^{302}$ The study also found that "being released to the outside world directly from" restrictive housing "did not have a large or significant impact" on recidivism. The authors wrote that future research "should disentangle the relationship" among restrictive housing, mental health, and recidivism, and should "examine the factors that increase, as well as decrease," the risk of placement in segregation. ${ }^{303}$

\section{Legislative Regulations}

Many legislatures have proposed and, in a few jurisdictions, enacted statutes to regulate and limit the use of restrictive housing. The bills are directed at the process of entry and oversight to make long-term stays less likely, ${ }^{304}$ at lessening isolation by mandating activities akin to those available to the general population for persons held for 60 days or more in restrictive housing, and at improving data collection and reporting on the use of restrictive housing. ${ }^{305}$ As of the summer of 2018, statutes on restrictive housing were enacted in Massachusetts, ${ }^{306}$ voted out of the legislature for signature by the governor in New York, ${ }^{307}$ and introduced in several jurisdictions across the U.S. - from Hawaii ${ }^{308}$ to Nebraska, ${ }^{309}$ New Jersey, ${ }^{310}$ Virginia, ${ }^{311}$ and the United States Senate. ${ }^{312}$

An example of a comprehensive reform comes from Massachusetts, which in April of 2018 put a packet of restrictive housing reforms into place for state and county correctional facilities. ${ }^{313}$ After becoming effective at the end of 2018, the legislation will eliminate the use of restrictive housing to protect individuals beyond 72 hours, "unless the commissioner, the sheriff or a designee of the commissioner or sheriff certifies in writing: (i) the reason why the prisoner may not be safely held in the general population; (ii) that there is no available placement in a unit comparable to general population; (iii) that efforts are being undertaken to find appropriate housing and the status of the efforts; and (iv) the anticipated time frame for resolution." ${ }^{314}$ Once appropriate housing is located for a prisoner in need of protection, that housing must afford the prisoner "approximately the same conditions, privileges, amenities and opportunities as in general population." 315

The Massachusetts legislation will also change the decision-making process for placing people in restrictive housing. The statute will require "placement reviews" by a "multidisciplinary" team ${ }^{316}$ and will establish a restrictive housing oversight committee, ${ }^{317}$ to which reports are to be made monthly on the number of prisoners in restrictive housing in each state and county correctional facility. ${ }^{318}$ For those held 60 days or more, the correctional department is to provide "access to vocational, educational, and rehabilitative programming, to the maximum extent possible consistent with the safety and security of the unit." 319

In addition, Massachusetts's 2018 law will bar using a person's gender identity or sexual orientation as a ground for placing a person in restrictive housing. ${ }^{320}$ The legislation will also ban restrictive housing for pregnant prisoners. ${ }^{321}$ The statute will impose limits on placement of people found to have "a serious mental illness," as discussed below. 
As of the spring of 2018, legislation to eliminate or to limit restrictive housing for subpopulations had been enacted in California, Colorado, Washington, D.C., and Tennessee, and proposed in several other jurisdictions, including Connecticut, Hawaii, Nebraska, New Jersey, New York, and Virginia. ${ }^{322}$ One focus is on juveniles, where "room confinement" is the term used to describe isolating young people. ${ }^{323}$ For example, beginning in 2016, California prohibited placing juveniles in room confinement "for the purposes of punishment, coercion, convenience, or retaliation by staff" 324 and required that before using room confinement, "other less restrictive options have been attempted and exhausted, unless attempting those options poses a threat to the safety or security of any minor, ward, or staff." 325 Room confinement is presumptively to be less than four hours, with renewed authorization from a facility supervisor required every four hours. ${ }^{326}$

Colorado's 2016 statute provides that "a youth may not be held in seclusion under any circumstances for more than eight total hours in two consecutive calendar days without a written court order." ${ }^{327}$ In 2017, Washington, D.C. enacted legislation requiring that room confinement for juveniles "be used for the briefest period of time possible and not for a time to exceed 6 hours," 328 and prohibiting "room confinement on a juvenile for the purposes of discipline, punishment, administrative convenience, retaliation, or staffing shortages." ${ }^{229}$ The Tennessee Juvenile Justice Reform Act of 2018 includes a provision prohibiting seclusion of children in detention. ${ }^{330}$ A bill in Nebraska proposes a limit of three hours of room confinement "in the case of a juvenile who poses a substantial and immediate risk of physical harm to others" and 30 minutes "in the case of a juvenile who poses a serious and immediate risk of physical harm to himself or herself." 331 The bill would also prohibit room confinement as punishment. ${ }^{332}$ Proposed legislation in Connecticut would limit the use of solitary confinement for children in pre-trial detention. $^{333}$

Other statutes focus on the use of restrictive housing for individuals with mental health issues. Statutes enacted or proposed generally provide for prohibitions, coupled with clauses permitting brief stays under exigent circumstances. For example, in 2017, Colorado prohibited the placement of "a person with a behavioral or serious mental health disorder in long-term isolated confinement except when exigent circumstances are present." ${ }^{334}$ In Massachusetts, a "prisoner shall not be held in restrictive housing if the prisoner has a serious mental illness or a finding has been made ... that restrictive housing is clinically contraindicated," 335 and within 72 hours after such a placement, the custodian certifies that the prisoner cannot "be safely held in the general population," that no space is available in a "secure treatment unit," that efforts are underway to identify alternative, "appropriate housing," and that a "time frame" to do so is laid out.

\section{Litigation and Consent Decrees}

Challenges to correctional systems as well as to decisions in individual cases continue to bring the harms of restrictive housing to the attention of judges. The case law is voluminous; the discussion here offers a few highlights of rulings since 2016. We begin with institutional cases focused on subpopulations of individuals with mental health issues, juveniles, and persons confined to restrictive housing solely because of their capital sentences. 
A major ruling came from the District Court for the Middle District of Alabama, ${ }^{336}$ which had certified a class of "all persons with a serious mental illness who are now, or will in the future be, subject to defendant's mental health care policies and practices" within the Alabama Department of Corrections facilities. ${ }^{337}$ At the time of the litigation, the Alabama system included 19,500 prisoners, of whom 3,400 were receiving "some type of mental-health treatment." 338 After a seven-week trial, the federal district court in 2017 found that "inadequacies in the mental-health care system start . . . with intake screening" in which "likely thousands" of prisoners with mental illness are missed. ${ }^{339}$ The court concluded that even when mental health issues were identified, "prisoners receive significantly inadequate care," including for those who had discussed committing suicide. ${ }^{340}$ The court held that the care provided to mentally ill persons violated the constitutional obligation not to be deliberately indifferent to the "serious medical needs of prisoners." 341 Included as Eighth Amendment violations were the placement of "seriously mentally ill prisoners in segregation without extenuating circumstances and for prolonged periods of time; placing prisoners with serious mental-health needs in segregation without adequate consideration of the impact of segregation on mental health; and providing inadequate treatment and monitoring in segregation." ${ }^{342}$ Since its ruling, the court has accepted proposed remedies, including a process to identify prisoners with serious mental illness so that they are not placed in segregation, absent extenuating circumstances. ${ }^{343}$

The South Carolina Department of Corrections recently agreed to a settlement in a class action lawsuit by incarcerated individuals with serious mental illness. ${ }^{344}$ The plaintiffs had claimed that the department's failure "to provide reasonably adequate medical treatment" to prisoners with serious mental illness violated the state constitutional prohibition against cruel and unusual punishment. ${ }^{345}$ The suit alleged that mentally ill prisoners were often punished by being placed for long periods of time in administrative segregation, which, the complaint stated, exacerbated mental illness. ${ }^{346}$ The complaint asserted that the prison system did not "have adequate treatment space or staff to adequately monitor or evaluate" mentally ill individuals in segregation. ${ }^{347}$ A state trial court judge held that South Carolina's treatment of seriously mentally ill prisoners violated the state constitution. ${ }^{348}$ One of the court's findings was that the "inappropriate and extended reliance on segregation to manage inmates with serious mental illness, particularly those in crisis, exposes them to a substantial risk of serious harm," which "contributed to the deaths" of multiple people in segregation. ${ }^{349}$ After the state and the plaintiffs reached an agreement, the state's appeal was dismissed. ${ }^{350}$ The settlement addressed the six areas of serious deficiencies that the trial court's ruling had outlined, including ending "inappropriate segregation of offenders in mental health crisis." $" 351$

South Carolina reported a number of changes to its restrictive housing regime since agreeing to these reforms. As South Carolina explained, the settlement contemplated "a multi-year compliance process with phased-in implementation," that will be assessed by "an Implementation Panel of two experts who conduct periodic site visits and review reports and records." The prison 
system described hiring a deputy director to oversee compliance with the settlement. The plan included the following measures:

(1) the development of a comprehensive mental health treatment program that prohibits the inappropriate segregation of inmates in mental health crisis; (2) access for segregated inmates to group and individual therapy to include more out of cell time for segregated mentally ill inmates; (3) timely sessions for segregated inmates with qualified mental health practitioners; (4) improvement in the cleanliness and temperature of segregation cells; (5) implementation of a formal quality management program under which segregation practices and conditions are reviewed; and (6) development of a training program for officers concerning appropriate methods of managing mentally ill inmates.

South Carolina also reported creating a "Quality Improvement and Risk Management Division within the Office of Legal and Compliance to monitor and report compliance with the settlement requirements." The correctional system further described implementing a "Behavioral Management Unit policy" in August 2016, "with the purpose of providing inmates whose mental health needs likely contribute to their segregation status with programming, treatment, and structure as an alternative to long term placement in restrictive housing." 352 Despite stating that it was "making steady progress" to comply with the agreement, South Carolina explained that it was "hampered by staffing deficits," which it was addressing with "retention teams to mentor new officers and work with officers considering leaving the agency."

In New York City, a settlement of a class action involving isolation of pre-trial detainees resulted in awards to individuals confined there. ${ }^{353}$ The plaintiffs, former detainees at Rikers Island, had alleged that the New York City Department of Corrections violated the U.S. Constitution by holding pretrial detainees in solitary confinement or punitive segregation for no legitimate purpose and without providing due process. ${ }^{354}$ The city agreed to pay a total of $\$ 5$ million to 470 individuals placed in solitary confinement between 2012 and 2015. ${ }^{355}$ Each member of the class was to receive a minimum of $\$ 175$ per day spent in solitary confinement or punitive segregation. Individuals diagnosed as having a serious mental illness or who were under the age of 18 at the time of confinement were to receive $\$ 200$ per day spent in confinement. ${ }^{356}$

In August 2018, a federal district court judge approved a $\$ 240,000$ settlement for four teenagers held in solitary confinement in Washington state. ${ }^{357}$ The youths had been held in adult detention facilities while awaiting trial. In October 2017, they filed a class action lawsuit alleging that King County's practice of holding them in long-term solitary confinement violated the Eighth and Fourteenth Amendments of the United States Constitution and Article 1, section 14 of the Washington Constitution, which provides that "cruel punishment" shall not be inflicted. ${ }^{358}$ Under the terms of the settlement, King County agreed that, in addition to compensating the four individuals, it would institute a ban on solitary confinement of juveniles in all of its detention facilities. The settlement provided for exceptions "when based on the juvenile's behavior," when "necessary to prevent imminent and significant physical harm" to the juvenile or others, and when 
"less restrictive alternatives were unsuccessful." 359 The settlement further stipulated that solitary confinement for all juvenile detainees "may not be used for disciplinary or punishment purposes." ${ }^{360}$ In addition, the county consented to having mental health or medical staff assess any juvenile within eight hours of placement, and to notify a parent or legal guardian when a juvenile is held in isolation for longer than eight consecutive hours. ${ }^{361}$

Many courts have determined that isolation of juveniles is unlawful. For example, in Tennessee in 2017, a federal district court held that a class of incarcerated youth were "likely to succeed on their claims that juveniles being detained in solitary confinement or isolation for punitive or disciplinary purposes constitutes ... inhumane treatment" ${ }^{362}$ and issued a preliminary injunction barring all solitary confinement for juveniles as punishment or discipline. ${ }^{363} \mathrm{In}$ another case, citing the "broad consensus among the scientific and professional community that juveniles are psychologically more vulnerable than adults," ${ }^{364}$ the federal district court for the Northern District of New York concluded that the plaintiffs were substantially likely to succeed on their claim that punitive solitary confinement of youth violated the Eighth Amendment. ${ }^{365}$ In 2017, the Juvenile Law Center and the ACLU of Wisconsin filed a lawsuit challenging state officials' use of solitary confinement, shackling, and pepper spray in two youth detention facilities ${ }^{366}$ and won a ruling barring the use of those forms of restraint for youths. ${ }^{367}$ In January of 2018, the Wisconsin legislature enacted legislation to close, by 2021, the two juvenile detention facilities at issue in the lawsuit. ${ }^{368}$ The case ended with a settlement to eliminate punitive juvenile solitary confinement within the coming year. ${ }^{369}$

Another set of cases focus on the practice of placing individuals in restrictive housing solely because they have capital sentences. That practice has repeatedly drawn the attention of U.S. Supreme Court justices. In 2015, in Davis v. Ayala, Justice Anthony Kennedy wrote a concurrence to underscore that "years on end of near-total isolation" impose "a terrible price." ${ }^{370}$ Further, he noted that judges putting a person in long-term solitary confinement ought to reflect on the harm to mental health entailed. ${ }^{371}$ In 2017, Justice Breyer responded to his colleagues' denial of a petition for a stay of execution in Texas by questioning the constitutionality of extended solitary confinement for death row prisoners: "If extended solitary confinement alone raises serious constitutional questions, then 20 years of solitary confinement, all the while under threat of execution, must raise similar questions, and to a rare degree, and with particular intensity."372

In the lower courts, several lawsuits have challenged the use of a capital sentence to place people into restrictive housing. Lawsuits filed in Arizona ${ }^{373}$ and in California ${ }^{374}$ sparked changes in the use of automatic solitary confinement for death-row prisoners. Other cases challenging automatic use of restrictive housing for individuals sentenced to death are pending in Florida, ${ }^{375}$ Louisiana, ${ }^{376}$ and Pennsylvania. ${ }^{377}$ In another case involving two individuals whose capital sentences were vacated and who remained in solitary confinement for years thereafter, the Court of Appeals for the Third Circuit held that "inmates on death row whose death sentences have been vacated have a due process right to avoid continued placement in solitary confinement on death row, absent ... meaningful protections" that the decision outlined. ${ }^{378}$ 
We should note that not all departments of corrections place individuals with capital sentences in restrictive housing. As detailed in Rethinking Death Row: Variations in the Housing of Individuals Sentenced to Death, ${ }^{379}$ most states give discretion to prison systems to decide how to house prisoners. ${ }^{380}$ This 2016 report provided accounts from correctional leaders in North Carolina, Missouri, and Colorado who had housed capital-sentenced prisoners in settings offering them meaningful opportunities to interact with others. ${ }^{381}$ Researchers on "mainstreaming" deathsentenced prisoners in Missouri concluded more than two decades ago that, while integration of these prisoners entailed some challenges, "integration was a viable, effective approach." 382 Moreover, a 2016 study found no evidence that integrating such prisoners was a source of more violence in prisons. ${ }^{383}$

Other cases, filed by individuals, have resulted in decisions about the harms of placement in restrictive housing for years, and in some instances, for decades. In one Pennsylvania case, a prisoner who had served 36 years in solitary confinement challenged the constitutionality of his continued confinement and won an injunction to release him to general population. ${ }^{384}$ The federal district court for the Middle District of Pennsylvania found that the "the extraordinary duration" of the prisoner's confinement, combined with "the harsh consequences of involuntary isolation" amount to a "deprivation of a constitutional proportion;"385 "retention in the RHU will protract his extant injuries and expose him to an imminent and probable risk of even greater psychological damage." 386

\section{Restrictive Housing as a Global Concern}

The close attention to restrictive housing practices in the United States is part of a worldwide trend of concern about this practice, ${ }^{387}$ which was addressed in the United Nations Standard Minimum Rules for the Treatment of Prisoners, commonly known as the "Nelson Mandela Rules." 388 The Rules define solitary confinement as being held for 22 hours or more a day for longer than 15 days without "meaningful human contact." 389 The rules state that "solitary confinement shall be used only in exceptional cases as a last resort, for as short a time as possible and subject to independent review, and only pursuant to the authorization by a competent authority," and "shall not be imposed by virtue of a prisoner's sentence." 390 In addition, the Rules provide that "solitary confinement should be prohibited in the case of prisoners with mental or physical disabilities when their conditions would be exacerbated by such measures." 391 Further, "indefinite" and "prolonged solitary confinement" should not be used, ${ }^{392}$ and women and children should not be held in solitary confinement. ${ }^{393}$

Litigation in various national courts, transnational commissions, and non-governmental organizations continues to document and in some instances circumscribe the harms of isolating confinement. In Canada, trial courts in Ontario and in British Columbia in 2017 found aspects of administrative segregation unlawful. ${ }^{394}$ The Ontario decision concluded that the lack of independent review of a decision to place a prisoner in restrictive housing violated the Charter of Rights and Freedoms because of failures "to provide the procedural safeguards required by the principles of fundamental justice." 395 The court found that putting people into "administrative 
segregation amounts to a significant deprivation of liberty" 396 and that "placing an inmate in administrative segregation imposes a psychological stress, quite capable of producing serious permanent observable negative health effects." 397 The court did not, however, find that prolonged administrative segregation for more than 15 days constitutes "cruel and unusual treatment or punishment," as prohibited under Section 12 of the Charter of Rights and Freedoms. ${ }^{398}$ The court also did not conclude that segregation of young adults and the mentally ill violated that prohibition. ${ }^{399}$ As of this writing, the decision has been stayed pending appeal. ${ }^{400}$

In British Columbia, after hearing from dozens of witnesses including experts on administrative segregation and prisoners in administrative segregation, ${ }^{401}$ a trial court declared that Canadian statutes and regulations providing for segregation violated Section 7 of the Charter's "right to life, liberty, and security of the person." The court based its finding on the fact that the relevant laws authorized "prolonged, indefinite administrative segregation," that internal review depended on the institutional head (warden), and that prisoners were deprived of "right to counsel at segregation hearings and reviews." 402 The court found that use of segregation also violated the Charter's Section 15 right to "equal protection and equal benefit of the law." 403 The court reached this determination based on the laws' authorization of "administrative segregation for the mentally ill and/or disabled" and "a procedure that resulted in discrimination against Aboriginal inmates." 404 The court concluded that "administrative segregation . . . is a form of solitary confinement that places all Canadian federal inmates subject to it at significant risk of serious psychological harm, including mental pain and suffering, and increased incidence of self-harm and suicide." The court stated that the "risks of these harms are intensified in the case of mentally ill inmates, but that all prisoners "subject to segregation are subject to the risk of harm to some degree." 405 The court held, however, that "not every application of the impugned legislation will" "amount to cruel and unusual punishment." 406 The court also found that the segregation laws were not "arbitrary." 407 As of this writing, the judgment was stayed pending appeal. ${ }^{408}$

In Europe, supranational and non-governmental organizations have called for reforms of restrictive housing practices. The Council of Europe's European Committee on Crime Problems issued a report in May 2018 analyzing the need to update the European Prison Rules ${ }^{409}$ so as to increase regulation of solitary confinement. Doing so would entail bringing the European Prison Rules in line with the standards of the Council of Europe's Committee for the Prevention of Torture and Inhuman or Degrading Treatment or Punishment (CPT) and with the Nelson Mandela Rules. ${ }^{410}$ That report called for a new rule on solitary confinement in accordance with the 2011 CPT standards to address administrative segregation as a form of solitary confinement. ${ }^{411}$ Those rules set forth principles of proportionality, lawfulness, accountability, necessity, and nondiscrimination in the use of solitary confinement, and called for the "material conditions" of such confinement to include "access to natural light," sufficient artificial light for reading, communication mechanisms, and showers as often as prisoners in the "normal regime."

In 2017, the CPT published a report on detention conditions in Germany. ${ }^{413}$ One of the areas of concern was the use of prolonged solitary confinement and solitary confinement for 
juveniles. The CPT recommended that prisoners be held for no more, and preferably fewer, than 14 days in disciplinary solitary confinement. ${ }^{414}$ In addition, the CPT endorsed the Nelson Mandela Rules' prohibition on solitary confinement for juveniles. ${ }^{415}$ The CPT also observed significant differences among institutions: in some prisons, disciplinary solitary confinement was imposed only rarely and usually for a short period of time, while in others, it was imposed much more frequently and in many cases for up to four weeks. ${ }^{416}$

In February 2018, the Irish Penal Reform Trust (IPRT) published a study on the use of solitary confinement and restricted regimes. ${ }^{417}$ The report defined "solitary confinement" as 22 or more hours of confinement a day in a cell, and "restricted regimes" as 19 hours a day or more in cell. ${ }^{418}$ The report found that while the number of prisoners in solitary confinement decreased from July 2013 to October 2017, the overall number of prisoners in restricted regimes had increased, with 428 individuals in restricted regimes, most subject to 21 hours in cell, in October 2017. ${ }^{419}$ The report made many recommendations including "full compliance with the Mandela Rules" and that provisions be made to "set the minimum out-of-cell time at 8 hours per day." The report also recommended that separation "not be permitted for reasons of punishment, but only for reasons of safety in emergency situations, and for the shortest possible period of time"; that "adults with mental health difficulties or mental or physical disabilities" not be put into solitary confinement; and that a parallel "absolute prohibition" be in place for "children." ${ }^{420}$ Further, the report called for the Irish Prison Service to "regularly collect and publish data relating to the length of time prisoners spend on restricted regimes in all prisons." ${ }^{, 421}$ 


\section{Comparing the Numbers of People in Restrictive Housing in 2015-2016 and in 2017-2018}

As we noted, we have data from 43 jurisdictions, housing collectively about $80.6 \%$ of the U.S. prison population and reporting 49,197 people in restrictive housing. We therefore estimated that, if the proportion of those held in restrictive housing in jurisdictions that did not provide information mirrored that of those that did, 61,000 people were in restrictive housing in the fall of 2017.

In this concluding section, we put together materials from the 2015-2016 and the 20172018 ASCA-Liman surveys by analyzing some of the data provided by the 40 jurisdictions that responded with information on restrictive housing populations in both surveys. ${ }^{422}$ That comparison permits insights into if and how the use of restrictive housing changed during the interval between the two surveys. As detailed below, the numbers of prisoners in restrictive housing decreased in some jurisdictions and increased in others. ${ }^{423}$

As displayed in Table 21, across these 40 jurisdictions, the aggregate number of prisoners reported to be in restrictive housing decreased by 9,444 prisoners, from 56,337 in 2015 to 46,893 in 2017. In 29 of these 40 jurisdictions, the number of prisoners reported in restrictive housing decreased from 2015 to $2017 .^{424}$ The five jurisdictions with the largest decreases in numbers of prisoners in restrictive housing population accounted for about three-quarters of the aggregate reduction across jurisdictions. ${ }^{425}$ In 11 jurisdictions, the number of prisoners reported in restrictive housing increased from 2015 to $2017 .{ }^{426}$

Across these 40 jurisdictions, the percentage of prisoners in restrictive housing decreased from $5.0 \%$ in 2015 to $4.4 \%$ in 2017 . In 28 jurisdictions, the percentage of prisoners reported to be in restrictive housing decreased from 2015 to $2017 .{ }^{427}$ The largest reduction in the percentage of prisoners in restrictive housing in a single jurisdiction was from $14.0 \%$ in 2015 to $4.7 \%$ in $2017 .{ }^{428}$ In 12 jurisdictions, the percentage of prisoners reported to be in restrictive housing increased during this time period. ${ }^{429}$ The largest increase in the percentage of prisoners in restrictive housing in a single jurisdiction grew from $14.5 \%$ in 2015 to $19.0 \%$ in $2017 .{ }^{430}$ Figure 15 and Figure 16 detail the percentage of prisoners in restrictive housing by jurisdiction in two ways: Figure 15 displays the percentages in both years, and Figure 16 provides change in percentages.

What accounts for the changing numbers is unclear. Variables include new policies and practices on restrictive housing, changes in facilities and budgets, litigation, statutes, and the overall numbers of people in prison systems as prisoners and staff. For example, in the 40 jurisdictions analyzed here, the total custodial population for which we also have data on restrictive housing decreased by 69,499 people from 1,124,695 incarcerated persons in 2015 to 1,055,196 in $2017 .{ }^{431}$ In 20 of the 29 jurisdictions in which restrictive housing numbers declined, so too did the total prison population. ${ }^{432}$ In two of the 11 jurisdictions that had an increase in restrictive housing, the total prison population increased as well. ${ }^{433}$ 
Those two variables - total prison population and restrictive housing population - do not always match up or move in the same direction. In the Federal Bureau of Prisons, for example, the total prison population decreased to a larger extent than did the restrictive housing population. In $2015,4.7 \%$ of the federal prison population was reported to be in restrictive housing. In $2017,5.2 \%$ of the federal prison population was reported to be in restrictive housing. Thus while the total number of federal prisoners in restrictive housing decreased, the percentage of federal prisoners in restrictive housing increased.

Table 21 Jurisdiction-by-Jurisdiction Comparisons of Restrictive Housing Populations in 2015-2016 and in 2017-2018

$(n=40)$

\begin{tabular}{|c|c|c|c|c|c|c|}
\hline & $\begin{array}{r}2015 \text { Total } \\
\text { Custodial } \\
\text { Population } \\
\text { for } \\
\text { Facilities } \\
\text { Reporting } \\
\text { Restrictive } \\
\text { Housing } \\
\text { Data }\end{array}$ & $\begin{array}{r}2015 \\
\text { Population } \\
\text { in } \\
\text { Restrictive } \\
\text { Housing }\end{array}$ & $\begin{array}{r}2015 \\
\text { Percentage } \\
\text { in } \\
\text { Restrictive } \\
\text { Housing }\end{array}$ & $\begin{array}{r}2017 \text { Total } \\
\text { Custodial } \\
\text { Population } \\
\text { for } \\
\text { Facilities } \\
\text { Reporting } \\
\text { Restrictive } \\
\text { Housing } \\
\text { Data }\end{array}$ & $\begin{array}{r}2017 \\
\text { Population } \\
\text { in } \\
\text { Restrictive } \\
\text { Housing }\end{array}$ & $\begin{array}{r}2017 \\
\text { Percentage } \\
\text { in } \\
\text { Restrictive } \\
\text { Housing }\end{array}$ \\
\hline Alabama* & 24,549 & 1,402 & $5.7 \%$ & 21,592 & 855 & $4.0 \%$ \\
\hline Alaska & 4,919 & 352 & $7.2 \%$ & 4,393 & 378 & $8.6 \%$ \\
\hline Arizona & 42,736 & 2,544 & $6.0 \%$ & 42,146 & 2,723 & $6.5 \%$ \\
\hline Colorado & 18,231 & 217 & $1.2 \%$ & 18,297 & 10 & $0.1 \%$ \\
\hline Connecticut & 16,056 & 128 & $0.8 \%$ & 14,137 & 328 & $2.3 \%$ \\
\hline Delaware* & 4,342 & 381 & $8.8 \%$ & 4,333 & 43 & $1.0 \%$ \\
\hline FBOP* & 189,181 & 8,942 & $4.7 \%$ & 153,839 & 7,974 & $5.2 \%$ \\
\hline Georgia & 56,656 & 3,880 & $6.8 \%$ & 54,723 & 3,200 & $5.8 \%$ \\
\hline Hawaii & 4,200 & 23 & $0.5 \%$ & 3,713 & 13 & $0.4 \%$ \\
\hline Idaho & 8,013 & 404 & $5.0 \%$ & 7,161 & 310 & $4.3 \%$ \\
\hline Illinois & 46,609 & 2,255 & $4.8 \%$ & 42,177 & 921 & $2.2 \%$ \\
\hline Indiana & 27,508 & 1,621 & $5.9 \%$ & 26,317 & 1,741 & $6.6 \%$ \\
\hline Iowa & 8,302 & 247 & $3.0 \%$ & 8,283 & 167 & $2.0 \%$ \\
\hline Kansas & 9,952 & 589 & $5.9 \%$ & 9,886 & 459 & $4.6 \%$ \\
\hline Kentucky & 11,669 & 487 & $4.2 \%$ & 12,000 & 408 & $3.4 \%$ \\
\hline Louisiana* & 18,515 & 2,689 & $14.5 \%$ & 14,291 & 2,709 & $19.0 \%$ \\
\hline Maryland & 19,687 & 1,485 & $7.5 \%$ & 21,785 & 1,417 & $6.5 \%$ \\
\hline Massachusetts & 10,004 & 235 & $2.3 \%$ & 9,047 & 443 & $4.9 \%$ \\
\hline Michigan & 42,826 & 1,339 & $3.1 \%$ & 39,858 & 903 & $2.3 \%$ \\
\hline Mississippi & 18,866 & 185 & $1.0 \%$ & 12,940 & 529 & $4.1 \%$ \\
\hline Missouri & 32,266 & 2,028 & $6.3 \%$ & 33,204 & 2,990 & $9.0 \%$ \\
\hline Montana & 2,554 & 90 & $3.5 \%$ & 1,769 & 113 & $6.4 \%$ \\
\hline
\end{tabular}




\begin{tabular}{lrrrrrr} 
Nebraska & 5,456 & 598 & $11.0 \%$ & 5,178 & 328 & $6.3 \%$ \\
\hline New Jersey & 20,346 & 1,370 & $6.7 \%$ & 19,368 & 1,011 & $5.2 \%$ \\
\hline New Mexico & 7,389 & 663 & $9.0 \%$ & 7,047 & 294 & $4.2 \%$ \\
\hline New York & 52,621 & 4,498 & $8.5 \%$ & 50,764 & 2,666 & $5.3 \%$ \\
\hline North Carolina & 38,039 & 1,517 & $4.0 \%$ & 37,259 & 1,109 & $3.0 \%$ \\
\hline North Dakota & 1,800 & 54 & $3.0 \%$ & 1,830 & 8 & $0.4 \%$ \\
\hline Ohio & 50,248 & 1,374 & $2.7 \%$ & 49,954 & 1,282 & $2.6 \%$ \\
\hline Oklahoma & 27,650 & 1,552 & $5.6 \%$ & 26,895 & 1,368 & $5.1 \%$ \\
\hline Oregon & 14,724 & 630 & $4.3 \%$ & 14,574 & 938 & $6.4 \%$ \\
\hline Pennsylvania & 50,349 & 1,716 & $3.4 \%$ & 46,920 & 1,498 & $3.2 \%$ \\
\hline South Carolina & 20,978 & 1,068 & $5.1 \%$ & 19,938 & 737 & $3.7 \%$ \\
\hline South Dakota & 3,526 & 106 & $3.0 \%$ & 3,927 & 90 & $2.3 \%$ \\
\hline Tennessee & 20,095 & 1,768 & $8.8 \%$ & 22,160 & 1,181 & $5.3 \%$ \\
\hline Texas & 148,365 & 5,832 & $3.9 \%$ & 145,409 & 4,272 & $2.9 \%$ \\
\hline Utah & 6,497 & 912 & $14.0 \%$ & 6,293 & 296 & $4.7 \%$ \\
\hline Washington & 16,308 & 274 & $1.7 \%$ & 17,046 & 387 & $2.3 \%$ \\
\hline Wisconsin* & 20,535 & 751 & $3.7 \%$ & 22,589 & 713 & $3.2 \%$ \\
\hline Wyoming & 2,128 & 131 & $6.2 \%$ & 2,154 & 81 & $3.8 \%$ \\
\hline Totals & $\mathbf{1 , 1 2 4 , 6 9 5}$ & $\mathbf{5 6 , 3 3 7}$ & $\mathbf{5 . 0 \%}$ & $\mathbf{1 , 0 5 5 , 1 9 6}$ & $\mathbf{4 6 , 8 9 3}$ & $\mathbf{4 . 4 \%}$ \\
\hline & & & & & &
\end{tabular}

* In 2015, the number used for total custodial population was the number of prisoners for which the jurisdiction had restrictive housing data. For the current survey, we used the total custodial population for which the jurisdiction had restrictive housing data and that was under the direct control of the jurisdiction. In 2015, some jurisdictions had restrictive housing data for facilities that were not under their direct control and included those prisoners in their 2015 survey response. Those jurisdictions are marked with an asterisk. Differences between the 2015 and 2017 total custodial population for these jurisdictions may therefore result from changes in the calculation of the total custodial population rather than changes in the jurisdictions' numbers of prisoners. 
Figure 15 Jurisdiction-by-Jurisdiction Comparisons of Percentages of Prisoners in Restrictive Housing Populations in 2015-2016 and in 2017-2018

$$
(\mathrm{n}=\mathbf{4 0})
$$

- 2015 - 2017

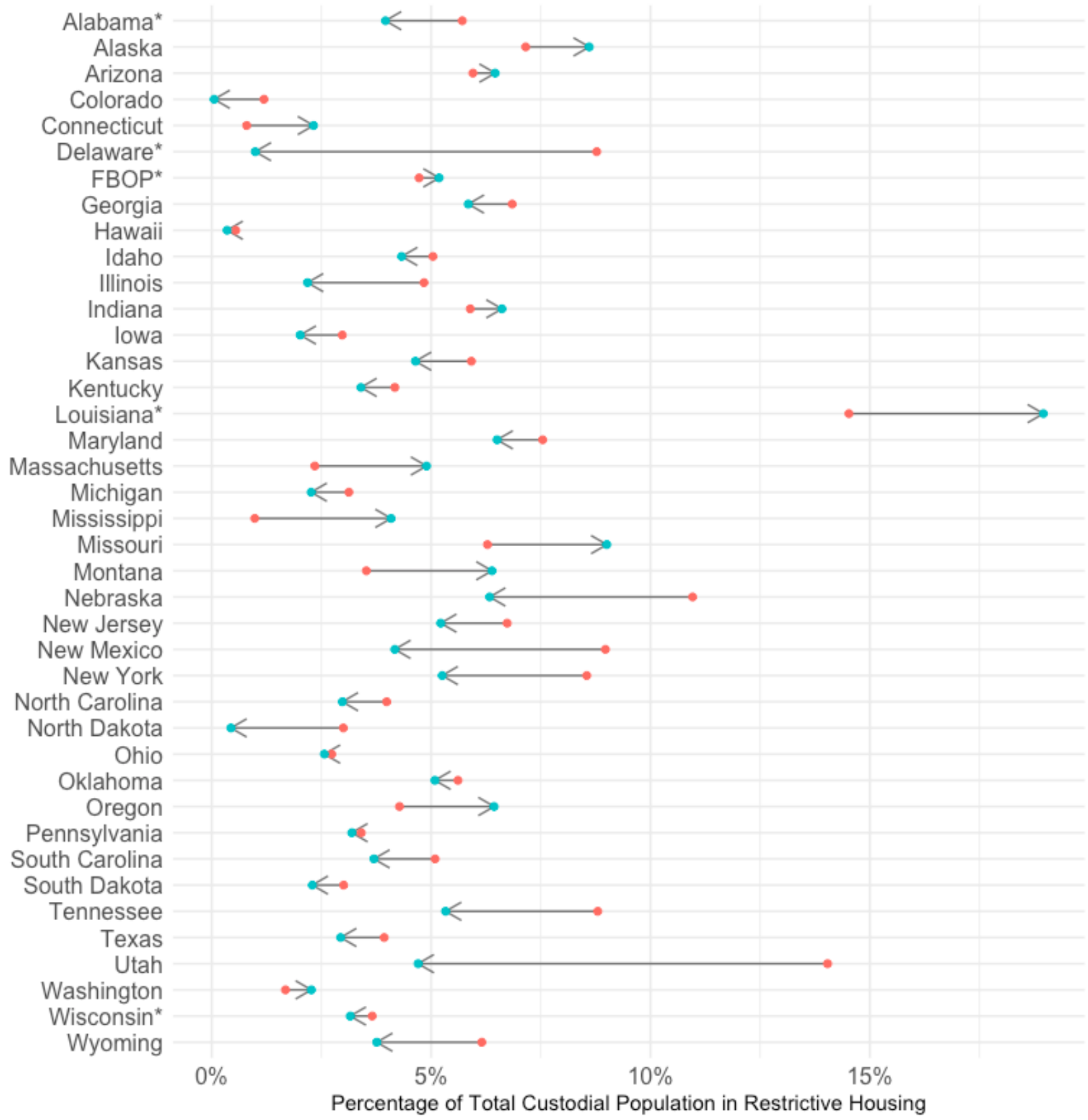


Figure 16 Jurisdiction-by-Jurisdiction Comparisons of the Changes in Percentage of Prisoners in Restrictive Housing Populations in 2015-2016 and in 2017-2018

$(n=40)$

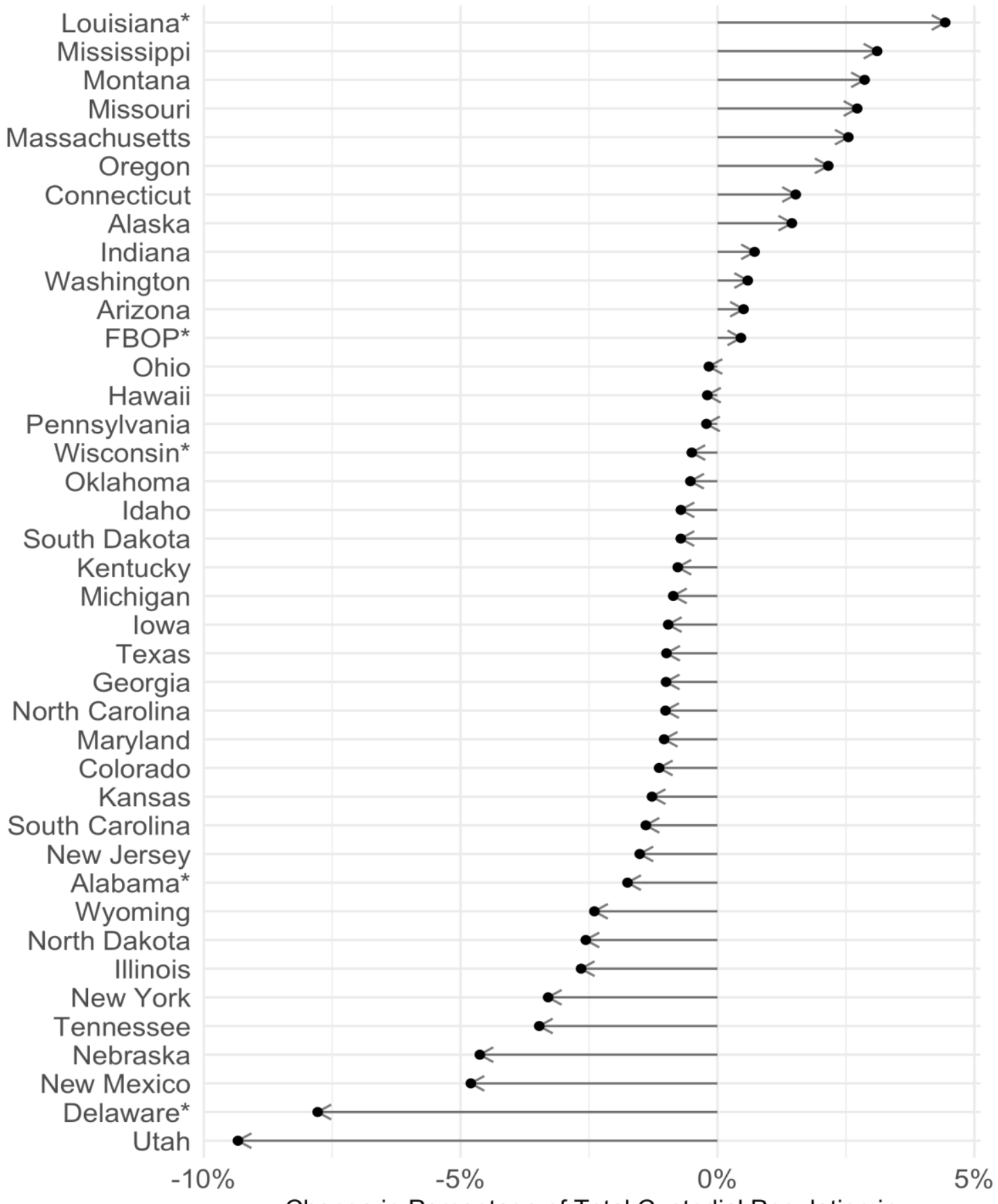

Change in Percentage of Total Custodial Population in Restrictive Housing from 2015 to 2017 
Another window into changes over time comes from the numbers on length of time in restrictive housing provided by the 31 jurisdictions responding to those questions in both surveys. ${ }^{434}$ Table 22 and Table 23 show that, overall, the numbers of individuals in restrictive housing across most time periods decreased from 2015 to 2017. The number of individuals in restrictive housing for 15 days to one month increased by $6.5 \%$; one to three months increased by $0.8 \%$; three to six months decreased by $13.2 \%$; six months to one year decreased by $30.0 \%$; one to three years decreased by $40.4 \%$; three to six years decreased by $33.1 \%$; and six or more years decreased by $25.9 \%$.

As shown in Table 22, the number of prisoners in restrictive housing for six months or less decreased in about as many jurisdictions as it increased. The number of prisoners in restrictive housing for time periods longer than six months decreased in more jurisdictions than it increased.

The number of individuals in restrictive housing who were being held from 15 days to one month decreased in 15 jurisdictions, stayed the same in one jurisdiction, and increased in 15 jurisdictions. The number of individuals in restrictive housing from one month to three months decreased in 14 jurisdictions, and increased in 17 jurisdictions. The number of individuals in restrictive housing from three months to six months decreased in 17 jurisdictions, stayed the same in one jurisdiction, and increased in 13 jurisdictions.

The number of individuals in restrictive housing from six months to one year decreased in 23 jurisdictions, stayed the same in one jurisdiction, and increased in seven jurisdictions. The number of individuals in restrictive housing from one year to three years decreased in 23 jurisdictions, stayed the same in one jurisdiction, and increased in seven jurisdictions. The number of individuals in restrictive housing from three years to six years decreased in 20 jurisdictions, stayed the same in four jurisdictions, and increased in seven jurisdictions. The number of individuals in restrictive housing over six years decreased in 18 jurisdictions, stayed the same in eight jurisdictions, and increased in five jurisdictions. 
Table 22 Comparing the Numbers of Prisoners in Restrictive Housing by Length of Time in 2015-2016 and in 2017-2018*

$(\mathbf{n}=\mathbf{3 1})$

\section{5 days -1
month 1-3 months 3-6 months $\begin{gathered}6 \text { months }- \\ 1 \text { year }\end{gathered}$ 1-3 years 3-6 years 6+ years}

\begin{tabular}{|c|c|c|c|c|c|c|c|c|c|c|c|c|c|c|}
\hline Alaska & 124 & 72 & 74 & 78 & 49 & 50 & 60 & 25 & 43 & 31 & 5 & 0 & 0 & \\
\hline Arizona & 140 & 428 & 472 & 831 & 530 & 433 & 809 & 462 & 488 & 489 & 34 & 72 & 71 & \\
\hline Colorado & 64 & 10 & 65 & 0 & 64 & 0 & 23 & 0 & 1 & 0 & 0 & 0 & 0 & \\
\hline Delaware & 25 & & 99 & 25 & 84 & 6 & 76 & 7 & 67 & 0 & 12 & 0 & 18 & . \\
\hline FBOP & 1,6901 & ,764 & 3,802 & 3,690 & 1,449 & 1,382 & 929 & 609 & 731 & 254 & 183 & 120 & 158 & 155 \\
\hline Hawaii & 21 & 23 & 2 & 0 & 0 & 9 & 0 & 0 & 0 & 0 & 0 & 0 & 0 & 0 \\
\hline Indiana & 212 & 131 & 224 & 348 & 388 & 281 & 496 & 354 & 175 & 391 & 80 & 121 & 46 & 115 \\
\hline Iowa & 97 & 56 & 80 & 98 & 30 & 10 & 24 & 3 & 16 & 0 & 0 & 0 & 0 & ( \\
\hline Kansas & 125 & 176 & 146 & 207 & 87 & 61 & 105 & 15 & 94 & 0 & 22 & 0 & 10 & 0 \\
\hline Kentucky & 139 & 671 & 222 & 130 & 52 & 45 & 41 & 14 & 28 & 1 & 4 & 0 & 1 & 0 \\
\hline Louisiana & 327 & 332 & 551 & 630 & 334 & 449 & 302 & 445 & 450 & 517 & 221 & 346 & 0 & 0 \\
\hline Massachusetts & 2 & 76 & 3 & 118 & 12 & 50 & 65 & 28 & 71 & 31 & 24 & 5 & 43 & 4 \\
\hline Mississippi & 3 & 399 & 21 & 69 & 29 & 40 & 41 & 12 & 69 & 7 & 17 & 1 & 5 & \\
\hline Montana & 58 & 8 & 0 & 34 & 67 & 30 & 2 & 24 & 4 & 11 & 0 & 6 & 3 & 0 \\
\hline Nebraska & 48 & 19 & 121 & 94 & 158 & 102 & 87 & 81 & 106 & 32 & 48 & 1 & 30 & 3 \\
\hline New Jersey & 54 & 150 & 247 & 398 & 295 & 178 & 354 & 100 & 184 & 79 & 128 & 36 & 108 & 70 \\
\hline New York & 1,615 & 757 & 1,454 & 1,218 & 671 & 416 & 257 & 182 & 101 & 73 & 32 & 13 & 0 & \\
\hline & 461 & 602 & 579 & 205 & 460 & 280 & 12 & 21 & 4 & 1 & 1 & 0 & 0 & \\
\hline North Dakota & 8 & 3 & 13 & 4 & 12 & 2 & 17 & 0 & 4 & 0 & 0 & 0 & 0 & \\
\hline Ohio & 119 & 226 & 360 & 228 & 181 & 243 & 253 & 271 & 162 & 183 & 43 & 49 & 22 & 22 \\
\hline Oklahoma & 169 & 384 & 270 & 481 & 206 & 224 & 270 & 156 & 490 & 106 & 77 & 17 & 70 & \\
\hline Oregon & 90 & 126 & 152 & 291 & 277 & 152 & 81 & 41 & 26 & 30 & 4 & 7 & 0 & \\
\hline Pennsylvania & 349 & 305 & 524 & 517 & 288 & 252 & 156 & 126 & 157 & 106 & 52 & 41 & 190 & 151 \\
\hline $\begin{array}{l}\text { South } \\
\text { Carolina }\end{array}$ & 238 & 138 & 370 & 207 & 128 & 105 & 114 & 131 & 151 & 102 & 67 & 12 & 0 & 42 \\
\hline South Dakota & 18 & 18 & 16 & 6 & 10 & 10 & 15 & 16 & 27 & 21 & 12 & 12 & 8 & 1 \\
\hline Tennessee & 89 & 110 & 239 & 276 & 222 & 237 & 353 & 280 & 500 & 244 & 166 & 31 & 205 & 3 \\
\hline Texas & 109 & 141 & 204 & 263 & 277 & 326 & 537 & 474 & 1,840 & 931 & 1,278 & 811 & 1,5871 & 1,326 \\
\hline Utah & 233 & 2 & 169 & 33 & 173 & 232 & 125 & 29 & 166 & 0 & 35 & 0 & 11 & 0 \\
\hline Washington & 16 & 5 & 55 & 82 & 68 & 107 & 70 & 106 & 37 & 64 & 16 & 11 & 12 & 12 \\
\hline Wisconsin & 278 & 221 & 285 & 345 & 88 & 91 & 60 & 41 & 36 & 13 & 4 & 2 & 0 & \\
\hline Wyoming & 8 & 21 & 30 & 31 & 24 & 25 & 59 & 2 & 9 & 1 & 0 & 1 & 1 & \\
\hline
\end{tabular}

* Shaded cells contain values from the 2015-2016 survey. Unshaded cells contain values from the 2017-2018 survey. 
We also calculated the distribution across time intervals-i.e., what percentage of individuals in restrictive housing were held for each time interval—for the populations in these 31 jurisdictions, as Table 23 reflects. The percentage of prisoners in restrictive housing for less than six months increased in more jurisdictions than it decreased, while the percentage of prisoners in restrictive housing for more than six months decreased in more jurisdictions than it increased.

The percentage of individuals in restrictive housing who were being held from 15 days to one month decreased in 12 jurisdictions, and increased in 19 jurisdictions. The percentage of individuals in restrictive housing from one month to three months decreased in nine jurisdictions and increased in 22 jurisdictions. The percentage of individuals in restrictive housing from three months to six months decreased in 12 jurisdictions, stayed the same in three jurisdictions, and increased in 16 jurisdictions.

The percentage of individuals in restrictive housing from six months to one year decreased in 20 jurisdictions, stayed the same in two jurisdictions, and increased in nine jurisdictions. The percentage of individuals in restrictive housing from one year to three years decreased in 20 jurisdictions, stayed the same in five jurisdictions, and increased in six jurisdictions. The percentage of individuals in restrictive housing from three years to six years decreased in 16 jurisdictions, stayed the same in nine jurisdictions, and increased in six jurisdictions. The percentage of individuals in restrictive housing over six years decreased in 14 jurisdictions, stayed the same in 14 jurisdictions, and increased in three jurisdictions.

Table 23 Comparing the Distributions of Prisoners in Restrictive Housing by Length of Time in 2015-2016 and in 2017-2018*

$(\mathbf{n}=31)$

\begin{tabular}{|c|c|c|c|c|c|c|c|c|c|c|c|c|c|c|}
\hline \multirow[b]{2}{*}{ Alaska } & \multicolumn{2}{|c|}{$\begin{array}{l}15 \text { Days up } \\
\text { to One } \\
\text { Month }\end{array}$} & \multicolumn{2}{|c|}{$\begin{array}{l}\text { One up to } \\
\text { Three } \\
\text { Months }\end{array}$} & \multicolumn{2}{|c|}{$\begin{array}{l}\text { Three up to } \\
\text { Six Months }\end{array}$} & \multicolumn{2}{|c|}{$\begin{array}{l}\text { Six up to } \\
\text { Twelve } \\
\text { Months }\end{array}$} & \multicolumn{2}{|c|}{$\begin{array}{l}\text { One up to } \\
\text { Three Years }\end{array}$} & \multicolumn{2}{|c|}{$\begin{array}{l}\text { Three up } \\
\text { to Six Years }\end{array}$} & \multicolumn{2}{|c|}{$\begin{array}{l}\text { Six Years } \\
\text { Plus }\end{array}$} \\
\hline & $35 \%$ & $28 \%$ & $21 \%$ & $30 \%$ & $14 \%$ & $20 \%$ & $17 \%$ & $10 \%$ & $12 \%$ & $12 \%$ & $1 \%$ & $0 \%$ & $0 \%$ & $0 \%$ \\
\hline Arizona & $6 \%$ & $16 \%$ & $19 \%$ & $31 \%$ & $21 \%$ & $16 \%$ & $32 \%$ & $17 \%$ & $19 \%$ & $18 \%$ & $1 \%$ & $3 \%$ & $3 \%$ & $0 \%$ \\
\hline Colorado & $29 \%$ & $100 \%$ & $30 \%$ & $0 \%$ & $29 \%$ & $0 \%$ & $11 \%$ & $0 \%$ & $0 \%$ & $0 \%$ & $0 \%$ & $0 \%$ & $0 \%$ & $0 \%$ \\
\hline Delaware & $7 \%$ & $12 \%$ & $26 \%$ & $58 \%$ & $22 \%$ & $14 \%$ & $20 \%$ & $16 \%$ & $18 \%$ & $0 \%$ & $3 \%$ & $0 \%$ & $5 \%$ & $0 \%$ \\
\hline FBOP & $19 \%$ & $22 \%$ & $43 \%$ & $46 \%$ & $16 \%$ & $17 \%$ & $10 \%$ & $8 \%$ & $8 \%$ & $3 \%$ & $2 \%$ & $2 \%$ & $2 \%$ & $2 \%$ \\
\hline Hawaii & $91 \%$ & $72 \%$ & $9 \%$ & $0 \%$ & $0 \%$ & $28 \%$ & $0 \%$ & $0 \%$ & $0 \%$ & $0 \%$ & $0 \%$ & $0 \%$ & $0 \%$ & $0 \%$ \\
\hline Indiana & $13 \%$ & $8 \%$ & $14 \%$ & $20 \%$ & $24 \%$ & $16 \%$ & $31 \%$ & $20 \%$ & $11 \%$ & $22 \%$ & $5 \%$ & $7 \%$ & $3 \%$ & $7 \%$ \\
\hline Iowa & $39 \%$ & $34 \%$ & $32 \%$ & $59 \%$ & $12 \%$ & $6 \%$ & $10 \%$ & $2 \%$ & $6 \%$ & $0 \%$ & $0 \%$ & $0 \%$ & $0 \%$ & $0 \%$ \\
\hline Kansas & $21 \%$ & $38 \%$ & $25 \%$ & $45 \%$ & $15 \%$ & $13 \%$ & $18 \%$ & $3 \%$ & $16 \%$ & $0 \%$ & $4 \%$ & $0 \%$ & $2 \%$ & $0 \%$ \\
\hline Kentucky & $29 \%$ & $78 \%$ & $46 \%$ & $15 \%$ & $11 \%$ & $5 \%$ & $8 \%$ & $2 \%$ & $6 \%$ & $0 \%$ & $1 \%$ & $0 \%$ & $0 \%$ & $0 \%$ \\
\hline Louisiana & $15 \%$ & $12 \%$ & $25 \%$ & $23 \%$ & $15 \%$ & $17 \%$ & $14 \%$ & $16 \%$ & $21 \%$ & $19 \%$ & $10 \%$ & $13 \%$ & $0 \%$ & $0 \%$ \\
\hline Massachusetts & $1 \%$ & $24 \%$ & $1 \%$ & $38 \%$ & $5 \%$ & $16 \%$ & $30 \%$ & $9 \%$ & $32 \%$ & $10 \%$ & $11 \%$ & $2 \%$ & $20 \%$ & $1 \%$ \\
\hline Mississippi & $2 \%$ & $75 \%$ & $11 \%$ & $13 \%$ & $16 \%$ & $8 \%$ & $22 \%$ & $2 \%$ & $37 \%$ & $1 \%$ & $9 \%$ & $0 \%$ & $3 \%$ & $0 \%$ \\
\hline Montana & $43 \%$ & $7 \%$ & $0 \%$ & $30 \%$ & $50 \%$ & $27 \%$ & $1 \%$ & $21 \%$ & $3 \%$ & $10 \%$ & $0 \%$ & $5 \%$ & $2 \%$ & $0 \%$ \\
\hline Nebraska & $8 \%$ & $6 \%$ & $20 \%$ & $28 \%$ & $26 \%$ & $31 \%$ & $15 \%$ & $24 \%$ & $18 \%$ & $10 \%$ & $8 \%$ & $0 \%$ & $5 \%$ & $1 \%$ \\
\hline New Jersey & $4 \%$ & $15 \%$ & $18 \%$ & $39 \%$ & $22 \%$ & $18 \%$ & $26 \%$ & $10 \%$ & $13 \%$ & $8 \%$ & $9 \%$ & $4 \%$ & $8 \%$ & $7 \%$ \\
\hline
\end{tabular}




\begin{tabular}{|c|c|c|c|c|c|c|c|c|c|c|c|c|c|c|}
\hline & $9 \%$ & $8 \%$ & $5 \%$ & $46 \%$ & $6 \%$ & $16 \%$ & $6 \%$ & $7 \%$ & $2 \%$ & $3 \%$ & $1 \%$ & $0 \%$ & & \\
\hline & $30 \%$ & $4 \%$ & $8 \%$ & $8 \%$ & & 507 & $1 \%$ & $2 \%$ & & $\%$ & $\%$ & 097 & & \\
\hline & & $3 \%$ & $4 \%$ & $4 \%$ & & 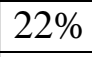 & & & & & $\%$ & & & $1 \%$ \\
\hline bi & $0 \%$ & $8 \%$ & $2 \%$ & $19 \%$ & $5 \%$ & $0 \%$ & $22 \%$ & $22 \%$ & $4 \%$ & $5 \%$ & $4 \%$ & $4 \%$ & $2 \%$ & $2 \%$ \\
\hline & $1 \%$ & $8 \%$ & $17 \%$ & $35 \%$ & $3 \%$ & $16 \%$ & $17 \%$ & $11 \%$ & $2 \%$ & $8 c$ & $5 \%$ & 19 & $5 \%$ & $0 \%$ \\
\hline & & $9 \%$ & $24 \%$ & & & & & $6 \%$ & & & & & & \\
\hline & $20 \%$ & $20 \%$ & $31 \%$ & $35 \%$ & $7 \%$ & $17 \%$ & $9 \%$ & $8 \%$ & $9 \%$ & $7 \%$ & $3 \%$ & $3 \%$ & $10 \%$ & $10^{\circ}$ \\
\hline & $22 \%$ & $19 \%$ & $35 \%$ & $28 \%$ & $2 \%$ & $14 \%$ & $11 \%$ & $18 \%$ & $14 \%$ & $14 \%$ & $6 \%$ & $2 \%$ & $0 \%$ & $6 \%$ \\
\hline & $7 \%$ & $0 \%$ & $5 \%$ & $7 \%$ & $9 \%$ & $11 \%$ & $14 \%$ & $18 \%$ & $5 \%$ & $23 \%$ & $11 \%$ & $13 \%$ & $\%$ & \\
\hline & $5 \%$ & $9 \%$ & $13 \%$ & $23 \%$ & $3 \%$ & $20 \%$ & $20 \%$ & $24 \%$ & $8 \%$ & $21^{\circ}$ & $9 \%$ & & $12 \%$ & $0 \%$ \\
\hline & $2 \%$ & $3 \%$ & $3 \%$ & $6 \%$ & $5 \%$ & $8 \%$ & $9 \%$ & $11 \%$ & $32 \%$ & $22 \%$ & $22 \%$ & $19 \%$ & $27 \%$ & $31 \%$ \\
\hline & $6 \%$ & $1 \%$ & $19 \%$ & $11 \%$ & $9 \%$ & $78 \%$ & $14 \%$ & $10 \%$ & $18 \%$ & $0 \%$ & 49 & $0^{c}$ & $1 \%$ & $0 \%$ \\
\hline & & & $0 \%$ & $21 \%$ & $5 \%$ & $28 \%$ & $26 \%$ & $27 \%$ & $14 \%$ & $17 \%$ & $6 \%$ & J & & 8 \\
\hline & $37 \%$ & 210 & 280 & & & & & & & $2 \%$ & & 0 & $0 \%$ & \\
\hline Vyoming & $6 \%$ & $26 \%$ & $23 \%$ & $38 \%$ & $18 \%$ & $31 \%$ & $45 \%$ & $2 \%$ & $7 \%$ & $1 \%$ & $0 \%$ & $1 \%$ & $1 \%$ & $0 \%$ \\
\hline
\end{tabular}

* Shaded cells contain values from the 2015-2016 survey. Unshaded cells contain values from the 2017-2018 survey.

To conclude, Figure 17 provides a summary of the comparison of the lengths of time that individuals spent in restrictive housing. This graph is one way to capture that the many efforts to limit the use and duration of restrictive housing are having effects on people's lives.

\section{Figure 17 Comparing the Distributions of Prisoners in Restrictive Housing by} Length of Time in 2015-2016 and in 2017-2018*
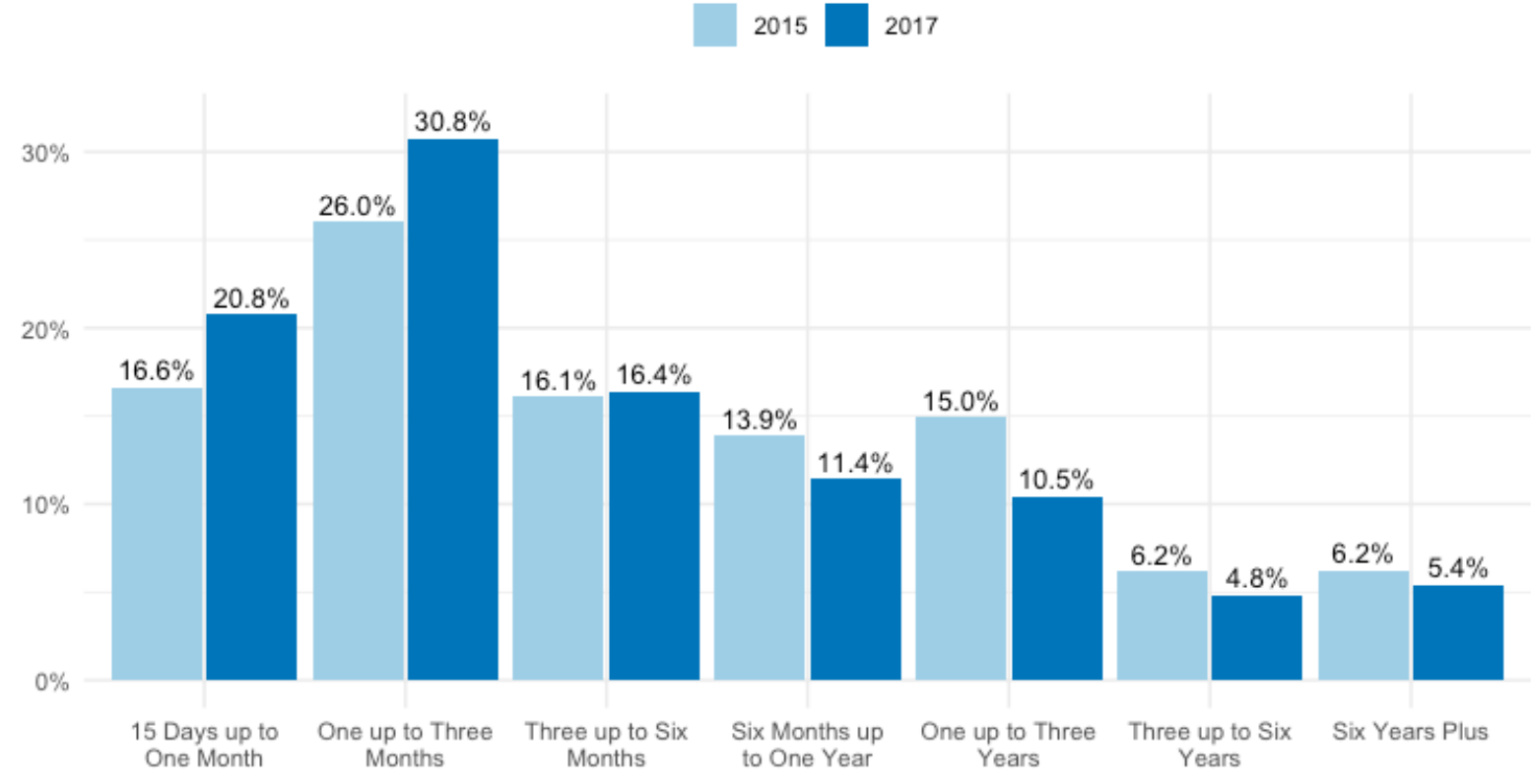
${ }^{1}$ See, e.g., Chesa Boudin, Trevor Stutz \& Aaron Littman, Prison Visitation Policies: A Fifty State Survey, 32 YALE LAW \& POLICY REVIEW: 149 (2013), available at http://digitalcommons.law.yale.edu/cgi/ viewcontent.cgi?article $=1654 \&$ context=ylpr; Giovanna Shay, Visiting Room: A Response to Prison Visitation Policies: A Fifty-State Survey, 32 YALE LAW \& POLICY REVIEW 191 (2013), available at http://digitalcommons.law.yale.edu/ylpr/vol32/iss1/6/; Ashbel T. Wall II, Why Do They Do It That Way?: A Response to Prison Visitation Policies: A Fifty-State Survey, 32 YAle LaW \& Policy ReVIEW 199 (2013), available at http://digitalcommons.law.yale.edu/ylpr/vol32/iss1/7/; David Fathi, An Endangered Necessity: A Response to Prison Visitation Policies: A Fifty-State Survey, 32 YALE LAW \& POLICY REVIEW 205 (2013), available at http://digitalcommons.law.yale.edu/ylpr/vol32/iss1/8/; Philip M. Genty, Taking Stock and Moving Forward to Improve Prison Visitation Practices: A Response to Prison Visitation Policies: A Fifty-State Survey, 32 YALE LAW \& POLICY REVIEW 211 (2013), available at http://digitalcommons.law.yale.edu/ylpr/vol32/iss1/9/.

${ }^{2}$ See, e.g, The Ninth Circuit Corrections Summit, Sacramento, California, November 4-6, 2015; The Ninth Circuit Corrections Summit, Santa Ana, California, April 25-27, 2018, Santa Ana, California; Racial Disparities in Prisons: A Seminar (Yale Law School, 2017).

${ }^{3}$ Hope Metcalf, Jamelia Morgan, Samuel Oliker-Friedland, Judith Resnik, Julia Spiegel, Haran tae, Alyssa Work, \& Brian Holbrook, Administrative SEgregation, Degrees of Isolation, and INCARCERATION: A NATIONAL OVERVIEW OF STATE AND FEDERAL CORRECTIONAL POLICIES (June 2013), available at https://law.yale.edu/system/files/area/center/liman/document/Liman_overview_segregation_June_25_2013_TO_ POST_FINAL(1).pdf [hereinafter ASCA-LimAn ADMINISTRATIVE SEGREGATION NATIONAL OVERVIEW 2013].

${ }^{4} I d$. at $5-11$.

${ }^{5} I d$. at $14-17$.

${ }^{6}$ Association of State Correctional Administrators \& Arthur Liman PUblic InTERest Program at Yale Law School, Time-IN-Cell: The ASCA-Liman 2014 National Survey of Administrative Segregation iN PRISON (Aug. 2015), available at https://law.yale.edu/system/files/documents/pdf/asca-liman_administrative_ segregation_report_sep_2_2015.pdf [hereinafter ASCA-LIMAN ADMINISTRATIVE SEGREGATION 2014].

${ }^{7} I d$. at 3 .

${ }^{8} I d$.

${ }^{9}$ U.S. DEPARTMENT OF JUSTICE, REPORT AND RECOMMENDATIONS CONCERNING THE USE OF RESTRICTIVE HOUSING (Jan. 2016), available at https://www.justice.gov/archives/dag/report-and-recommendations-concerning-userestrictive-housing.

${ }^{10}$ Jess Bravin, Large Number of Inmates in Solitary Poses Problem for Justice System, Study Says, THE WALL STREET JOURNAL, Sept. 2, 2015, available at https://www.wsj.com/articles/large-number-of-inmates-in-solitary-posesproblem-for-justice-system-study-says-1441209772.

${ }^{11}$ Timothy Williams, Prison Officials Join Movement to Curb Solitary Confinement, THE NEW YoRK TIMES, Sept. 2, 2015, available at https://www.nytimes.com/2015/09/03/us/prison-directors-group-calls-for-limiting-solitaryconfinement.html.

${ }^{12}$ Kevin Johnson, More than a Decade after Release, They All Come Back, USA ToDAY, Nov. 4, 2015, available at https://www.usatoday.com/story/news/nation/2015/11/04/solitary-confinement-prisoners-impact/73830286/. 
${ }^{13}$ Association of State Correctional Administrators \& ARTHUR Liman Public Interest Program at Yale

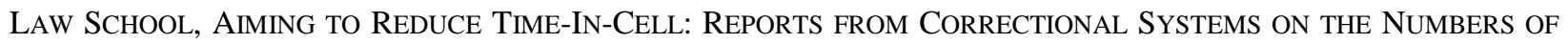
PRisoners in Restricted Housing AND ON THE Potential of Policy ChANGes to Bring About Reforms (Nov. 2016), available at https://law.yale.edu/system/files/area/center/liman/document/aimingtoreducetic.pdf [hereinafter ASCA-Liman Aiming to RedUCE Time-IN-CELl 2016].

${ }^{14} I d$. at 20.

${ }^{15} I d$. at 28 .

${ }^{16} I d$. at $27-28$.

${ }^{17} I d$. at 55-60. In the 2016 report, 45 jurisdictions provided information about policies related to restrictive housing.

${ }^{18}$ See, e.g., Anna Flag, Alex Tatusian, \& Christie Thompson, Who's in Solitary Confinement, The MarshaLl PROJECT, Nov. 2016, available at https://www.themarshallproject.org/2016/11/30/a-new-report-gives-the-mostdetailed-breakdown-yet-of-how-isolation-is-used-in-u-s-prisons; Daniel Teehan, What Chris Christie Got Wrong About Solitary Confinement, THE MARSHALl PROJECT, Dec. 2016, available at https://www.themarshallproject.org/2016/12/14/what-chris-christie-got-wrong-about-solitary-confinement; Juleyka Lantigua-Williams, More Prisons Are Phasing Out the 'Box,' THE ATLANTIC, Dec. 2016, available at https://www.theatlantic.com/politics/archive/2016/12/more-prisons-are-phasing-out-the-box/509225/; Juleyka Lantigua-Williams, The Link Between Race and Solitary Confinement, THE ATLANTIC, Dec. 2016, available at https://www.theatlantic.com/politics/archive/2016/12/race-solitary-confinement/509456/; Cassandra Basler, Yale Report Tries to Count People Held in Solitary Confinement, WSHU, Dec. 2016, available at http://wshu.org/post/yalereport-tries-count-people-held-solitary-confinement\#stream/0.

${ }^{19}$ ASCA-Liman Aiming to RedUCE TIME-IN-Cell 2016, supra note 13, at 16.

${ }^{20}$ The 2017-2018 survey asked about "separating prisoners from the general population and holding them in their cells for an average of 22 or more hours per day for 15 or more continuous days." Under this definition, for example, a person in cell for 24 hours per day for four days, 21 hours per day for three days, 23 hours a day for five days, and 21-and-a-half hours a day for 8 days would be included as held in restrictive housing. The 2016 survey did not include "average" in its definition, and thus a jurisdiction may or may not have included such persons in their count of restrictive housing.

${ }^{21}$ American Correctional Association Restrictive Housing Performance Based Standards August 2016, available at https://www.asca.net/pdfdocs/8.pdf [hereinafter ACA 2016 RESTRICTIVE HOUSING STANDARDS].

${ }^{22}$ The jails were the District of Columbia, Los Angeles County, New York City, and Philadelphia.

${ }^{23}$ Most jurisdictions provided initial data as of September 2017. Other jurisdictions responded using different initial dates. Minnesota Department of Corrections provided data as of July 2017. Colorado Department of Corrections, Pennsylvania Department of Corrections, and Texas Department of Corrections provided data as of August 2017. Georgia Department of Corrections, Indiana Department of Corrections, Mississippi Department of Corrections, New Hampshire Department of Corrections, New York Department of Corrections, North Carolina Department of Corrections, Rhode Island Department of Corrections, and Utah Department of Corrections provided data as of October 2017. New Mexico Department of Corrections provided data as of November 2017. Idaho Department of Corrections, Illinois Department of Corrections, and Michigan Department of Corrections provided data as of December 2017. Alaska Department of Corrections provided data as of February 2018. Los Angeles County Jail provided data as of March 2018. 
${ }^{24}$ The jurisdictions that did not provide any responses were California, Florida, Maine, Vermont, Virginia, and the District of Columbia.

${ }^{25}$ The responding jails were Los Angeles County and Philadelphia.

${ }^{26}$ The data we gathered focused on the fall of 2017. National data on the baseline prison population comes from 2016 and became available in 2018, with revisions in April 2018. See E. Ann Carson, Prisoners in 2016, BUREAU OF JUSTICE STATISTICS 4, Tbl.2 (Jan. 2018), https://www.bjs.gov/content/pub/pdf/p16.pdf [hereinafter BJS Prisoners in 2016].

${ }^{27}$ Other organizations have done site visits or worked with jurisdictions to evaluate their policies. See e.g., LEON DigARD, ELENA VANKO \& SARA SULLIVAN, RETHINKING RESTRICTIVE HOUSING: LESSONS FROM FIVE U.S. JAILS AND PRISON SYSTEMS, VERA INSTITUTE OF JUSTICE (May 2018), available at https://www.vera.org/rethinking-restrictivehousing [hereinafter Vera RETHINKING RESTRICTIVE Housing 2018]. See also Vera Institute of Justice, Reducing Segregation, https://www.vera.org/projects/reducing-segregation.

28 Zhen Zeng, Jail Inmates in 2016, BurEaU OF Justice STAtistics 1 (Feb. 2018), https://www.bjs.gov/content/pub/pdf/ji16.pdf [hereinafter BJS Jail Inmates in 2016].

${ }^{29}$ The full survey is set forth in Appendix A. A few jurisdictions, noted in Table 1, responded that their information was based on a definition different from that of the survey.

${ }^{30}$ Of the 46 jurisdictions that responded, three states (Minnesota, New Hampshire, and West Virginia) did not provide data on the number of prisoners in restrictive housing.

${ }^{31}$ This total custodial population comes from requests for information about prisoners held under the direct control of the jurisdictions. The survey defined direct control as "your jurisdiction hires and supervises staff (even if some are through subcontracts, such as health care services) and provides the governing rules and policies."

A few jurisdictions raised questions about the definition of direct control. Three jurisdictions commented either about the definition or that their answers included individuals held by the jurisdiction but in facilities whose personnel were not hired by the jurisdiction. For example, Ohio noted that it did "not differentiate" its "custodial population" based on whether or not it hired the staff, as the prisoners were "under our direct control whether or not they are in a private prison, or whether or not the staff are state employees." Rather, Ohio was "responsible for" all prisoners incarcerated in Ohio, and it reported data on all of them, whether in private facilities or not. Similarly, Idaho replied that its restrictive housing numbers included prisoners at "private prisons and contract facilities," which was to say its "whole population," not only those under its "direct control."

Almost all jurisdictions reported that some prisoners are housed not under their control —in local jails or out of state under the Interstate Compact Agreement-but states that have a substantial number (more than 10\%) not housed under their direct control are listed in the endnotes to Table 1 . The 43 responding jurisdictions reported a total of 111,094 (10\%) of prisoners sentenced by their jurisdictions but not under the direct control of each state's correctional system.

${ }^{32}$ BJS Prisoners in 2016, supra note 26, at 4, Tbl.2.

${ }^{33} \mathrm{We}$ calculate this estimate by dividing the number of people in restrictive housing based on the survey responses $(49,197)$ by the percentage of the U.S. prison population that the responding jurisdictions represented according to the BJS data (80.6\%). However, as noted above, this may be an undercount because some jurisdictions provided restrictive housing data for fewer people than their entire custodial population. That is, the population over which the systems had direct control and for which they had restrictive housing data, which is the total custodial population we used, may not have represented the entire custodial population. To mitigate this issue, another estimation method could be 
used. The second method would apply the overall percentage of people in restrictive housing (4.5\%) to the number of people in prisons, according to BJS statistics, in the jurisdictions that did not respond to the survey, and then add that figure to the number of individuals in restrictive housing in the responding jurisdictions. This method results in a total of almost 62,400 people in restrictive housing across the country. The different methods of estimation result in numbers that are relatively similar.

${ }^{34}$ The jurisdiction at the lowest part of that range was Colorado, and the jurisdiction at the highest was Louisiana. Louisiana reported taking "numerous steps over the last year to address the use of restrictive housing." Louisiana reported that these "efforts have led to a decrease in the number of restrictive housing beds by $1,168 . "$

Louisiana joined with the Vera Institute of Justice in the Safe Alternatives to Segregation initiative. Louisiana reported that doing so entailed evaluating what was driving placements and the amounts of time spent in isolation. The state then wrote new restrictive housing regulations, which were "being piloted at a couple of institutions with positive results." Louisiana described the most significant changes as "using terminology consistent with the Department of Justice," and using "a disciplinary matrix that specifies definitive sanctions" including the time that will be spent in segregation and the violations that will lead to isolation. Louisiana stated that these reforms "will lead to" fewer prisoners "being placed in RH and for shorter durations."

Louisiana also described implementing "a pilot at Elayn Hunt Correctional Center totally eliminating the use of restrictive housing." Louisiana explained that the facility was "allowing all offenders greater than two hours out of cell time per day. The time spent out of cell is a combination of recreational, educational, and treatment driven." In addition Louisiana reported that on February 11, 2018, it closed "Camp J," which "previously served as a disciplinary camp located at Louisiana State Penitentiary." This closure eliminated "416 RH beds. The facility that once housed the inmates with the most significant disciplinary history is being evaluated to be re-purposed into an assisted living / medical housing area." Louisiana also stated that it had put into place "a pilot at Louisiana State Penitentiary allowing inmates on Death Row to be out of cell for greater than 2 hours per day ( 70 beds)." This program "allows all offenders the opportunity to be out of their cells for at least 4 hours per day. They are allowed congregate for recreational activities and are afforded treatment programs such as Thinking for a Change."

${ }^{35}$ For some jurisdictions unable to clarify which definition they used, when constructing Figure 1, Figure 2, and Table 1, we used their responses to the question about length of time in restrictive housing, which provided again the 15-29 day definition. These jurisdictions were Arizona, Kansas, Maryland, Michigan, Montana, and Utah. Maryland's figure came from an aggregate number provided in response to the question about length of time in restrictive housing. Maryland was unable to provide numbers by periods of time, so we used only the aggregate number. The jurisdictions that are marked with an asterisk did not provide responses to the question about length of time in restrictive housing.

${ }^{36}$ The column "Total Custodial Population" presents jurisdictions' answers to the question about the total custodial population under the jurisdiction's direct control. In addition, below we note variations coming from responses from specific jurisdictions.

Alabama reported that it housed an additional 5,258 prisoners in local jails and "Community Corrections" facilities over which it did not have direct control; these prisoners were not included in the data on total custodial population or the population in restrictive housing.

Alaska's data were as of February 2018 rather than the fall of 2017.

Arizona reported that it housed an additional 8,740 prisoners in facilities over which it did not have direct control; these prisoners were not included in the data on total custodial population or the population in restrictive housing. 
Arkansas reported that it housed an additional 2,245 prisoners in facilities over which it did not have direct control; these prisoners were not included in the data on total custodial population or the population in restrictive housing.

Delaware's reported total custodial population of 4,333 came from its answer to the questions about the number of people in its total custodial population by age and by race. In answer to the general question about its total custodial population, Delaware counted 5,556 people, which included non-sentenced individuals. Because Delaware did not report restrictive housing data for non-sentenced individuals, we used the 4,333 number, which excluded that population. Because Delaware is a unified system with direct control over its jail system, the total custodial population included jail data for sentenced individuals.

The Federal Bureau of Prisons reported that it housed an additional 18,941 prisoners in private facilities over which it did not have direct control; these prisoners were not included in the data on total custodial population or the population in restrictive housing.

Georgia's figure was taken from a question regarding the gender and age of the total custodial population. Georgia reported that it housed an additional 7,862 prisoners in private facilities and 4,550 in local jails over which it did not have direct control; these prisoners were not included in the data on total custodial population or the population in restrictive housing.

As of the fall of 2017, Hawaii reported placing 1,617 inmates at Saguaro Detention Center, a private prison in Arizona, over which it did not have direct control; these prisoners were not included in the data on total custodial population or the population in restrictive housing. Further, Hawaii noted that it collected data on restrictive housing totals for only part of its restrictive housing population: "We collect data for Admin Segregation and not disciplinary segregation or protective custody housing." Hawaii is a unified system with direct control over its jail system; the totals therefore included jail data.

Idaho's figure was taken from an answer to a question regarding the gender and age of the total custodial population.

Kentucky reported that it housed an additional 11,556 prisoners in county jails over which it did not have direct control; these prisoners were not included in the data on total custodial population or the population in restrictive housing.

Louisiana reported housing an additional 20,122 prisoners in county jails over which it did not have direct control; these prisoners were not included in the data on total custodial population or the population in restrictive housing. Louisiana noted that it was unable to provide restrictive housing data for female inmates due to a "2016 flood that impacted our women's facility," resulting in the women being "displaced to multiple locations."

Montana reported housing an additional 922 prisoners in facilities over which it did not have direct control; these prisoners were not included in the data on total custodial population or the population in restrictive housing.

Nebraska's figure was taken from a question regarding the gender and age of the total custodial population.

New Jersey reported housing an additional 2,660 prisoners in facilities over which it did not have direct control; these prisoners were not included in the data on total custodial population or the population in restrictive housing.

Ohio's total custodial population figure was from Sept. 21, 2017, and its restrictive housing data was from Sept. 14, 2017.

Rhode Island is a unified system with direct control over its jail system; the totals therefore included jail data. 
Tennessee reported housing an additional 8,277 prisoners in county jails over which it did not have direct control; these prisoners were not included in the data on total custodial population or the population in restrictive housing. Tennessee's count of its total custodial population and its restrictive housing population included people in private prisons.

Utah reported housing an additional 1,346 "county jail inmates," four prisoners at Utah State Hospital, an additional five prisoners in "Hospital," and one prisoner in "Youth Corrections," as individuals in facilities over which it did not have direct control. These prisoners are not included in the data on total custodial population or the population in restrictive housing.

Washington noted it defined "short term" as 47 days or less. This definition did not affect the reports on the total restrictive housing population. Washington also reported that "up to 75 female offenders may be housed in county jail" over which it does not have direct control. These prisoners were not included in the data on the total custodial population or the data on restrictive housing.

Wyoming reported that it housed an additional 244 prisoners in facilities over which it did not have direct control; these prisoners were not included in the data on total custodial population or the population in restrictive housing.

${ }^{37}$ The column "Population in Restrictive Housing" presents jurisdictions' answers to a question about the total number of people in short-term and extended (more than 29 days) restrictive housing, with the exceptions noted at Figure 1. Additional notes for specific states follow.

Alaska's data were as of February 2018 rather than fall 2017. Alaska noted that "reported data was compiled from 12 facilities with somewhat different recording systems in place. While we do have a common electronic database, not all of the requested information was inputted or available. Unfortunately, some facilities were not able to provide numbers in all areas," which resulted in different sums for different questions. The number of prisoners reported to be in RH varied from 256 for the length-of stay question to 287 for the short-term and long-term restrictive housing question to 378 for the gender and age question.

Delaware is a unified system with direct control over its jail system; the totals here therefore include jail data.

Iowa noted that "restrictive housing for us means that an offender is held in their cell for at least 23 hours." This is higher than the standard definition of 22 or more hours. Kentucky similarly reported that all prisoners in restrictive housing were "housed in for 23 hours per day."

Montana's figure was taken from the question on length of stay.

Nevada's figure was taken from a question regarding the gender and age of the restrictive housing population.

New Mexico's figure was taken from a comment related to the question on length of time in restrictive housing. New Mexico noted that “we don't define short-term and long-term. The longest you can be in disciplinary RHU is 30 days. We have a long-term RHU program that is a step down program. That is a one year program but time can be enhanced for assaulting staff or returning to the program as a habitual. We do have inmates in RHU for periods of time less than 30 days."

${ }^{38}$ Of the 46 responding jurisdictions, Indiana did not respond to this question.

${ }^{39}$ Six jurisdictions did not provide data on length of time in restrictive housing for this report despite stating that they regularly collect it. These jurisdictions were Arkansas, Connecticut, Nevada, New Hampshire, New Mexico, and West Virginia. 
${ }^{40}$ The jurisdictions that reported not regularly collecting data on length of time in restrictive housing were Arizona, Georgia, Idaho, Louisiana, Michigan, Minnesota, Ohio, and Wisconsin. Arizona explained, "Data regarding length of stay in restrictive housing is managed through our Adult Information Management System (AIMS). Data is utilized as needed to develop reports on an individual basis."

${ }^{41}$ The five jurisdictions that reported not regularly collecting data on length of time in restrictive housing but that provided data on length of time for this report were Arizona, Louisiana, Michigan, Ohio, and Wisconsin.

${ }^{42}$ For example, a prisoner held for three years could be counted as having been in restrictive housing for only one year if the jurisdiction has kept data for one year and did not include information on years before data collection began. Of the 30 jurisdictions responding, 18 reported starting to collect data in 2014 or later, including four jurisdictions in 2017 and four in 2016.

${ }^{43}$ Some jurisdictions responding to the question about length of time in restrictive housing filled in a number for certain time periods and left other time periods blank. Some jurisdictions filled in zeros rather than leaving blanks. For this table, we filled in zeros for all time periods left blank as long as the jurisdiction had filled in numbers for some time periods.

When counting the numbers of prisoners in restrictive housing for various lengths of time, the following caveats apply. Alaska reported 378 people in restrictive housing and 256 people in restrictive housing by length of time. When responding to the question about length of stay, Alaska noted, "The numbers are the best estimate as the tracking is informal and not broken down in these quantities. Each facility maintains a separate roster for holding hearings. The required review and hearing for prisoners is: initial review is 24 hours from placement in segregation. The prisoner can be released at that time, the second review is 36 hours, and then every 30 days. Generally though a prisoner can be reviewed and released at any time the unit management team determines the prisoner can be released from segregation." Hawaii reported 13 people in restrictive housing and 32 people in restrictive housing by length of time. Further, Hawaii noted that it collected data on restrictive housing totals for only part of its restrictive housing population: "We collect data for Admin Segregation and not disciplinary segregation or protective custody housing." Illinois reported 921 people in restrictive housing and 1,098 people in restrictive housing by length of time. Kentucky reported 408 people in restrictive housing and 861 people in restrictive housing by length of time. Louisiana reported 2,709 people in restrictive housing and 2,719 people in restrictive housing by length of time. Massachusetts reported 443 people in restrictive housing and 312 people in restrictive housing by length of time. Missouri reported 2,990 people in restrictive housing and 2,510 people in restrictive housing by length of time. Nebraska reported 328 people in restrictive housing and 332 people in restrictive housing by length of time. North Dakota reported eight people in restrictive housing and nine people in restrictive housing by length of time. Oregon reported 938 people in restrictive housing and 638 people in restrictive housing by length of time.

Michigan noted that its length of stay data "reflects the number of days a prisoner spent in his/her current cell and does not account for the number of days in restrictive housing prior to placement in their current cell."

Washington reported, "Short term duration for us is 47 days. The numbers provided for the survey in regards to short term were 47 days or less."

${ }^{44}$ The numbers for Illinois were calculated by subtracting the numbers of people in protective custody by length of time from the total numbers of people reported to be in restrictive housing by length of time. Illinois reported that prisoners identified as being in protective custody "are job assignments such as barber, clerk, maintenance, etc., and are not in RH." The number of prisoners reported to be in protective custody was 601 .

${ }^{45}$ The high end of the range was Louisiana. The low end of the range was Colorado. 
${ }^{46}$ When counting the number of men in the total custodial population, the following caveats apply. Kansas reported 9,886 prisoners in the total custodial population and 9,896 prisoners by gender. Kentucky reported 12,000 prisoners in the total custodial population and 23,566 prisoners by gender. This discrepancy is accounted for by Kentucky's inclusion of its 11,566 person jail population in the calculations by gender. Louisiana reported 14,291 prisoners in the total custodial population and 34,987 prisoners by gender. This discrepancy is partially accounted for by Louisiana's inclusion of its 20,122 person jail population in the calculations by gender. Nevada reported 13,718 prisoners in the total custodial population and 13,714 prisoners by gender.

Connecticut reported 328 prisoners in the restrictive housing population and 406 prisoners in the restrictive housing population by gender. Connecticut's reported overall number of people in restrictive housing came from data as of September 2017 while the reported number of people in restrictive housing by gender came from data as of April 2018. Illinois reported 921 prisoners in the restrictive housing population and 1,560 prisoners in the restrictive housing population by gender. This discrepancy may be a result of counting people in isolation from one to 14 days. Indiana reported 1,741 prisoners in the restrictive housing population and 1,971 prisoners in the restrictive housing population by gender. This discrepancy may be a result of counting people in isolation from one to 14 days. Kentucky reported 408 prisoners in the restrictive housing population and 1,015 prisoners in the restrictive housing population by gender. Maryland reported 1,417 prisoners in the restrictive housing population and 1,567 prisoners in the restrictive housing population by gender. Nebraska reported 328 prisoners in the restrictive housing population and 397 prisoners in the restrictive housing population by gender. New Jersey reported 1,011 prisoners in the restrictive housing population and 1,173 prisoners in the restrictive housing population by gender. New Mexico reported 550 prisoners in the restrictive housing population and 294 prisoners in the restrictive housing population by gender. North Dakota reported eight prisoners in the restrictive housing population and nine prisoners in the restrictive housing population by gender. Oregon reported 938 prisoners in the restrictive housing population and 1,031 prisoners in the restrictive housing population by gender. The 938 number came from a population snapshot as of September 2017. The 1,031 number came from a population snapshot in December 2017 after a follow-up. Tennessee reported 1,181 prisoners in the restrictive housing population and 555 prisoners in the restrictive housing population by gender. The 1,181 number came from data as of October 2017. The 555 number came from data as of January 2018. Tennessee did not provide data for the restrictive housing population by gender for the 1,181 number. Texas reported 4,272 prisoners in the restrictive housing population and 4,269 prisoners in the restrictive housing population by gender. Utah reported 296 prisoners in the restrictive housing population and 282 prisoners in the restrictive housing population by gender. Washington reported 387 prisoners in the restrictive housing population and 409 prisoners in the restrictive housing population by gender. Wyoming reported 81 prisoners in the restrictive housing population and 85 prisoners in the restrictive housing population by gender.

Oregon explained that restrictive housing data based on length of stay and by type of restrictive housing was to be provided quarterly from a reporting tool that it was building with the help of the Vera Institute, while other data were a one-day snapshot.

In response to a later inquiry, Missouri wrote: "Missouri doesn't define segregation the same as the survey defines restrictive housing. When the initial survey was submitted, each facility had to review their offenders assigned to segregation to determine if they met the definition of restrictive housing for the survey. This was a cumbersome task. There is no way to go back now and provide the demographics of the offenders identified in the original survey."

${ }^{47}$ The high end of the range (4.6\% of the female custodial population, or 59 out of 1,280 female prisoners) was in Nevada; Colorado, Delaware, North Dakota, and Rhode Island housed no women in restrictive housing.

${ }^{48}$ When counting the number of women in the total custodial population, the same caveats as listed in note 47, supra, about data on men apply. In addition, as mentioned earlier, Louisiana noted in a follow-up email that it was unable to provide restrictive housing data for female prisoners. 
${ }^{49}$ Most jurisdictions were able to report data in each of these categories, but some jurisdictions used different race and ethnicity categories that did not match the categories that we provided. For example, Connecticut and Illinois did not use the racial category Native Hawaiian/Pacific Islander, and Kentucky uses the category Asian/Pacific Islander, instead of Native Hawaiian/Pacific Islander and Asian as separate categories. Where these varying definitions created challenges in understanding the data reported, we followed up with the jurisdictions and have reported definitional differences in the relevant sections of the report.

${ }^{50}$ We reported based on correctional systems' methods for categorizing prisoners into racial and ethnic groups. Twenty-four correctional systems identified race and ethnicity based on prisoners' self-identification. Seventeen jurisdictions identified race and ethnicity based on a combination of self-report, court documentation, and police documentation. Alabama explained that "race is certified to us on a sentencing transcript, which comes from the circuit clerk's office of the sentencing county." Arizona stated that identification was "based on self-reporting and/or court documents." Arkansas reported using "the Inmate's Judgment \& Commitment Order." Delaware reported that race and ethnicity was "imported/received as part of individual's electronic file received from Court" and that it could "be manually updated." The Federal Bureau of Prisons stated, "this information comes to the BOP from the Pre-Sentence Investigation report," and that it "is believed to be self-report in most instances." Kansas reported that race and ethnicity is "self selected," and that while "Hispanic ethnicity is recorded in addition to self selected race, for purposes of this survey those identifying as Hispanic ethnicity have been separated from their self selected race." Los Angeles responded it relied on "self identification and law enforcement records." Louisiana related using "LA State Police criminal records and birth certificate." Minnesota reported using "self reports and/or from court/arrest documents." Mississippi reported it relied on "court documents and/or NCIC [National Crime Information Center]." Missouri stated it utilized "the race captured in their criminal history." Montana responded that it followed "the NCIC standards for race reporting." Nevada stated that the information was "mostly, self reported or available from the pre-sentence investigation report." New Jersey said it used "an inmate's pre-sentencing information which provides nationality and race information in conjunction with self reporting during the classification process upon an inmate's transfer to the department." Oregon stated it relied on information from "LEDS [Law Enforcement Data System] or self report." Tennessee reported, "as offenders enter the diagnostic centers, we use the Judgment Orders from the courts, NCIC data, government issued identification, and self reporting." Utah stated, "staff are obtaining the information from our Bureau of Criminal Identification (BCI)."

Three jurisdictions reported specific policies on Hispanic ethnicity. Colorado stated, "ethnicity information is forwarded from Colorado Judicial and sent to us electronically along with mittimus information," and that "DOC determines which prisoners are included in the Hispanic demographic during the Intake process." New York related:

An inmate's self-reported race and ethnicity are both examined to determine into which racial/ethnic category he or she should be placed. An inmate is first categorized as white, black, other (this category includes Asian, Native American, and Other) or unknown based on self-reported race. Then, the inmate's ethnicity is determined; if the inmate's self-reported ethnicity is Hispanic, he or she is included in the "Hispanic" category. Next, the inmate's place of birth is examined; if he or she is born in a Spanish-speaking country or Puerto Rico, he or she is included in the "Hispanic" category, regardless of the inmate's self-reported ethnicity. Finally, the inmate's mother's place of birth and father's place of birth are examined; if either parent was born in a Spanish-speaking country or Puerto Rico, he or she is included in the "Hispanic" category, regardless of the inmate's self-reported ethnicity. So, an inmate's Hispanic ethnicity (as determined by inmate self-report, place of birth, or parental place of birth) is the overriding factor in determining race/ethnicity on the ETHNIC2 variable. The one exception to this is if the inmate's self-reported race is Asian; if so, he or she is included in the "Other" category, and not in the "Hispanic" category.

Washington responded that it used "offender self report," and that "race is self-identified separately from Hispanic origin. Ethnicity is self-identified separately from Race or Hispanic origin and relates to subpopulations such as specific Asian country of familial origin or Tribal affiliation."

ASCA-Liman Restrictive Housing 2018 revised September 252018 
Iowa did not clarify how identifications were made, stating, "by race or ethnicity." Texas made identifications based on physical appearance: "Race is determined by physical appearance, not ethnicity or offender preference." New Hampshire and West Virginia and did not provide answers.

${ }^{51}$ Alabama reported that "Other" included people "other than Black, White, and Indian. Hispanics are grouped as Caucasian, and Asians are Grouped in 'Other."'

${ }^{52}$ Iowa reported that "Native Hawaiian or Pacific Islander" prisoners were counted under "Asian."

${ }^{53}$ When counting the number of men in the total custodial population, the following caveats apply. Kansas reported 9,886 prisoners in the total custodial population and 9,896 prisoners by race. Kentucky reported 12,000 prisoners in the total custodial population and 23,604 prisoners by race. This discrepancy is partially accounted for by Kentucky's inclusion of its 11,566 person jail population in the calculations by race. Louisiana reported 14,291 prisoners in the total custodial population and 34,987 prisoners by race. This discrepancy is partially accounted for by Louisiana's inclusion of its 20,122 person jail population in the calculations by race. Nevada reported 13,718 prisoners in the total custodial population and 13,714 prisoners by race. New Mexico reported 7,047 prisoners in the total custodial population and 7,037 prisoners by race. Washington reported 17,046 prisoners in the total custodial population and 17,076 prisoners by race. Wisconsin reported 22,589 prisoners in the total custodial population and 22,579 prisoners by race.

In addition, Alabama reported 21,592 prisoners in the total custodial population and the same number by race. However, Alabama reported 20,282 men in the total custodial population, and 20,268 men by race. Alabama reported 1,310 women in the total custodial population, and 1,324 women by race.

Connecticut reported 328 prisoners in the restrictive housing population and 74 prisoners in the restrictive housing population by race. Illinois reported 921 prisoners in the restrictive housing population and 1,560 prisoners in the restrictive housing population by race. This discrepancy may be a result of counting people in isolation from one to 14 days. Indiana reported 1,741 prisoners in the restrictive housing population and 1,971 prisoners in the restrictive housing population by race. This discrepancy may be a result of counting people in isolation from one to 14 days. Kentucky reported 408 prisoners in the restrictive housing population and 1,015 prisoners in the restrictive housing population by race. Maryland reported 1,417 prisoners in the restrictive housing population and 1,544 prisoners in the restrictive housing population by race. Nebraska reported 328 prisoners in the restrictive housing population and 397 prisoners in the restrictive housing population by race. New Jersey reported 1,011 prisoners in the restrictive housing population and 1,173 prisoners in the restrictive housing population by race. New Mexico reported 550 prisoners in the restrictive housing population and 294 prisoners in the restrictive housing population by race. North Dakota reported eight prisoners in the restrictive housing population and nine prisoners in the restrictive housing population by race. Oregon reported 938 prisoners in the restrictive housing population and 1,031 prisoners in the restrictive housing population by race. The 938 number came from a population snapshot as of September 2017. The 1,031 number came from a population snapshot in December 2017 after a follow-up. Tennessee reported 1,181 prisoners in the restrictive housing population and 555 prisoners in the restrictive housing population by race. The 1,181 number came from data as of October 2017. The 555 number came from data as of January 2018. Tennessee did not provide data for the restrictive housing population by race for the 1,181 number. Texas reported 4,272 prisoners in the restrictive housing population and 4,269 prisoners in the restrictive housing population by race. Utah reported 296 prisoners in the restrictive housing population and 282 prisoners in the restrictive housing population by race. Washington reported 387 prisoners in the restrictive housing population and 409 prisoners in the restrictive housing population by race.

As mentioned earlier, Oregon explained that restricted housing data based on length of stay and by type of restrictive housing was to be provided quarterly from a reporting tool that it was building with the help of the Vera Institute, while other data were a one-day snapshot. 
Throughout this report, Iowa's definition of Asian includes Native Hawaiian/Pacific Islander.

${ }^{54}$ As previously mentioned, Alabama reported that "Other" included people "other than Black, White, and Indian. Hispanics are grouped as Caucasian, and Asians are Grouped in 'Other'."

${ }^{55}$ When counting the number of women in the total custodial population, the same caveats as listed in note 54, supra, with regards to men apply. In addition, as mentioned, Louisiana noted in a follow-up email that it was unable to provide restrictive housing data for female prisoners.

${ }^{56}$ ACA Standard 4-RH-0034, ACA 2016 RESTRICTIVE Housing STANDARD, supra note 21, at 39.

${ }^{57}$ Alaska, Louisiana, Maryland, and North Carolina were the jurisdictions reporting juveniles in restrictive housing.

${ }^{58}$ Some jurisdictions responding to the questions about prisoners' ages filled in a number for certain age ranges and left other age ranges blank. Some jurisdictions filled in zeros rather than leaving blanks. For the tables relating to age, we filled in zeros for all age ranges left blank as long as the jurisdiction had filled in numbers for some age ranges.

When counting the number of men in the total custodial population, the following caveats apply. Kansas reported 9,886 prisoners in the total custodial population and 9,896 prisoners by age. Kentucky reported 12,000 prisoners in the total custodial population and 23,566 prisoners by age. This discrepancy is accounted for by Kentucky's inclusion of its 11,566 person jail population in the calculations by age. Louisiana reported 14,291 prisoners in the total custodial population and 34,987 prisoners by age. This discrepancy is partially accounted for by Louisiana's inclusion of its 20,122 person jail population in the calculations by age. Nevada reported 13,718 prisoners in the total custodial population and 13,714 prisoners by age. New York reported 50,764 prisoners in the total custodial population and 50,767 prisoners by age.

Connecticut reported 328 prisoners in the restrictive housing population and 406 prisoners in the restrictive housing population by age. Connecticut's reported overall number of people in restrictive housing came from data as of September 2017 while the reported number of people in restrictive housing by age came from data as of April 2018. Illinois reported 921 prisoners in the restrictive housing population and 1,560 prisoners in the restrictive housing population by age. This discrepancy may be a result of counting people in isolation from one to 14 days. Indiana reported 1,741 prisoners in the restrictive housing population and 1,971 prisoners in the restrictive housing population by age. This discrepancy may be a result of counting people in isolation from one to 14 days. Kentucky reported 408 prisoners in the restrictive housing population and 1,015 prisoners in the restrictive housing population by age. Maryland reported 1,417 prisoners in the restrictive housing population and 1,557 prisoners in the restrictive housing population by age. Nebraska reported 328 prisoners in the restrictive housing population and 397 prisoners in the restrictive housing population by age. New Jersey reported 1,011 prisoners in the restrictive housing population and 1,173 prisoners in the restrictive housing population by age. New Mexico reported 550 prisoners in the restrictive housing population and 294 prisoners in the restrictive housing population by age. North Dakota reported eight prisoners in the restrictive housing population and nine prisoners in the restrictive housing population by age. Oregon reported 938 prisoners in the restrictive housing population and 1,031 prisoners in the restrictive housing population by age. The 938 number came from a population snapshot as of September 2017. The 1,031 number came from a population snapshot in December 2017 after a follow-up. Tennessee reported 1,181 prisoners in the restrictive housing population and 555 prisoners in the restrictive housing population by age. The 1,181 number came from data as of October 2017. The 555 number came from data as of January 2018. Tennessee did not provide data for the restrictive housing population by age for the 1,181 number. Texas reported 4,272 prisoners in the restrictive housing population and 4,269 prisoners in the restrictive housing population by age. Utah reported 296 prisoners in the restrictive housing population and 282 prisoners in the restrictive housing population by age. Washington reported 387 prisoners in the restrictive housing population and 409 prisoners in the restrictive housing population by age. Wyoming reported 81 prisoners in the restrictive housing population and 85 prisoners in the restrictive housing population by age. 
In addition, Wisconsin reported 713 prisoners in the restrictive housing population and the same number by age. However, Wisconsin reported 661 men in the restrictive housing population and 632 men by age. Wisconsin reported 52 women in the restrictive housing population and 81 women by age.

As previously mentioned, Oregon explained that restrictive housing data based on length of stay and by type of restrictive housing was to be provided quarterly from a reporting tool that it was building with the help of the Vera Institute, while other data were a one-day snapshot.

Washington originally reported 2,844 men ages $50+$ and 182 women ages $50+$. These were the same numbers as were reported for men ages 36-50 and women ages 36-50. Washington later explained that the numbers were inadvertently repeated and that the correct totals excluded the repeated numbers. We included 2,844 under the column for men ages 36-50 and 182 under the column for women ages 36-50. However, these numbers may include men and women ages $36-50$ and older than 50 .

${ }^{59}$ When counting the number of women in the total custodial population, the same caveats as listed in note 59, supra, with regards to men apply. As mentioned earlier, Louisiana noted in a follow-up email that it was unable to provide restrictive housing data for female prisoners.

${ }^{60}$ According to a 2017 report by the Bureau of Justice Statistics, 37\% of prisoners were told in the past by a mental health professional that they had a "mental disorder," and 14\% of state and federal prisoners "reported experiences that met the threshold for serious psychological distress" within 30 days prior to a survey in 2011 and 2012. Jennifer Bronson \& Marcus Berzofksy, Indicators of Mental Health Problems Reported by Prisoners and Jail Inmates, 201112, NCJ 2506121 (June 2017), available at https://www.bjs.gov/content/pub/pdf/imhprpji1112.pdf.

${ }^{61}$ ACA Standard 4-RH-0010, ACA 2016 RESTRICTIVE HOUSING STANDARDS, supra note 21, at 15.

${ }^{62} I d$.

${ }^{63} I d$.

${ }^{64} I d$.

${ }^{65}$ ACA Standard 4-RH-0011, ACA 2016 ReSTRICTIVE Housing STANDARDS, supra note 21, at 16.

${ }^{66} I d$.

${ }^{67} I d$.

${ }^{68} I d$.

${ }^{69}$ ACA Standard 4-RH-0029, ACA 2016 ReSTRICTIVE Housing STANDARDS, supra note 21, at 34.

${ }^{70} I d$.

${ }^{71}$ ACA Standard 4-RH-0031, ACA 2016 ReSTRICTIVE Housing STANDARDS, supra note 21, at 35; Id. at 3.

${ }^{72} I d$.

${ }^{73}$ Some jurisdictions answered the question, "Please provide data on how many prisoners are classified as seriously mentally ill in your jurisdiction's general population." The question was later clarified to read: "Please provide data on how many prisoners are classified as seriously mentally ill in your total custodial population." Total custodial population means all individuals housed in general population, restrictive housing, or any other units within the correctional department. General population is sometimes used interchangeably with total custodial population, but 
refers to a subset of the total custodial population, usually those who are not in restrictive or other specialized housing units. Where there was ambiguity in which definition of general population a jurisdiction was using, we followed up to clarify.

${ }^{74}$ The Federal Bureau of Prisons reported that it does not track numbers on prisoners with serious mental illness. South Carolina explained that it did not have data to provide on seriously mentally ill prisoners because it had recently implemented a special tracking system:

The South Carolina Department of Correction (SCDC) implemented a special indicator the latter part of 2017, to easily identify prisoners who are seriously mentally ill. Due to how recently this indicator was added to our system, there has not been sufficient time to review the entire mental health caseload to determine which prisoners should be identified as seriously mentally ill. Any numbers reported would not be an accurate representation/reflection of our Seriously Mentally Ill population.

${ }^{75}$ See Appendix C: Definitions of "Serious Mental Illness" in 43 Jurisdictions.

${ }^{76}$ Mississippi Definition of Serious Mental Illness, Appendix C.

${ }^{77}$ Nebraska Definition of Serious Mental Illness, Appendix C.

${ }^{78}$ See, e.g., New York Definition of Serious Mental Illness ("New York State DOCCS Definition of Serious Mental Illness (Section 137 Correction Law) (e) An inmate has a serious mental illness when he or she has been determined by a mental health clinician to meet at least one of the following criteria: (i) he or she has a current diagnosis of, or is diagnosed at the initial or any subsequent assessment conducted during the inmate's segregated confinement with, one or more of the following types of Axis I diagnoses, as described in the most recent edition of the Diagnostic and Statistical Manual of Mental Disorders, and such diagnoses shall be made based upon all relevant clinical factors, including but not limited to symptoms related to such diagnoses: (A) schizophrenia (all sub-types), (B) delusional disorder, (C) schizophreniform disorder, (D) schizoaffective disorder, (E) brief psychotic disorder, (F) substanceinduced psychotic disorder (excluding intoxication and withdrawal), (G) psychotic disorder not otherwise specified, (H) major depressive disorders, or (I) bipolar disorder I and II; (ii) he or she is actively suicidal or has engaged in a recent, serious suicide attempt; (iii) he or she has been diagnosed with a mental condition that is frequently characterized by breaks with reality, or perceptions of reality, that lead the individual to experience significant functional impairment involving acts of self-harm or other behavior that have a seriously adverse effect on life or on mental or physical health; (iv) he or she has been diagnosed with an organic brain syndrome that results in a significant functional impairment involving acts of self-harm or other behavior that have a seriously adverse effect on life or on mental or physical health; (v) he or she has been diagnosed with a severe personality disorder that is manifested by frequent episodes of psychosis or depression, and results in a significant functional impairment involving acts of selfharm or other behavior that have a seriously adverse effect on life or on mental or physical health; or (vi) he or she has been determined by a mental health clinician to have otherwise substantially deteriorated mentally or emotionally while confined in segregated confinement and is experiencing significant functional impairment indicating a diagnosis of serious mental illness and involving acts of self-harm or other behavior that have a serious adverse effect on life or on mental or physical health.”).

${ }^{79}$ Tennessee reported 505 prisoners with serious mental illness in its total custodial population. This number is not included in Tables 15, 16, 17 or 18 because it is not known how many of the 505 prisoners are female and how many are male.

${ }^{80}$ Texas stated that it did "not define 'serious mental illness." Its numbers in Table 15 and Table 16 reflect prisoners who were "on an inpatient mental health caseload." 
${ }^{81}$ ACA Standard 4-RH-0033, ACA 2016 ReSTRICTIVE Housing STANDARDS, supra note 21, at 38.

${ }^{82}$ These jurisdictions were Arkansas, Montana, and North Dakota.

${ }^{83}$ The other 38 jurisdictions were Alabama, Alaska, Arizona, Colorado, Connecticut, Delaware, Idaho, Illinois, Indiana, Iowa, Kansas, Kentucky, Louisiana, Maryland, Massachusetts, Michigan, Minnesota, Mississippi, Missouri, Nebraska, Nevada, New Jersey, New Mexico, New York, North Carolina, Ohio, Oklahoma, Oregon, Pennsylvania, Rhode Island, South Carolina, South Dakota, Tennessee, Texas, Utah, Washington, Wisconsin, and Wyoming.

${ }^{84}$ ACA Standard 4-RH-0035, ACA 2016 Restrictive Housing STANDARDS, supra note 21, at 40. The National Standards under the Prison Rape Elimination Act (PREA) also call for careful attention to the needs and safety of transgender individuals, defined as "a person whose gender identity (i.e., internal sense of feeling male or female) is different from the person's assigned sex at birth." NATIONAL STANDARDS TO PREVENT, DETECT, AND RESPOND TO PRISON RAPE UNDER THE PRISON RAPE ELIMINATION ACT (PREA) 28 C.F.R. § 115.5 (2012); see generally 28 C.F.R. $\S \S 115.15,115.31,115.41,115.42,115.86$.

${ }^{85}$ Those jurisdictions were Alabama, Alaska, Arizona, Arkansas, Colorado, Connecticut, Delaware, the Federal Bureau of Prisons, Idaho, Illinois, Iowa, Kansas, Kentucky, Louisiana, Maryland, Massachusetts, Michigan, Minnesota, Mississippi, Missouri, Montana, Nebraska, Nevada, New Jersey, New Mexico, New York, North Carolina, North Dakota, Ohio, Oklahoma, Oregon, Pennsylvania, South Carolina, South Dakota, Tennessee, Texas, Utah, Washington, Wisconsin, and Wyoming.

${ }^{86}$ These jurisdictions were Hawaii (responding "N/A"), Indiana ("not tracked"), Rhode Island ("RIDOC does not maintain these statistics electronically — only on a case by case basis and maintained in the inmates medical record"), and Utah ("We do not track transgender inmates").

${ }^{87}$ That jurisdiction was North Dakota.

${ }^{88}$ Four jurisdictions did not provide information beyond the definition they used for transgender: Kansas, Minnesota, Nebraska, and Utah. Twenty-one jurisdictions reported that prisoners self-report whether they are transgender: Alaska, Arizona, Colorado, Delaware (may self-identify at intake), the Federal Bureau of Prisons, Iowa, Louisiana, Maryland, Missouri, Montana (may self-identify at intake), New York, North Carolina (may self-identify at intake or upon transfer to another facility), North Dakota, Ohio, Oklahoma, Oregon, Pennsylvania, Texas (may self-identify at any point), Washington (may self-identify at any point), and Wisconsin (may self-identify at any point during incarceration). An additional nine jurisdictions indicated that transgender prisoners were identified through a combination of self-reporting and diagnosis: Connecticut, Illinois, Kentucky, Massachusetts, Michigan, Nevada, New Jersey, New Mexico, and Wyoming.

${ }^{89}$ These jurisdictions were the Federal Bureau of Prisons, Hawaii, Indiana, Rhode Island, and Utah.

${ }^{90}$ These 17 jurisdictions were Alabama, Colorado, Connecticut, Delaware, Iowa, Kansas, Massachusetts, Minnesota, Mississippi, Montana, Nebraska, New Mexico, North Carolina, North Dakota, South Carolina, Tennessee, and Wyoming.

${ }^{91}$ Maryland and South Dakota each reported one transgender prisoner in restrictive housing. Alaska, Louisiana, Nevada, New Jersey, and Oklahoma each reported two transgender prisoners in restrictive housing. Arkansas and Idaho each reported three transgender prisoners in restrictive housing. Kentucky and Michigan each reported six transgender prisoners in restrictive housing. New York reported seven transgender prisoners in restrictive housing. Ohio reported eight transgender prisoners in restrictive housing. Pennsylvania and Washington each reported nine transgender prisoners in restrictive housing. Arizona, Oregon, and Wisconsin each reported ten transgender prisoners 
in restrictive housing. Illinois reported 19 transgender prisoners in restrictive housing. Missouri reported 21 transgender prisoners in restrictive housing. Texas reported 24 transgender prisoners in restrictive housing.

${ }^{92}$ BJS Jail Inmates in 2016, supra note 28, at Tbls. 1, 4.

${ }^{93}$ See Allen J. Beck, Use of Restrictive Housing in U.S. Prisons and Jails, 2011-12, BUREAU OF Justice Statistics (Oct. 2015), http://www.bjs.gov/content/pub/pdf/urhuspj1112.pdf.

${ }^{94}$ BJS Prisoners in 2016, supra note 26, at 4, Tbl.2. Maryland, which reported on the survey that it has control over jails, was not included in the BJS description. Vermont did not respond to the survey.

${ }^{95}$ These populations are included in the total custodial populations of Table 1.

${ }^{96}$ We did not receive responses from the District of Columbia and New York City.

${ }^{97}$ Philadelphia's total custodial population numbers included privately contracted facilities.

${ }^{98}$ Philadelphia noted: "Each of the Philadelphia Department of Prisons facilities that have inmates in restrictive housing has a Deputy Warden for Administration that oversees all RHU inmates. The Deputy Warden reviews each inmate in segregated housing weekly (for those in segregation under 30 days) or monthly (for those in segregated housing more than 30 days). The Warden also reviews the case files for those inmates using the same schedule. Because we are a local (jail) jurisdiction, our length of stay overall is much lower than the state facilities, and, as such, our length of stay in segregated housing is much lower, also."

${ }^{99}$ Los Angeles's numbers on people by age in restrictive housing population totaled 511, while its total restrictive housing population count in response to another question was 619.

${ }^{100}$ Los Angeles cited United States v. County of Los Angeles and Los Angeles County Sheriff Jim McDonnell, CV 155903 (C.D. Cal. 2015), Settlement Agreement, available at https://www.justice.gov/crt/file/761256/download.

${ }^{101}$ In its initial response, Philadelphia had reported two pregnant individuals in its total custodial population, with both reported to be housed in short-term restrictive housing.

${ }^{102}$ When asked to explain other changes, Los Angeles noted a "major overhaul" of its "classification policies."

103 ASCA-Liman Administrative SEgREGation 2014, supra note 6, at 54-57.

${ }^{104}$ ASCA-LIMAN AIMING TO REDUCE TIME-IN-CELL 2016, supra note 13, at 55-60.

105 The jurisdictions responding to questions on policies were: Alabama, Alaska, Arizona, Arkansas, Colorado, Connecticut, Delaware, FBOP, Georgia, Hawaii, Idaho, Illinois, Indiana, Iowa, Kansas, Kentucky, Louisiana, Maryland, Massachusetts, Michigan, Minnesota, Mississippi, Missouri, Montana, Nebraska, Nevada, New Jersey, New Mexico, New York, North Carolina, North Dakota, Ohio, Oklahoma, Oregon, Pennsylvania, Rhode Island, South Carolina, South Dakota, Tennessee, Texas, Utah, Washington, Wisconsin, and Wyoming. The Federal Bureau of Prisons did so by linking to its revised policies.

106 The jurisdictions providing supplemental information were Alabama, Colorado, FBOP, Idaho, Massachusetts, New York, North Dakota, Ohio, Oklahoma, Pennsylvania, South Carolina, and Utah.

${ }^{107}$ ASCA-LimAn Administrative SEgREgation NATIONAL OVERVIEW 2013, supra note 3, at 4-5.

${ }^{108}$ Thirty-eight jurisdictions responded to this question. The jurisdictions that changed their criteria were: Alabama, Alaska, Arkansas, Colorado, Hawaii, Idaho, Illinois, Kentucky, Maryland, Massachusetts, Minnesota, Missouri, 
Montana, Nebraska, Nevada, New Mexico, North Carolina, North Dakota, Ohio, Oregon, South Carolina, South Dakota, Utah, and Washington.

${ }^{109}$ Thirty-two jurisdictions answered this question.

110 The jurisdictions that reported removing some behaviors from the list of infractions prompting placement in restrictive housing were Arkansas, Delaware, Idaho, Illinois, Maryland, Massachusetts, Minnesota, Nebraska, Nevada, North Carolina, Ohio, Oregon, Pennsylvania, South Carolina, Texas, and Washington.

${ }^{111}$ That jurisdiction was Washington.

112 That jurisdiction was North Carolina.

${ }^{113}$ That jurisdiction was Maryland.

114 That jurisdiction was Arkansas.

115 That jurisdiction was Texas.

${ }^{116}$ New Mexico reported that it had, "due to an increase in prison violence, . . . added enhancements to stays in longterm" restrictive housing "if the incident was a repeat violation (habitual offender type charge), was a violent assault on staff and/or was gang-related."

117 That jurisdiction was North Dakota.

118 The jurisdictions that had created such a policy were Alaska, Colorado, Hawaii, Maryland, Massachusetts, Minnesota, Mississippi, Montana, Nebraska, North Carolina, North Dakota, Ohio, Pennsylvania, South Carolina, Utah, and Washington.

119 Those jurisdictions were Alabama, Alaska, Arizona, Arkansas, Colorado, Hawaii, Illinois, Maryland, Massachusetts, Minnesota, Mississippi, Montana, Nebraska, Nevada, North Carolina, North Dakota, Ohio, South Carolina, Utah, and Wisconsin.

${ }^{120}$ Those jurisdictions were Alabama, Alaska, Arizona, Colorado, Maryland, Massachusetts, Minnesota, Mississippi, Nevada, North Carolina, North Dakota, Ohio, Utah, and Wisconsin. Arizona explained that a "screening upon arrival occurs for inmates arriving into detention status. Prior to placement if feasible."

${ }^{121}$ Nebraska reported that it had added screening "by medical and mental health within 24 hours of placement" in restrictive housing, effective July 1, 2016. South Carolina reported that it had added mental health screenings for prisoners "classified as mentally ill ... within 72 hours of initial placement" in restrictive housing and "within 30 days" of placement for other prisoners. Illinois and Montana also reported that they had added screenings after placement in restrictive housing.

122 Those jurisdictions were Hawaii, Maryland, Ohio, and Washington.

${ }^{123}$ Alaska reported this form of screening.

${ }^{124}$ The jurisdictions that had created policies requiring consideration of less-restrictive alternatives were Alabama, Alaska, Arizona, Colorado, Delaware, Illinois, Kentucky, Maryland, Massachusetts, Mississippi, Montana, Nebraska, Nevada, New Mexico, North Carolina, North Dakota, Ohio, Oregon, Utah, Washington, and Wisconsin. Other alternatives included, in Massachusetts, placement in a unit "which is not a locked-in unit but has less privileges" or, in Ohio, "Limited Privilege Housing, which requires congregate activity, out-of-cell dining, access to programming, and at least 2.5 hours of out-of-cell time daily." Ohio explained that this had "become the new default placement for 
low to moderate misbehavior." Arizona described converting restrictive-housing beds to "close custody"specifically, "152 beds from restrictive housing," "192 restrictive-housing sex offender beds," "192 restrictive housing PC beds," "72 CB7 restrictive-housing beds, and " 42 Central Unit restrictive-housing beds."

Michigan had not created such a policy at the time of the survey but reported that there were "plans in process to implement an alternative to restrictive housing by utilizing 'Start Units'."

125 That jurisdiction was Alabama.

${ }^{126}$ That jurisdiction was Oregon.

${ }^{127}$ That jurisdiction was Alaska.

${ }^{128}$ That jurisdiction was New Mexico.

${ }^{129}$ The 28 jurisdictions that reported making changes were Alabama, Alaska, Arizona, Arkansas, Colorado, Delaware, Hawaii, Illinois, Iowa, Kentucky, Maryland, Massachusetts, Minnesota, Montana, Nebraska, Nevada, New Jersey, New Mexico, New York, North Carolina, North Dakota, Ohio, Oregon, Pennsylvania, South Carolina, Texas, Utah, and Washington.

${ }^{130}$ Iowa, Minnesota, North Dakota, and Ohio reported requiring weekly reviews. Iowa reported that restrictive housing status was reviewed weekly "by the Long Term Restrictive Housing Committee." Minnesota reported that prisoners in restrictive housing were "now reviewed weekly." North Dakota reported that it administered reviews "once a week by the chief of security, Director of Treatment and Deputy Warden-Programs. If on restrictive housing for a year, the resident is reviewed by the DOCR Director. All severely mentally ill cases are staffed with the warden on a weekly basis. If placement is contraindicated, the resident's case is reviewed and staffed with the Clinical Director." Ohio reported that "every 7 days a member of the unit classification committee reviews the status of the inmate and has the power to initiate release procedures."

Alaska, Arkansas, Delaware, Hawaii, Kentucky, Montana, and New York reported requiring monthly reviews. Alaska reported that it conducted initial reviews at 24 hours and 72 hours, with subsequent reviews "every 30 days as needed," and also noted that "our facilities are reviewing prisoners sooner than the 30 day hearing standard. If the prisoner is believed not to be a threat he/she will be returned to general population." Arkansas reported that it conducted initial reviews every seven days for the first 60 days and every 30 days thereafter; at every other 30-day review, "the inmate will be personally interviewed by the Classification Committee or authorized staff;" and the warden must approve continued placement in restrictive housing for any inmate confined for more than one year. Arkansas specified that mental health review occurred within seven days of placement in restrictive housing and at least every 30 days afterward for prisoners with behavioral health diagnoses, at least every 90 days afterward for prisoners without diagnoses, and "more frequently if clinically indicated." Delaware reported every-seven-day reviews for the first 60 days, and "at least every 30 days thereafter," with review by the warden for inmates in restrictive housing for 90 days or more. Hawaii reported initial placement reviews within 24 hours, personal interviews with the warden or designee within 72 hours, and review every 30 days thereafter. Kentucky reported that the restrictive housing status of a prisoner was reviewed "at least every 30 days but often more frequently." Montana reported that "monthly reviews are now done by the unit management teams." New York explained that "inmates housed in restricted housing for other than disciplinary reasons (protection, administrative segregation, etc.) have their status reviewed by a facility three-member committee (consisting of a representative of the facility executive staff, a security supervisor, and a member of the guidance and counseling staff) every 7 days for the first 2 months, and then every 30 days thereafter. Prior to 7/18/2017, reviews were conducted every 60 days."

Arizona, Illinois, Nebraska, New Mexico, and Oregon reported requiring reviews over longer time periods. Arizona reported reviewing placement "at 180 days of initial placement followed by annual review." Illinois reported 
that prisoners could "request a review for reduction in their disciplinary segregation terms every 90 days," and that the Deputy Director or Director must review placement in restrictive housing "every 180 days after the initial review if the segregation term is more than one year." Nebraska reported that "Wardens review and approve the immediate placement," and the "central office MDRT reviews all" restrictive housing cases "every 90 days." New Mexico reported reviewing restrictive housing status "annually or as needed." Oregon reported that restrictive housing status of a prisoner was reviewed "at least every 90 days" for certain types of restrictive housing, and that the policy was under review.

${ }^{131}$ Jurisdictions were asked whether they had made changes to the "decision-making authority to continue individuals in restrictive housing" and whether they had implemented "centralized monitoring." Thirteen of 26 jurisdictions reported that they had implemented "centralized monitoring" (Alaska, Colorado, Delaware, Illinois, Kentucky, Maryland, Massachusetts, Minnesota, Nebraska, New Jersey, New Mexico, Ohio, and South Carolina), and 16 of 28 jurisdictions reported changes in decision-making authority (Alaska, Delaware, Hawaii, Illinois, Iowa, Kentucky, Minnesota, Montana, Nebraska, New Jersey, New Mexico, North Carolina, North Dakota, Ohio, Oregon, and South Carolina).

132 The jurisdictions that reported new grievance policies were Hawaii, Maryland, Montana, Nebraska, Nevada, New Jersey, and New Mexico.

${ }^{133}$ Twenty-six jurisdictions responded to this question. The 22 jurisdictions that reported increased monitoring of the mental health of prisoners in restrictive housing were Alabama, Alaska, Arizona, Colorado, Georgia, Hawaii, Idaho, Illinois, Indiana, Kentucky, Massachusetts, Missouri, Montana, Nebraska, Nevada, North Dakota, Ohio, Pennsylvania, Rhode Island, South Carolina, Utah, and Washington.

134 Three jurisdictions reported requiring daily mental health rounds. Alaska reported, "all prisoners in segregation are contacted by mental health on a daily basis and monitored for indications of issues." Montana reported that "daily rounds are done on each block by our mental health staff." Washington reported:

Per policy, offenders in restrictive housing receive a visit from a health care provider at a minimum of daily. Mental Health staff will conduct rounds in restricted housing at least once a week. An offender can request to be seen by mental health and will be seen in person within 48 hours . . . If there is concern for a person when ... rounds are conducted, the person will have a face-to-face evaluation. If the evaluation determines the restrictive housing environment is detrimental to their mental health, an alternative setting will be recommended with greater access to mental health services.

Eight jurisdictions reported rounds once or more per week. Alabama reported that "Mental Health staff tour" the restrictive housing unit "4 times per week." Arizona reported, "weekly rounds occur to assess for decompensation"; "If mental health needs are identified, the inmate is placed on a caseload and seen routinely .... Alternative placements are considered to determine if placement into a mental health program is required." Georgia reported that prisoners in restrictive housing are "monitored weekly and per request." Idaho reported that "clinicians walk the units weekly and immediately make notification to administration if someone is found to be decompensating." Illinois reported that "DR 504 changes require mental health to make visits to segregation not less than 1 time/week." Massachusetts reported requiring "rounds by a consistent qualified mental health professional twice weekly who monitors for any changes in mental status and/or behavior that would suggest additional assessment for signs and symptoms of mental illness"; "if status changes," a "full mental health assessment is completed and determination of treatment needs of that evaluation." Ohio reported, any prisoner "in Restrictive Housing is seen by Mental Health every week and has a review conducted every 30 days." South Carolina reported, "one year ago SCDC went from Monthly rounds to Weekly rounds." 
${ }^{135}$ Massachusetts reported that people with serious mental illness in restrictive housing "for more than 30 days are reviewed monthly by a high level central office multi-disciplinary team." Ohio reported a similar policy of "review conducted every 30 days." Pennsylvania described implementing clinical "contacts by psychology for all RHU/DTU [Restricted Housing Units / Diversionary Treatment Units] . . for three consecutive days after admission . . . to focus on suicidality" and had also made available "on the RHU/DTU 24 hours per day" "Certified Peer Specialists" who "shall be informed of new receptions so they can check in with them."

136 The jurisdictions that reported increasing restrictive-housing prisoners' time out-of-cell were Alaska, Arizona, Arkansas, Colorado, Delaware, Georgia, Idaho, Illinois, Maryland, Massachusetts, Minnesota, Montana, Nebraska, New Jersey, New York, North Carolina, Oregon, Texas, Utah, and Washington.

137 The jurisdictions reporting adding more structured time out-of-cell were Alaska, Colorado, Delaware, Georgia, Idaho, Illinois, Kentucky, Maryland, Massachusetts, Minnesota, Missouri, Nebraska, Nevada, New Jersey, North Carolina, North Dakota, Ohio, Rhode Island, Utah, and Washington. Two jurisdictions indicated that they were in the process of increasing their structured out-of-cell time. Montana explained that it was "still in the production phase right now and will be completed in the next year." Oregon reported it was "working to increase structured out-of-cell time in certain types of RH." Examples of initiatives to increase out-of-cell time included a "peer group led by community mental health peers" in Nebraska, and twice-a-month game nights or movie nights in North Dakota.

${ }^{138}$ The jurisdictions that reported that they had enabled restrictive-housing prisoners to eat meals in social settings were Arizona (for Step 2 and Step 3 prisoners), Delaware, Kentucky, Maryland, Minnesota, and South Dakota.

${ }^{139}$ The jurisdictions that reported adding more "unstructured (recreational)" time out-of-cell were Alaska, Arizona ("Step 3 inmates are permitted out of cell leisure time"), Delaware, Georgia, Illinois, Massachusetts, Minnesota, Montana, North Dakota, Oregon, and Texas.

${ }^{140}$ Those jurisdictions were Alaska, Arizona, Georgia, Kentucky, Maryland, Montana, Nevada, New York, North Dakota, and Texas.

${ }^{141}$ The jurisdictions that reported adding classes were Alaska, Arizona, Delaware, Georgia, Kentucky, Maryland, Montana, Nebraska, New Mexico, North Dakota, and Oregon.

${ }^{142}$ The jurisdictions that reported adding a GED or diploma program were Alabama, Arizona, Colorado, Georgia, Idaho, Kentucky, Maryland, Massachusetts, North Carolina, North Dakota, Oregon, Utah, and Washington. These 13 jurisdictions did not include Alaska, Minnesota, New Jersey, or Ohio, all of which reported having a GED or diploma program prior to the 2016 ACA revisions. Montana stated such a program was "under review and production."

${ }^{143}$ The jurisdictions that reported increased visitation hours were Colorado, Iowa, Minnesota, Nevada, New York, North Carolina, North Dakota, Ohio, and Washington. Montana reported it was reviewing its visiting policy.

${ }^{144}$ The jurisdictions that reported increased phone time were Colorado, Delaware, Iowa, Maryland, Minnesota, Nevada, New York, North Carolina, North Dakota, and South Dakota. Montana reported it was reviewing its visiting policy.

145 The jurisdictions that reported increased out-of-cell group programming and/or classes were Alabama, Alaska, Arizona, Arkansas, Colorado, Delaware, Georgia, Illinois, Iowa, Kentucky, Maryland, Massachusetts, Minnesota, Missouri, Nebraska, New Jersey, New Mexico, North Carolina, North Dakota, Ohio, Oregon, Utah, Washington, and Wisconsin. Among these jurisdictions, the topics of such group classes included anger management in Alaska, Arkansas, Delaware, and North Carolina; life skills in North Carolina and Utah; group educational programming in Colorado, Missouri, New Jersey, North Carolina, and Ohio; substance use recovery in North Carolina and Ohio; and other mental health or therapeutic programming in Alaska, Delaware, Illinois, Iowa, Kentucky, Maryland, Minnesota, 
Missouri, Nebraska, New Jersey, New Mexico, North Carolina, North Dakota, and Ohio. Examples of other mental health or therapeutic programming included "behavior modification" and "self-reflection" in Delaware; "Thinking for change" in Iowa and North Dakota, which reported using a modified program; and "EAGLE (Emotions, Attitude, Growth, Learning, and Excelling)" in Missouri. Maryland reported its programming was a "recent implementation," and noted that it was "in the process of developing further programming opportunities with case management, psychology and social work."

146 That jurisdiction was North Carolina.

147 That jurisdiction was Missouri.

148 That jurisdiction was North Carolina.

${ }^{149}$ That jurisdiction was Alaska.

150 The jurisdictions that reported adding more group recreation opportunities were Alaska, Arizona, Colorado, Delaware, Georgia, Iowa, Kentucky, Maryland, Missouri, Montana, New Jersey, North Carolina, North Dakota, Ohio, Utah, and Washington.

151 The jurisdictions that reported increased in-cell learning opportunities were Alabama, Alaska, Arizona, Arkansas, Colorado, Georgia, Idaho, Iowa, Kentucky, Maryland, Massachusetts, Montana, Nebraska, New York, North Carolina, North Dakota, Ohio, Pennsylvania, Texas, Utah, Washington, and Wisconsin. Twenty-two of 36 jurisdictions also reported increased access to resources such as reading materials, videos, and music for prisoners in restrictive housing. Those 22 jurisdictions were Alabama, Alaska, Colorado, Delaware, Georgia, Idaho, Iowa, Kentucky, Maryland, Minnesota, Missouri, Montana, Nebraska, Nevada, New York, North Carolina, North Dakota, Rhode Island, South Carolina, South Dakota, Utah, and Washington. Eight of these 22 jurisdictions reported distributing to prisoners personal devices such as tablets, televisions, MP3 players, or radios. Those eight jurisdictions were Alaska, Delaware, Montana, Nebraska, New York, Rhode Island, South Carolina, and South Dakota. Alaska, Colorado, Georgia, Maryland, and Nevada described allowing access to "literary materials," and Georgia, North Carolina, and Washington reported allowing access to a common television. Maryland and Nevada specifically reported adding access to legal materials. Montana reported that it was "in the process of implementing a tablet system with in cell learning opportunities."

152 Those jurisdictions were Alaska; Colorado, which provided for post-secondary education; Georgia, which provided for GED education; and New York, which noted that cell study was available at the prisoners' own expense.

153 That jurisdiction was Texas.

154 Arizona reported having "CCTV in-cell self-help study programs." Maryland reported having "video opportunities." Ohio reported allowing "use of television" in some cases. Texas reported that prisoners in restrictive housing had the ability to "watch videos."

${ }^{155}$ Idaho reported that prisoners "in restrictive housing can access kiosk with JP5 device." Ohio reported allowing "the JPlayer." Wisconsin reported that "portable smartboards were purchased in addition to computers for improved access to education for $<20$-year-old at risk special needs inmates in restrictive housing."

${ }^{156}$ North Carolina reported that prisoners "receive in-cell learning opportunities by use of interactive journals published by the Change Companies." Ohio reported providing "paper based programs."

${ }^{157}$ The jurisdictions that had added some form of mental health training for staff were Alabama, Alaska, Arizona, Arkansas, Colorado, Connecticut, Delaware, Illinois, Iowa, Kansas, Kentucky, Maryland, Massachusetts, Minnesota, Mississippi, Missouri, Nebraska, Nevada, New Jersey, North Carolina, North Dakota, Ohio, Rhode Island, South 
Carolina, Tennessee, Texas, Utah, Washington, and Wisconsin. Montana reported that its mental health training for staff was still being reviewed. Idaho's draft revised policies, to be implemented in summer 2018, established additional mental health training for restrictive housing staff.

${ }^{158}$ Alabama reported training with the Department of Justice, the National Institute of Corrections, and the National Commission on Correctional Health Care. Arizona explained that it had "contracted with NIC concluding training for 40 key staff that work in restrictive housing in Mental Health First Aid." Delaware stated: "DOC has sent staff to ACA and NIC sponsored trainings on behavioral health and mental health first aid. DOC offers educational assistance to employees who wish to pursue additional studies in a chosen relevant field. DOC has partnered with other state agencies in Delaware to provide training on behavioral health issues."

${ }^{159}$ Thirty-one jurisdictions responded to this question. The jurisdictions that reported having opportunities for staff education related to restrictive housing were Arkansas, Connecticut, Delaware, Illinois, Iowa, Kentucky, Maryland, Mississippi, North Carolina, North Dakota, Ohio, and Wisconsin. Two jurisdictions, Montana and Nebraska, reported that they were reviewing their policies.

${ }^{160}$ Arizona reported having "specialized 24-hour mental health training with classes starting in October 2017," and contracting with NIC for "training for 40 key staff that work in restrictive housing in Mental Health First Aid." Connecticut reported "Mental Health Training is organized by Correctional Managed Health Care." Delaware reported that "mental health first aid" was "a part of Correctional Employee Initial Training class and offered to existing correctional staff on a voluntary basis." Delaware also explained that it "sent staff to ACA and NIC sponsored trainings on behavioral health and mental health first aid." Illinois stated that "IDOC was mandated to train ALL staff in NAMI training per Rasho agreement." Maryland reported that "Mental Health First Aid" training was provided to staff. Massachusetts related that "MADOC staff receive centralized annual in-service training on Recognizing the Signs and Symptoms of Mental Illness and Suicide Prevention and Intervention. At the site level, Mental Health Directors provide specific mental health training tailored to the needs of the facility and its population." Missouri stated that it provided "annual mental health training to staff," and "has been expanding the use of Crisis Intervention Training for staff, especially those staff assigned to segregation." North Carolina reported that staff "are required to have training in Motivational Interviewing and Crisis Intervention," and that "TDU staff have completed the ACA Behavioral Health Certification training." Rhode Island stated that mental health training "is part of normal in-service training but is not specific to" restrictive housing. South Carolina reported that all "security staff receive Mental Health training. Tennessee reported that staff receive "Correctional Behavioral Health Training." Texas explained that the "Pre-Service Training Academy ... includes 32 hours of mental health/crisis intervention training," and that additional "mental health/crisis intervention training has been incorporated into annual in-service training." In addition, Texas reported that each unit "provides turnout training regarding suicide prevention and mental health/crisis intervention on a regular and frequent basis." Utah stated that the "UDC certified staff received basic annual training on mental health." Washington reported that a "large portion of restricted housing staff have received "Working with Offenders with Mental Health' training, Individual Behavioral Management Plan (IBMP) training, and in some cases Motivational Interviewing."

${ }^{161}$ Those jurisdictions were Colorado, Kansas, Maryland, Massachusetts, Minnesota, South Carolina, and Texas. Colorado, Massachusetts, and Minnesota reported providing these programs annually for all staff. Texas stated that each "unit provides turnout training regarding suicide prevention ... on a regular and frequent basis."

162 Those jurisdictions were Maryland, Minnesota, Missouri, Nevada, North Carolina, North Dakota, Ohio, South Carolina, and Texas.

${ }^{163}$ Those jurisdictions were Arizona, North Carolina, and Washington.

164 That jurisdiction was North Dakota. 
165 That jurisdiction was Minnesota.

166 That jurisdiction was Alabama.

167 Thirty-one jurisdictions responded to this question. The 14 jurisdictions that reported a staff rotation policy were Alaska, Arizona, Arkansas, Connecticut, Idaho, Kentucky, Maryland, Massachusetts, Minnesota, Missouri, Montana, North Dakota, South Carolina, and Wisconsin. Alaska explained, "generally staff are rotated out after a year in the segregation unit." Arizona reported that "ADC rotates staff as a statewide measure every five years or by request." Arkansas reported having a staff rotation policy related to staffing of restrictive housing. Connecticut stated that "Correctional Officer post rotations occur every 56 or 112 days depending on the facility and shift." Idaho noted that job postings for restrictive housing were "exempt from seniority bidding and staff must apply to work in these units." Kentucky stated that staff rotations were "considered annually and by request." Maryland explained that staff rotations varied "from facility to facility." Massachusetts reported that "security staff are rotated annually" in restrictive housing units and "specialized units." Minnesota stated that "officers in restrictive housing units are rotated out of the assignment for a minimum of 3 months after 2 years." Missouri explained that "uniformed custody staff are not rotated," but that "case management staff are rotated at a minimum of every two years." Montana stated it provided staff rotations "once every 2 to 3 years if staffing allows." North Dakota explained it tried "not to allow" staff "to work past 18 months in the Behavioral Health Unit." South Carolina reported that staff rotate "every 18 months" and "may request to remain in RHU longer with 24 months being the maximum." Wisconsin stated that staff rotations varied "depending on the institution."

${ }^{168}$ That jurisdiction was Connecticut.

169 That jurisdiction was Arizona.

${ }^{170}$ Thirty-eight jurisdictions responded to this question. The 20 jurisdictions that required this advance information be given to prisoners were Alabama, Alaska, Arkansas, Colorado, Georgia, Kentucky, Maryland, Mississippi, Montana, Nebraska, Nevada, New Mexico, New York, North Carolina, North Dakota, Ohio, Pennsylvania, Utah, Washington, and Wisconsin.

Kentucky, Maryland, Montana, Nevada, and Utah stated that they made their restrictive housing handbook or disciplinary manual accessible to prisoners. Mississippi required prisoners to "familiarize themselves with the offender handbook and acknowledge participation and understanding of the rules and regulations of the program by signing a written contract." Alaska, Colorado Maryland, New York, North Dakota, Ohio, and Washington provided information about the criteria directly to prisoners through an orientation or meeting. North Dakota noted that the "behavioral plan" is not shared with the "resident" "if doing so would jeopardize the safety of the resident, staff, other residents, or the public."

171 Thirty-five jurisdictions answered this question. The 21 jurisdictions that reported that they have already implemented this change were Alaska, Arizona, Arkansas, Colorado, Delaware, Georgia, Hawaii, Kentucky, Maryland, Massachusetts, Montana, Nebraska, New Mexico, New York, North Carolina, North Dakota, Ohio, Pennsylvania, South Carolina, Texas, and Utah. In addition to these 21 jurisdictions, Mississippi reported that its process involved a "committee recommendation" but that the "offender services director" made the "final decision." North Carolina reported that it was developing a policy, "targeted for implementation November, 2017," that would "move classification decisions to a committee process."

172 The 2016 ACA Standards offer the definition of a step-down program as "a program that includes a system of review and establishes criteria to prepare an inmate for transition to general population or the community." ACA 2016 RESTRICTIVE HOUSING STANDARDS, supra note 21, at 4. 
${ }^{173}$ Twenty-seven jurisdictions reported having added step-down or transition programs. Those jurisdictions were Alabama, Alaska, Arizona, Arkansas, Colorado, Delaware, Georgia, Illinois, Iowa, Kentucky, Maryland, Minnesota, Mississippi, Missouri, Montana, Nebraska, Nevada, New Jersey, New Mexico, New York, North Carolina, North Dakota, Oklahoma, Pennsylvania, South Carolina, Utah, and Washington.

Three jurisdictions - Idaho, Massachusetts, and Oregon — noted they were developing step-down programs. Idaho reported it was "in the draft phase of a mandatory step up program." Massachusetts reported it piloted "a stepdown unit in our largest medium security prison in November, 2017" in the form of "a 90-day program targeting the criminogenic needs that originally created the pathway" to restrictive housing. "It is a dorm style housing unit so no one is locked in cells at all, just restricted privileges with a clear pathway back to general population." Oregon reported that a step-down program was "in development."

${ }^{174}$ For example, Alaska reported using "progressive reduction of restrictions ... awarded after periods of demonstrated good behavior and programming." Colorado stated that its "close custody units/designations" allowed for "increasing privileges/incentives as offenders progress." Maryland explained that its restrictive housing policy had "a level-system built in that provides for the increase of both programs and privileges to make for a smooth transition into general population." Minnesota reported that its step-down plan included increasing privileges, amenities, and movement." Montana stated that "step downs occur as inmates progress through a 6 level system where their privileges increase." New Mexico described a progressive four-step program. Oklahoma reported a pilot step-down program, which consisted of "four phases that are progressively less restrictive." Pennsylvania stated it had created a "step down unit and portal program, which used "a progressive four-tiered phase system based on the inmate's adjustment and attainment of goals/objectives." Utah reported that prisoners in restrictive housing must "progress through three phases" of restrictive housing.

${ }^{175}$ Colorado reported having a "Management Control Unit High Risk, Management Control Unit, and Close Custody Transition Unit (CCTU)." Nebraska stated it "established several mission specific housing units," which included "protective management, active senior unit, veterans unit, and the challenge program," as alternatives to or "transition out of" restrictive housing. Nevada reported adding a Behavior Modification Unit. North Carolina reported having two different units, the "Therapeutic Diversion Unit" and the "Rehabilitative Diversion Unit." North Dakota stated it had a "transition unit ... to help prepare people who have been living in the behavior intervention unit for general population." Ohio described a "hybrid sanctioning system" with a "Limited Privilege Housing" step-down. Oklahoma explained its "Step-Down Program" was a separate housing unit. Pennsylvania stated its PORTAL program was housed in a separate unit. Washington reported that one of its facilities added a "transition pod," which allowed two prisoners "assigned to Maximum custody to be on the tier with each other without restraints on for several hours a day," and to be "around custody staff on the tier without restraints as well."

176 That jurisdiction was Minnesota.

177 That jurisdiction was North Dakota.

${ }^{178}$ Alabama reported that step-down programs were "in use at 2 facilities. The inmates must be in medium custody and have shown a pattern of improved behavior to be considered for return to population."

Alaska stated its facilities had "a step-down program for Maximum Custody prisoners which allows progressive reduction of restrictions that are awarded after periods of demonstrated good behavior and programming."

Arizona explained that there were five step-down segments: upon entry in restrictive housing, prisoners are "evaluated and placed into a step reduction system based on behavior and/or reason for placement. Inmates begin the process at Browning, (our most restrictive and secure) and reduce to our Special Management Unit (SMU). SMU is considered an intermediary placement with increased programing and interaction opportunity. From SMU, inmates transition to Central Unit where they are offered more group program/recreational opportunity." 
Arkansas reported it had created a step-down program.

Colorado related that all prisoners in extended restrictive housing were "eligible for progression and placement in the step-down/transition program based upon their actions/behaviors. The close custody units/designations allow for increasing privileges/incentives as offenders progress . . . The cognitive programming provided within CCTU normally takes 12 weeks to complete."

Delaware related that its policy required a step-down program, but it had "not yet been implemented into practice." Georgia reported it had "Tier II step down units for offenders on phase 3+, who have been in restrictive housing for $270+$ days."

Idaho reported a "step-up program" in which prisoners in "long-term restrictive housing are automatically enrolled." Idaho provided its policy on the step-up program, which stated: "During the first 30-day review, the chairperson must provide written goals required to move from step one to step two. Inmates will continue to receive goals in writing for each successive step as they progress, until completion of the step-up program .... The designated deputy chief of prisons must develop a tracking process with the assistance of the research and analysis group at headquarters to measure effectiveness of the step-up program ...."

Iowa reported that "small modifications" "connected to recreation time, out of cell time and property modifications" had occurred in its step-down program.

Kentucky reported step-down programs at three institutions (two male, one female): "Each program lasts 612 months. Inmates are eligible based on treatment team and classification referral."

Maryland explained that its restrictive housing policy had "a level-system built in that provides for the increase of both programs and privileges to make for a smooth transition into general population. Within the review process alternative programs and incentives are considered, such as drug counseling or cognitive aimed at reducing violence. Within the MaxII Structured Housing there are phases and incentives geared to transition the inmate to a less restrictive environment. Once sanction is completed, individual moves to structured, less restrictive housing and has opportunity to progress with out of cell activities in small group settings. As behavior dictates, he continues to progress (or regress) with available programming."

Massachusetts stated it was piloting "a step down unit in our largest medium security prison in November, 2017. It is a 90 day program targeting the criminogenic needs that originally created the pathway to RH. It is a dorm style housing unit so no one is locked in cells at all, just restricted privileges with a clear pathway back to general population."

As noted above, Minnesota related that prisoners "who have a history of staff or offender assault, or who have served more than 90 days in disciplinary segregation are evaluated for a step-down plan to general population."

Mississippi reported having a "High Risk Incentive Tier" that provided the opportunity for prisoners to "receive services and privileges as part of a program to encourage and promote good institutional behavior."

Missouri reported that it had not changed its policy but that several of its facilities had "created step-down or transition programs."

Montana stated that "step downs occur as inmates progress through a 6 level system where their privileges increase. Treatment programs are also coordinated through their case managers in association with the levels."

Nebraska explained it had "established several mission specific housing units which are alternatives to RH or act as a transition out of RH." 
Nevada described a "Behavior Modification Unit" "intended to transition an inmate from a segregation unit to one that is similar to general population. Placement in BMU provides the inmate with a period of adjustment to interact with staff and other inmates and work towards the development of proper social skills. Inmates who are still serving disciplinary sanctions and are within 30 days of the projected release date to the community are transferred to a BMU, depending on the inmates propensity for misconduct."

New Jersey reported: "Inmates placed in administrative segregation as a result of a sanction may be assigned to a SDU by a centralized committee for transition to GP or the community. The placement phases are Reception/Initial, Congregate and Extended Congregate. Therapeutic activity and services are available. A SDU committee will review and advance the inmate through each phase."

New Mexico described a four step program: "Step 1 Evaluation 30 days. Step 2 Self Accountability 90 days but if enhancements needed up to 240 days. Step 3 is Cultural Competency which is 120 days but up to 360 days with enhancements. Step 4 is reintegration with 120 days but up to 300 days with enhancements. For females step 1 is 15 days. Step 2 is 30 days. Step 3 is 45 days and Step 4 is 90 days. No enhancements with the females."

New York stated that, effective October 2016, "SHU Step-down to the Community Programs" were "established at Green Haven Correctional Facility ("Green Haven") and Wende Correctional Facility ("Wende") to provide re-entry programming to inmates who have been in a SHU cell for 60 days or more serving a SHU or keep lock sanction and who have a minimum of 45 days and a maximum of 60 days to release .... The program goal is to assist participants with the development of a comprehensive release plan, incorporating social skills practice, relapse prevention, family reintegration and employment readiness. Behavior modification and relapse prevention will be addressed by modalities such as identifying high-risk behaviors, emotional regulation exercises, social skills practice, discussing how to deal with fear and the feelings of others, and how to ask and respond to questions."

North Carolina related it had two step-down programs available: "the Therapeutic Diversion Units for those with a higher mental health acuity, and the Rehabilitative Diversion Unit. The inmates eligible for the RDU are close custody males over 21 years old, who have received a sanction of RH for Control Purposes for assaultive or violent infractions. This program takes a minimum of 13 months to complete, and incorporates three phases. In each phase, the step-down includes less restrictions and increased out-of-cell time and privileges, such as more options in canteen, increase in phone calls, movement throughout the facility and program opportunities such as high school equivalency. The first inmates to participate began $2 / 22 / 16$. The TDUs are intended to enhance the care and custody for individuals diagnosed with mental illness, decrease incidents involving violence and/or self-harm, decrease the need for placement in a restrictive housing setting and improve the quality of life for this population. The TDU assists individuals with mental illness in developing effective emotional regulation and self-management skills, understanding their symptom presentation and patterns, and helps prepare for re-entry into a less restrictive environment within the prison and ultimately successful transition to the community."

North Dakota's description of its step-down program is reported in the text above.

Ohio reported it had a "transition from Extended Restrictive Housing to General Population for 6 years." Ohio explained: "We have concluded that short-term Restrictive Housing does not need a mandatory step down, but we do have a hybrid sanctioning system where an inmate can be first placed in short-term Restrictive Housing and then stepped down into Limited Privilege Housing."

Oklahoma provided a detailed program of its piloted step-down program at Oklahoma State Penitentiary. The policy, adopted in September 2017, stated that the "purpose of Step-Down Programs are to provide inmates transferred to maximum security a safe and secure way to earn their return to lower security. Upon arrival, inmates will be evaluated to determine appropriate housing needs and assessed to identify their level of social functioning and motivation to change .... Step-Down Programs will be comprised of components that are designed to address criminal 
thinking and encourage pro-social behaviors. Programs will consist of four phases that are progressively less restrictive with Phase I being the most restrictive and Phase IV the least restrictive ...."

Pennsylvania also provided a detailed overview of its step-down unit and PORTAL program. That summary stated, that the "Department established a Positive Outcome Restructuring Through Assessments and Learning (PORTAL) program designed specifically to provide therapeutic programming, education, and socialization opportunities for individuals confined to a Level 5 (L-5) setting for extended periods. The goal of the program is to provide the skills necessary to gain recommendation for placement into a step down unit and return to general population .... After facility recommendation and approval by the Executive staff, the inmate will transfer to an approved institution to complete re-integration into general population. The program will use a progressive four-tiered phase system based on the inmate's adjustment and attainment of goals/objectives noted in his/her Individual Treatment Plan (ITP).”

South Carolina reported "The Step-Down Program is an incentive-based offender management program which creates a pathway for offenders to transition from Restrictive Housing. The Intensive Management Program is a one year program. And Restrictive Management Step-Down is a six month program for inmates in Security Detention, Disciplinary Detention or Short Term Detention."

Utah explained that prisoners in restrictive housing "must progress through the three phases of RH to reach completion. Each phase is 45 days and each phase has a corresponding program. The inmate must also remain discipline free to successfully complete the RH phases."

Washington stated that a "transition pod" had been "developed and implemented at the Monroe Correctional Complex (MCC) Intensive Management Unit (IMU). The transition pod allows for two offenders assigned to Maximum custody to be on the tier with each other without restraints on for several hours a day. The offenders are around custody staff on the tier without restraints as well."

${ }^{179}$ Those jurisdictions were Arkansas, Colorado, Illinois, Iowa, Massachusetts, Minnesota, Montana, North Carolina, Ohio, South Carolina, South Dakota, Utah, and Wisconsin.

${ }^{180}$ That jurisdiction was Montana.

181 That jurisdiction was North Carolina, which reported that "mentally ill inmates have a 30 day maximum as determined by the multidisciplinary team. This time can be extended if it is determined that the inmate poses a safety or security risk and RH is not considered detrimental to their health."

182 Those jurisdictions were Iowa, which reported "60 days DD maximum prior to moving through the programming"; Massachusetts, which reported "the maximum for our disciplinary unit is ten years. Short term, non-disciplinary segregation does not have a duration attached to it"; Minnesota, which reported a maximum of "90 days for disciplinary segregation"; and South Carolina, which reported that "Disciplinary Detention is a maximum of 60 days."

${ }^{183}$ Montana reported a total length of stay of 1.7 years in restrictive housing across all stages. Utah reported a 45 -day maximum for each of its three restrictive-housing stages. South Dakota reported shortening the maximum duration for two of its restrictive-housing stages, from 90 and 120 days to 60 and 90 days, respectively. South Dakota stated, "on March 7, 2017, changes were made in the duration for two levels in the administrative restrictive housing Level System. Level 2 was changed from 90 to 60 days and Level 4 was changed from 120 to 90 days. This change reduced the overall duration for the program to 360 days instead of 420 for those completing the program on a timely basis."

184 Those jurisdictions were Colorado, Illinois, Kentucky, and Ohio. Colorado reported that the "maximum durations for specific infractions/behavior" were "either up to 6 months or up to 12 months." Illinois reported that maximum "penalties per charge" had been "reduced," resulting in a reduction of "the total, maximum amount of restrictive 
housing time for all offenses by 107 months ( 8.9 years)," although there was "no maximum duration" to a prisoner's placement in restrictive housing if the prisoner received "continuous sanctions for separate incidents that would run consecutively." Kentucky reported that its "disciplinary penalty structure has been altered to reduce the amount of days to be issued per offense." Ohio reported a prisoner could "only be given a maximum of 29 days" in restrictive housing "for an individual offense," which was "the extent of authority any local official" had "to place an inmate into" restrictive housing. "In rare cases, an inmate can be housed" in restrictive housing "longer than 29 days for an investigation or pending classification action, but these must be reviewed by a higher authority."

185 Those jurisdictions were Wisconsin, which reported maximum durations on restrictive housing of up to "120 days without review" and "up to 360 days with review"; and South Carolina, which reported that "Security Detention" prisoners were "reviewed every 90 days to determine eligibility for removal from RHU."

186 Seeking Accreditation, AMERICAN CORRECTIONAL ASSOCIATION, available at http://www.aca.org/ ACA_Prod_IMIS/ACA_Member/Standards_and_Accreditation/Seeking_Accreditation_Home.aspx.

187 American Correctional Association, Manual of AcCreditation Policy \& Procedure 6, 9-10 (Mar. 15, 2017), available at $\mathrm{http}: / / \mathrm{www}$. aca.org/ACA_Prod_IMIS/docs/standards\%20and\%20accreditation/ALM-1-3_15_17Final.pdf.

\section{${ }^{188}$ ACA 2016 Restrictive Housing STANDARDS, supra note 21.}

${ }^{189} I d$. at 4. The ASCA-Liman Survey asked: "Has your jurisdiction reviewed its policies since then on restrictive housing?" "Does your jurisdiction rely on these standards to make policies?" We also asked about whether jurisdictions had implemented the ACA Standards regarding juveniles, pregnant women, and individuals diagnosed with serious mental illness and regarding the release of prisoners from restrictive housing directly into the community. We further sought to learn whether any other policies had been "revised in light of the 2016 ACA restrictive housing standards.”

${ }^{190}$ Forty-three jurisdictions responded to this question. The 36 jurisdictions that reported that they reviewed their policies since the release of the ACA Standards were Alabama, Arkansas, Colorado, Connecticut, Delaware, Georgia, Illinois, Iowa, Kansas, Kentucky, Louisiana, Maryland, Massachusetts, Minnesota, Mississippi, Missouri, Montana, Nebraska, Nevada, New Jersey, New Mexico, New York, North Carolina, North Dakota, Ohio, Oklahoma, Oregon, Pennsylvania, Rhode Island, South Dakota, Tennessee, Texas, Utah, Washington, Wisconsin, and Wyoming. Both Illinois and Nevada responded that they had not revised their policies since 2016. However, Illinois elaborated that in April 2017 it had worked "to institute changes to the Corrections' Administrative Codes, changing policies as related to discipline and restrictive housing." Similarly, Nevada reported that the "Nevada Legislature mandated that the NDOC evaluate its restrictive housing policies. The NDOC's leadership has also voluntarily instituted regulations and practices that are intended to improve the wellbeing of inmates and reduce the length of stay in prison." Nebraska reported that it would be reviewing its policies again by July 1, 2018 .

Of the 43 jurisdictions that responded, Arizona, Indiana, Missouri, and Utah reported that they were undergoing review of their restrictive housing policies in the fall of 2017, when the survey was underway. Missouri reported that it had not revised its policies since 2016 but that "this survey and revised 2016 ACA standards have provided guidance and are assisting the Missouri Department of Corrections in improving our automation, as well as policy changes related to restrictive housing. The department has established a team for this purpose and it is our intent that this team will be able to develop a policy that will put us better in compliance with the 2016 ACA standards." Utah likewise reported that it had not revised its policies since 2016 but that its "Division of Prison Operations" was working with the Vera Institute of Justice "to look at alternatives to segregation," and was "using NIC guidelines and reviewing ACA guidelines for comparison to NIC, and adjusting policy as necessary." In addition, Colorado noted it had piloted "the standards prior to implementation" and had since "codified all standards in policy." 
191 Those jurisdictions were Alabama, Arkansas, Colorado, Connecticut, Delaware, Indiana, Iowa, Kentucky, Maryland, Massachusetts, Minnesota, Montana, Nebraska, Nevada, New Mexico, New York, North Carolina, North Dakota, Ohio, Oklahoma, Oregon, Pennsylvania, South Dakota, Tennessee, and Wyoming.

192 Those jurisdictions were Illinois, Louisiana, Missouri, New Jersey, Rhode Island, Texas, Utah, Washington, and Wisconsin.

${ }^{193}$ Those jurisdictions were Alaska, Arizona, Georgia, Hawaii, Idaho, Kansas, Mississippi, and South Carolina. Of these eight, Georgia responded that it intended to rely on the ACA Standards in the future.

${ }^{194}$ ACA Standard 4-RH-0030, ACA 2016 ReSTRICTIVE Housing STANDARDS, supra note 21, at 35.

${ }^{195}$ Twenty jurisdictions of the 42 reported that they implemented the policy after the ACA Standards were issued. Those jurisdictions were Arkansas, Connecticut, Delaware, Idaho, Illinois, Indiana, Iowa, Maryland, Massachusetts, Minnesota, Nebraska, Nevada, New Jersey, New Mexico, New York, North Dakota, Ohio, South Dakota, Utah, and Wisconsin. Six jurisdictions reported that not releasing prisoners directly to the community from restrictive housing had been their policy prior to the ACA revisions. Those jurisdictions were Colorado, Georgia, Kentucky, Mississippi, Rhode Island, and Texas.

196 Those jurisdictions were Kansas, North Carolina, Oregon, Pennsylvania, and Washington. Alabama, Alaska, Arizona, Louisiana, Missouri, Montana, Oklahoma, South Carolina, Tennessee, and Wyoming reported that they had not implemented this Standard. Hawaii responded, "N/A."

${ }^{197}$ North Carolina reported that it had established two step-down units: a Rehabilitative Diversion Unit (RDU) and Therapeutic Diversion Units (TDUs). The RDU was for "close custody males over 21 years old who have received a sanction" of restrictive housing "for Control Purposes for assaultive or violent infractions. This program takes a minimum of 13 months to complete and incorporates three phases. In each phase, the step-down includes less restrictions and increased out-of-cell time and privileges, such as more options in canteen, increase in phone calls, movement throughout the facility and program opportunities such as high school equivalency." The TDUs were "intended to enhance the care and custody for individuals diagnosed with mental illness, decrease incidents involving violence and/or self-harm, decrease the need for placement in a restrictive housing setting and improve the quality of life for this population. The TDU assists individuals with mental illness in developing effective emotional regulation and self-management skills, understanding their symptom presentation and patterns, and helps prepare for re-entry into a less restrictive environment within the prison and ultimately successful transition to the community."

Oregon reported that it did its best to avoid directly releasing people from restrictive housing into the community but that "there are situations in which the safety of the individual or others would be compromised if he/she were removed from" restrictive housing "prior to release." Pennsylvania explained that this "policy was in place as part of" its January 2015 "Disability Rights Network settlement" with the Department of Corrections. Washington stated that it did its best to ensure prisoners transition back to general population before they are released to the community, but that there were "times and situations" where direct release to the community could not be avoided, such as when people in restrictive housing had six months or less remaining time in their sentences. In such cases, it focused "on ensuring all services that are available can be provided upon release, housing vouchers, medication, access to treatment, etc." Kansas reported that it had "addressed" this Standard "through practices" but had not made a corresponding "policy change."

Sixteen jurisdictions reported that they had not implemented this Standard. Those jurisdictions were Alaska, Arizona, Idaho, Louisiana, Minnesota, Missouri, Nebraska, New Mexico, Oklahoma, Rhode Island, South Carolina, South Dakota, Tennessee, Washington, Wisconsin, and Wyoming.

${ }^{198}$ ACA Standard 4-RH-0033, ACA 2016 ReSTRICTIVE Housing STANDARDS, supra note 21, at 9. 
${ }^{199}$ ACA Standard 4-RH-0031, id. at 36.

${ }^{200}$ Forty-one jurisdictions responded to this question. Twelve jurisdictions reported that they had implemented the Standard after the ACA Standards were issued. Those jurisdictions were Alabama, Arkansas, Connecticut, Delaware, Indiana, Iowa, Kentucky, Massachusetts, Montana, Nevada, North Dakota, and Utah. Nine jurisdictions indicated that it was their policy before the ACA Standards. Those jurisdictions were Colorado, Georgia, Kansas, Maryland, Mississippi, New Jersey, New York, Oregon, and Texas. Colorado explained that before "the 2016 ACA revisions all offenders with serious mental illness were removed from administrative segregation and placed in a Residential Treatment Program in January 2014. There have been no exceptions." Alabama reported that it had "substantially implemented this policy, with exceptions" but explained that "inmates diagnosed with serious mental illness have been removed from RH and are housed in a RTU. Additional MH staff are being hired."

201 Those jurisdictions were Illinois, North Carolina, Ohio, and Pennsylvania. Illinois reported involving mental health resources. It described notifying a mental health professional when placement in disciplinary restrictive housing was possible for a mentally ill prisoner. The mental health professional "reviews if the offender's mental health condition may have been a factor in the incident, or if placement in restrictive housing may be detrimental to the mental health. They may also make a recommendation as to the maximum amount of restrictive housing an offender may serve." North Carolina reported using extended restrictive housing as a safety measure when no alternative was available. North Carolina reported that it considered placement in a less-restrictive therapeutic diversion unit (TDU). It also reported taking into account whether confinement will have a "detrimental impact" on individuals with mental illness and that a "multidisciplinary team" reviewed placements of this population in restrictive housing every 30 days "to determine if continuation of RH is indicated based on safety and security factors." Ohio reported that it had "dramatically reduced" the use of extended restrictive housing for prisoners with serious mental illness. Pennsylvania stated that this "policy was in place as part of the Disability Rights Network settlement" with the Department of Corrections.

202 The data described in Section II of this report (discussing placement of those with serious mental illness in restrictive housing) relied on each jurisdiction's own definition of serious mental illness.

${ }^{203}$ ACA Standard 4-RH-00004, ACA 2016 Restrictive Housing STANDARDS, supra note 21, at 9.

${ }^{204}$ Eleven of these 22 jurisdictions implemented the policy after the ACA Standards were issued. Those jurisdictions were Arkansas, Colorado, Delaware, Indiana, New Jersey, New Mexico, North Carolina, Ohio, Pennsylvania, Washington, and Wisconsin. North Carolina explained that "Restrictive Housing was totally eliminated from this population effective June 2016," and that it had "a Youthful Offender Program" where prisoners under age 18 were "placed on Modified Housing when serious incidents occur." Washington explained that "WDOC has jurisdiction over individuals sentenced as adults. Those under age 18 sentenced as adults are managed by a different agency and will not come to our facilities until sometime after age 18. It is rare to have an individual come to a DOC facility while they are under age 18 for more than a short amount of time." Another 11 jurisdictions stated that this was their policy before 2016. Those jurisdictions were Connecticut, Georgia, Kansas, Mississippi, Montana, Nevada, New York, Oregon, South Dakota, Tennessee, and Texas.

205 Those jurisdictions were Minnesota and Oklahoma. Fifteen jurisdictions responded that they had not implemented this Standard. Those jurisdictions were Alabama, Alaska, Idaho, Illinois, Iowa, Kentucky, Louisiana, Massachusetts, Missouri, Nebraska, North Dakota, Rhode Island, South Carolina, Utah, and Wyoming. Idaho explained that its draft revised policies, to be implemented in the summer of 2018, would prevent placement of individuals under 18 years old in restrictive housing.

Oklahoma reported that, "consistent with PREA standards, specific facilities and housing units within these facilities have been designated for inmates under 18 years of age." Minnesota reported a seven-day maximum duration 
for juveniles in disciplinary restrictive housing, except "for offenders who continue to assault staff," and explained that "offenders under 18 housed in adult facilities participate in incentive programs to deter disruptive behavior."

${ }^{206}$ ACA 2016 ReSTRICTIVE Housing STANDARDS, supra note 21, at 3. The survey results regarding the placement of pregnant prisoners in restrictive housing are discussed in Section II of this Report.

${ }^{207}$ Seventeen jurisdictions said they had implemented the policy after the ACA Standards were issued. Those jurisdictions were Alabama, Arkansas, Delaware, Indiana, Iowa, Kentucky, Maryland, Massachusetts, Minnesota, Nevada, New Mexico, North Carolina, Ohio, Oregon, Pennsylvania, Tennessee, and Wyoming. Eight jurisdictions reported that this was their policy before 2016. Those jurisdictions were Colorado ("CDOC does not have Extended Restrictive Housing for female offenders and does not have restrictive housing for any female offenders."), Connecticut, Georgia, Idaho, Mississippi, New York, Oklahoma, and Texas.

208 Those jurisdictions were Illinois, New Jersey, South Dakota, and Washington. Among these four jurisdictions that had "substantially implemented this policy, with exceptions," South Dakota reported that it complied with this Standard in practice and was currently revising its written policy accordingly. Illinois responded that "medical conditions of offenders shall be considered at the time of the committing offense." Two jurisdictions explained that, in "rare" or "extreme" cases, placement of a pregnant prisoner in restrictive housing was necessary for safety reasons: New Jersey reported that it "prohibits" the placement of pregnant prisoners in administrative segregation but that "in extreme cases an inmate who is pregnant, is postpartum, recently had a miscarriage, or recently had a terminated pregnancy may be placed in MCU [the Management Control Unit] for repeated infractions." At the time of the survey, New Jersey reported that no pregnant women were in its MCU. Washington reported that in "very rare situations, a woman who is pregnant, is postpartum, recently had a miscarriage, or recently had a terminated pregnancy may be placed in restrictive housing as a temporary response to behavior that poses a serious and immediate risk of physical harm." Washington reported that procedural safeguards were involved when a pregnant or recently-pregnant woman was placed in restrictive housing: "this decision must be approved by the agency's senior official overseeing women's programs and services, in consultation with senior officials in health services, and must be reviewed every 24 hours."

Twelve jurisdictions indicated that they had not implemented this Standard. Those jurisdictions were Alaska, Arizona, Kansas, Louisiana, Missouri, Montana, Nebraska, North Dakota, Rhode Island, South Carolina, Utah, and Wisconsin.

We also asked jurisdictions to describe any other changes to their restrictive-housing policies in light of the revised ACA Standards. Nine of 20 jurisdictions that responded to the question indicated that they had or were in the process of doing so. Those jurisdictions were Arkansas, Colorado, Maryland, Montana, Ohio, Oregon, Pennsylvania, Utah, and Wisconsin. Three jurisdictions of the nine reported additional broad policy changes. Arkansas had "made changes to our Protective Custody, Disciplinary Court Review, Punitive-Segregation Policies as well as our Inmate Disciplinary Manual." Colorado had updated 16 department policies: 100-19 Communication with Offenders, 100-40 Prison Rape Elimination Procedure, 300-01 Offender Visiting Program, 500-02 Library Services, 550-11 Offender Release, 600-01 Offender Classification, 600-09 Management of Close Custody Offenders, 700-03 Mental Health Scope of Service, 700-29 Mental Health Interventions, 750-01 Legal Access, 850-10 Emergency Notification, 850-12 Telephone Regulations for Offenders, 850-07 Offender Reception and Orientation 1, 000-01 Recreation and Hobby Work 1, 350-02 Victim Notification Program 1, and 550-02 Food Service Menu Planning and Service. Ohio had "updated over 30 policies, including medical, mental health, classification, special management, recreation, education, business, Reentry, Health and Safety, Unit Management, Security, and a myriad of other policies." Montana reported structural changes to its restrictive-housing system: "Our special management policy has been changed and our classification policy has been changed as we used to have Administrative segregation for long term and then Max custody for our extended stay in segregation. Now all are under the Maximum custody following a 6-level system." 
${ }^{209}$ Fourteen jurisdictions responded to this question. The jurisdictions that reported new or changed data collection practices were Arizona, Delaware, Hawaii, Kentucky, Massachusetts, Minnesota, Nebraska, New Jersey, New Mexico, North Dakota, Ohio, Oregon, South Carolina, and Washington.

210 Those jurisdictions were Arkansas, Iowa, Kentucky, Maryland, Massachusetts, Minnesota, Nebraska, New Mexico, and Washington.

${ }^{211}$ Those jurisdictions were Arizona, Iowa, Kentucky, Maryland, Massachusetts, and Washington.

${ }^{212}$ Those jurisdictions were Arkansas, Iowa, and Washington.

${ }^{213}$ Those jurisdictions were Arizona, Arkansas, Iowa, Massachusetts, and Washington.

${ }^{214}$ Those jurisdictions were Iowa, Kentucky, Massachusetts, Nebraska, Nevada, and Washington.

215 Those jurisdictions were Arizona, Arkansas, Iowa, Kentucky, Nebraska, and Washington.

216 Those jurisdictions were Delaware, Iowa, Kentucky, Nebraska, Nevada, Washington, and Wisconsin.

${ }^{217}$ Those jurisdictions were Iowa and Wisconsin.

${ }^{218}$ Those jurisdictions were Alabama, Delaware, Nebraska, and Washington. Of these four, Nebraska referenced a "new data system effective November 2017" that was "tracking a number of metrics" but that had not yet yielded "reportable data." Washington reported that it "has started to evaluate the effectiveness of congregate classroom programming within restricted housing." Delaware explained that, pursuant to a settlement agreement, it would for the next five years conduct monthly audits of the "number of inmates" in restrictive housing and of "demographics and out of cell data (structured and unstructured), disciplinary info, and mental health status for that population."

${ }^{219}$ That jurisdiction was Oregon.

${ }^{220}$ That jurisdiction was Arizona.

${ }^{221}$ That jurisdiction was North Dakota.

${ }^{222}$ The jurisdiction was Arizona, which referred to Travis J. Meyers, Arynn Infante \& Kevin Wright, Addressing Serious Violent Misconduct in Prison: Examining an Alternative Form of Restrictive Housing, _ INT'L J. OFFENDER THERAPY \& COMP. CRIMINOLOGY 1, 1 (2018). The article described its focus as "the future behavioral and mental health outcomes associated with completing an alternative approach to restrictive housing in the Arizona Department of Corrections." Id.

Other efforts to study the impact of changes were reported to be underway in Nebraska (reporting that it had redesigned its "housing data system" to be able to track individuals and what happened to them); Nevada (a study of "length of stay in prison due to a reduction in credits forfeited"); and Washington (indicating that it had "started to evaluate the effectiveness of congregate classroom programming within restricted housing").

${ }^{223}$ That jurisdiction was Utah.

${ }^{224}$ The question was open-ended: "In an ideal situation (i.e., if you had the necessary resources, and if you could do so consistent with institutional safety), what number of hours out-of-cell do you believe is desirable for prisoners?" The question did not direct jurisdictions to respond in hours per day or hours per week; nor did it ask about the ways in which time out-of-cell should be spent. Answers therefore varied, with some jurisdictions measuring time in hours per day and others in hours per week, and with some jurisdictions providing information on the way in which they believed prisoners should spend time out-of-cell. 
${ }^{225}$ The jurisdictions that responded to this question were Alabama, Alaska, Arizona, Arkansas, Colorado, Connecticut, Delaware, Hawaii, Idaho, Illinois, Indiana, Iowa, Kansas, Kentucky, Louisiana, Maryland, Massachusetts, Minnesota, Missouri, Montana, Nebraska, Nevada, New Jersey, New Mexico, New York, North Carolina, North Dakota, Ohio, Oklahoma, Oregon, Pennsylvania, Rhode Island, South Dakota, Tennessee, Texas, Utah, Wisconsin, and Wyoming.

${ }^{226}$ The jurisdictions that specified a certain number of hours were Alabama, Alaska, Arizona, Arkansas, Delaware, Hawaii, Idaho, Illinois, Indiana, Iowa, Kansas, Kentucky, Louisiana, Maryland, Massachusetts, Minnesota, Missouri, Montana, New Mexico, New York, North Carolina, North Dakota, Oklahoma, Oregon, Pennsylvania, Rhode Island, Tennessee, Texas, Utah, Wisconsin, and Wyoming.

${ }^{227}$ Some of the jurisdictions that provided a certain number of hours did not specify whether this was measured as hours per day or hours per week, and the measurement could not be determined from the answer. The jurisdictions for which the measurement was unclear were Alaska, Iowa, Kansas, Louisiana, Massachusetts, Montana, New Mexico, Texas, and Wyoming.

${ }^{228}$ That jurisdiction was Pennsylvania, which responded that, at a minimum, three hours per day would be desirable.

${ }^{229}$ Those jurisdictions were North Carolina and Idaho. North Carolina responded 15-16 hours per day would be desirable. Idaho responded 16 hours per day would be desirable.

${ }^{230}$ That jurisdiction, Arizona, specified a three-step system: "Step $1=7.5$ hours, Step $2=8.5$ hours, and Step $3=9.5$ hours per week. Inmates classified as SMI minimally offered 20 hours in out of cell time per week."

${ }^{231}$ That jurisdiction was Illinois.

${ }^{232}$ Those jurisdictions were Alabama, Arizona, and Maryland.

233 That jurisdiction was Maryland, which stated: "General Population-minimum of 12 hours daily; Disciplinary Segregation-2 hours daily; Administrative Segregation-minimum of 3 hours daily; Maximum Security General Population-minimum of 8 hours daily."

${ }^{234}$ Those jurisdictions were Alabama, Colorado, Delaware, Minnesota, Nebraska, Nevada, New Jersey, New York, North Carolina, and North Dakota.

235 That jurisdiction was Minnesota.

236 That jurisdiction was Nevada.

${ }^{237}$ That jurisdiction was Nevada.

${ }^{238}$ This response came from New York, which further explained: "The most desirable program would consist of 2 hours AM programming, 2 hours PM programming and an additional 2 hours exercise, with an incentive-based option to earn more and/or congregate recreation. This has worked well for us in our current SHU Alternative and Mental Health programs."

${ }^{239}$ Those jurisdictions were Colorado, Connecticut, Nebraska, New Jersey, Ohio, and South Dakota.

${ }^{240}$ That jurisdiction was Ohio. In response to this question, South Dakota stated that "the amount of out of cell time considered ideal varies by custody levels, housing type and arrangement, work and programming, and other out of cell activities so it is not possible for us to respond to this question."

${ }^{241}$ For example, the Vera Institute of Justice, with the "support of the National Institute of Justice, and in collaboration with the University of North Carolina School of Social Work and Oregon Health and Science University" has 
undertaken a multi-year study in prisons in Oregon, North Carolina, and Missouri to "assess the impact of working in restrictive housing on correctional officers' mental, emotional, and physical wellbeing." See https://www.vera.org/projects/restrictive-housing-impact-officer-wellbeing/overview.

Vera also has a "Safe Alternatives to Segregation Initiative," and has worked on ways to reduce the use of segregation at "16 jurisdictions in total." See https://www.safealternativestosegregation.org/. As of the spring of 2018, Vera had projects in Louisiana, Minnesota, Nevada, Utah, and Virginia. Vera reported reductions in populations in restrictive housing in several sites, including over 85\% in New York City; about 50\% in Middlesex County, NJ; 27\% in North Carolina; and $11 \%$ in Nebraska. See https://www.vera.org/rethinking-restrictive-housing\#where-are-theynow.

242 Thirty jurisdictions reported tracking in 2013 the numbers of individuals released directly to the community. Among those jurisdictions reporting, 4,400 people were released from administrative segregation to their communities. ASCA-LimAn AdMINISTRATIVE SEgREgATION 2014, supra note 6, at 29. See also Christie Thompson, From Solitary to the Street: What Happens when Prisoners Go from Complete Isolation to Complete Freedom in a Day?, The Marshall PROJeCt, June 11, 2015, available at https://www.themarshallproject.org/ 2015/06/11/fromsolitary-to-the-street.

243 Vera Rethinking Restrictive Housing 2018, supra note 27, at 10. Reports on the Findings and Recommendations specific to each site are available at https://www.vera.org /publications/safe-alternativessegregation-initiative-findings-recommendations. Vera is currently working with additional states including Louisiana, Minnesota, Nevada, Utah, and Virginia.

${ }^{244}$ ASCA-LiMAN ADMINISTRATIVE SEGREGATION NATIONAL OVERVIEW 2013, supra note 3.

${ }^{245} I d$. at $4-5,11$.

246 ASCA-Liman Administrative SEgREgation 2014, supra note 6; ASCA-LimAn AIMING to RedUCE TIME-INCELL 2016, supra note 13.

${ }^{247}$ VERA RETHINKING ReSTRICTIVE HOUSING 2018, supra note 27, at 14.

${ }^{248} I d$. at 15

${ }^{249} I d$. at 17.

${ }^{250} I d$. at $18-19$.

${ }^{251} I d$. at 21.

252 See ASCA-Liman Aiming to RedUCE Time-IN-Cell 2016, supra note 13, at 49. Among 34 jurisdictions providing data in 2016, 5,146 male prisoners with serious mental health issues were held in restrictive housing, and among 32 jurisdictions providing data on female prisoners in 2016, 297 female prisoners with serious mental health issues were held in restrictive housing. See also Section II, Subpopulations, Prisoners with Mental Health Issues.

${ }^{253}$ See Section II, The Demographics of Restrictive Housing, Race and Ethnicity. As noted there, among the 34 reporting jurisdictions, Black male prisoners comprised $45.7 \%$ of the restrictive housing populations and $42.3 \%$ of the total male custodial population. In 29 of the 34 jurisdictions, the male restrictive housing population contained a smaller percentage of White prisoners than in the total male custodial population. Among the 29 jurisdictions reporting numbers on women, Black female prisoners comprised $38.6 \%$ of the restrictive housing population and $22.6 \%$ of the total custodial population. In 21 of the 29 jurisdictions, the female restrictive housing population contained a smaller percentage of White prisoners than the total female custodial population. 
${ }^{254}$ VERA RETHINKING RESTRICTIVE HOUSING 2018, supra note 27, at 23.

${ }^{255} I d$. at 24 .

${ }^{256} I d$. at 25 .

${ }^{257}$ Thirty jurisdictions reported that 4,400 people were released from administrative segregation directly to their communities. ASCA-LimAn ADMINISTRATIVE SEGREGATION 2014, supra note 6, at 29.

${ }^{258}$ Vera identified 348 people in Oregon and 1,892 people in North Carolina released from restrictive housing directly to the community. Vera RethinKING Restrictive Housing 2018, supra note 27, at 28.

${ }^{259} I d$. at $28-29$.

${ }^{260} I d$. at 8.

${ }^{261} I d$. at 29.

${ }^{262} I d$. at 30.

${ }^{263} I d$. at 34 .

${ }^{264} I d$. at $38-39$.

26560 Minutes, Reforming Solitary Confinement at an Infamous California Prison, Jul. 22, 2018, https://www.cbsnews.com/news/60-minutes-reforming-solitary-confinement-at-an-infamous-california-prison/.

${ }^{266}$ Cheryl Corley, North Dakota Prison Officials Think Outside the Box to Revamp Solitary Confinement, Morning Edition, NPR, Jul. 31 2018, available at https://www.npr.org/2018/07/31/630602624/north-dakota-prison-officialsthink-outside-the-box-to-revamp-solitary-confineme.

${ }^{267}$ Dashka Slater, North Dakota's Norway Experiment: Can Humane Prisons Work in America? A Red State Aims to Find Out, Mother Jones, July/Aug. 2017, available at https://www.motherjones.com/crime-justice/2017/07/northdakota-norway-prisons-experiment/.

${ }^{268}$ Rick Raemisch, Why We Ended Long-Term Solitary Confinement in Colorado, New York Times, Oct. 12 2017, available at https://www.nytimes.com/2017/10/12/opinion/solitary-confinement-colorado-prison.html.

${ }^{269}$ Oregon Prisons Cut Use of Solitary Confinement, KTVZ.COM, available at https://www.ktvz.com/news/oregonprisons-cut-use-of-solitary-confinement/746191882.

${ }^{270}$ Keri Blakinger, Texas Prisons Eliminate Use of Solitary Confinement for Punitive Reasons, Houston Chronicle, Sep. 21 2017, available at https://www.houstonchronicle.com/news/houston-texas/houston/article/Texas-prisonseliminate-use-of-solitary-12219437.php.

${ }^{271}$ See Craig Haney, Restricting the Use of Solitary Confinement, 1 Ann. Rev. CRIMINOLOGy 285, 298 (2018), available at https://www.annualreviews.org/doi/pdf/10.1146/annurev-criminol-032317-092326. In his view, the "research consistently documents and details the risk of psychological harm that social isolation creates, including mental pain and suffering and the increased incidence of self-harm and suicide."

272 American Psychological Association, Letter to Senator Booker, June 8, 2017, available at https://www.apa.org/advocacy/criminal-justice/juvenile-solitary-confinement.pdf. 
${ }^{273}$ Cyrus Ahalt, Craig Haney, Sarah Rios, Matthew P. Fox, David Farabee \& Brie Williams, Reducing the Use and Impact of Solitary Confinement in Corrections, 13 InTERnATIONAL JouRnal OF PRISONER HEALTH 41, 43 (2017) (citing Carla M. Perissinotto, Irena Stijacic Cenzer \& Kenneth E. Covinsky, Loneliness in Older Persons: A Predictor of Functional Decline and Death, 172 ARCHIVES OF INTERNAL MEDICINE, 1078-83 (2012); BRIE A. WiLLIAMS, ANNA Change, Cyrus Ahalt, Helen Chen, rebecca Conant, C. Seth landefeld, Christine Ritchie \& Michi Yukawa, Current Diagnosis \& Treatment: Geriatrics, 2E (2014); Brie A. Williams, Older Prisoners and the Physical Health Effects of Solitary Confinement, 106 AmEriCAN Journal OF PUBlic Health, 2126-2127 (2016)).

${ }^{274}$ American Civil Liberties Union, Caged In: Solitary Confinement's Devastating Harm on People with Physical Disabilities (2017), available at https://www.aclu.org/sites/default/files/field_document/010916-aclusolitarydisabilityreport-single.pdf.

${ }^{275} I d$. at 7, Table 1.

${ }^{276} I d$. at 12 .

${ }^{277}$ Id. at $10,28-34,35-39$.

${ }^{278} I d$. at $4,28-35$.

${ }^{279} I d$. at 9.

28042 U.S.C. § 12101 et seq.; 29 U.S.C. § 794.

${ }^{281}$ See, e.g., Dunn v. Dunn, 318 F.R.D. 652 (M.D. Ala. 2016); Pierce v. District of Columbia, 128 F. Supp. 3d 250 (D.D.C. 2015).

282 American Psychiatric Association, Position Statement on Segregation of Prisoners with Mental Illness (2012), available at http://www.dhcs.ca.gov/services/MH/Documents/2013_04_AC_06c_APA_ps2012_PrizSeg.pdf.

283 Committee on Causes and Consequences of High Rates of Incarceration, The Growth of InCARCERATION IN THE United States: ExPloRing CAUSES AND CONSEQuences 201 (Jeremy Travis, Bruce Western, and Steve Redburn eds.) (2014).

${ }^{284}$ See National Commission Correctional Health Care, Position Statement, Solitary Confinement (Isolation), adopted April 2016, available at https://www.ncchc.org/filebin/Positions/Solitary-Confinement-Isolation.pdf.

${ }^{285} I d$. at 4 , principle 1.

${ }^{286} I d$. at 4 , principle 3.

${ }^{287} I d$. at 4, principle 5.

${ }^{288} I d$. at 4, principle 9.

${ }^{289} I d$. at 5, principle 15.

${ }^{290}$ Robert Morgan, Paul Gendreau, Paula Smith, Andrew Gray, Ryan Labrecque, Nina MacLean, Stephanie Van Horn, Angelea Bolanos, Ashley Batastini \& Jeremy Mills, Quantitative Synthesis of the Effects of Administrative Segregation on Inmates' Well-Being, 22 PsYCHOLOGY, Public POLICY, AND LAW 439, 455 (2016). A central reference in this essay was a study, O'Keefe, Maureen, Kelli Klebe, Alysha Stucker, Kristin Sturm \& William Leggett, One Year Longitudinal Study of the Psychological Effects of Administrative Segregation, Final Report to the National Institute of Justice, US Department of Justice, National Institute of Justice (2010). 
${ }^{291}$ See Craig Haney, The Psychological Effects of Solitary Confinement: A Systemic Critique, 47 CRIME AND JUSTICE 365, 399-402 (2018). This essay noted that the 2016 discussion, which described doing a synthesis, did not include a fair representation of studies finding that solitary confinement caused serious psychological harms.

${ }^{292}$ Id. at $402-07$.

${ }^{293}$ Id. at 378-98.

${ }^{294} I d$. at 372.

295 Terry Kupers, The SHU-Post Release Syndrome: A Preliminary Report, 17 CoRreCtional Mental Health REPORT 81 (2016), available at https://www.civicresearchinstitute.com/online/article_abstract.php?pid=14 \&iid=1172\&aid=7652. See generally TERRY ALLEN KUPERS, SOLITARY: THE INSIDE STORY OF SUPERMAX ISOLATION AND How WE CAN ABOLISH IT (2017). These findings parallel those of a 2018 report, Human Rights in Trauma Mental Health Lab, Stanford University, Mental Health Consequences Following Release from Long-Term Solitary Confinement in California, available at https://handacenter.stanford.edu/sites/default/files/publications/ mental_health_consequences_following_release_from_long-term_solitary_confinement_in_california.pdf

[hereinafter Mental Health Consequences in California]. This study concerned the mental health consequences of long-term solitary confinement, and was conducted by Stanford University's Human Rights in Trauma Mental Health Laboratory, working at the behest of the Center for Constitutional Rights, which represented a class of California prisoners held in isolation. See Ashker v. The Governor of California, 09-CV-05796-CW (N.D. Cal. 2009). After interviewing individuals, the Lab concluded that the men "experienced severe psychological disturbances with lasting detrimental consequences," with the most common responses to isolation being "emotional numbing and desensitization," which continued "to be problematic for prisoners following the transition to the general population." Mental Health Consequences in California at 2.

${ }^{296}$ Research in animals has raised concerns that isolation results in brain wave and behavioral changes. See Huda Akil, Panel on Solitary Confinement: Legal, Clinical, and Neurobiological Perspectives, American Association for the Advancement of Science 2014 Annual Meeting, Feb. 14, 2014, https://thinkprogress.org/solitary-confinement- maydramatically-alter-brain-shape-in-just-days-neuroscientist-says-ae939f8e7685/. See also Michael Zigmond \& Richard Jay Smeyne, Neurobiological Effects of Isolation: Historical and Current Perspectives, in Solitary Confinement: Effects, Practices and Pathways Towards Reform (Jules Lobel \& Peter Scharff Smith eds., Oxford University Press, forthcoming 2018).

${ }^{297}$ Fatos Kaba, Andrea Lewis, Sarah Glowa-Kollisch, James Hadler, David Lee, Howard Alper, Daniel Selling, Ross MacDonald, Angela Solimo, Amanda Parsons \& Homer Venters, Solitary Confinement and Risk of Self-Harm Among Jail Inmates, 104 AmERICAN JouRnAl OF PUBliC HEALTH 442 (2014).

${ }^{298}$ Brian O. Hagan, Emily A. Wang, Jenerius A. Aminawung, Carmen E. Albizu-Garcia, Nickolas Zaller, Sylviah Nyamu, Shira Shavit, Joseph Deluca \& Aaron D. Fox, History of Solitary Confinement Is Associated with PostTraumatic Stress Disorder Symptoms among Individuals Recently Released from Prison, 95 JOURNAL OF URBAN HEALTH 141 (2018).

${ }^{299}$ Valerie Clark \& Grant Duwe, The Effects of Restrictive Housing on Recidivism, Minnesota Department of Corrections, December 2017, available at https://mn.gov/doc/assets/Effects\%20of\%20Restrictive\%20Housing\% 20on\%20Recidivism_tcm1089-320093.pdf.

${ }^{300} I d$. at 10.

${ }^{301} I d$. at 4. 
${ }^{302} I d$.

${ }^{303}$ Id. at 23. Minnesota reported that the Justice Research and Statistics Association (JRSA) awarded the study its Excellence in Research/Policy Award in 2018.

${ }^{304}$ See 2017 Hawaii Senate Bill No. 2859, Hawaii Twenty-Ninth Legislature - Regular Session of 2018 [hereinafter Hawaii Senate Bill 2859]. Section 1(b)(2) of the bill would require that "on every third day, or sooner, following initial placement in administrative segregation, the facility program committee shall hold a hearing to determine if continued placement in administrative segregation is warranted." Section $\S 1$ (c)(2) would require that "on every tenth day, or sooner, of disciplinary segregation, an adjustment committee shall hold a hearing and any recommendations to extend the disciplinary segregation shall be approved by the institutions division administrator, medical director, and staff psychiatrist." See also 2018 New Jersey Assembly Bill No. 314, New Jersey Two Hundred Eighteenth Legislature First Annual Session [hereinafter New Jersey Assembly Bill 314]. Section 4a(4) of the bill would require that, with exceptions for lockdown, "an inmate shall only be held in isolated confinement pursuant to initial procedures and reviews which provide timely, fair and meaningful opportunities for the inmate to contest the confinement. These procedures shall include the right to an initial hearing within 72 hours of placement and a review every 15 days thereafter, in the absence of exceptional circumstances, unavoidable delays, or reasonable postponements; the right to appear at the hearing; the right to be represented at the hearing; an independent hearing officer; and a written statement of reasons for the decision made at the hearing." See also 2018 Virginia House Bill No. 795, Virginia 2018 Regular Session [hereinafter Virginia House Bill 795]. Section 53.1-39.1(F) of the bill would provide that "the Department shall create an administrative process by which an inmate may contest his isolated confinement within 72 hours of being placed in isolated confinement. The process shall include a hearing before an independent hearing officer. The inmate shall have the right to appear at the hearing, present evidence, and be represented by counsel."

305 See, e.g., 2017 Nebraska Legislative Bill No. 560, Nebraska One Hundred Fifth Legislature - First Regular Session [hereinafter Nebraska Legislative Bill 560]. Section Four of the bill would provide that:

The director shall issue an annual report on or before September 15 to the Governor and the Clerk of the Legislature .... For all inmates who were held in restrictive housing during the prior year, the report shall contain the race, gender, age, and length of time each inmate has continuously been held in restrictive housing. The report shall also contain: (a) The number of inmates held in restrictive housing; (b) The reason or reasons each inmate was held in restrictive housing; (c) The number of inmates held in restrictive housing who have been diagnosed with a mental illness or behavioral disorder and the type of mental illness or behavioral disorder by inmate; (d) The number of inmates who were released from restrictive housing directly to parole or into the general public and the reason for such release; (e) The number of inmates who were released from restrictive housing based upon an order of a district judge under subsection (2) of section 83-173.03; (f) The number of inmates who were placed in restrictive housing for his or her own safety and the underlying circumstances for each placement; (g) To the extent reasonably ascertainable, comparable statistics for the nation and each of the states that border Nebraska pertaining to subdivisions (4)(a) through (f) of this section; and (h) The mean and median length of time for all inmates held in restrictive housing.

See also New Jersey Assembly Bill 314, supra note 304. Section 7(e) would

Requir[e] posting on the official website of the Department of Corrections of quarterly reports on the use of isolated confinement, by age, sex, gender identity, ethnicity, incidence of mental illness, and type of confinement status, at each facility, including a county correctional facility; these reports shall include the population on the last day of each quarter and a non-duplicative cumulative count of people exposed to isolated confinement for each fiscal year. These inmate reports also shall include the incidence of emergency confinement, self-harm, suicide, and assault in any isolated confinement unit, as well as explanations for each instance of facility-wide lockdown. 
See also 2017 New York Senate Bill No. 4784, New York Two Hundred Fortieth Legislative Session [hereinafter New York Senate Bill 4784]. Section 4(n) would require that:

The department shall make publicly available monthly reports of the number of people as of the first day of each month, and semi-annual and annual cumulative reports of the total number of people, who are (i) in segregated confinement; and (ii) in residential rehabilitation units; along with a breakdown of the number of people (iii) in segregated confinement and (iv) in residential rehabilitation units by (A) age; (B) race; (C) gender; (D) mental health level; (E) health status; (F) drug addiction status; (G) pregnancy status; (H) lesbian, gay, bisexual, transgender, or intersex status; and (I) total continuous length of stay, and total length of stay in the past sixty days, in segregated confinement or a residential rehabilitation unit.

The New York legislature passed the bill, which is awaiting signature by the governor. See also Virginia House Bill 795, supra note 304. Section 53.1-39.1 (H) would require that:

The Department shall report to the Governor and the General Assembly on or before June 30 and December 31 of each year the following information: 1 . The total prison population; 2 . The number of inmates who have been placed in isolated confinement and the age, sex, gender identity, and ethnicity of such inmates; 3 . The number of inmates who are a member of a vulnerable population who have been placed in isolated confinement and the category of vulnerable population of such inmates; 4 . The average length and median length of isolated confinement for (i) inmates placed in isolated confinement and (ii) inmates who are a member of a vulnerable population who have been placed in isolated confinement, calculated for each category of vulnerable population; 5 . The number of inmates who have been placed in isolated confinement who have attempted to harm themselves or others; and 6. The number of inmates who have been placed in isolated confinement who have been released from the correctional facility while placed in isolated confinement.

${ }^{306}$ CRIMES AND OfFEnSES, 2018 Mass. Legis. Serv. Ch. 69 (S.B. 2371) [hereinafter CRIMES AND OfFENSES].

307 New York Senate Bill 4784, supra note 305, § 4(h) would prohibit holding any person "in segregated confinement for longer than necessary and never more than fifteen consecutive days nor twenty total days within any sixty day period. At these limits, persons must be released from segregated confinement or diverted to a separate secure residential rehabilitation unit." Section 4(j)(iv) provides "No person may be held in segregated confinement for protective custody."

${ }^{308}$ Hawaii Senate Bill 2859, supra note 304. One facet of the proposal would limit the "the maximum length of time" a prisoner could be held in administrative segregation to no more than 14 days in any 30 day period. Id. at $\S 1$ (b)(1). Another provision would limit placement in disciplinary segregation to no more than 60 days in 180. Id. at $\S 1$ (c)(1). Both provisions would require oversight with hearings, for administrative segregation on every third day, and for disciplinary segregation, on every tenth day. Id. at $\S 1(\mathrm{~b})(2), \S 1(\mathrm{c})(2)$. Extensions of time for disciplinary segregation would require approval by "the institutions division administrator, medical director, and staff psychiatrist." Id. at $\S$ $1(\mathrm{c})(1)$.

${ }^{309}$ Nebraska Legislative Bill 560, supra note 305, § 4(3) provides that "no person shall be placed in solitary confinement," which is defined as confinement to cell for an average of 22 or more hours per day. Section 3(1) limits the use of restrictive housing, defined as confinement that provides limited contact with other offenders, strictly controlled movement while out-of-cell, and out-of-cell time less than 24 hours per week, such that "no inmate shall be held in restrictive housing unless done in the least restrictive manner consistent with maintaining order in the facility and pursuant to rules and regulations adopted and promulgated by the department pursuant to the Administrative Procedure Act." Section 2(2) would provide for a review process by the district court for any prisoner placed in restrictive housing for 90 days. The bill is set to be reintroduced in 2019. 
${ }^{310}$ New Jersey Assembly Bill 314, supra note 304, places limitations on the use of "isolated confinement," defined as "confinement of an inmate in a correctional facility, pursuant to disciplinary, administrative, protective, investigative, medical, or other classification, in a cell or similarly confined holding or living space, alone or with other inmates, for approximately 20 hours or more per day with severely restricted activity, movement, and social interaction." Section 4.a(1) provides that "an inmate shall not be placed in isolated confinement unless there is reasonable cause to believe that the inmate would create a substantial risk of immediate serious harm to himself or another, as evidenced by recent threats or conduct, and a less restrictive intervention would be insufficient to reduce this risk." Section 4.a (2) prohibits placing a prisoner "in isolated confinement for non-disciplinary reasons," with exceptions for facility-wide lockdowns, emergency confinement, medical isolation, and protective custody.

${ }^{311}$ Virginia House Bill 795, supra note 304, § 53.1-39.1(A) defines isolated confinement as "confinement of an inmate to his cell for more than 20 hours per day" and $\S 53.1-39.1$ (B) provides that "an inmate who is not a member of a vulnerable population shall not be placed in isolated confinement for longer than 15 consecutive days or in excess of 20 days in any 60-day period." Section 53.1-39.1(F) requires the Department of Corrections to "create an administrative process by which an inmate may contest his isolated confinement within 72 hours of being placed in confinement," and Section 53.1-39.1(D) requires a "comprehensive medical and mental health evaluation conducted by a medical professional within 12 hours of confinement."

3122017 U.S. Congress S. 2724, 115th CONGRESS, 2nd Session.

${ }^{313}$ CRIMES AND OFFENSES, supra note 306, at $\S 93 \mathrm{f}$.

${ }^{314} I d$. at $\S 39 \mathrm{~A}(\mathrm{~b})$.

${ }^{315} I d$. at $\S 39 \mathrm{~A}(\mathrm{~b})$.

${ }^{316} I d$. at $\S 39 \mathrm{~B}$ : “(a) All prisoners confined to restrictive housing shall receive placement reviews at the following intervals, and may receive them more frequently, if a prisoner: (i) is being confined to restrictive housing pursuant to subsection (a) of section 39A, every 72 hours; (ii) is being confined to restrictive housing pursuant to subsection (b) of section 39A, every 72 hours; (iii) is awaiting adjudication of an alleged disciplinary breach, every 15 days;(iv) has been committed to disciplinary restrictive housing, not later than 6 months and every 90 days thereafter; and (v) is being held for any other reason, every 90 days."

317 The committee is to include "the secretary of the executive office of public safety and security or a designee, who shall serve as chair; the commissioner of the department of correction or a designee; the commissioner of mental health or a designee; and 9 members to be appointed by the governor, 1 of whom shall be a correctional administrator with expertise in prison discipline or prison programming, 1 of whom shall be a member of a correctional officers union, 1 of whom shall have significant and demonstrated experience in criminal justice or corrections policy research; 1 of whom shall be the president of Massachusetts Sheriffs Association, Inc. or a designee, 1 of whom shall be a former judge designated by the chief justice of the supreme judicial court, 1 of whom shall be the executive director of Disability Law Center, Inc. or a designee, 1 of whom shall be the executive director of Prisoners' Legal Services or a designee, 1 of whom shall be the executive director of the Massachusetts Association for Mental Health, Inc. or a designee and 1 of whom shall be a licensed social worker designated by the Massachusetts chapter of the National Association of Social Workers, Inc.” Id. at § 39G.

${ }^{318}$ Id. at § 39D: “(a) The commissioner shall publish monthly and provide directly to the restrictive housing oversight committee the number of prisoners held in each restrictive housing unit within each state and county correctional facility. (b) The commissioner shall publish a report quarterly and provide directly to the restrictive housing oversight committee, as to each restrictive housing unit within each state correctional facility, and annually, as to each restrictive housing unit within each county correctional facility: (i) the number of prisoners as to whom a finding of serious mental illness has been made and the number of such prisoners held for more than 30 days; (ii) the number of prisoners 
who have committed suicide or committed non-lethal acts of self-harm; (iii) the number of prisoners according to the reason for their restrictive housing; (iv) as to prisoners in disciplinary restrictive housing, a listing of prisoners with names redacted, including an anonymized identification number that shall be consistent across reports, age, race, gender and ethnicity, whether the prisoner has an open mental health case, the date of the prisoner's commitment to discipline, the length of the prisoner's term and a summary of the reason for the prisoner's commitment; (v) the number of placement reviews conducted pursuant to clause (iv) and (v) of subsection (a) of section 39B and the number of prisoners released from restrictive housing as a result of such placement reviews; (vi) the length of original assignment to and total time served in disciplinary restrictive housing for each prisoner released from disciplinary restrictive housing as a result of a placement review; (vii) the count of prisoners released to the community directly or within 30 days of release from restrictive housing; (viii) the known disabilities of every prisoner who was placed in restrictive housing during the previous 3 months; (ix) the number of mental health professionals who work directly with prisoners in restrictive housing; (x) the number of transfers to outside hospitals directly from restrictive housing; and (xi) such additional information as the commissioner may determine. (c) The committee shall gather information regarding the use of restrictive housing in correctional institutions to determine the impact of restrictive housing on inmates, rates of violence, recidivism, incarceration costs and self-harm within correctional institutions."

${ }^{319} I d$. at $\S 39 \mathrm{E}$.

${ }^{320} I d$. at $\S 39 \mathrm{~A}(\mathrm{c}):$ "The fact that a prisoner is lesbian, gay, bisexual, transgender, queer or intersex or has a gender identity or expression or sexual orientation uncommon in general population shall not be grounds for placement in restrictive housing."

${ }^{321} I d$. at $\S 39 \mathrm{~A}(\mathrm{~d}):$ :A pregnant inmate shall not be placed in restrictive housing."

${ }^{322}$ Hawaii Senate Bill 2859, supra note 304, at $\S 1(\mathrm{~d})$ would prohibit placement of a member of a "vulnerable population" in restrictive housing unless all other less restrictive means of intervention have been attempted and only after a mental and physical exam. New Jersey Assembly Bill 314, supra note 304, § 3 would limit placement of members of "vulnerable population" in restrictive housing. New York Senate Bill 4784, supra note 305, § 4(g) would prohibit placement in restrictive housing of person in a "special population." The New York legislature passed the bill, which is awaiting signature by the governor. Virginia House Bill 795, supra note 304, § 53.1-39.1 (B) would prohibit, with some exceptions, placement of a member of a "vulnerable population" in restrictive housing.

${ }^{323}$ See e.g., Cal Welf. \& Inst. Code $\S 208.3$ (West), which states: "Room confinement means the placement of a minor or ward in a locked sleeping room or cell with minimal or no contact with persons other than correctional facility staff and attorneys. Room confinement does not include confinement of a minor or ward in a single-person room or cell for brief periods of locked room confinement necessary for required institutional operations.”; Neb. Rev. Stat. § 83-4,125, which states: "Room confinement means the involuntary restriction of a juvenile to a cell, room, or other area, alone, including a juvenile's own room, except during normal sleeping hours."

${ }^{324}$ Cal. Welf. \& Inst. Code $§ 208.3(b)(2)$.

${ }^{325} \mathrm{Id}$. at $\S 208.3(\mathrm{~b})(1)$.

${ }^{326} I d$. at $\S 208.3(\mathrm{c}),(\mathrm{d})$.

${ }^{327}$ Colo. Rev. Stat. Ann. § 26-20-104.5 (West).

${ }^{328}$ Comprehensive Youth Justice Amendment Act of 2016, 2017 District of Columbia Law 21-238 § 203(e). The Act provided: 
Except for room confinement occurring under subsection (c) of this section, room confinement shall be used for the briefest period of time possible and not for a time to exceed 6 hours. After 6 hours, the youth shall be returned to the general population, transported to a mental health facility upon the recommendation of a mental health professional, transferred to the medical unit in the facility, or provided special individualized programming.

${ }^{329} I d$. at $\S 203(\mathrm{a})$.

${ }^{330}$ Tennessee Public Chapter No. 1052, House Bill No. 2271, Juvenile Justice Reform Act of $2018 \S 13$. The Act provided that the "use of seclusion for punitive purposes pre-adjudication or post-adjudication for any child detained in any facility pursuant to $\S 37-1-114$ is prohibited."

${ }^{331}$ Nebraska Legislative Bill 870, supra note 305, at § 2(5).

${ }^{332} I d$. at $\S 2(a)$.

3332018 Connecticut House Bill No. 5041 §33(e), Connecticut General Assembly - February Session, 2018. The bill would require that "no child shall at any time be held in solitary confinement or held for a period that exceeds six hours."

${ }^{334}$ Colo. Rev. Stat. Ann. § 17-1-113.8 (West).

${ }^{335}$ CRIMES AND OFFENSES, supra note 306, at $§ 39 \mathrm{~A}(\mathrm{a})$. The law provided:

A prisoner shall not be held in restrictive housing if the prisoner has a serious mental illness or a finding has been made, pursuant to subsections (c) or (d) of section 39 or otherwise, that restrictive housing is clinically contraindicated unless, not later than 72 hours after the finding, the commissioner, the sheriff or a designee of the commissioner or sheriff certifies in writing: (i) the reason why the prisoner may not be safely held in the general population; (ii) that there is no available placement in a secure treatment unit; (iii) that efforts are being undertaken to find appropriate housing and the status of the efforts; and (iv) the anticipated time frame for resolution. A copy of the written certification shall be provided to the prisoner. A prisoner in restrictive housing shall be offered additional mental health treatment in accordance with clinical standards adopted by the department of correction.

${ }^{336}$ Braggs v. Dunn, 257 F. Supp. 3d 1171 (M.D. Ala. 2017).

${ }^{337}$ Braggs v. Dunn, 317 F.R.D. 634, 673-74 (M.D. Ala. 2016). Excluded were those at "work release centers and Tutwiler Prison for Women." A co-plaintiff, the Alabama Disabilities Advocacy Program (ADAP), which is a designated protection agency under federal law, pursued claims on behalf of women at Tutwiler. See Braggs v. Dunn, 257 F. Supp. 3d at 1181.

${ }^{338}$ Braggs v. Dunn, 257 F. Supp. 3d at 1181.

${ }^{339} I d$. at $1184-85$.

${ }^{340} I d$. at $1185-86$. Two people committed suicide during the course of the trial, including one of the named plaintiffs who testified in the case. $I d$.

${ }^{341}$ Id. at 1267-68. The standard comes from Estelle v. Gamble, 429 U.S. 97, 104 (1976), which held that "deliberate indifference to serious medical needs of prisoners constitutes the unnecessary and wanton infliction of pain proscribed by the Eighth Amendment" (internal citations and quotation marks omitted). 
${ }^{342}$ Braggs v. Dunn, 257 F. Supp. 3d at 1268.

${ }^{343}$ See Braggs v. Dunn, 2018 WL 985759 (M.D. Ala. Feb 20, 2018); Braggs v. Dunn, 2018 WL 2057467 (M.D. Ala. Mar 30, 2018); Braggs v. Dunn, 2018 WL 1805594 (M.D. Ala. Apr 9 2018); Braggs v. Dunn, 2018 WL 2168705 (M.D. Ala. Apr. 25, 2018); Braggs v. Dunn, 2018 WL 2440287 (M.D. Ala. Apr. 25, 2018).

${ }^{344}$ See South Carolina Department of Corrections, Protection \& Advocacy for People with Disabilities, Inc., SCDC, Mental Health Advocates Reach Historic Agreement, June 1, 2016, available at http://www.pandasc.org/wpcontent/uploads/2016/06/PA-and-SCDC-Press-Release-6-1-16.pdf.

${ }^{345}$ T.R., et al. v. South Carolina Department of Corrections, 2005-CP-40-02925 (S.C. Com. Pl. Oct. 6, 2011), Fifth Amended Complaint, p. 21, available at https://www.clearinghouse.net/chDocs/public/PC-SC-0006-0001.pdf.

${ }^{346} I d$. at $16-17$.

${ }^{347} I d$. at 18.

348 Id., Order Granting Judgment in Favor of Plaintiffs, Jan. 8, 2014, p. 3, 5, available at https://www.clearinghouse.net/chDocs/public/PC-SC-0006-0006.pdf.

${ }^{349} I d$. at 6.

${ }^{350}$ T.R. v. South Carolina Department of Corrections, Appellate Case No. 2014-001080 (S.C. Dec. 14, 2016), Order Dismissing Appeal.

${ }^{351}$ Id., Settlement Agreement, available at http://www.pandasc.org/wp-content/uploads/2016/06/ SettlementAgreement-May-31-2016.pdf. See also South Carolina Department of Corrections; Protection \& Advocacy for People with Disabilities, Inc.; SCDC, Mental Health Advocates Reach Historic Agreement, June 1, 2016, available at http://www.pandasc.org/wp-content/uploads/2016/06/PA-and-SCDC-Press-Release-6-1-16.pdf.

${ }^{352}$ South Carolina elaborated on the Behavioral Management Unit policy:

The Behavioral Management Units (BMUs) are designed as a possible alternative to long-term segregation placement for inmates designated as having a mental health classification who are suffering from severe personality disorders and associated disruptive disorders. BMUs are therapeutic programs aimed to disrupt the cycle of repeated disciplinary infractions resulting in frequent, repetitive sanctions that result in longterm segregation placement. The goal of placement in BMUs is to assist inmates in achieving their highest level of functionality by developing alternative coping skills that result in behavioral stability sufficient to return safely to general population. In some cases, the goal will be preparation for re-entry to the community at the expiration of their sentence.

The prison system further explained that it planned "to open a specially designed yard" for prisoners in restrictive housing "due to their safety concerns." South Carolina described the plan:

The focus will be segregation reduction and re-entry preparation for general population and society. Inmates will be screened for participation using specific criteria and a contract will require disagreements to be resolved through a community meeting or small staff/inmate forum. The program will consist of reception phases to introduce the program, functions, and expectations to incoming inmates. Upon completion of the reception requirements, inmates will be placed in housing units. Each inmate will be assigned a job function within the housing unit aimed at assuming responsibility and learning acceptable work habits. One program to be offered is designed to work with inmates fearful of general population environments with the goal of returning them to a yard as well as preparing them for re-entry into society. The program will determine the 
reason for maladapted behavior or refusal to be housed in general population, develop a specific management plan, and thereafter move inmates to one of the therapeutic units.

South Carolina also noted that "an on-going RHU committee" was convening "a special session" to review prisoners with "high mental health needs" in restrictive housing to determine whether restrictive housing placement "is correct or whether the housing assignment should be adjusted."

${ }^{353}$ Roy Parker et al. v. City of New York, 15 CV 6733 (CLP) (E.D.N.Y. Settlement Dec. 2017) (Memorandum and Order), available at https://cases.justia.com/federal/district-courts/new-york/nyedce/1:2015cv06733/378243/58/ 0.pdf?ts=1517255506.

${ }^{354} I d$. They alleged that after having been placed in solitary confinement while serving one sentence, released from custody, and then returned to custody on another charge, they were placed back in solitary confinement solely on the basis of having been there previously. Id. at 2 .

${ }^{355}$ See Ashley Southall, City Agrees to Pay Rikers Inmates It Forced Back into Solitary Confinement, New York Times (Dec. 12 2017), https://www.nytimes.com/2017/12/12/nyregion/rikers-settlement-solitary-confinement.html.

${ }^{356} I d$.

357 C.S., et al., v. King County, 2:17-CV-01560-JCC (W.D. Wa. 2017), Order, available at http://www.columbialegal.org/sites/default/files/KingCounty-OrderGrantingMotionforDismissal.pdf. See also https://www.seattletimes.com/seattle-news/crime/king-county-reaches-deal-to-ban-placing-jailed-juveniles-insolitary-confinement/.

${ }^{358}$ Id., First Amended Complaint for Injunctive and Declaratory Relief, available at http://www.columbialegal.org/ sites/default/files/17_1023_Complaint_CS-v-KingCounty.pdf.

${ }^{359} I d$., Exhibit A, available at http://www.columbialegal.org/sites/default/files/KC_Isolation_24-1.\%20Exhibit $\% 20$ A_RedactedSM.pdf.

${ }^{360} I d$.

${ }^{361} I d$.

${ }^{362}$ Doe by \& through Frazier v. Hommrich, No. 3-16-0799, 2017 WL 1091864, at *2 (M.D. Tenn. Mar. 22, 2017).

${ }^{363} I d$. at *3. Thereafter, Tennessee enacted a law that defined seclusion as "the intentional, involuntary segregation of an individual from the rest of the resident population for the purposes of preventing harm by the child to oneself or others; preventing harm to the child by others; aiding in de-escalation of violent behavior; or serving clinically defined reasons," and prohibited the "use of seclusion for punitive purposes pre-adjudication or post-adjudication for any child detained in any facility." Tennessee Public Chapter No. 1052, House Bill No. 2271, Juvenile Justice Reform Act of $2018 \S 13$, signed into law by the governor on May 21, 2018.

${ }^{364}$ V.W. v. Conway, 236 F. Supp. 3d 554, 583 (N.D.N.Y. Feb. 22, 2017). Plaintiffs in that case were supported by the Department of Justice, which submitted a brief discussing the harms of solitary confinement for juveniles. Statement of Interest of the United States, Jan. 3, 2017, available at https://www.justice.gov/opa/file/922386/download.

${ }^{365} I d$.

${ }^{366}$ J.J. v. Litscher, No. 17-CV-47 (W.D. Wi. 2017), available at https://www.clearinghouse.net/chDocs/public/JI-WI0004-0002.pdf. 
${ }^{367} I d$., Preliminary Injunction, available at https://www.clearinghouse.net/chDocs/public/JI-WI-0004-0003.pdf.

${ }^{368} 2017$ Wisconsin Act 1855. Laurel White, Walker Signs Law Closing Lincoln Hills Youth Prison, Wisconsin Public Radio, Mar. 30, 2018, https://www.wpr.org/walker-signs-law-closing-lincoln-hills-youth-prison.

369 J.J. v. Litscher, No. 17-CV-47 (W.D. Wi. 2017), Stipulation for Consent Decree and Permanent Injunction, available at https://jlc.org/sites/default/files/attachments/2018-06/2018.6.1\%20Decl\%20RTM\%20in\%20Supp. $\% 20 \mathrm{Mo} \% 20$ for\%20Settlement\%20Approval\%20-\%20Settl\%20Agree.pdf.

${ }^{370}$ Davis v. Ayala, 135 S. Ct. 2187, 2210 (2015) (Kennedy, J., concurring). Justice Thomas concurred specifically to disagree, as he pointed to the harms that the prisoner had imposed by killing others. Id. at 2210 (Thomas, J., concurring).

${ }^{371} I d$. at 2209. Justice Kennedy stated that it was "as if a judge had no choice but to say:

'In imposing this capital sentence, the court is well aware that during the many years you will serve in prison before your execution, the penal system has a solitary confinement regime that will bring you to the edge of madness, perhaps to madness itself."”

${ }^{372}$ Ruiz v. Texas, 137 S. Ct. 1246 (2017) (Breyer, J., dissenting). See also Glossip v.Gross, 135 S. Ct 2726, 2765 (2015) (Breyer, J. \& Ginsburg, J., dissenting). In 2018, Justice Breyer reiterated the concern in another dissent from a denial of certiorari. He commented that the death-sentenced prisoner had been incarcerated since 1977 and spent "most of the time on death row living in isolated, squalid conditions." Jordan v. Mississippi, 138 S.Ct. 2567, 2568 (2018) (Breyer, J., dissenting) (citing petition for certiorari).

373 Nordstrom v. Ryan, CV-15-02176 (D. Ariz. 2015). See also https://deathpenaltyinfo.org/node/6824; http://www.abajournal.com/news/article/condemned_to_death_and_solitary_confinement1. As a result of a settlement reached in that case, the plaintiff and others with clear disciplinary records will be moved from solitary confinement.

${ }^{374}$ Lopez v. Brown, 4:15 CV 02725 (N.D. Ca 2015), available at https://www.clearinghouse.net/chDocs/public/PCCA-0071-0001.pdf. See also http://solitarywatch.com/2017/10/10/lawsuits-challenge-the-cruelty-of-decades-insolitary-confinement-on-death-row/. A settlement reached in this suit placed a five-year limit on placement in restrictive housing on death row, and provided for more frequent placement reviews.

${ }^{375}$ Davis et al. v. Jones et al., 3:17CV820J34PDB (M.D. Fl. 2017), available at https://www.venable.com/ files/upload/Complaint-David-v-Jones.pdf. On July 19, 2017, a group of nine death-row prisoners filed a class-action lawsuit against the Florida Department of Corrections, and challenged its practice of automatically keeping death-row prisoners in solitary confinement until the prisoners' release or execution. Plaintiffs Mark Davis and others-whose stays in solitary confinement range from four to thirty years and total over 150 years - asked the United States District Court for the Middle District of Florida to hold the practice unconstitutional in violation of the Eighth Amendment prohibition against cruel and unusual punishment and the Due Process Clause of the Fourteenth Amendment.

${ }^{376}$ Hamilton et al v. Vannoy et al, 3:17CV00194 (M.D. La. 2017), available at https://cardozo.yu.edu/sites/ default/files/Angola\%20filed\%5DNEW.pdf. In March 2017, prisoners on death row at Louisiana State Penitentiary filed a class-action lawsuit seeking to change the prison's policy of keeping all people sentenced to death in solitary confinement for the duration of their time in prison. The complaint alleged that Marcus Hamilton and his co-plaintiffs were in isolation "between twenty-five and thirty-one years." Id. at para. 1. The case is pending, and a settlement conference was set to take place in August 2018. Meanwhile, starting in May 2017, Louisiana began allowing deathrow prisoners to be let out of their cells together for four hours a day. See Julia O'Donoghue, Louisiana Tests Relaxed 
Restrictions on Death Row Inmates, The Times-Picayune, Oct. 25, 2017, https://www.nola.com/politics/index.ssf/ 2017/10/louisiana_death_row_changes.html.

377 Reid et al. v. Wetzel, 1:18-CV-00176-JEJ (M.D. Pa 2018), available at https://www.aclupa.org/files/ 6915/1691/6235/1_Complaint.pdf. On January 25, 2018, prisoners held on death row filed a lawsuit challenging Pennsylvania's practices, alleging that holding "death-sentenced prisoners in permanent, degrading, and inhuman solitary confinement until their capital sentence is overturned, or they die by execution or natural causes." Id. at 1. Their complaint alleged that individuals had been held in solitary confinement "for between sixteen and twenty-seven years." Id. at 2 .

${ }^{378}$ Williams v. Sec'y Pennsylvania Dep't of Corr., 848 F. 3d 549, 576 (3d Cir.), cert. denied sub nom. Walker v. Farnan, 138 S. Ct. 357 (2017), and cert. denied sub nom. Williams v. Wetzel, 138 S. Ct. 357 (2017).

379 Judith Resnik, Johanna Kalb, Celina Aldape, Ryan CoOper, Katie HaAs, April Hu, Jessica Hunter \& Shelle Shimizu, The ARTHUR Liman Public Interest Program at Yale Law School, Rethinking Death Row: VARIATIONS IN THE HOUSING OF INDIVIDUALS SENTENCED TO DEATH, July 2016, available at: https://law.yale.edu/system/files/documents/pdf/Liman/deathrow_reportfinal.pdf.

${ }^{380} I d$. at Appendix A: Statutes, Administrative Regulations, and Case Law by Jurisdiction.

${ }^{381}$ Id. at 9-10, 11-13, 14-16.

${ }^{382}$ George Lombardi, Richard D. Sluder \& Donald Wallace, Mainstreaming Death-Sentenced Inmates: The Missouri Experience and its Legal Significance, 61 FEDERAL PROBATION 3 (1997).

${ }^{383}$ Mark D. Cunningham, Thomas J. Reidy \& Jon R. Sorenssen, Wasted Resources and Gratuitous Suffering: The Failure of a Security Rationale for Death Row, 22 PSYCHOLOGY PUBLIC POLICY AND LAW 185 (2016).

${ }^{384}$ Johnson v. Wetzel, 209 F. Supp. 3d 766, 770, 781 (M.D. Pa. 2016).

${ }^{385} \mathrm{Id}$. at 776.

${ }^{386} I d$. at 781.

387 See generally Sharon Shalev, A Sourcebook On Solitary Confinement, Mannheim Centre for Criminology, London School of Economics and Political Science (Oct. 2008), available at http://solitaryconfinement.org/ sourcebook.

${ }^{388}$ United Nations Standard Minimum Rules for the Treatment of Prisoners (Nelson Mandela Rules), U.N. ESC Committee on Crime Prevention and Criminal Justice, $24^{\text {th }}$ Sess., U.N. Doc. E/CN.15/2015/L.6/Rev.1 (May 22, 2015), https://www.unodc.org/documents/justice-and-prison-reform/GA-RESOLUTION/E_ebook.pdf [hereinafter Nelson Mandela Rules].

${ }^{389}$ Nelson Mandela Rules, supra note 388, Rule 44.

${ }^{390} I d$. at Rule 45.1.

${ }^{391} I d$. at Rule 45.2.

${ }^{392}$ Id. at Rule 43.1.

${ }^{393} I d$. at Rule 45.2. 
${ }^{394}$ See Corporation of the Canadian Civil Liberties Association v. Canada (Attorney General), 2017 ONSC 7491 (Dec. 18, 2017), available at https://ccla.org/cclanewsite/wp-content/uploads/2017/12/Corp-of-the-Canadian-CivilLiberties-Association-v-HMQ-121117.pdf [hereinafter CCLA v. Canada], para. 272; British Columbia Civil Liberties Association v. Canada (Attorney General), 2018 BCSC 62 (Jan. 17, 2018), available at https://www.canlii.org/en/bc/bcsc/doc/2018/2018bcsc62/2018bcsc62.html [hereinafter BCCLA v. Canada], para. 2.

${ }^{395}$ CCLA v. Canada, supra note 394, at para. 272. In response to a suit brought by the Corporation of the Canadian Association of Civil Liberties (CCLA), the Ontario Superior Court of Justice ruled that so-called "fifth working day review" of a decision to place a prisoner in administrative segregation was insufficient. The court analyzed the claim under Baker v. Canada (Minister of Citizenship and Immigration) [1999] 2 S.C.R. 817. The Baker decision listed five factors affecting procedural fairness: the nature of the decision, and the process followed in making it; the nature of the statutory scheme; the importance of the decision to the individual; the legitimate expectations of the person challenging the decision; and the choices of procedure made by the agency. The court held that given that the institutional head (akin to a warden) controls the decision to place, maintain, and release a prisoner from administrative segregation - i.e. there is no independent review_- "the decision to segregate is procedurally unfair." Id. at para. 155. This aspect of the decision relied on Section 7 of the Charter of Rights and Freedoms, which provides, "Everyone has the right to life, liberty and security of the person and the right not to be deprived thereof except in accordance with the principles of fundamental justice." Canadian Charter of Rights and Freedoms, § 7, Part I of Constitution Act, 1982, being Schedule B to the Canada Act 1982 (U.K.), 1982, c. 11.

${ }^{396}$ CCLA v. Canada, supra note 394 , at para. 87.

${ }^{397} I d$. at para. 89.

${ }^{398}$ Id. at para. 230-232. Section 12 of the Charter of Rights and Freedoms provides, "Everyone has the right not to be subjected to any cruel and unusual treatment or punishment." Canadian Charter of Rights and Freedoms, § 12, Part I of Constitution Act, 1982, being Schedule B to the Canada Act 1982 (U.K.), 1982, c. 11.

${ }^{399}$ CCLA v. Canada, supra note 394, at paras. 212, 228.

${ }^{400}$ Id. at para. 277. See also Canadian Civil Liberties Association, Legal Fight Against Solitary Confinement Continues, Jan. 17, 2018, available at https://ccla.org/legal-fight-solitary-confinement-continues/.

${ }^{401}$ BCCLA v. Canada, supra note 394, at para 2. The British Columbia Civil Liberties Association and the John Howard Society of Canada brought the suit, alleging that laws authorizing administrative segregation are contrary to the Canadian Charter of Rights and Freedoms and that these laws have a disproportionate impact on Aboriginal and mentally ill prisoners $I d$. at para. 9 .

${ }^{402} I d$. at para. 609.

${ }^{403}$ Section 15 provides, "Every individual is equal before and under the law and has the right to the equal protection and equal benefit of the law without discrimination and, in particular, without discrimination based on race, national or ethnic origin, colour, religion, sex, age or mental or physical disability." Canadian Charter of Rights and Freedoms, $\S 15$, Part I of Constitution Act, 1982, being Schedule B to the Canada Act 1982 (U.K.), 1982, c. 11. See BCCLA v. Canada, supra note 394, at para. 2.

${ }^{404} I d$. at para. 609.

${ }^{405} I d$. at para. 247.

${ }^{406} I d$. at para. 533. 
${ }^{407} I d$. at para. 543.

${ }^{408}$ Id. at para. 610. See also Anna Mehler Paperny, Canada's Government Appeals Court Ruling on Solitary Confinement, Reuters, Feb. 19, 2018, https://www.reuters.com/article/us-canada-prison-solitary/canadasgovernment-appeals-court-ruling-on-solitary-confinement-idUSKCN1G321R.

${ }^{409}$ Council of Europe, European Committee on Crime Problems, Updating the European Prison Rules: Analytical Report, prepared by Professor Dirk Van Zyl Smit and Harvey Slade, (May 2, 2018), available at https://rm.coe.int/pcc-2018-4rev-e-memo-to-cdpc-updating-the-european-prison-rules-analy/16807c0eba.

${ }^{410} I d$. at 2.

${ }^{411}$ Id. See European Commission for the Prevention of Torture and Inhuman or Degrading Treatment of Prisoners CPT), Solitary Confinement of Prisoners, extract from the $21^{\text {st }}$ General Report of the CPT, published in 2011 at 2-6, available at https://rm.coe.int/16806ccc6.

${ }^{412} I d$.

${ }^{413}$ Council of Europe, Report to the German Government on the Visit to Germany Carried Out by the European Committee for the Prevention of Torture and Inhuman or Degrading Treatment or Punishment (CPT) from 25 November 2015 to 7 December 2015, available at https://rm.coe.int/168071803e.

${ }^{414} I d$. at 35 .

${ }^{415} I d$. at 36 . During its visit, the CPT found that ten individuals had been held in solitary confinement for security reasons for more than one year, including one individual who had been subjected to solitary confinement for almost 20 years. Id. at 28 .

${ }^{416} I d$. at 35. In response to the CPT's report, the German government declined to make changes. It stated that instances in which disciplinary solitary confinement was ordered for more than 14 days were "exceptional and extremely rare cases to which the courts have never objected upon review." Council of Europe, Response of the German Government to the report of the European Committee for the Prevention of Torture and Inhuman or Degrading Treatment or Punishment (CPT) on its visit to Germany from 25 November 2015 to 7 December 2015, p. 57, available at https://rm.coe.int/response-of-the-german-government-to-the-report-of-the-european-commit/16807182d1. The government reported it did not believe that amendments to the relevant statutory provisions to limit the time in segregation were necessary and that it would be "hard to get the large number of prisoners who abide by the prison rules to understand why effective disciplinary sanctions are being abandoned." Id. at 57-58.

${ }^{417}$ Irish Penal Reform Trust, 'Behind the Door': Solitary Confinement in the Irish Penal System, available at http://www.iprt.ie/files/Solitary_Confinement_web.pdf.

${ }^{418} I d$. at 6.

${ }^{419} I d$.

${ }^{420} I d$. at 8.

${ }^{421} I d$. at $8-9$.

${ }^{422}$ The 40 jurisdictions that provided numbers of prisoners in restrictive housing in both 2015 and 2017 were Alabama, Alaska, Arizona, Colorado, Connecticut, Delaware, FBOP, Georgia, Hawaii, Idaho, Illinois, Indiana, Iowa, Kansas, Kentucky, Louisiana, Maryland, Massachusetts, Michigan, Mississippi, Missouri, Montana, Nebraska, New Jersey, 
New Mexico, New York, North Carolina, North Dakota, Ohio, Oklahoma, Oregon, Pennsylvania, South Carolina, South Dakota, Tennessee, Texas, Utah, Washington, Wisconsin, and Wyoming.

Three jurisdictions (Arkansas, Nevada, and Rhode Island) responded to the survey in 2017 but not in 2015. Eight jurisdictions (California, D.C., Florida, Minnesota, New Hampshire, Vermont, Virgin Islands, and Virginia) responded in 2015 but not 2017.

${ }^{423}$ We clarified the definition of restrictive housing in 2017-2018. In 2015-2016, the survey defined restrictive housing as being in-cell for 22 hours or more for 15 continuous days or more; in 2017-2018, the survey defined restrictive housing as being in cell for an average of 22 hours or more for 15 continuous days or more. See supra note 20.

${ }^{424}$ The 29jurisdictions with decreases in the number of prisoners reported in restrictive housing were, in order of number of prisoners: New York (decrease of 1,832); Texas (1,560); Illinois (1,334); FBOP (968); Georgia (680); Utah (616); Tennessee (587); Alabama (547); Michigan (436); North Carolina (408); New Mexico (369); New Jersey (359); Delaware (338); South Carolina (331); Nebraska (270); Pennsylvania (218); Colorado (207); Oklahoma (184); Kansas (130); Idaho (94); Ohio (92); Iowa (80); Kentucky (79); Maryland (68); Wyoming (50); North Dakota (46); Wisconsin (38); South Dakota (16); and Hawaii (10).

${ }^{425}$ Together, New York, Texas, Illinois, FBOP, and Georgia accounted for a reduction of 6,374 prisoners in restrictive housing from 2015 to 2017.

${ }^{426}$ The 11 jurisdictions with increases in the number of prisoners reported in restrictive housing were, in order of number of prisoners: Missouri (increase of 962); Mississippi (344); Oregon (308); Massachusetts (208); Connecticut (200); Arizona (179); Indiana (120); Washington (113); Alaska (26); Montana (23); and Louisiana (20).

${ }^{427}$ Those 28 jurisdictions, starting with the largest decrease in percentage points, were Utah (from 14.0\% to 4.7\%); Delaware (from 8.8\% to 0.8\%); New Mexico (from 9.0\% to 4.2\%); Nebraska (from 11.0\% to 6.3\%); Tennessee (from $8.8 \%$ to $5.3 \%$ ); New York (from $8.5 \%$ to $5.3 \%$ ); Illinois (from $4.8 \%$ to $2.2 \%$ ); North Dakota (from $3.0 \%$ to $0.4 \%$ ); Wyoming (from 6.2\% to 3.8\%); Alabama (from 5.7\% to 4.0\%); New Jersey (from 6.7\% to 5.2\%); South Carolina (from 5.1\% to 3.7\%); Kansas (from 5.9\% to $4.6 \%$ ); Colorado (from $1.2 \%$ to $0.1 \%$ ); Maryland (from $7.5 \%$ to $6.5 \%$ ); Georgia (from $6.8 \%$ to $5.8 \%$ ); North Carolina (from $4.0 \%$ to $3.0 \%$ ); Texas (from 3.9\% to 2.9\%); Iowa (from $3.0 \%$ to 2.0\%); Kentucky (from 4.2\% to 3.4\%); Michigan (from 3.1\% to 2.3\%); Idaho (from 5.0\% to 4.3\%); South Dakota (from $3.0 \%$ to $2.3 \%$ ); Oklahoma (from $5.6 \%$ to $5.1 \%$ ); Wisconsin (from $3.7 \%$ to $3.2 \%$ ); Pennsylvania (from $3.4 \%$ to $3.2 \%$ ); Ohio (from $2.7 \%$ to $2.6 \%$ ); and Hawaii (from $0.5 \%$ to $0.4 \%$ ).

${ }^{428}$ That jurisdiction was Utah.

${ }^{429}$ Those 12 jurisdictions, starting with the largest increase in percentage points, were Louisiana (from $14.5 \%$ to 19.0\%); Mississippi (from 1.0\% to 4.1\%); Montana (from 3.5\% to 6.4\%); Missouri (from 6.3\% to 9.0\%); Massachusetts (from 2.3\% to 4.9\%); Oregon (from 4.3\% to 6.4\%); Connecticut (from $0.8 \%$ to $2.3 \%$ ); Alaska (from (7.2\% to $8.6 \%$ ); Indiana (from 5.9\% to $6.6 \%$ ); Washington (from $1.7 \%$ to $2.3 \%$ ); Arizona (from $6.0 \%$ to $6.5 \%$ ); and FBOP (from $4.7 \%$ to $5.2 \%$ ).

${ }^{430}$ That jurisdiction was Louisiana.

${ }^{431}$ The number used for total custodial population in 2015 is the total custodial population about which the jurisdiction had restrictive housing data. See ASCA-LIMAN AIMING TO REDUCE TIME-IN-CELL 2016, supra note 13, at 22. 
432 Those jurisdictions were Alabama, FBOP, Georgia, Hawaii, Idaho, Illinois, Iowa, Kansas, Michigan, Nebraska, New Jersey, New Mexico, New York, North Carolina, Ohio, Oklahoma, Pennsylvania, South Carolina, Texas, and Utah.

${ }^{433}$ Those jurisdictions were Missouri and Washington.

${ }^{434}$ As previously noted, we clarified the definition of restrictive housing in 2017-2018. In 2015-2016, the survey defined restrictive housing as being in-cell for 22 hours or more for 15 continuous days or more; in 2017-2018, the survey defined restrictive housing as being in cell for an average of 22 hours or more for 15 continuous days or more. See supra note 20.

The 31 jurisdictions that provided numbers on length of stay in restrictive housing in both 2015 and 2017 were Alaska, Arizona, Colorado, Delaware, FBOP, Hawaii, Indiana, Iowa, Kansas, Kentucky, Louisiana, Massachusetts, Mississippi, Montana, Nebraska, New Jersey, New York, North Carolina, North Dakota, Ohio, Oklahoma, Oregon, Pennsylvania, South Carolina, South Dakota, Tennessee, Texas, Utah, Washington, Wisconsin, and Wyoming.

Five jurisdictions (Alabama, Illinois, Michigan, Missouri, and Rhode Island) provided data on length of stay in 2017 but not in 2015. Ten jurisdictions (California, Connecticut, District of Columbia, Florida, Idaho, Maryland, Minnesota, Vermont, Virgin Islands, and Virginia) provided data in 2015 but not 2017. 


\section{Appendix A: ASCA-Liman 2017-2018 Restrictive Housing Survey}

In the fall of 2017 we sent a survey in to the corrections departments in all 50 states, the District of Columbia, and the Federal Bureau of Prisons, and to four large metropolitan jail systems. We corrected the survey in February 2018 to eliminate errors in drafting. The survey reproduced below is a Word version of the full survey distributed on the Qualtrics platform.

Q1. As you know, ASCA and Yale's Liman Center have an ongoing data collection project to understand the use of restrictive housing in departments of corrections. The goal is to continue to map changes by keeping data current. Further, since the last survey, the American Correctional Association (ACA) has new standards for restrictive housing.

This brief questionnaire therefore gathers basic information about all forms of restrictive housing so as to provide a national picture of the number of people in all forms of restrictive housing, the length of their stay, policy reforms, and the impact of the ACA 2016 Standards. As we did in the 2014 and 2015 surveys, we ask for responses to this survey. Thereafter, ASCA members will receive a draft report of the analysis, and after we review the comments and corrections, the report will be finalized for publication. Much of the survey repeats questions from 2015, to which almost all of the ASCA membership responded.

\section{Instructions and Definitions}

The questionnaire need not be filled out in one sitting. The Qualtrics platform automatically saves your answers in your browser, so that you can return to the survey again at a later time, but ONLY if you use the same computer for inputting the answers. Most questions can be answered by checking boxes in a list; a few questions provide opportunities for open-ended responses. The Qualtrics Program alerts users when numbers do not add up to the total. If your answers prompt that flag, please recheck or explain the variations (such as subtotals not equaling the total). Because we may have follow-up questions to clarify the information provided, please include the name, contact information, and title for the person to whom such questions should be directed.

We ask first about all individuals in your jurisdiction's correctional facilities, including both sentenced prisoners and pre-trial detainees, as well as about whether you are reporting on facilities operated state-wide, and/or by either local entities housing state prisoners at your behest, or by private entities with whom your jurisdiction contracts. We also want to learn the numbers of prisoners held outside your jurisdiction. That background enables us to understand the context for the numbers provided on the facilities for which you have accessible data on the use of restrictive 
housing, on the numbers in restrictive housing, the length of stay, and demographics. A section is also devoted to learning about policies and reforms.

Please answer all the questions with information about your jurisdiction that is current as of on or about September 24, 2017, and indicate the date on which the data was collected. (For example, some jurisdictions collect data on the first or the fifteenth of every month.)

Not all jurisdictions have information on all the questions. A general "not applicable" (N/A) answer can be confusing. Therefore, we have set up the questionnaire to enable you to clarify if your jurisdiction does not track the information at all, or the information is not available for other reasons. In contrast, if your jurisdiction tracks information and has no prisoners under these conditions, then answer with a " 0. ."

For the purposes of this questionnaire, the term "restrictive housing" refers to separating prisoners from the general population and holding them in their cells for an average of 22 or more hours per day, for 15 or more continuous days. The definition includes prisoners held both in single cells and in double cells, if held for an average of 22 hours per day or more in a cell, for 15 or more continuous days. Thus, the questionnaire aims to gather data on all forms of restrictive housing populations, whether called administrative segregation, disciplinary segregation, protective custody, intensive management, or otherwise categorized.

Also provided is an email address (ascalimansurvey@yale.edu) and a phone number (203436-3532) to use to let us know that you have questions and that you want a response for clarification.

PLEASE COMPLETE AND RETURN THIS QUESTIONNAIRE BY MARCH 2. THANK YOU.

Q2. To facilitate your completion of this survey across multiple sessions, here is a PDF of this survey for download (however, please be sure to enter your responses into this online form):

Q3. SECTION 1. Please indicate the jurisdiction for which you are filling out the survey and the date on which data are regularly collected; if the data are collected only for this survey, please indicate the last date on which you finished gathering the data to respond. 
If it is possible for your jurisdiction to report data as of September 24, 2017, this would be appreciated in order to have consistency with other jurisdictions.

Jurisdiction:

Data current as of (MM/DD/YYYY):

Q4. SECTION 2. Please indicate whether the following types of facilities are under the direct control of your jurisdiction's Department of Corrections (check all that apply). By control, the survey means that your jurisdiction hires and supervises staff (even if some are through subcontracts, such as health care services) and provides the governing rules and policies.

Prisons

Jails

Juvenile facilities

Mental health facilities

Special facilities for death-sentenced prisoners

Private prisons

Immigration detention

Other (please specify)

Q5. Please provide the total custodial population for all facilities in your system as identified in Question 4 above (for example, if you indicated in Question 4 that your system includes prisons, jails, juvenile facilities, and mental health facilities, you would provide the total custodial population for those four types of facilities).

Q6. Does your jurisdiction have prisoners housed in privately contracted facilities?

Yes

No 
Q7. Does your jurisdiction regularly collect data on prisoners in privately contracted facilities?

Yes

No (please explain)

Q8. Does your jurisdiction contract with the federal government to provide housing for immigration detention?

Yes

No

Q9. Answer only if you answered "Yes" to the above question. Does your jurisdiction keep data on the population and the use of restrictive housing in these facilities?

Yes

No (please explain)

Q10. SECTION 2a. This survey focuses on data in your jurisdiction in facilities under your control. We also want to understand the numbers of individuals not included to learn the size of the population for which we will not have the kinds of information provided by answers to the questions below.

Q11. Are there prisoners sentenced through the state system who are NOT under your control and who are housed in other facilities (such as out of state, private, jails, and community residential centers)?

Yes

No

Q12. Answer only if you answered "Yes" to Question 11 above. Are any of these prisoners housed in local or other facilities WITHIN your jurisdiction?

Yes

No 
Q13. Answer only if you answered "Yes" to Question 12 above. Please provide data, if available, on the numbers of such prisoners.

Q14. Answer only if you answered "Yes" to Question 11 above. Are any of these prisoners housed OUTSIDE of your jurisdiction?

Yes

No

Q15. Answer only if you answered "Yes" to Question 14 above. Please indicate the numbers of such prisoners and to what jurisdictions they are sent.

Q16. Section 2b. Please indicate which facilities use restrictive housing (check all that apply).

Prisons

Jails

Juvenile facilities

Mental health facilities

Privately contracted facilities

Special facilities for death-sentenced prisoners

Immigration detention contract facilities

Other (please specify) 
Q17. Please indicate the facilities for which you have data on the use of restrictive housing (check all that apply).

Prisons

Jails

Juvenile facilities

Mental health facilities

Privately contracted facilities

Special facilities for death-sentenced prisoners

Immigration detention contract facilities

Other (please specify)

Q18. Please provide the total custodial population in each type of facility for which you have data on the use of restrictive housing. (For example, if you indicated in the question above that you have data on the use of restrictive housing in prisons, jails, and juvenile facilities, you would provide the custodial population in these three types of facilities.)

Prisons :

Jails :

Juvenile facilities :

Mental health facilities :

Special facilities for death-sentenced prisoners :

Private prisons :

Immigration detention :

Other (please explain) :

Total : 
Q19. SECTION 2c. Please provide available data on restrictive housing.

Note: For all questions in this survey, if your jurisdiction moves prisoners from one restrictive housing status or type to another without releasing them to a non-restrictive housing living unit, please provide the total number of days in restrictive housing REGARDLESS of status or type. In these cases, please include a comment noting that the total number of days includes time in two or more restrictive housing classifications or types.

Example: A prisoner is housed for 10 days in restrictive housing as a disciplinary sanction and upon completion of that sanction remains in restrictive housing for another 10 days for administrative reasons. For the purposes of the survey, the amount of time in restrictive housing would be 20 days, with a comment that the response reflects a time in both disciplinary and administrative statuses.

Q20. How many people are in restrictive housing in the facilities for which you have data?

\begin{tabular}{|c|c|c|}
\hline & $\begin{array}{l}\text { Short-term restrictive housing } \\
\text { (15 up to } 29 \text { days) }\end{array}$ & $\begin{array}{l}\text { Extended restrictive housing } \\
\text { (> } 29 \text { days) }\end{array}$ \\
\hline \multicolumn{3}{|l|}{ Prisons } \\
\hline \multicolumn{3}{|l|}{ Jails } \\
\hline \multicolumn{3}{|l|}{ Juvenile facilities } \\
\hline \multicolumn{3}{|l|}{ Mental health facilities } \\
\hline \multicolumn{3}{|l|}{$\begin{array}{l}\text { Special facilities for death- } \\
\text { sentenced prisoners }\end{array}$} \\
\hline \multicolumn{3}{|l|}{$\begin{array}{l}\text { Privately contracted } \\
\text { facilities }\end{array}$} \\
\hline \multicolumn{3}{|l|}{$\begin{array}{l}\text { Immigration detention } \\
\text { contract facilities }\end{array}$} \\
\hline Other (please specify) & & \\
\hline
\end{tabular}

Q21. Do you house persons in short-term restrictive housing (15 up to 29 days) with others in the same cell?

Yes

No (please explain) 
Q22. Do you house persons in extended restrictive housing (> 29 days) with others in the same cell?

Yes

No (please explain)

Q23. Answer only if you answered "Yes" to Question 22 above. Of the restrictive-housing cells you have, how many are designed to hold MORE THAN one prisoner?

Q24. Answer only if you answered "Yes" to Question 22 above. Of the restrictive-housing cells you have, how many are designed to hold ONLY one prisoner?

Q25. Answer only if you answered "Yes" to Question 22 above. As of September 15th, 2017, how many prisoners (including males and females of all ages) were in restrictive housing and sharing a cell with another prisoner?

Short-term restrictive housing (15 up to 29 days)

Extended restrictive housing (> 29 days) 
Q26. SECTION 3. Please provide available data regarding prisoners' duration in restrictive housing.

Q27. For all facilities for which you have data on the numbers of persons in restrictive housing, do you regularly gather, collect, or report information on each prisoner's length of stay in restrictive housing? Please select all that apply.

Yes, for each individual prisoner

Yes, in aggregate

Yes, grouped by prisoners' reason for placement

Yes, grouped by some other measure (please explain)

No (please explain)

Q28. In what year did your jurisdiction begin to track length-of-stay data? (YYYY) 
Q29. SECTION 4. Please provide the number of prisoners held in each type of restrictive housing for the specified period (under 1 month, under three months, etc. in continuous/consecutive days or months). Include both male and female prisoners.

Reminder: Please check that these totals comport with the information provided elsewhere in the questionnaire or if not, please explain the differences.

Note: If you collect duration data but not data on reason or type of housing, please provide what information is available.

Please enter "N/A" if data is not available.

\begin{tabular}{|c|c|c|c|c|c|}
\hline & Protective & Disciplinary & Administrative & Other & TOTAL \\
\hline \multicolumn{6}{|l|}{15 days -1 month } \\
\hline \multicolumn{6}{|l|}{$\begin{array}{l}1 \text { month and } 1 \text { day }-3 \\
\text { months }\end{array}$} \\
\hline \multicolumn{6}{|l|}{$\begin{array}{l}3 \text { months and } 1 \text { day to } 6 \\
\text { months }\end{array}$} \\
\hline \multicolumn{6}{|l|}{$\begin{array}{l}6 \text { months and } 1 \text { day - } \\
12 \text { months }\end{array}$} \\
\hline \multicolumn{6}{|l|}{$\begin{array}{l}12 \text { months and } 1 \text { day - } \\
36 \text { months ( } 1-3 \text { years) }\end{array}$} \\
\hline \multicolumn{6}{|l|}{$\begin{array}{l}36 \text { months and } 1 \text { day - } \\
72 \text { months ( } 3-6 \text { years) }\end{array}$} \\
\hline $\begin{array}{c}72 \text { months and } 1 \text { day or } \\
\text { more (more than } 6 \\
\text { years) }\end{array}$ & & & & & \\
\hline
\end{tabular}

Q30. If you were not able to provide some of these numbers, please explain why. 
Q31. If the data include prisoners in an "Other" category of restrictive housing, please specify and explain the type(s) of restrictive housing to which you are referring.

Q32. SECTION 5. Please provide available data regarding prisoners' demographics (age, race, ethnicity, gender, mental health, special populations).

Q33. What categories do you use?

White

Black (African American)

Native Hawaiian or Pacific Islander

Native American or Alaskan Native

Hispanic or Latino

Asian

Other 
Q34. Please explain how you define each, as some jurisdictions have variation.

White:

Black (African American):

Native Hawaiian or Pacific Islander:

Native American or Alaskan Native:

Hispanic or Latino:

Asian:

Other:

Q35. What ethnic/racial categories fall within “Other”?

Q36. If you use additional categories, please list them and how you define them.

Q37. How are identifications of race and ethnicity made?

Q38. SECTION 5a. Please provide available data on the TOTAL CUSTODIAL POPULATION for all facilities that you identified. 
Q39. Please provide information on the number of total male and female prisoners by age group.

\begin{tabular}{c|c|c} 
& Male & Female \\
\hline Under 18 years old & & \\
\hline 18-25 years old & & \\
\hline 26-35 years old & & \\
\hline 36-50 years old & & \\
\hline Over 50 years old & & \\
\hline TOTAL & &
\end{tabular}

Q40. If your system breaks down women and men by race and ethnicity, please give information on the number of male and female prisoners by those categories.

\begin{tabular}{|c|c|c|c|c|c|c|c|}
\hline & White & Black & $\begin{array}{l}\text { Native } \\
\text { Hawaiian } \\
\text { / Pacific } \\
\text { Islander }\end{array}$ & $\begin{array}{l}\text { Native } \\
\text { American } \\
\text { / Alaskan } \\
\text { Native }\end{array}$ & $\begin{array}{l}\text { Hispanic } \\
\text { or Latino }\end{array}$ & Asian & Other \\
\hline Male & & & & & & & \\
\hline Female & & & & & & & \\
\hline TOTAL & & & & & & & \\
\hline
\end{tabular}


Q41. SECTION 5b. Please provide available data on the RESTRICTIVE HOUSING POPULATION for all facilities that you identified.

Q42. Please provide information on the number of total male and female prisoners by age group who are in restrictive housing.

\begin{tabular}{c|c|c} 
& Male & Female \\
\hline Under 18 years old & & \\
\hline $18-25$ years old & & \\
\hline 26-35 years old & & \\
\hline $36-50$ years old & & \\
\hline Over 50 years old & & \\
\hline TOTAL & &
\end{tabular}

Q43. If your system breaks down women and men by race and ethnicity, please give information on the number of male and female prisoners by those categories who are in restrictive housing.

\begin{tabular}{c|c|c|c|c|c|c|c} 
& White & Black & $\begin{array}{c}\text { Native } \\
\text { Hawaiian } \\
\text { / Pacific } \\
\text { Islander }\end{array}$ & $\begin{array}{c}\text { Native } \\
\text { American } \\
\text { / Alaskan } \\
\text { Native }\end{array}$ & $\begin{array}{l}\text { Hispanic } \\
\text { or Latino }\end{array}$ & Asian & Other \\
\hline Male & & & & & & \\
\hline Female & & & & & & \\
\hline TOTAL & & & & & & \\
\hline
\end{tabular}

Q44. SECTION 5c. Please provide available data on the population of prisoners with SERIOUS MENTAL ILLNESS for all facilities that you identified.

Q45. How does your jurisdiction define serious mental illness? Please provide the definition you use. If you use a manual, please identify the manual (with its date or edition) that you use. 
Q46. Please provide data on how many prisoners are classified as SERIOUSLY MENTALLY ILL in your jurisdiction's TOTAL CUSTODIAL POPULATION.

\begin{tabular}{|c|c|c|c|c|c|c|c|c|}
\hline & White & Black & $\begin{array}{l}\text { Native } \\
\text { Hawaiian } \\
\text { / Pacific } \\
\text { Islander }\end{array}$ & $\begin{array}{l}\text { Native } \\
\text { American } \\
\text { / Alaskan } \\
\text { Native }\end{array}$ & $\begin{array}{l}\text { Hispanic } \\
\text { / Latino }\end{array}$ & Asian & Other & TOTAL \\
\hline Male & & & & & & & & \\
\hline Female & & & & & & & & \\
\hline ГOTAL & & & & & & & & \\
\hline
\end{tabular}

Q47. Using your definition of serious mental illness, what percentage of prisoners with serious mental illness are in restrictive housing in your jurisdiction?

Short-term restrictive housing (15 up to 29 days): (1)

Extended restrictive housing (> 29 days): (2) 
Q48. Please provide data on how many prisoners are classified as SERIOUSLY MENTALLY ILL and are in RESTRICTIVE HOUSING in your jurisdiction.

\begin{tabular}{|c|c|c|c|c|c|c|c|c|}
\hline & White & Black & $\begin{array}{l}\text { Native } \\
\text { Hawaiian } \\
\text { / Pacific } \\
\text { Islander }\end{array}$ & $\begin{array}{c}\text { Native } \\
\text { American } \\
\text { / Alaskan } \\
\text { Native }\end{array}$ & $\begin{array}{c}\text { Hispanic } \\
\text { / Latino }\end{array}$ & Asian & Other & TOTAL \\
\hline $\begin{array}{c}\text { Male, } \\
\text { short-term } \\
\text { restrictive } \\
\text { housing } \\
\text { (15 up to } \\
29 \text { days) }\end{array}$ & & & & & & & & \\
\hline $\begin{array}{c}\text { Male, } \\
\text { extended } \\
\text { restrictive } \\
\text { housing (> } \\
29 \text { days) }\end{array}$ & & & & & & & & \\
\hline $\begin{array}{l}\text { Female, } \\
\text { short-term } \\
\text { restrictive } \\
\text { housing } \\
\text { (15 up to } \\
29 \text { days) }\end{array}$ & & & & & & & & \\
\hline $\begin{array}{l}\text { Female, } \\
\text { extended } \\
\text { restrictive } \\
\text { housing ( } \\
29 \text { days) }\end{array}$ & & & & & & & & \\
\hline TOTAL & & & & & & & & \\
\hline
\end{tabular}


Q49. To understand the capacity of your jurisdiction to respond to the problems faced by the seriously mentally ill, the following questions focus on resources.

What resources does your system have to respond to prisoners with serious mental illness wherever such prisoners are housed?

How many trained clinicians does your system have to respond to prisoners with serious mental illness?

How many related health professionals (such as nurse practitioners) does your system have to respond to prisoners with serious mental illness?

What additional resources would you need to enable you to move prisoners with serious mental illness out of restrictive housing?

Q50. SECTION 5d. Please provide available data on the population of prisoners who are TRANSGENDER and who are in RESTRICTIVE HOUSING in your jurisdiction.

Note: Please enter N/A if you do not track this information. Enter "0" if you do track the information, and the answer to the question is zero.

How are prisoners identified as transgender within your system?

How many transgender prisoners are in your system?

How many transgender prisoners are in short-term restrictive housing (15 up to 29 days)?

How many transgender prisoners are in extended restrictive housing (> 29 days)? 
Q51. SECTION 5e. Please provide available data on the population of prisoners who are PREGNANT and who are in RESTRICTIVE HOUSING in your jurisdiction.

Note: Please enter N/A if you do not track this information. Enter "0" if you do track the information, and the answer to the question is zero.

How many pregnant prisoners are in your system?

How many pregnant prisoners in your system are in short-term restrictive housing (15 up to 29 days)?

How many pregnant prisoners are in extended restrictive housing (> 29 days)?

Q52. SECTION 6. Some jurisdictions house prisoners for most of the hours of the day in cells (in restrictive housing, segregated housing, or general population) for 15 days or more but for an average of less than 22 hours a day. Given this variation, the following section asks about the 20 22-hour interval, which reflects long amounts of time-in-cell not captured in the definition of restrictive housing, even if the placement approximates restrictive housing in other ways.

Q53. Please provide the total number of prisoners, if any, who as of the date the data were collected were not in restrictive housing as defined earlier in this survey but who have been otherwise held in cell (either in single or double cells) for an average of 20-22 hours a day for 15 days or more.

\begin{tabular}{c|c} 
& Number of prisoners \\
\hline Male & \\
\hline Female & \\
\hline TOTAL & \\
\hline
\end{tabular}


Q54. Please indicate which of the following facilities are included in the data in the above table. Select all that apply.

Prisons

Jails

Juvenile facilities

Mental health facilities

Privately contracted facilities

Special facilities for death-sentenced prisoners

Immigration detention contract facilities

Other (please specify)

Q55. In an ideal situation (i.e., if you had the necessary resources, and if you could do so consistent with institutional safety), what number of hours out of cell do you believe is desirable for prisoners?

Q56. SECTION 7. Since January 1, 2016, has your jurisdiction changed any of its policies regarding restrictive housing? If so, for the following questions, please check what changes apply, and specify when the policy change was made and whether it has been implemented. If applicable, please cite to the relevant policy statement or memorandum. 
Q57. Entry Criteria

Whether the criteria for placement in restrictive housing have been changed, and if so, how the criteria have been changed

Whether behaviors were removed from the list of infractions qualifying prisoners for restrictive housing placement, and if so, what behavior

Whether the decision to place individuals in restrictive housing required approval from the central administration or other senior officials (please specify)

Whether pre-entry mental health screening affected placement in restrictive housing, and, if so, when those screenings were conducted

Whether individualized needs assessments were conducted prior to placement in $\mathrm{RH}$, and when those were conducted

Whether placement in less restrictive alternatives to restrictive housing were considered

Other (please describe any policy changes not listed above)

Q58. Criteria for Release from Restrictive Housing

Creation of step-down or transition programs (if so, please describe the program/s, their implementation timeline, and which prisoners in restrictive housing are eligible)

Programs and policies prohibiting direct release from restrictive housing to the community and/or to the general population

Whether the decision to release or transition an individual from restrictive housing is now made by a committee, rather than by an individual

Whether maximum durations on restrictive housing are in place (if so, please specify what the maximum duration is) 
Whether policies have been implemented mandating that prisoners be told the criteria for their release in advance (if so, please describe the policies)

Q59. Oversight and Review of Restrictive Housing Placement and Use

Changes in the frequency of review of the placement of prisoners in restrictive housing

Changes in the decision-making authority to continue individuals in restrictive housing

Whether a prisoner grievance policy has been added

Whether monitoring for mental illness has been increased (if so, how often are prisoners evaluated for mental illness, and what steps are taken if they are found to have developed mental health issues?)

Whether new oversight programs have been created (if so, please describe the oversight program)

Whether centralized monitoring has been implemented

Whether improved tracking services and data collection have been introduced

Other (please describe)

Q60. Please specify how often the restrictive housing status of a prisoner is reviewed and by whom. If the policy has changed, please specify how it has changed and when. 
Q61. Mandated Time Out of Cell for Restrictive Housing Prisoners

Increased total time out of cell (if so, please specify how many additional hours out of cell and which prisoners in restrictive housing qualify)

Addition of structured time out of cell (therapeutic, programming) (if so, please specify how many additional hours of structured time out of cell and which prisoners in restrictive housing qualify) (if so, please specify how many additional hours out of cell and which prisoners in restrictive housing qualify)

Addition of unstructured (recreational) time out of cell

Addition of outdoor recreation

Addition of more classes

Addition of meals in social setting/cafeteria

Other (please specify)

Q62. Addition of Programming in Restrictive Housing

Addition of in-cell learning opportunities (if so, please describe which prisoners in restrictive housing qualify)

Access to more entertainment or literary materials (if so, please describe which prisoners in restrictive housing qualify)

More out-of-cell group programming (if so, please describe which prisoners in restrictive housing qualify)

Addition of GED/diploma program (if so, please describe which prisoners in restrictive housing qualify) 
Q63. Additional Provisions for Social Contact in Restrictive Housing

Q64. Have visitation hours/opportunities been increased?

Yes

No

Q65. Answer only if answered yes to question 64. With regard to the increased visitation hours/opportunities:

For what number of hours is visitation now available?

What use is there by individuals in restrictive housing?

Which prisoners in restrictive housing qualify?

Q66. Has phone time been increased?

Yes

No

Q67. Answer only if answered yes to question 66. With regard to the increased phone time:

By what frequency and length has it been increased?

Which prisoners in restrictive housing qualify?

Q68. Has group recreation been added?

Yes

No 
Q69. Answer only if answered yes to question 68. With regard to the added group recreation:

For what number of hours is group recreation now available?

Is it available with Security Desks only?

Which prisoners in restrictive housing qualify?

Q70. Have group classes or other programming been added?

Yes

No

Q71. Answer only if answered yes to question 70. With regard to the added group classes or other programming:

What kind of programming is now available?

For what number of hours is the programming now available?

Is it available with Security Desks only?

Which prisoners in restrictive housing qualify?

Q72. Policies or Training Related to Staffing of Restrictive Housing

Mental health training

Staff rotations (if so, please specify the intervals)

Additional opportunities for education 
Q73. Other

Q74. Has your jurisdiction studied the effects of the policy changes in terms of any of the following? Please select all that apply.

Incidents of violence

Incidents of prisoner self-harm

Prisoner morale

Staff morale

Numbers of persons (or subsets of persons) placed in restrictive housing or subsets of individuals (if so, please provide specific numbers)

\section{Duration of placement}

Prisoner successes in coping with the general population, programs, and other activities

Prisoner successes in returning to communities

Changing costs

Other (please explain)

Q75. If you have any research on your work in this area, please direct us to its place of publication, if applicable. Please note if you are able to email us (ascalimansurvey@yale.edu) both the policies and the research, if available. 
Q76. SECTION 8. Please answer the following questions with regard to the revised ACA standards.

Q77. In August of 2016, the American Correctional Association (ACA) adopted new standards on restrictive housing. Has your jurisdiction reviewed its policies since then on restrictive housing?

Yes

No (please explain)

Q78. Does your jurisdiction rely on these standards to make policies?

Yes

No (please explain)

Q79. Below we ask whether four facets of the 2016 ACA standards have been implemented in your jurisdiction.

Q80. Has your jurisdiction implemented the requirements of ACA standard 4-RH-0034, which prohibits the use of extended restrictive housing (more than 29 continuous days) for offenders under the age of 18 ?

Yes

No

We have substantially implemented this policy, with exceptions

This was the policy before the 2016 ACA revisions

Q81. Answer only if you answered "We have substantially implemented this policy, with exceptions" to question 80. Please explain how you have implemented this policy (prohibiting extended restrictive housing for offenders under the age of 18) and what exceptions you have made. 
Q82. Has your jurisdiction implemented the requirements of ACA standard 4-RH-0033, which prohibits the use of extended restrictive housing (more than 29 continuous days) for females determined to be pregnant?

Yes

No

We have substantially implemented this policy, with exceptions

This was the policy before the 2016 ACA revisions

Q83. Answer only if you answered "We have substantially implemented this policy, with exceptions" to question 82. Please explain how you have implemented this policy (prohibiting extended restrictive housing for prisoners who are pregnant) and what exceptions you have made.

Q84. Has your jurisdiction implemented the requirements of ACA standard 4-RH-0031, which prohibits the use of extended restrictive housing (more than 29 continuous days) for inmates diagnosed as seriously mentally ill?

Yes

No

We have substantially implemented this policy, with exceptions

This was the policy before the 2016 ACA revisions

Q85. Answer only if you answered "We have substantially implemented this policy, with exceptions" to question 84. Please explain how you have implemented this policy (prohibiting extended restrictive housing for inmates with serious mental illness) and what exceptions you have made. 
Q86. Has your agency implemented ACA standard 4-RH-0030, whereby it attempts not to release inmates from restrictive housing directly into the community?

Yes

No

We have substantially implemented this policy, with exceptions

This was the policy before the 2016 ACA revisions

Q87. Answer only if you answered "We have substantially implemented this policy, with exceptions" to question 86. Please explain how you have implemented this policy (attempting not to release inmates from restrictive housing directly into the community) and what exceptions you have made.

Q88. Please explain any other policies your jurisdiction has revised in light of the 2016 ACA restrictive housing standards.

\section{END OF QUESTIONS}




\section{Appendix B: This Report's Table and Figures}

\section{List of Tables}

Table 1 Numbers and Percentages of Men and Women in Restrictive Housing (RH)

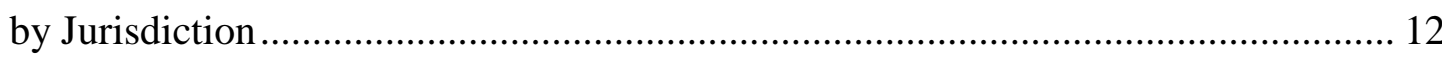

Table 2 Numbers of Prisoners in Restrictive Housing by Length of Time and

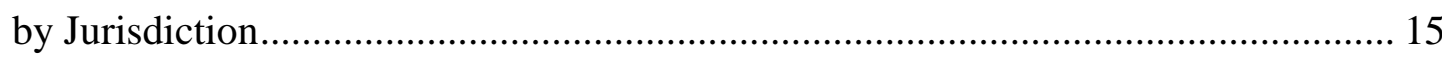

Table 3 Years When Tracking Length of Time in Restrictive Housing Began in

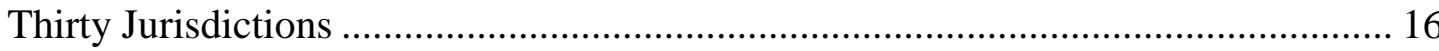

Table 4 Number and Percentage of Male Custodial Population in Restrictive Housing......... 19

Table 5 Number and Percentage of Female Custodial Population in Restrictive Housing ..... 21

Table 6 Number of Jurisdictions Reporting on Racial or Ethnic Groups ............................... 22

Table 7 Demographic Composition of Total Male Custodial Population and Male Restrictive Housing Population .............................................................................. 27

Table 8 Demographic Percentage Composition of Total Male Custodial Population and Male Restrictive Housing Population ........................................................................... 29

Table 9 Demographic Composition of Total Female Custodial Population and Female Restrictive Housing Population ………………………………….......................... 32

Table 10 Demographic Percentage Composition of Total Female Custodial Population and Female Restrictive Housing Population........................................................................ 34

Table 11 Age Cohorts of Male Total Custodial Population and of Male Restrictive Housing Population 38

Table 12 Age Cohorts Percentage of Male Total Custodial Population and of Male Restrictive Housing Population

Table 13 Age Cohorts of Female Total Custodial Population and of Female Restrictive Housing Population.

Table 14 Age Cohorts Percentage of Female Total Custodial Population and of Female Restrictive Housing Population

Table 15 Male Prisoners with Serious Mental Illness (SMI, variously defined) in Restrictive Housing (RH) 
Table 16 Female Prisoners with Serious Mental Illness (SMI, variously defined) in Restrictive Housing (RH)

Table 17 Male Prisoners with Serious Mental Illness by Race and Ethnicity in the Total Custodial Population and in the Restrictive Housing Population 51

Table 18 Female Prisoners with Serious Mental Illness by Race and Ethnicity in the Total Custodial Population and in the Restrictive Housing Population

Table 19 Total Custodial Population by Race and Ethnicity and Delineated by Sex/Gender in Los Angeles and Philadelphia Jails.

Table 20 Age Cohorts of Men and Women in the Total Custodial Population in Los Angeles and Philadelphia Jails and in the Restrictive Housing Population in Los Angeles Jails

Table 21 Jurisdiction-by-Jurisdiction Comparisons of Restrictive Housing Populations in 2015-2016 and in 2017-2018

Table 22 Comparing the Numbers of Prisoners in Restrictive Housing by Length of Time in 2015-2016 and in 2017-2018

Table 23 Comparing the Distributions of Prisoners by Length of Time in Restrictive Housing in 2015-2016 and in 2017-2018. 102

\section{List of Figures}

Figure 1 Percentages of Prisoners in Restrictive Housing by Jurisdiction 11

Figure 2 Percentages of Prisoners in Restrictive Housing by Percentage ............................. 12

Figure 3 Prisoners in Restrictive Housing by Length of Time ....................................... 14

Figure 4 Percent of Total Population in Restrictive Housing by Gender ............................. 17

Figure 5 Percentage of Male Prisoners in Restrictive Housing by Jurisdiction...................... 18

Figure 6 Percentage of Male Prisoners in Restrictive Housing by Percentage...................... 18

Figure 7 Percentage of Female Prisoners in Restrictive Housing by Jurisdiction ................... 20

Figure 8 Percentage of Female Prisoners in Restrictive Housing by Percentage ................... 20

Figure 9 Racial and Ethnic Composition of Male Prisoners in Total Custodial Population and in Restrictive Housing Population 
Figure 10 Racial and Ethnic Composition of Female Prisoners in Total Custodial Population and in Restrictive Housing Population

Figure 11 Differences in Restrictive Housing and Total Custodial Population for Black

Male Prisoners

Figure 12 Differences in Restrictive Housing and Total Custodial Population for Hispanic

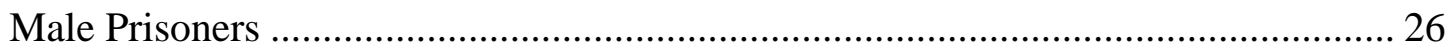

Figure 13 Age Distribution of Male Prisoners in Restrictive Housing and Total Custodial Population......................................................................................... 37

Figure 14 Age Distribution of Female Prisoners in Restrictive Housing and Total Custodial Population..... 37

Figure 15 Jurisdiction-by-Jurisdiction Comparisons of Percentages of Prisoners in Restrictive Housing Populations in 2015-2016 and in 2017-2018. 98

Figure 16 Jurisdiction-by-Jurisdiction Comparisons of the Changes in Percentage of Prisoners in Restrictive Housing Populations in 2015-2016 and in 2017-2018

Figure 17 Comparing the Distributions of Prisoners by Length of Time in Restrictive Housing in 2015-2016 and in 2017-2018 103 


\section{Appendix C: Definitions of "Serious Mental Illness" in 43 Jurisdictions}

\begin{tabular}{|c|c|}
\hline Alabama & $\begin{array}{l}\text { Psychotic disorders, bipolar disorders, and major depressive disorders; any } \\
\text { diagnosed mental disorder currently associated with serious impairment in } \\
\text { psychological, cognitive, or behavioral function that substantially interferes } \\
\text { with the person's ability to meet the demands of living and requires an } \\
\text { individualized treatment plan by a qualified mental health provider. }\end{array}$ \\
\hline Alaska & $\begin{array}{l}\text { Mental Illness is an organic mental or emotional impairment that reduces an } \\
\text { individual's exercise of conscious control over the individual's actions and } \\
\text { reduces an individual's ability to perceive reality, to reason or understand. }\end{array}$ \\
\hline Arizona & $\begin{array}{l}\text { ADC Mental Health Technical Manual, } 06 / 18 / 2015 \text { Defined: Those who } \\
\text { according to a licensed mental health clinician or provider possess: 1) A } \\
\text { qualifying mental health diagnosis as indicated on the SMI determination } \\
\text { form, and 2) A severe functional impairment directly relating to their mental } \\
\text { illness. }\end{array}$ \\
\hline Arkansas & $\begin{array}{l}\text { Serious Mental Illness-Psychotic, Bipolar and Major Depressive Disorders } \\
\text { and any other diagnosed mental disorder (excluding substance use disorders) } \\
\text { associated with serious behavioral impairment as evidenced by examples of } \\
\text { acute decompensation, self-injurious behaviors, and mental health } \\
\text { emergencies that require an individualized treatment plan by a qualified } \\
\text { mental health professional. }\end{array}$ \\
\hline Colorado & $\begin{array}{l}\text { CDOC Clinical Services uses the Diagnostic and Strategic Manual of Mental } \\
\text { Disorder, Fifth Edition (DSM-5) Serious Mental Illness: The current } \\
\text { diagnosis of any of the following DSM diagnoses accompanied by the P-code } \\
\text { qualifier of M or psychological coding of P4 or P5, denoting the presence of } \\
\text { a major mental disorder: schizophrenia, schizoaffective disorder, delusional } \\
\text { disorder, schizophreniform disorder, brief psychotic disorder, substance- } \\
\text { induced psychotic disorder (excluding intoxication and withdrawal), } \\
\text { unspecified schizophrenia spectrum and other psychotic disorder (previously } \\
\text { psychotic disorder not otherwise specified), major depressive disorders, and } \\
\text { bipolar disorders. Offenders, regardless of diagnosis, indicating a high level } \\
\text { of mental health needs based upon high symptom severity and/or high } \\
\text { resource demands, which demonstrate significant impairment in their ability } \\
\text { to function within the correctional environment. }\end{array}$ \\
\hline Connecticut & $\begin{array}{l}\text { MH5 Assessment: Crisis level mental disorder (acute conditions, temporary } \\
\text { classification). Requires } 24 \text { hour nursing care. Examples of mental health } \\
\text { conditions meeting the MH-5 level include but are not limited to acute } \\
\text { psychosis, severe depression, suicidal ideation, suicidal gestures or attempts, } \\
\text { and overwhelming anxiety. Moreover, these inmates can be actively suicidal } \\
\text { or self-mutilators. They require suicide watch, } 15 \text {-minute watch or one-to-one }\end{array}$ \\
\hline
\end{tabular}




\begin{tabular}{|c|c|}
\hline & $\begin{array}{l}\text { monitoring. Refer to Appendix for further information. This is in accordance } \\
\text { with the } 2012 \text { Offender Classification Manual }\end{array}$ \\
\hline Delaware & Bureau of Prisons Policy 4.3, p. 3. DSM-5 is used. \\
\hline FBOP & $\begin{array}{l}\text { Serious Mental Illness includes offenders diagnosed with the following: } \\
\text { Schizophrenia; Delusional Disorder; Schizophreniform Disorder; } \\
\text { Schizoaffective Disorder; Brief Psychotic Disorder; Bipolar I, II Disorder; } \\
\text { Substance-Induced Psychotic Disorder (excluding intoxication or } \\
\text { withdrawal); Other Specified Psychotic Disorder; Major [D]epressive } \\
\text { Disorder; Other Specified Bipolar Disorder. Anyone who has Significant } \\
\text { Functional Impairment (see definition) due to their mental health (including } \\
\text { severe Personality Disorders, Intellectual Disability, Autism Spectrum } \\
\text { Disorder) defined as: Self-harming behaviors (i.e., cutting, head-banging, } \\
\text { suicide attempts, self-strangulation, self-mutilation, swallowing foreign } \\
\text { bodies, etc.); Demonstrated difficulty in his or her ability to engage in } \\
\text { activities of daily living (i.e., eating, grooming, participation in recreation, } \\
\text { etc.); Demonstrated a pervasive pattern of dysfunctional or disruptive social } \\
\text { interactions (i.e., social isolation, bizarre behavior, disruptive behavior, etc.). }\end{array}$ \\
\hline Hawaii & $\begin{array}{l}\text { A diagnosable mental disorder characterized by alternation in thinking, mood, } \\
\text { or impaired behavior associated with distress and/or impaired functioning; } \\
\text { primarily inclusive of schizophrenia, severe depression, and bipolar disorder, } \\
\text { and severe panic disorder, obsessive compulsive disorder, and post-traumatic } \\
\text { stress disorder. }\end{array}$ \\
\hline Idaho & $\begin{array}{l}\text { IDOC does not have a formal definition of Serious Mental Illness. We do, } \\
\text { however, assign inmates with Levels of Care. I believe our two highest levels } \\
\text { of care (Acute Correctional Mental Health Services-ACMHS and } \\
\text { Intermediate Correctional Mental Health Services-ICMHS) are generally } \\
\text { housed in specialized mental health housing and serve as an appropriate } \\
\text { analogue for Serious Mental Illness }\end{array}$ \\
\hline Illinois & $\begin{array}{l}\text { Gravely disabled-a condition where a person, as a result of a mental } \\
\text { disorder, is in danger of serious physical harm, resulting from a failure to } \\
\text { provide for his or her essential human needs of health or safety, or manifests } \\
\text { severe deterioration in routine functioning evidenced by repeated and } \\
\text { escalating loss of cognitive or volitional control over his or her actions. }\end{array}$ \\
\hline Iowa & $\begin{array}{l}\text { Schizophrenia, Recurrent Major Depressive Disorder, Bipolar Disorder, other } \\
\text { Chronic and Recurrent Psychosis, Dementia and other Organic Disorder. }\end{array}$ \\
\hline Kansas & DSM-V \\
\hline Kentucky & $\begin{array}{l}\text { Serious Mental Illness means a current diagnosis by a Department of } \\
\text { Corrections psychological or psychiatric provider or a recent significant }\end{array}$ \\
\hline
\end{tabular}




\begin{tabular}{|c|c|}
\hline & $\begin{array}{l}\text { history of any of the following DSM-5 (or most current revision thereof) } \\
\text { diagnoses: Schizophrenia, delusional disorder, schizophreniform disorder, } \\
\text { schizoaffective disorder, brief psychotic, substance-induced psychotic } \\
\text { disorder (excluding intoxication and withdrawal), Psychotic Disorder Not } \\
\text { Otherwise Specified, Major Depression disorders, Bipolar I and Bipolar II } \\
\text { disorders, or current diagnosis by a DOC psychological or psychiatric } \\
\text { provider of a serious personality disorder that includes breaks with reality and } \\
\text { /or results in significant functional impairment. }\end{array}$ \\
\hline Louisiana & $\begin{array}{l}\text { HC Policy \# } 36 \text { defines as major depressive disorder, schizophrenia disorder, } \\
\text { bipolar disorder, psychotic disorder, severe anxiety disorder, and severe } \\
\text { personality disorder. }\end{array}$ \\
\hline Maryland & $\begin{array}{l}\text { The Department defines "Serious Mental Illness" (SMI) in accordance with } \\
\text { the Code of Maryland Regulations (COMAR), as follows: COMAR } \\
10.21 .17 .02 \text { (76) (76) "Serious mental illness" means a mental disorder that } \\
\text { is: (a) Manifest in an individual } 18 \text { years old or older; (b) Diagnosed, } \\
\text { according to a current diagnostic classification system that is recognized by } \\
\text { the Secretary as: (i) Schizophrenic disorder; (ii) Major affective disorder; (iii) } \\
\text { Other psychotic disorder; or (iv) Borderline or schizotypal personality } \\
\text { disorder, with the exclusion of an abnormality that is manifested only by } \\
\text { repeated criminal or otherwise antisocial conduct; and (c) Characterized by } \\
\text { impaired functioning on a continuing or intermittent basis, for at least } 2 \text { years, } \\
\text { and includes at least three of the following: (i) Inability to maintain } \\
\text { independent employment; (ii) Social behavior that results in interventions by } \\
\text { the mental health system; (iii) Inability, due to cognitive disorganization, to } \\
\text { procure financial assistance to support living in the community; (iv) Severe } \\
\text { inability to establish or maintain a personal support system; or (v) Need for } \\
\text { assistance with basic living skills. }\end{array}$ \\
\hline Massachusetts & $\begin{array}{l}\text { Serious Mental Illness (SMI) - For purposes of assessing whether } \\
\text { Segregation may be clinically contraindicated, or whether an inmate in } \\
\text { Segregation should be placed in a Specialized Treatment Unit, the term } \\
\text { "Serious Mental Illness" shall be defined as the following: 1. Inmates } \\
\text { determined by the Department's mental health vendor to have a current } \\
\text { diagnosis or a recent significant history of any of the following types of DSM- } \\
\text { V diagnoses: a. Schizophrenia b. Delusional Disorder c. Schizophreniform } \\
\text { Disorder d. Schizoaffective Disorder e. Brief Psychotic Disorder f. } \\
\text { Substance-Induced Psychotic Disorder (excluding intoxication and } \\
\text { withdrawal) g. Psychotic Disorder Not Otherwise Specified h. Major } \\
\text { Depressive Disorder i. Bipolar Disorder I and II. For purposes of this } \\
\text { definition, "recent significant history" shall be defined as a diagnosis } \\
\text { specified above in section (a)(1)-(9) upon discharge within the past year from } \\
\text { an inpatient psychiatric hospital. 2. Inmates diagnosed with disorders that are } \\
\text { commonly characterized by the mental health vendor with other DSM-V } \\
\text { breaks with reality, or perceptions of reality, that lead the individual to }\end{array}$ \\
\hline
\end{tabular}




\begin{tabular}{|c|c|}
\hline & $\begin{array}{l}\text { experience significant functional impairment involving acts of self-harm or } \\
\text { other behaviors that have a seriously adverse effect on life or on mental or } \\
\text { physical health. 3. Inmates diagnosed by the Department's medical or mental } \\
\text { health vendor with a developmental disability, dementia or other cognitive } \\
\text { disorders that result in a significant functional impairment involving acts of } \\
\text { self-harm or other behaviors that have a seriously adverse effect on life or on } \\
\text { mental or physical health. } 4 \text {. Inmates diagnosed by the Department's mental } \\
\text { health vendor with a severe personality disorder that is manifested by } \\
\text { episodes of psychosis or depression, and results in significant functional } \\
\text { impairment involving acts of self-harm or other behaviors that have a } \\
\text { seriously adverse effect on life or on mental or physical health. Significant } \\
\text { Functional Impairment Factors for consideration when assessing significant } \\
\text { functional impairment shall include the following: a. The inmate has engaged } \\
\text { in self harm which shall be defined as a deliberate act by the inmate that } \\
\text { inflicts damage to, or threatens the integrity of, one's own body. Such acts } \\
\text { include but are not limited to the following behaviors: hanging, self- } \\
\text { strangulation, asphyxiation, cutting, self-mutilation, ingestion of a foreign } \\
\text { body, insertion of a foreign body, head banging, drug overdose, jumping and } \\
\text { biting. b. The inmate has demonstrated difficulty in his or her ability to engage } \\
\text { in activities of daily living, including eating, grooming and personal hygiene, } \\
\text { maintenance of housing area, participation in recreation, and ambulation, as } \\
\text { a consequence of any DSM-V disorder. c. The inmate has demonstrated a } \\
\text { pervasive pattern of dysfunctional or disruptive social interactions including } \\
\text { withdrawal, bizarre or disruptive behavior, etc. as a consequence of any DSM- } \\
\text { V disorder. }\end{array}$ \\
\hline Michigan & $\begin{array}{l}\text { Prisoners with a mental illness have been diagnosed with a substantial } \\
\text { disorder of thought or mood that significantly impairs judgment, behavior, } \\
\text { capacity to recognize reality or cope with demands of basic living. We } \\
\text { consider classifications of what we have called major mental illness } \\
\text { including: psychotic schizophrenia, spectrum disorders, bipolar } 1 \text { and } 2 \text {, } \\
\text { major depressive disorders, neurocognitive disorders. }\end{array}$ \\
\hline Minnesota & $\begin{array}{l}\text { Minnesota has a statutory definition of Serious and Persistent Mental Illness } \\
\text { that we use (MN Stat. 245.462 Subd. 20). (c) For purposes of case } \\
\text { management and community support services, a "person with serious and } \\
\text { persistent mental illness" means an adult who has a mental illness and meets } \\
\text { at least one of the following criteria: (1) the adult has undergone two or more } \\
\text { episodes of inpatient care for a mental illness within the preceding } 24 \text { months; } \\
\text { (2) the adult has experienced a continuous psychiatric hospitalization or } \\
\text { residential treatment exceeding six months' duration within the preceding } 12 \\
\text { months; (3) the adult has been treated by a crisis team two or more times } \\
\text { within the preceding } 24 \text { months; (4) the adult: (i) has a diagnosis of } \\
\text { schizophrenia, bipolar disorder, major depression, schizoaffective disorder, } \\
\text { or borderline personality disorder; (ii) indicates a significant impairment in } \\
\text { functioning; and (iii) has a written opinion from a mental health professional, }\end{array}$ \\
\hline
\end{tabular}




\begin{tabular}{|c|c|}
\hline & $\begin{array}{l}\text { in the last three years, stating that the adult is reasonably likely to have future } \\
\text { episodes requiring inpatient or residential treatment, of a frequency described } \\
\text { in clause (1) or (2), unless ongoing case management or community support } \\
\text { services are provided; (5) the adult has, in the last three years, been committed } \\
\text { by a court as a person who is mentally ill under chapter } 253 \mathrm{~B} \text {, or the adult's } \\
\text { commitment has been stayed or continued; (6) the adult (i) was eligible under } \\
\text { clauses (1) to (5), but the specified time period has expired or the adult was } \\
\text { eligible as a child under section } 245.4871 \text {, subdivision } 6 \text {; and (ii) has a written } \\
\text { opinion from a mental health professional, in the last three years, stating that } \\
\text { the adult is reasonably likely to have future episodes requiring inpatient or } \\
\text { residential treatment, of a frequency described in clause (1) or (2), unless } \\
\text { ongoing case management or community support services are provided; or } \\
\text { (7) the adult was eligible as a child under section } 245.4871 \text {, subdivision } 6 \text {, } \\
\text { and is age } 21 \text { or younger. }\end{array}$ \\
\hline Mississippi & Chronic mental health treatment or inpatient mental health treatment \\
\hline Missouri & $\begin{array}{l}\text { The department does not define "serious mental illness" in policy. All } \\
\text { offenders classified MH-3 and above (Form 931-0730 Classification Analysis } \\
\text { - Mental Health Needs) are enrolled in mental health chronic care and are } \\
\text { offenders with a serious mental illness. Our working definition is that defined } \\
\text { by Substance Abuse and Mental Health Services Administration (SAMHSA, } \\
\text { Department Health and Human Services, } \\
\text { https://www.samhsa.gov/disorders): Serious mental illness among people } \\
\text { ages } 18 \text { and older is defined at the federal level as having, at any time during } \\
\text { the past year, a diagnosable mental, behavior, or emotional disorder that } \\
\text { causes serious functional impairment that substantially interferes with or } \\
\text { limits one or more major life activities. }\end{array}$ \\
\hline Montana & No definition as of yet, still a work in progress. \\
\hline Nebraska & $\begin{array}{l}\text { Any mental health condition that current medical science affirms is caused by } \\
\text { a biological disorder of the brain and that substantially limits the life activities } \\
\text { of the person with the serious mental illness. Serious mental illness includes } \\
\text { but is not limited to (i) schizophrenia, (ii) schizoaffective disorder, (iii) } \\
\text { delusional disorder, (iv) bipolar affective disorder, (v) major depression, and } \\
\text { (vi) obsessive compulsive disorder. (Neb. Rev. Stat. 44-792) }\end{array}$ \\
\hline Nevada & $\begin{array}{l}\text { An individual is classified seriously mentally ill or SMI by a mental health } \\
\text { professional when the individual has a condition of such a nature that is a } \\
\text { threat to him or herself or others or is disruptive to the orderly operation of } \\
\text { the facility or institution. The Department ensures that inmates are evaluated } \\
\text { and a mental health diagnoses history is analyzed. The evaluation includes, at } \\
\text { minimum, the following components: suicide potential, symptoms of mental } \\
\text { illness, level of intellectual function, level of aggression, potential for escape, }\end{array}$ \\
\hline
\end{tabular}




\begin{tabular}{|c|c|}
\hline & $\begin{array}{l}\text { deviant sexual behavior, history of sexual abuse or aggression, and need of } \\
\text { psychotropic medication. Seriously impaired individuals: a) require special } \\
\text { housing and ongoing mental treatment; b) might be assigned to an extended } \\
\text { care unit (ECU) or mental health unit (MHU), c) typically require single- } \\
\text { celled housing, and d) are administered psychotropic medications monitored } \\
\text { by a psychiatrist. The disorder is defined as a condition that affects an } \\
\text { individual at least } 18 \text { years of age, and it must be of sufficient duration. The } \\
\text { NDOC follows the guidelines provided in the Diagnostic and Statistical } \\
\text { Manual of Mental Disorders (DSMS)5. }\end{array}$ \\
\hline New Jersey & $\begin{array}{l}\text { The NJDOC defines it as any inmate having a mental health problem which } \\
\text { impairs the functioning of the inmate to the extent which the MH clinical team } \\
\text { determines that treatment warrants admission to a mental health unit. The } \\
\text { below mentioned numbers represent the total number of inmates in the mental } \\
\text { health units for both males and females. It incorporates those on the SU, RTU } \\
\text { and TCU units. It should be noted the Department currently utilizes the } \\
\text { Diagnostic Statistical Manual, 5th Edition. The figure below reflects the } \\
\text { inmates placed in these specialized mental health units. }\end{array}$ \\
\hline New Mexico & $\begin{array}{l}\text { We have no definition of seriously mentally ill. What we have is a Mental } \\
\text { Health Treatment Center where we place inmates who have cognitive, } \\
\text { affective, and/or behavioral functioning deficits inhibit them from functioning } \\
\text { in general population. This could be long-term or short-term based on the } \\
\text { needs of the individual inmate.... We have a unit in the MHTC that houses } \\
\text { inmates in a segregated environment. }\end{array}$ \\
\hline New York & $\begin{array}{l}\text { New York State DOCCS Definition of Serious Mental Illness (Section } 137 \\
\text { Correction Law) (e) An inmate has a serious mental illness when he or she } \\
\text { has been determined by a mental health clinician to meet at least one of the } \\
\text { following criteria: (i) he or she has a current diagnosis of, or is diagnosed at } \\
\text { the initial or any subsequent assessment conducted during the inmate's } \\
\text { segregated confinement with, one or more of the following types of Axis I } \\
\text { diagnoses, as described in the most recent edition of the Diagnostic and } \\
\text { Statistical Manual of Mental Disorders, and such diagnoses shall be made } \\
\text { based upon all relevant clinical factors, including but not limited to symptoms } \\
\text { related to such diagnoses: (A) schizophrenia (all sub-types), (B) delusional } \\
\text { disorder, (C) schizophreniform disorder, (D) schizoaffective disorder, (E) } \\
\text { brief psychotic disorder, (F) substance-induced psychotic disorder (excluding } \\
\text { intoxication and withdrawal), (G) psychotic disorder not otherwise specified, } \\
\text { (H) major depressive disorders, or (I) bipolar disorder I and II; (ii) he or she } \\
\text { is actively suicidal or has engaged in a recent, serious suicide attempt; (iii) he } \\
\text { or she has been diagnosed with a mental condition that is frequently } \\
\text { characterized by breaks with reality, or perceptions of reality, that lead the } \\
\text { individual to experience significant functional impairment involving acts of } \\
\text { self-harm or other behavior that have a seriously adverse effect on life or on } \\
\text { mental or physical health; (iv) he or she has been diagnosed with an organic }\end{array}$ \\
\hline
\end{tabular}




\begin{tabular}{|c|c|}
\hline & $\begin{array}{l}\text { brain syndrome that results in a significant functional impairment involving } \\
\text { acts of self-harm or other behavior that have a seriously adverse effect on life } \\
\text { or on mental or physical health; (v) he or she has been diagnosed with a severe } \\
\text { personality disorder that is manifested by frequent episodes of psychosis or } \\
\text { depression, and results in a significant functional impairment involving acts } \\
\text { of self-harm or other behavior that have a seriously adverse effect on life or } \\
\text { on mental or physical health; or (vi) he or she has been determined by a mental } \\
\text { health clinician to have otherwise substantially deteriorated mentally or } \\
\text { emotionally while confined in segregated confinement and is experiencing } \\
\text { significant functional impairment indicating a diagnosis of serious mental } \\
\text { illness and involving acts of self-harm or other behavior that have a serious } \\
\text { adverse effect on life or on mental or physical health. }\end{array}$ \\
\hline North Carolina & $\begin{array}{l}\text { Psychotic Disorders, Bi-polar Disorders, Major Depressive Disorder, and any } \\
\text { diagnosed mental disorder (excluding substance abuse disorders) currently } \\
\text { associated with serious impairment in psychological, cognitive, or behavioral } \\
\text { functioning that substantially interferes with the person's ability to meet the } \\
\text { ordinary demands of living and requires an individualized treatment plan by } \\
\text { a qualified Mental Health professional(s). M3 and above is inclusive of all } \\
\text { inmates diagnosed with a mental illness receiving both psychological and } \\
\text { psychiatric services. }\end{array}$ \\
\hline North Dakota & $\begin{array}{l}\text { Serious Mental Illness: People found to have current symptoms or who are } \\
\text { currently receiving treatment for the following types of Diagnostic and } \\
\text { Statistical Manual, 5th Edition diagnoses that cause or have caused significant } \\
\text { functional impairment: Delusional Disorder, Psychotic Disorders of all types } \\
\text { including Schizophrenia, Major Depressive Disorders, Bipolar I and II } \\
\text { Disorders, Obsessive Compulsive Disorder (OCD), Panic Disorder, Post } \\
\text { Traumatic Stress Disorder (PTSD) or Borderline Personality. }\end{array}$ \\
\hline Ohio & $\begin{array}{l}\text { Serious Mental Illness (SMI) - Adults with a serious mental illness are } \\
\text { persons who are age eighteen (18) and over, who currently or at any time } \\
\text { during the past year, have a diagnosable mental, behavioral, or emotional } \\
\text { disorder of sufficient duration to meet diagnostic criteria specified within the } \\
\text { most current Diagnostic and Statistical Manual of Mental Disorders and that } \\
\text { has resulted in functional impairment which substantially interferes with or } \\
\text { limits one or more major life activities. These disorders have episodic, } \\
\text { recurrent, or persistent features; however, they vary in terms of severity and } \\
\text { disabling effects. }\end{array}$ \\
\hline Oklahoma & $\begin{array}{l}\text { OP-140201, Attachment B, November 2, 2006, defines serious mental illness } \\
\text { as mental health levels B through D. Policy attachment emailed as } \\
\text { supplemental materials to ascalimansurvey@yale.edu }\end{array}$ \\
\hline
\end{tabular}




\begin{tabular}{|c|c|}
\hline Oregon & $\begin{array}{l}\text { Serious Mental Illness: An inmate that, in the judgment of the department, } \\
\text { because of a mental disorder is one or more of the following: } \\
\text { (a) Dangerous to self or others; } \\
\text { (b) Unable to provide for basic personal needs and would likely benefit from } \\
\text { receiving additional care for the inmate's health or safety; } \\
\text { (c) Chronically mentally ill, as defined in ORS 426.495; or } \\
\text { (d) Will continue, to a reasonable medical probability, to physically or } \\
\text { mentally deteriorate so to become a person described in (c) above unless } \\
\text { treated. }\end{array}$ \\
\hline Pennsylvania & 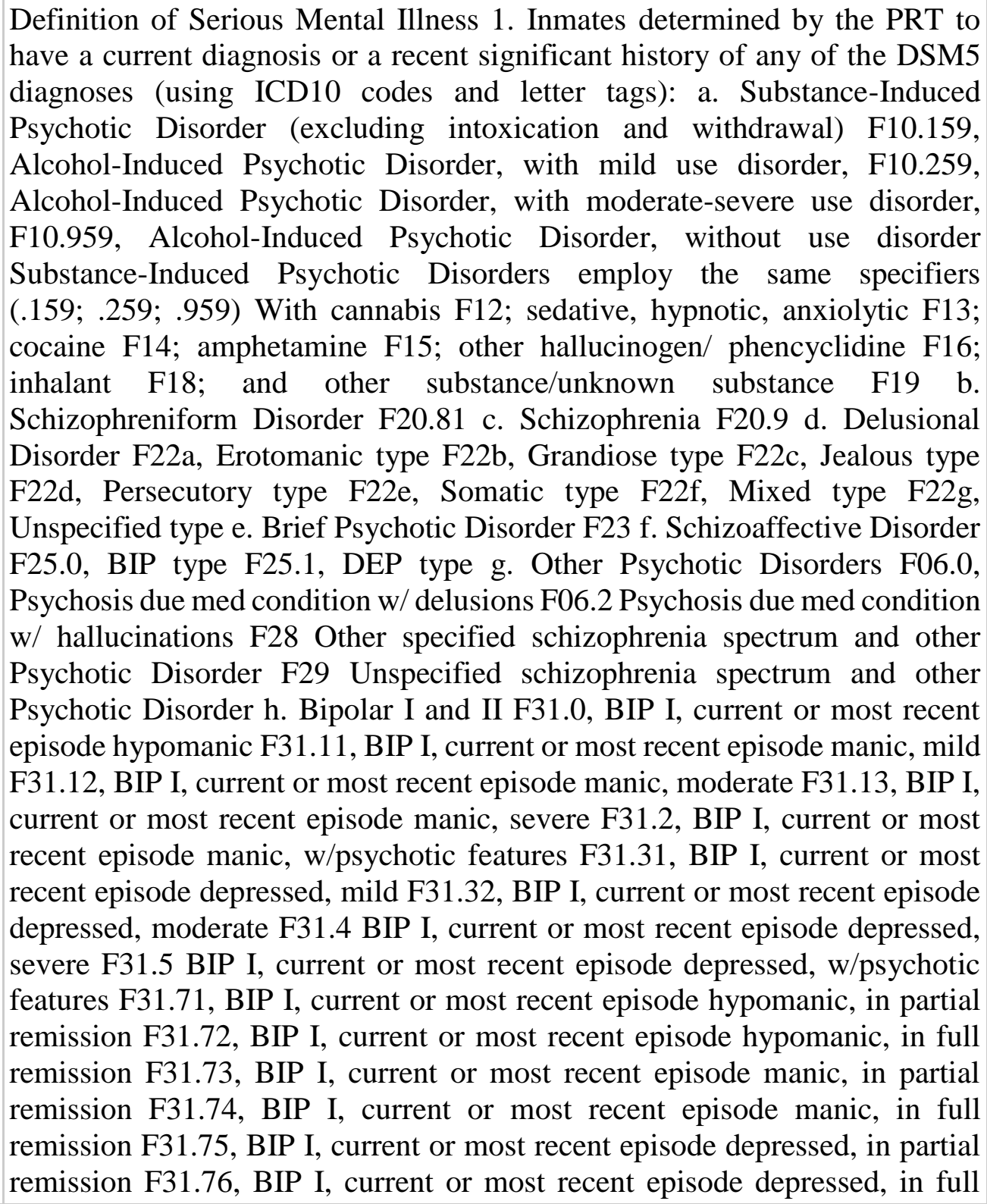 \\
\hline
\end{tabular}


remission F31.81, BIP II disorder F31.9a, BIP I, current or most recent depressed, unspecified F31.9b, BIP I, current or most recent episode hypomanic, unspecified F31.9c, BIP I, current or most recent episode manic, unspecified F31.9d, BIP I, current most recent episode unspecified i. Major Depressive Disorder F32.0, MDD, single episode, mild F32.1, MDD, single episode, moderate F32.2, MDD, single episode, severe F32.3, MDD, single episode, w/psychotic features F32.4, MDD, single episode, in partial remission F32.5, MDD, single episode, in full remission F32.9a, MDD, single episode, unspecified F33.0, MDD, recurrent, mild F33.1, MDD, recurrent, moderate F33.2, MDD, recurrent, severe F33.3, MDD, recurrent, w/psychotic features F33.41, MDD, recurrent, in partial remission F33.42, MDD, recurrent, in full remission F33.9, MDD, recurrent, unspecified NOTE: For the purpose of this definition, the term "recent significant history" shall be defined as "currently in existence or within the preceding three months." 2. Inmates diagnosed by PRT with DSM5 disorders that are commonly characterized by breaks with reality, or perceptions of reality, that lead the individual to experience significant functional impairment involving acts of self-harm or other behaviors that have a seriously adverse effect on life or on mental or physical health. 3. Inmates diagnosed by PRT with Intellectual Disability, a dementia, or other cognitive disorders that result in a significant impairment involving acts of self-harm or other behaviors that have seriously adverse effect on life or on mental or physical health. 4. Any inmate sentenced GBMI. B. Clinical Guidelines for Functional Impairment Factors for consideration when assessing significant functional impairment shall include the following: 1. whether the inmate has engaged in self-harm which shall be defined as a "deliberate, intentional, direct injury of body tissue with or without suicidal intent." Such acts include, but are not limited to the following behaviors: hanging, self-strangulation, asphyxiation, cutting, self-mutilation, ingestion of a foreign body, insertion of a foreign body, head banging, drug overdose, jumping, and biting themselves; 2 . the inmate has demonstrated significant difficulty in his or her ability to engage in activities of daily living, including eating, grooming and personal hygiene, maintenance of housing area, participation in recreation, and ambulation; and 3. the inmate has demonstrated a pervasive pattern of dysfunctional or disruptive social interactions including withdrawal, bizarre or disruptive behavior. C. Intellectual Disability Inmates scoring 70 or below on the BETA-III will be administered an individual IQ test (WASI-II or WAIS-IV) at the parent facility. If their WASI-II IQ is 70 or below then a full WAIS-IV will be administered. If this WAIS-IV comes out to 70 or below, a measurement of adaptive behavior including the following will be assessed: 1. conceptual skills-language and literacy; money, time and number concepts; and selfdirection; 2. social skills - interpersonal skills, social responsibility, selfesteem, gullibility, naiveté, social problem solving, the ability to follow rules/obey laws and to avoid being victimized; and 3. practical skillsactivities of daily living (personal care), occupational skills, healthcare, travel/transportation, schedules/routines, safety, use of money, and use of 


\begin{tabular}{|c|c|}
\hline & $\begin{array}{l}\text { telephone. NOTE: An assessment to determine if the disability originated } \\
\text { during the developmental period should be conducted to establish if the } \\
\text { intellectual and adaptive deficits were present during childhood or } \\
\text { adolescence. This assessment should include corroborative information } \\
\text { obtained from complementary reliable and valid sources, which reflect } \\
\text { functioning outside of the prison setting. Additional factors to take into } \\
\text { account include the community environment typical of the individual's peers } \\
\text { and culture, linguistic diversity, cultural differences in the way people } \\
\text { communicate, move, and behave. Assessments must also assume that } \\
\text { limitations often coexist with strengths, and that a person's level of life } \\
\text { functioning will improve if appropriate personalized supports are provided } \\
\text { over a sustained period. F70, Intellectual Disability (Intellectual } \\
\text { Developmental Disorder) mild }=50 / 55-70 \mathrm{~F} 71 \text {, IDD, moderate }=35 / 40-50 / 55 \\
\text { F72, IDD, severe }=20 / 25-35 / 40 \text { F73, IDD, profound }=<20 / 25 \mathrm{~F} 74 \text {, IDD, } \\
\text { severity unspecified }\end{array}$ \\
\hline Rhode Island & $\begin{array}{l}\text { The Rhode Island Department of Corrections (RIDOC) defines serious and } \\
\text { persistent mental illness (SPMI) as being a condition that affects persons aged } \\
18 \text { or older who currently or at any time in the past year have had a diagnosed } \\
\text { mental, behavioral or emotional disorder of sufficient duration to meet the } \\
\text { criteria specified within DSM-V (with the exception of substance use } \\
\text { disorders and developmental disorders) that has resulted in significant } \\
\text { functional impairment that has occurred on either a continuous or intermittent } \\
\text { basis. The qualifying diagnoses recognized by our jurisdiction are as follows: } \\
\text { Schizophrenia, Schizoaffective Disorder, Other Specified Schizophrenia } \\
\text { Spectrum and other Psychotic Disorders, Bipolar Disorder(s), Delusional } \\
\text { Disorder, Major Depressive Disorder, Panic Disorder, Agoraphobia, Post- } \\
\text { Traumatic Stress Disorder, Obsessive-Compulsive Disorder and Borderline } \\
\text { Personality Disorder. }\end{array}$ \\
\hline South Carolina & $\begin{array}{l}\text { A Diagnosed Mental Health Disorder from the DSM } 5 \text { associated with serious } \\
\text { behavioral impairment as evidenced by examples of acute decompensation or } \\
\text { self-injurious behaviors affecting ability to function and requiring } \\
\text { individualized treatment by a mental health professional. }\end{array}$ \\
\hline South Dakota & $\begin{array}{l}\text { The following are the criteria used by mental health staff to identify someone } \\
\text { who has a serious mental illness (SMI) and would benefit from those higher } \\
\text { levels of care. (1) The consumer's severe and persistent emotional, } \\
\text { behavioral, or psychological disorder causes the consumer to meet at least one } \\
\text { of the following criteria: (a) The consumer has undergone psychiatric } \\
\text { treatment more intensive than outpatient care and more than once in a } \\
\text { lifetime, such as, emergency services, alternative residential living, or } \\
\text { inpatient psychiatric hospitalization; (b) The consumer has experienced a } \\
\text { single episode of psychiatric hospitalization with an Axis I or Axis II } \\
\text { diagnosis per the DSM-IV-TR as defined in } \S 46: 20: 01: 01 \text {; (c) The consumer } \\
\text { has been treated with psychotropic medication for at least one year; or (d) The }\end{array}$ \\
\hline
\end{tabular}




\begin{tabular}{|c|c|}
\hline & $\begin{array}{l}\text { consumer has had frequent crisis contact with a center, or another provider, } \\
\text { for more than six months as a result of a severe and persistent mental illness; } \\
\text { and (2) The consumer's severe and persistent emotional, behavioral, or } \\
\text { psychological disorder meets at least three of the following criteria: (a) The } \\
\text { consumer is unemployed or has markedly limited job skills or poor work } \\
\text { history; (b) The consumer exhibits inappropriate social behavior which results } \\
\text { in concern by the community or requests for mental health or legal } \\
\text { intervention; (c) The consumer is unable to obtain public services without } \\
\text { assistance; (d) The consumer requires public financial assistance for out-of- } \\
\text { hospital maintenance; (e) The consumer lacks social support systems in a } \\
\text { natural environment, such as close friends and family, or the consumer lives } \\
\text { alone or is isolated; or (f) The consumer is unable to perform basic daily living } \\
\text { skills without assistance. }\end{array}$ \\
\hline Tennessee & $\begin{array}{l}\text { TDOC Policy 113.87: Serious Mental Illness (SMI): A substantial disorder of } \\
\text { thought or mood that significantly impairs judgment, behavior, capacity to } \\
\text { recognize reality or cope with ordinary demands of life within the correctional } \\
\text { environment and is manifested by substantial impairment or disability. } \\
\text { Serious mental illness requires a diagnosable mental, behavioral, or emotional } \\
\text { disorder of sufficient duration to meet diagnostic criteria specified within the } \\
\text { most current Diagnostic and Statistical Manual (DSM) or International } \\
\text { Classification of Disease (ICD) equivalent (and subsequent revisions) in } \\
\text { accordance with an individualized treatment plan }\end{array}$ \\
\hline Texas & $\begin{array}{l}\text { TDCJ does not define "serious mental illness." The numbers provided below } \\
\text { are those offenders who are on an inpatient mental health caseload. }\end{array}$ \\
\hline Utah & $\begin{array}{l}\text { SPMI: Generally well known to mental health, consistently requires } \\
\text { "intensive level of mental health treatment, observation and services." Severe } \\
\text { to significant impairment in functioning due to mental illness. }\end{array}$ \\
\hline Washington & $\begin{array}{l}\text { A substantial disorder of thought or mood which significantly impairs } \\
\text { judgment, behavior, capacity to recognize reality or cope with the ordinary } \\
\text { demands of life within the prison environment and is manifested by } \\
\text { substantial pain or disability. Serious mental illness requires a mental health } \\
\text { diagnosis, prognosis and treatment, as appropriate, by mental health staff. It } \\
\text { is expressly understood that this definition does not include inmates who are } \\
\text { substance abusers, substance dependent, including alcoholics and narcotics } \\
\text { addicts, or persons convicted of any sex offense, who are not otherwise } \\
\text { diagnosed as seriously mentally ill. }\end{array}$ \\
\hline West Virginia & $\begin{array}{l}\text { A manifestation in a person of significantly impaired capacity to maintain } \\
\text { acceptable levels of functioning in the areas of intellect, emotion, and physical } \\
\text { wellbeing. W.Va. Code } \S 27-1-2 \text {. }\end{array}$ \\
\hline
\end{tabular}




\begin{tabular}{|l|l|}
\hline Wisconsin & $\begin{array}{l}\text { MH-2a-A current diagnosis of, or being in remission from, the following } \\
\text { conditions: Schizophrenia, Delusional Disorder, Schizophreniform Disorder, } \\
\text { Schizoaffective Disorder, Other Specified (and Unspecified) Schizophrenia } \\
\text { Spectrum and Other Psychotic Disorder, Major Depressive Disorder, Bipolar } \\
\text { I Disorder, and Bipolar II Disorder. MH2-a also includes inmates with current } \\
\text { or recent symptoms of the following conditions: Brief Psychotic Disorder, } \\
\text { Substance / Medication-Induced Psychotic Disorder, head injury or other } \\
\text { neurological impairments that result in behavioral or emotional dyscontrol, } \\
\text { chronic and persistent mood or anxiety disorders, and other conditions that } \\
\text { lead to significant functional disability. MH-2b-Inmates with a primary } \\
\text { personality disorder that is severe, accompanied by significant functional } \\
\text { impairment, and subject to periodic decompensation; i.e., psychosis, } \\
\text { depression, or suicidality. If an inmate has stable behavior for two years, the } \\
\text { code may be reassessed. Excluded from MH-2B classification are inmates } \\
\text { who have a primary diagnosis of Antisocial Personality Disorder and whose } \\
\text { behavior is primarily the result of targeted goals rather than impairment from } \\
\text { diagnosed mental illness. }\end{array}$ \\
\hline Wyoming & $\begin{array}{l}\text { Major Depressive Disorder, Bipolar Disorder, Schizophrenia, or any type of } \\
\text { long term Psychosis. Psychosis due to a medical or substance use condition } \\
\text { that resolved is not included. }\end{array}$ \\
\hline &
\end{tabular}

